Aumento da eficiência do cálculo da energia de van der Waals em algoritmos genéticos para predição de estruturas de proteínas 



\title{
Aumento da eficiência do cálculo da energia de van der Waals em algoritmos genéticos para predição de estruturas de proteínas
}

\author{
Daniel Rodrigo Ferraz Bonetti
}

\section{Orientador:}

Prof. Dr. Alexandre Cláudio Botazzo Delbem

Dissertação apresentada ao Instituto de Ciências Matemáticas e de Computação - ICMC-USP, como parte dos requisitos para obtenção do título de Mestre em Ciências - Ciências de Computação e Matemática Computacional.

\section{USP - São Carlos}

Abril/2010

SERVIÇO DE PÓS-GRADUAÇÃO DO ICMC-USP

Data de Depósito:

Visto do orientador: 

Dedico este trabalho aos meus familiares. 



\section{Agradecimentos}

A todos os meus familiares que deram todo o tipo de apoio, em especial, meu pai, minha mãe e minha irmã, que acreditaram na realização deste trabalho.

A minha namorada, Vanessa Cerignoni Benites, que esteve ao meu lado em todos os momentos, exercendo um papel especial na realização deste trabalho, apoiando-me de todas as maneiras possíveis garantindo que fosse possível desenvolver de forma agradável um trabalho com qualidade.

Ao meu orientador prof. Alexandre Cláudio Botazzo Delbem, pelo apoio, amizade e enorme dedicação à este trabalho, o qual sempre esteve preocupado em realizar uma boa pesquisa e ao mesmo tempo garantir meu aprendizado.

Ao prof. Paulo Sérgio Lopes de Souza, pela dedicação e oportunidade de compartilhar seus conhecimentos, fundamentais para este trabalho e o desenvolvimento intelectual.

Ao prof. Gonzalo Travieso do IFSC, pela dedicação e grande contribuição para que fosse possível alcançar o objetivo deste trabalho.

À amiga Telma Woerle de Lima, que contribuiu com a base deste trabalho, bem como mantevese disposta o tempo todo em esclarecer as eventuais dúvidas surgidas.

Aos amigos do laboratório LCR, Bruno Franciscon Mazzotti e Francisco de Souza Junior, pela amizade e por estarem sempre dispostos a me ajudar em alguns processos de implementação. À Christiane Regina Soares Brasil, pela amizade e cooperação em algumas etapas deste trabalho. Ao amigo Paulo Henrique Ribeiro Gabriel, pela presença e amizade, ajudando no desenvolvimento do projeto. Ao Vinícius Veloso Melo, pela amizade e esclarecimentos de dúvidas que contribuíram para gerar os gráficos deste trabalho. Ao Felipe Brunelli de Andrade, por fornecer o ambiente de execução dos experimentos.

Aos meus grandes amigos de Piracicaba, José Carlos Libardi Junior, Danilo Vendemiatti, Bruno Vêneri Neto, Adriano Spolidori e Larissa Cerignoni Benites, que me forneceram momentos de alegria em suas companhias.

Aos pais da minha namorada, pela amizade e auxílio na permanência em São Carlos.

Ao amigo William Oliveira, pelos momentos divertidos e de distração.

Ao programa de pós-graduação do ICMC, pela oportunidade de participar deste mestrado.

Aos funcionários do ICMC, pelo empenho em suas funções.

Ao CNPq, pelo fundamental suporte financeiro destinado à execução desta pesquisa. 



\section{Resumo}

$\mathcal{A}$

s proteínas são moléculas presentes nos seres vivos e essenciais para a vida deles. Para entender a função de uma proteína, devese conhecer sua estrutura tridimensional (o posicionamento correto de todos os seus átomos no espaço). A partir da estrutura de uma proteína vital de um organismo causador de uma doença é possível desenvolver fármacos para o tratamento da doença. Para encontrar a estrutura de uma proteína, métodos biofísicos, como Cristalografia de Raio-X e Ressonância Nuclear Magnética têm sido empregados. No entanto, o uso desses métodos tem restrições práticas que impedem a determinação de várias estruturas de proteínas. Para contornar essas limitações, métodos computacionais para o problema de predição da estrutura da proteína (PSP, Protein Structure Prediction) têm sido investigados. Várias classes de métodos computacionais têm sido desenvolvidas para o problema de PSP. Entre elas, as abordagens $a b$ initio são muito importantes, pois não utilizam nenhuma informação prévia de outras estruturas de proteínas para fazer o PSP, apenas a sequência de aminoácidos da proteína e o gráfico de Ramachandran são empregados. O PSP $a b$ initio é um problema combinatorial que envolve relativamente grandes instâncias na prática, por exemplo, as proteínas em geral têm centenas ou milhares de variáveis para determinar. Para vencer esse entrave, metaheurísticas como os Algoritmos Genéticos (AGs) têm sido investigados. As soluções geradas por um AG são avaliadas pelo cálculo da energia potencial da proteína. Entre elas, o cálculo da interação da energia de van der Waals é custoso computacionalmente tornando o processo evolutivo do AG muito lento mesmo para proteínas pequenas. Este trabalho investiga técnicas para reduzir significativamente o tempo de execução desse cálculo. Basicamente, foram propostas modificações de técnicas de paralelização utilizando MPI e OpenMP para os algoritmos resultantes. Os resultados mostram que o cálculo pode ser 1.500 vezes mais rápido para proteínas gigantes quando aplicadas as técnicas investigadas neste trabalho. 


\section{Abstract}

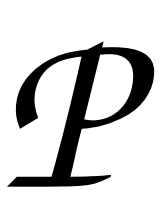

roteins are molecules present in the living organism and essential for their life. To understand the function of a protein, its threedimensional structure (the correct positions of all its atoms in the space) should be known. From the structure of a vital protein of an organism that causes a human disease, it is possible to develop medicines for treatment of the disease. To find a protein structure, biophysical methods, as Crystallography of X-Ray and Magnetic Nuclear Resonance, have been employed. However, the use of those methods have practical restrictions that impede the determination of several protein structures. Aiming to overcome such limitation, computational methods for the problem of protein structure prediction (PSP) has been investigated. Several classes of computational methods have been developed for PSP. Among them, ab initio approaches are very important since they use no previous information from other protein structure, only the sequence of amino acids of the protein and the Ramachandran graph are employed. The ab initio PSP is a combinatorial problem that involves relatively large instances in practice, i. e. proteins in general have hundreds or thousands of variables to be determined. To deal with such problem, metaheuristics as Genetic Algorithms (GAs) have been investigated. The solutions generated by a GA are evaluated by the calculus of the potencial energies of the protein. Among them, the calculation of the interaction of van der Waals energy is computationally intense making the evolutionary process of a GA very slow even for non-large proteins. This work investigated techniques to significantly reduce the running time for that calculus. Basically, we proposed modifications parallelization of the resultant algorithm using MPI and OpenMP techniques. The results show that such calculus can be 1.500 times faster when applying the techniques investigated in this work for large proteins. 



\section{Lista de Figuras}

2.1 Estrutura geral de um aminoácido f . . . . . . . . . . . . . . 6

2.2 Ligação Polipeptídica . . . . . . . . . . . . . . . . . . . . . . . . . . . . . . . . .

2.3 Estrutura de uma $\alpha$-hélice . . . . . . . . . . . . . . . . . . . . 8

2.4 Estrutura de uma folha- $\beta \ldots \ldots \ldots \ldots \ldots$

2.5 Estrutura terciária de uma proteína . . . . . . . . . . . . . . . . 10

2.6 Esquema de cristalografia de raio-x . . . . . . . . . . . . . . . . . . . . 12

2.7 Espectro bidimensional Ressonância Nuclear Magnética . . . . . . . . . . . . . . 14

2.8 Mascaramento causado pelo RMSD . . . . . . . . . . . . . . . . . . . . . . . . . . . . . .

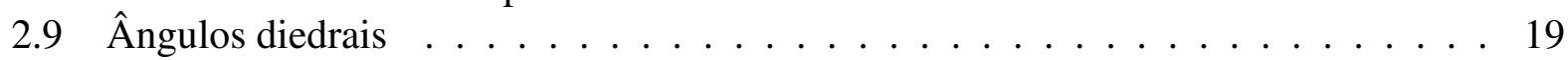

2.10 Diagrama de Ramachandran . . . . . . . . . . . . . . . . . 20

2.11 Mínimo global . . . . . . . . . . . . . . . . . . . . 21

2.12 Gráfico de van der Waals . . . . . . . . . . . . . . . . . 23

3.1 Paradigmas de programação sequencial e paralelo . . . . . . . . . . . . . . 28

3.2 Exemplos de decomposição de tarefas e de granularidade . . . . . . . . . . . . . . 31

3.3 Exemplos de grafo de dependência . . . . . . . . . . . . . . . . . . . . . 31

3.4 Modelos de programação paralela . . . . . . . . . . . . . . . . . 33

4.1 Exemplo da população de indivíduos . . . . . . . . . . . . . . . . . 38

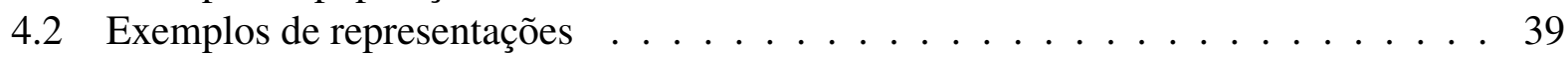

4.3 Exemplo de bit alterado pela mutação . . . . . . . . . . . . . . . . . . . . . . . . . . . . . .

4.4 Crossover de um ponto de corte . . . . . . . . . . . . . . . . . 40

4.5 Classificação de AG paralelo Mestre-Escravo . . . . . . . . . . . . . . . . . . . . 44

4.6 Gráfico comparativo Mestre-Escravo . . . . . . . . . . . . . . . . . . . . . . . . . . . . . . . . . . .

4.7 Gráfico Mestre-Escravo com Send não-bloqueante . . . . . . . . . . . . . . . . . . 45

4.8 Conjunto de subpopulações utilizados na classificação de múltipla-população . . 46

4.9 Esquema de um AG Paralelo Celulares . . . . . . . . . . . . . . . . . . . 48

4.10 Exemplo de AG Paralelo Híbrido . . . . . . . . . . . . . . . . . . . . . . . . . . 49

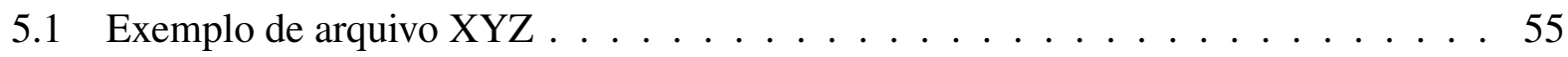

6.1 Aproveitamento do cálculo pela recombinação . . . . . . . . . . . . . . . . . . . 59

6.2 Exemplo de utilização do PGM . . . . . . . . . . . . . . . . . . . 59

6.3 Matriz de bitmap gerada para cinco proteínas . . . . . . . . . . . . . . . 61

6.4 Aproveitamento do cálculo pela recombinação . . . . . . . . . . . . . . . . . 62 
6.5 Exemplo do cálculo da energia utilizando COF . . . . . . . . . . . . . . 63

6.6 Abordagem de LC com grade $3 \times 3 \ldots \ldots \ldots$. . . . . . . . . . . 65

6.7 Exemplo do uso de LC para DM e em AGs . . . . . . . . . . . . . . . . . 66

7.1 Dependência de tarefas para o cálculo da energia de van der Waals . . . . . . . . 72

7.2 Balanceamento de carga para a matriz triangular superior . . . . . . . . . . . 73

7.3 Mapeamento de processos para LCP . . . . . . . . . . . . . . 75

7.4 Modelo híbrido de varrer as células . . . . . . . . . . . . . . . . . . . . 79

8.1 Imagem do cluster com identificação dos grupos G1 e G2 . . . . . . . . . . . . 83

8.2 Tempo para enviar as coordenadas dos átomos. . . . . . . . . . . . . . . . 84

8.3 Estruturas de proteínas selecionadas . . . . . . . . . . . . . . 85

8.4 ABS executado em dois processadores diferentes . . . . . . . . . . . . . . 86

8.5 Speedup de um processador de G2 sobre G1 . . . . . . . . . . . . . . . . . 87

8.6 Speedup de ABSO em relação ao ABS executado em dois processadores diferentes 88

8.7 Gráfico do ganho de eficiência utilizando ACR . . . . . . . . . . . . . . . . . . 89

8.8 Desempenho obtido pelo método COF . . . . . . . . . . . . . . . . . . 91

8.9 Comparação do tempo computacional para quatro tipos de precisão . . . . . . . . . . 92

8.10 Gráfico da comparação entre ABSO e LUZ executado em G1 . . . . . . . . . . . 94

8.11 Speedup de LUZ executado em dois processadores diferentes . . . . . . . . . . . . 94

8.12 Ganho de desempenho para ABP-1 utilizando 18 processadores . . . . . . . . . . 96

8.13 Comparação de desempenho entre ABS e ABP-1 com matriz densa de interações . 97

8.14 Ganho de desempenho para ABP-2 utilizando 18 processadores . . . . . . . . . 98

8.15 Ganho de desempenho para LC em relação ao ABSO . . . . . . . . . . . . . . . 100

8.16 Ganho de desempenho para LC . . . . . . . . . . . . . . . . . . . . 100

8.17 Gráfico do speedup de LCP-1 para 5 proteínas diferentes em G1 . . . . . . . . . . 102

8.18 Speedup de LCP-2a e LCP-2b em relação a LC (executados em G1) . . . . . . . . 104

8.19 Ganho de desempenho para LCP-3 em relação ao ABSO executados no G2 . . . 105

8.20 Comparação do speedup entre LCP-3 com LC e LCP-2a executados no G2 . . . . . 106

8.21 Gráfico do speedup obtido de LCP-3 em relação a ABSO utilizando G2 . . . . . . 106

8.22 Comparação do speedup de LCP-4, LCP-2a e LCP-3 em relação a LC para 8 proteínas executadas em $\mathrm{G} 2$. . . . . . . . . . . . . . . . . . . . 108

8.23 Speedup de LCP4, LCP-2a e LCP-3 em relação ao LC variando o número de átomos. 109

8.24 Eficiência de LCP-4 em relação ao algoritmo de LC. . . . . . . . . . . . . . . . . 109

8.25 Ganho de desempenho de LCP-4 em relação ao ABS executado em G1 . . . . . . . 110

8.26 Ganho de desempenho por técnica executado em G1 . . . . . . . . . . . . . . . 112

8.27 Ganho de desempenho por técnica executado em G2 . . . . . . . . . . . . 113

8.28 Comparação entre a proteína 1 A11 predita e a nativa . . . . . . . . . . . 116

8.29 Tempo de execução do ProtPred com ABS e LCP-3 . . . . . . . . . . . . . . . . . 116 


\section{Lista de Tabelas}

2.1 Tabela de aminoácidos . . . . . . . . . . . . . . . . . 7

3.1 Tabela de características de interação entre tarefas . . . . . . . . . . . . . . 30

6.1 Tabela do uso de memória utilizando ACR . . . . . . . . . . . . . . . . . 60

8.1 Tabela de proteínas selecionadas . . . . . . . . . . . . . . 85

8.2 Tabela de precisão por proteína . . . . . . . . . . . . . . . . . 9 91

8.3 Tabela com o tempo de ABSO e o custo de comunicação . . . . . . . . . . . . . . 99

8.4 Tabela de dimensões do espaço para estruturas de proteínas nativa . . . . . . . . . 102

8.5 Tabela do tempo de LC e tempo de transmissão . . . . . . . . . . . . . . . . . . 103

8.6 Tabela de estimativa do tempo de execução para um AG com 80 mil conformações utilizando a técnica de LCP-3 . . . . . . . . . . . . . . . . . . 115 



\section{Lista de Abreviaturas e Siglas}

ABP Algoritmo Básico Paralelo

ABP-1 Algoritmo Básico Paralelo sem enviar átomos

ABP-2 Algoritmo Básico Paralelo enviando átomos

ABS Algoritmo Básico Sequencial

ABSO Algoritmo Básico Sequencial Otimizado

ACR Aproveitamento do Cálculo pela Recombinação

AG Algoritmo Genético

COF Cálculo Off-Line

CRX Cristalografia de Raio-X

DM Dinâmica Molecular

G1 Grupo de 10 máquinas do cluster com processador AMD

G2 Grupo de 4 máquinas do cluster com processador Intel

LC Lista de Células

LCP Lista de Células em Paralelo

LCP-1 Lista de Células em Paralelo sem enviar átomos

LCP-2 Lista de Células em Paralelo enviando átomos

LCP-2a Lista de Células em Paralelo enviando todos os átomos

LCP-2b Lista de Células em Paralelo enviando átomos específicos

LCP-3 Lista de Células em Paralelo com memória compartilhada

LCP-4 Lista de Células em Paralelo Híbrido - MPI e memória compartilhada

LUZ Método das Luzes

PDB Protein Data Bank

PGM Portable Gray Map

PSP Predição de Estruturas de Proteínas

RMSD Root mean square deviation

RNM Ressonância Nuclear Magnética 



\section{Sumário}

$\begin{array}{lll}\text { Resumo } & \text { i }\end{array}$

$\begin{array}{lll}\text { Abstract } & \text { iii }\end{array}$

$\begin{array}{ll}\text { Lista de Abreviaturas e Siglas } & \text { ix }\end{array}$

1 Introdução 1

1.1 Motivação . . . . . . . . . . . . . . . . . . . . . 1

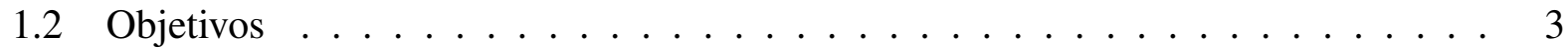

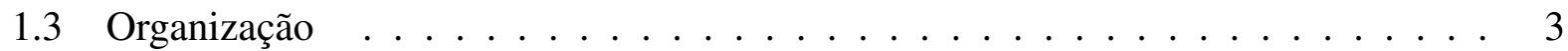

2 Estruturas de Proteínas 5

2.1 Características das Proteínas . . . . . . . . . . . . . . . . 5

2.2 Hierarquias das Estruturas das Proteínas . . . . . . . . . . . . . . . . . . . . . . . . .

2.3 O Problema da Predição da Estrutura de Proteínas . . . . . . . . . . . . . . . . . . 10

2.4 Técnicas in vitro . . . . . . . . . . . . . . . . . . . . . . . 11

2.4.1 Cristalografia de Raio-X . . . . . . . . . . . . . . . . . 11

2.4.2 Ressonância Nuclear Magnética . . . . . . . . . . . . . . . . 13

2.5 Técnicas in silico . . . . . . . . . . . . . . . . . . . . 13

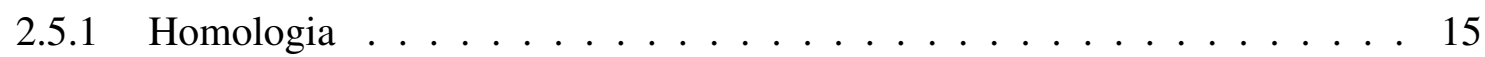

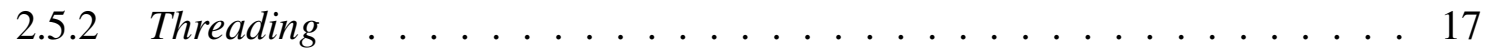

2.5 .3 Ab initio . . . . . . . . . . . . . . . . . 18

2.6 Funções de Energia . . . . . . . . . . . . . . . . . . . . . . . . . . . . . . . . . . . . . . . . . . . . . .

2.7 Energia de van der Waals . . . . . . . . . . . . . . . . . . . . . . . . . . . . . . . . . . . . . . .

2.8 Considerações Finais . . . . . . . . . . . . . . . . . . . . . . . . 24

3 Algoritmos Paralelos $\quad 27$

3.1 Técnicas de Paralelização . . . . . . . . . . . . . . . . . . 27

3.2 Desenvolvimento de Algoritmos Paralelos . . . . . . . . . . . . . . . . . . . 29

3.3 Modelos de Programação Paralela . . . . . . . . . . . . . . . . . . . . . . 32

3.3.1 Programação por Passagem de Mensagens . . . . . . . . . . . . . . . . 32

3.3.2 Programação Utilizando Memória Compartilhada . . . . . . . . . . . . . . 33

3.4 Métricas Utilizadas nos Sistemas Paralelos . . . . . . . . . . . . . . . . . 34

3.5 Considerações Finais . . . . . . . . . . . . . . . . . . . . . . 35 
4 Algoritmos Genéticos $\quad 37$

4.1 Base Biológica . . . . . . . . . . . . . . . . . . . 37

4.2 População Inicial . . . . . . . . . . . . . . . . . . . . . 38

4.3 Representação de Indivíduos . . . . . . . . . . . . . . . . . . . . . . . . 39

4.4 Operadores de Reprodução . . . . . . . . . . . . . . . . . . . . . . . . . . . . 39

4.4 .1 Mutação . . . . . . . . . . . . . . . . . . . 39

4.4 .2 Crossover . . . . . . . . . . . . . . . . . 40

4.4 .3 Seleção de Indivíduos . . . . . . . . . . . . . . . . . . . . . . . . . . . . . . . 41

4.4 Elitismo ........................ 41

4.5 Algoritmo Base . . . . . . . . . . . . . . . . . . . . . 42

4.6 Algoritmos Genéticos Paralelos . . . . . . . . . . . . . . . . . . 42

4.6.1 Single-population master-slave ................ 43

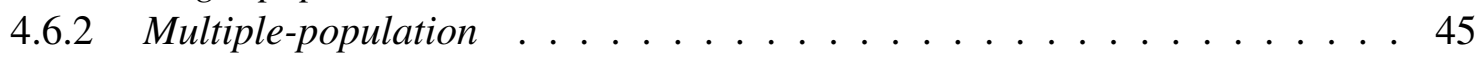

4.6 .3 AG Paralelo Celular . . . . . . . . . . . . . . . . . . . 47

4.6 .4 AG Paralelo Híbrido . . . . . . . . . . . . . . . . . . . . . 49

4.7 Considerações Finais . . . . . . . . . . . . . . . . . . 50

5 Van der Waals e AGs para PSP $\quad 51$

5.1 O ProtPred . . . . . . . . . . . . . . . . . . . . . . . 51

5.2 O software de modelagem molecular Tinker . . . . . . . . . . . . . . . 53

5.3 Método das Luzes . . . . . . . . . . . . . . . . . . . . . 53

5.4 Algoritmo Base de van der Waals . . . . . . . . . . . . . . . . . . . . . . . . . . . . . . . . . . . 54

5.5 Considerações Finais . . . . . . . . . . . . . . . . . . . . . 54

6 Propostas para Aumento da Eficiência $\quad 57$

6.1 Algoritmo Básico Sequencial Otimizado . . . . . . . . . . . . . . . . . 57

6.2 Aproveitamento do cálculo pela recombinação . . . . . . . . . . . . . . . . 58

6.2.1 Representação esparsa da memória . . . . . . . . . . . . . . . 59

6.3 Cálculo off-line . . . . . . . . . . . . . . . . . . . . . 60

6.4 Lista de Células . . . . . . . . . . . . . . . . . . . . . . 62

6.5 AGs para PSP com Lista de Células . . . . . . . . . . . . . . . . 65

6.6 Considerações Finais . . . . . . . . . . . . . . . . . . . . 66

7 Propostas de implementações paralelas $\quad 69$

7.1 Algoritmo Básico Paralelo . . . . . . . . . . . . . . . . . . . . . . . . . 69

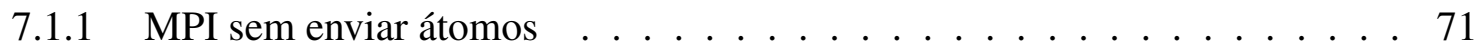

7.1 .2 MPI enviando átomos . . . . . . . . . . . . . 71

7.2 Lista de Células em Paralelo . . . . . . . . . . . . . . . . . 73

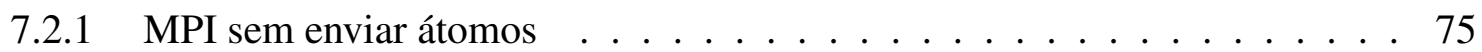

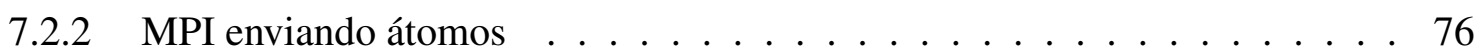

7.2 .3 Memória Compartilhada . . . . . . . . . . . . . . . . . 77

7.2 .4 Híbrido . . . . . . . . . . . . . . . . . . . . . 78

7.3 Considerações Finais . . . . . . . . . . . . . . . . . . 80

8 Resultados Experimentais $\quad \mathbf{8 1}$

8.1 Avaliação de Desempenho . . . . . . . . . . . . . . . . . . . 81

8.1 .1 Medição de Tempo . . . . . . . . . . . . . . . . . . . . 82

8.1 .2 Características do Cluster . . . . . . . . . . . . . 82

8.1 .3 Teste de Desempenho . . . . . . . . . . . . . . 83 
8.2 Proteínas selecionadas . . . . . . . . . . . . . . . . . 84

8.3 Algoritmo Base Sequencial . . . . . . . . . . . . . . . . . 86

8.4 Algoritmo Base Sequencial Otimizado . . . . . . . . . . . . . . . . . . . 86

8.5 Aproveitamento do cálculo pela recombinação . . . . . . . . . . . . . . . 87

8.6 Cálculo off-line . . . . . . . . . . . . . . . . . . . . . . . . . . . 89

8.7 Método das Luzes . . . . . . . . . . . . . . . . . . . . . . 93

8.8 Algoritmo Base MPI sem enviar átomos . . . . . . . . . . . . . . . . 95

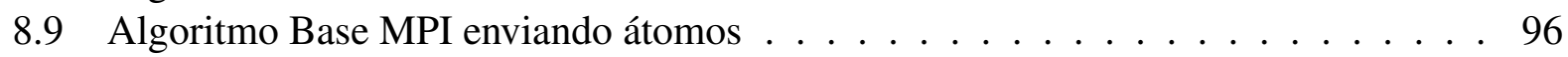

8.10 Lista de Células . . . . . . . . . . . . . . . . . . . . . . . 98

8.11 Lista de Células MPI sem enviar átomos . . . . . . . . . . . . . . . 101

8.12 Lista de Células MPI enviando átomos . . . . . . . . . . . . . . 102

8.13 Lista de Células e OpenMP . . . . . . . . . . . . . . . . . 103

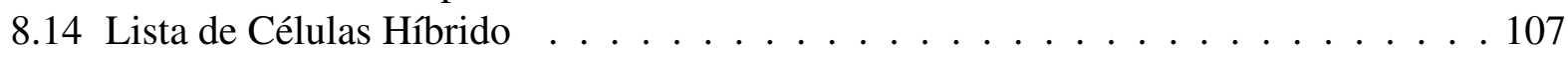

8.15 Comparação entre as técnicas . . . . . . . . . . . . . . 110

8.16 Desempenho do ProtPred . . . . . . . . . . . . . . . . 114

8.16 .1 Lista de Células e OpenMP . . . . . . . . . . . . . . . . . . 114

8.16 .2 Resultados com o ProtPred . . . . . . . . . . . . . . . 115

8.17 Considerações Finais . . . . . . . . . . . . . . . . . . 117

9 Conclusões $\quad 119$

9.1 Trabalhos Futuros . . . . . . . . . . . . . . . . 121 


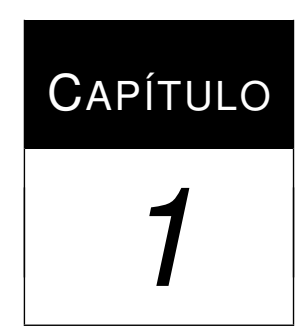

\section{Introdução}

\subsection{Motivação}

As Proteínas são moléculas existentes nos seres vivos e desempenham funções essenciais para o processo da vida, tais como: transporte e armazenamento de outras moléculas, catalização, estrutura, defesa, entre muitas outras funções (Berg et al., 2002). As funções das proteínas são determinadas pela sua estrutura tridimensional. Por exemplo, o sistema humano imunológico produz anticorpos com a estrutura complementar à superfície do antígeno, como proteínas de vírus e bactérias, formando complexos de proteínas capazes de proteger as células (Lodish et al., 2003; Clote \& Backofen, 2002).

Conhecendo a estrutura tridimensional da proteína é possível desenvolver fármacos para o tratamento de diversas doenças. Entretanto, para se obter a cura de uma doença é necessário muito tempo e dinheiro (DiMasi et al., 2003). Para o desenvolvimento de um novo fármaco, deve-se investigar a proteína em questão, sendo que esse processo é muito complicado (Lengauer, 2002). Da descoberta da proteína-alvo até o desenvolvimento de um novo fármaco podem passar mais de 11 anos (da Silva \& Silva, 2007) e o processo custar mais de 800 milhões de dólares (DiMasi et al., 2003).

Sabe-se que as estruturas tridimensionais das proteínas são obtidas a partir das interações interatômicas ${ }^{1}$, da sequência de aminoácidos e do meio em que se encontram (Bujnicki, 2009). No entanto, ainda não existe um modelo eficiente, confiável e robusto que consiga determinar a estrutura tridimensional da proteína (Setubal \& Meidanis, 1997), sendo esse um dos maiores problemas

\footnotetext{
${ }^{1}$ Interações que os átomos de uma proteína exercem sobre os átomos da mesma.
} 
da Biologia Molecular Celular (Webster, 2000) na atualidade. Os métodos mais utilizados para determinar a estrutura da proteína são: Cristalografia de Raio-X (CRX) e a Ressonância Nuclear Magnética (RNM) (Lima, 2006; Webster, 2000), porém, ambos possuem muitas limitações. Os principais problemas da CRX são: (1) por razões desconhecidas uma proteína ou outra não pode ser cristalizada, (2) é um processo muito lento que pode demorar até mais de um ano, apenas para determinar a estrutura de uma proteína, (3) a taxa como são determinadas novas sequências de aminoácidos é muito maior que as estruturas de proteínas determinadas (Webster, 2000). Por outro lado, a RNM é, em média, mais rápida que a cristalografia, porém, não pode ser aplicada às proteínas grandes com mais de 100 aminoácidos. Utilizando apenas esses métodos, seriam necessários aproximadamente 500 anos para se obter a estrutura tridimensional apenas das proteínas com sequências conhecidas (Webster, 2000).

Em contrapartida, existem várias pesquisas que têm por objetivo encontrar a estrutura terciária da proteína, ou seja, a posição espacial de todos os átomos que compõe a proteína utilizando métodos computacionais, os quais podem ser: métodos ab initio e métodos baseados em conhecimento. Estes últimos utilizam conhecimento prévio de estruturas de proteínas obtidas por meio de outros métodos, como a CRX e RNM. Os métodos baseados em conhecimento têm sido amplamente empregados, porém, possuem várias limitações: (1) a dificuldade do controle de proteínas redundantes, (2) problemas de alinhamento de sequências (etapa necessária para determinação da similaridade entre sequências), (3) e a necessidade da utilização de métodos computacionais eficientes (Becker et al., 2001; Lima, 2006).

O método ab initio, diferentemente dos métodos baseados em conhecimento, não depende de nenhuma informação prévia, mas apenas da sequência primária de aminoácidos e, em geral, do mapa de Ramachandran, que restringe os ângulos diedrais aos valores que correspondem a dobramentos factíveis (Berg et al., 2002). Sabe-se que, em geral, uma proteína dobra-se em seu estado de menor energia potencial livre, portanto, esse método busca minimizar essa energia baseado na dinâmica da física molecular. A partir desse conhecimento é encontrado o posicionamento espacial dos átomos que corresponde a esse nível de energia. Dessa forma, o problema de Predição de Estrutura de Proteína (PSP, Protein Structure Prediction) pode ser definido como um problema de minimização da energia potencial. Entretanto, até hoje, não se sabe exatamente como as proteínas se dobram impulsionando pesquisadores a utilizarem modelos aproximados (Webster, 2000). A quantidade de conformações possíveis, mesmo para uma pequena proteína, é enorme, o que inviabiliza a utilização de uma técnica de computação exata para métodos ab initio.

Por esse motivo, técnicas de otimização baseadas em populações (investigação de um conjunto de pontos do espaço de busca em paralelo), assim como os Algoritmos Genéticos (AGs), têm sido amplamente utilizados para o problema de PSP. Entretanto, apesar do grande número de pesquisas nessa área, ainda não existe um método eficiente que determine a estrutura da proteína baseando apenas em sua sequência de aminoácidos. Os fatores que limitam a aplicação do método ab initio utilizando os AGs são: (1) as funções de energia utilizadas no cálculo da energia livre da proteína 
não modelam completamente a interação entre os átomos; (2) as funções de energia exigem muitos recursos computacionais e demandam muito tempo.

O algoritmo utilizado neste trabalho é um AG utilizado para PSP que foi inicialmente proposto por Lima (2006). As rotinas de cálculo das funções de energia utilizadas na implementação desse AG são adaptações das rotinas correspondentes no pacote de modelagem molecular Tinker (Ponder, 2001). Dentre o conjunto de funções de energia utilizadas pelo algoritmo, determinou-se empiricamente que o cálculo da energia de van der Waals e o cálculo da energia eletrostática representam em torno de $99 \%$ do tempo total utilizado no cálculo das funções. Isso também pode ser visto no recente trabalho de (Jain et al., 2009).

\subsection{Objetivos}

Este projeto de pesquisa baseia-se no trabalho feito inicialmente por Lima (2006). O objetivo deste trabalho é reduzir o tempo do cálculo da energia de van der Waals por meio de implementações paralelas. Devido ao fato de que o cálculo da função eletrostática possui a mesma estrutura da energia de van der Waals, uma vez conseguido encontrar uma maneira eficiente de paralelizar o cálculo da energia de van der Waals, essa também poderá ser aplicada ao cálculo da energia eletrostática. Com o aumento da eficiência dos cálculos dessas energias, espera-se reduzir significativamente o tempo de execução do AG para PSP, possibilitando a execução de experimentos com proteínas maiores, bem como explorar melhor o espaço de busca.

Dessa maneira, é necessário estudar as possíveis formas de paralelização do cálculo da energia de van der Waals para melhorar o desempenho do algoritmo inicialmente proposto por Lima (2006). Essa energia envolve cálculos de interações entre a combinação de todos os pares de átomos da molécula, e por ser uma energia simétrica, pode-se usar uma matriz triangular superior para armazenar os resultados dos cálculos, onde cada posição da matriz representa o resultado da interação de um par de átomos. Com isso, pode-se aplicar procedimentos bem estabelecidos de paralelização para esse tipo de matriz. Esta pesquisa busca também explorar a própria característica do AG de investigação de soluções em paralelo para identificação de estratégias de paralelização mais eficientes para o cálculo da energia. Além disso, o uso de métodos utilizados em sistemas de dinâmica molecular pode trazer resultados significativos quando aplicados a AGs para PSP.

Acredita-se que alcançando os objetivos propostos, haverá um avanço significativo às áreas de pequisas relacionadas, refletindo assim em contribuições à Biologia Molecular Celular e ao desenvolvimento de fármacos.

\subsection{Organização}

Este trabalho está organizado da seguinte maneira. No Capítulo 2 é apresentado uma introdução ao problema de predição da estrutura terciária da proteína. Nos Capítulos 3 e 4 são intro- 
duzidas as técnicas computacionais, como os AGs e as técnicas de paralelização. O Capítulo 5 mostra detalhes do cálculo da energia de van der Waals aplicados em AGs. No Capítulo 6 é apresentado propostas para aumentar a eficiência do cálculo para a energia de van der Waals aplicado em AGs. As propostas de paralelização dessas técnicas são apresentadas no Capítulo 7. O Capítulo 8 apresenta os resultados experimentais obtidos para cada técnica individual. Por fim, no Capítulo 9 é descrito a conclusão para este trabalho de mestrado. 


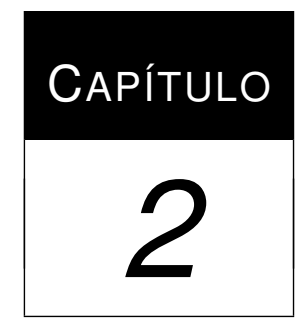

\section{Estruturas de Proteínas}

As proteínas são responsáveis por dar forma e estrutura às células, assim como também participam de quase todas as funções celulares. Seus componentes básicos são os aminoácidos, que quando encadeados, constituem a proteína. Essas moléculas são formadas por longas cadeias de aminoácidos conectadas por meio de ligações covalentes ${ }^{1}$ peptídicas (Figura 2.2), gerando moléculas de diferentes formas e funções. Apesar do pequeno número de aminoácidos, é possível encontrar longas cadeias formando uma proteína, sendo conhecidas como as moléculas mais sofisticadas e complexas (Alberts et al., 2007). Uma molécula de proteína pode ter várias dezenas de milhares de átomos enquanto que uma simples molécula de água tem apenas três átomos $\left(\mathrm{H}_{2} \mathrm{O}\right)$ (Marzzoco \& Torres, 1999).

As funções desempenhadas pelas proteínas variam com a maneira em que estão dispostas tridimensionalmente. Elas são capazes de atuar como proteínas enzimáticas, catalisando ligações covalentes ou quebrando; proteínas estruturais, que dão rigidez aos tecidos celulares; proteínas transportadoras, que transportam moléculas como o oxigênio; proteínas sinalizadoras, que transmitem sinais às outras células; proteínas motoras, que dão movimentos às células e tecidos e proteínas reguladoras capazes de ligar-se ao DNA, controlando as funções do gene (Alberts et al., 2007; Lodish et al., 2003).

\subsection{Características das Proteínas}

As proteínas são constituídas a partir de uma sequência de 20 aminoácidos (Tabela 2.1). Cada aminoácido possui um grupo amino $\left(-\mathrm{NH}_{2}\right)$, um carbono central chamado carbono alfa e um

\footnotetext{
${ }^{1}$ Uma ligação covalente é formada quando dois átomos compartilham o mesmo elétron unindo os dois átomos.
} 


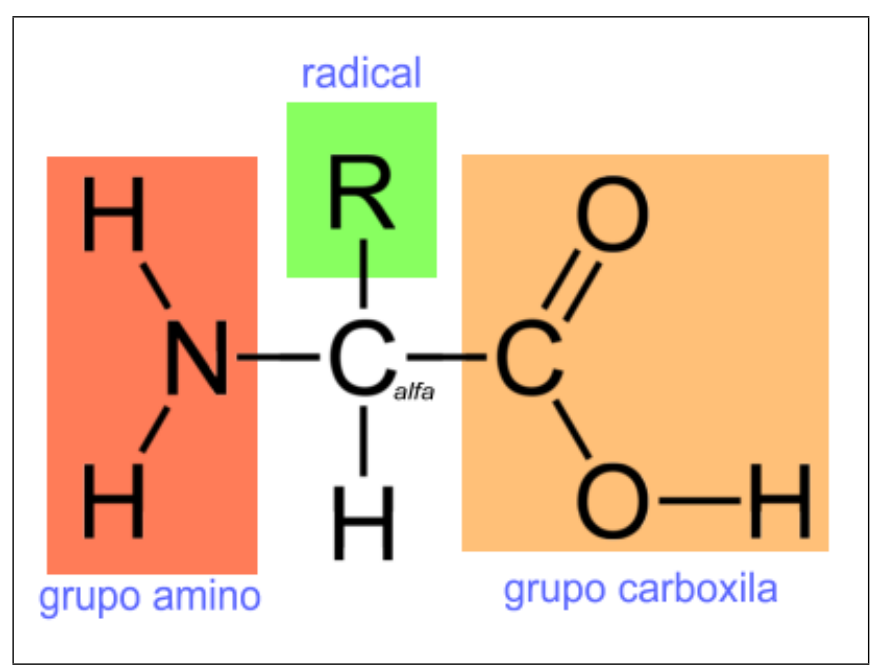

Figura 2.1: Estrutura geral de um aminoácido.

grupo carboxila $(-\mathrm{COOH})$. Ao carbono alfa é ligada uma cadeia lateral denotada por um radical $(-R)$. Cada aminoácido possui um radical próprio, que é responsável por suas propriedades químicas (Figura 2.1). As proteínas são diferentes pela quantidade de aminoácidos que estão encadeados e pela ordem em que aparecem na sequência (Marzzoco \& Torres, 1999). Toda cadeia de proteína é formada pela sequência de aminoácidos que se ligam por meio de ligações peptídicas (Figura 2.2). Nas extremidades da cadeia polipeptídica, o aminoácido que possui o grupo amino livre é chamado de $\mathrm{N}$-terminal e a terminação que possui o grupo carboxila livre é chamada de C-terminal (Alberts et al., 2007).

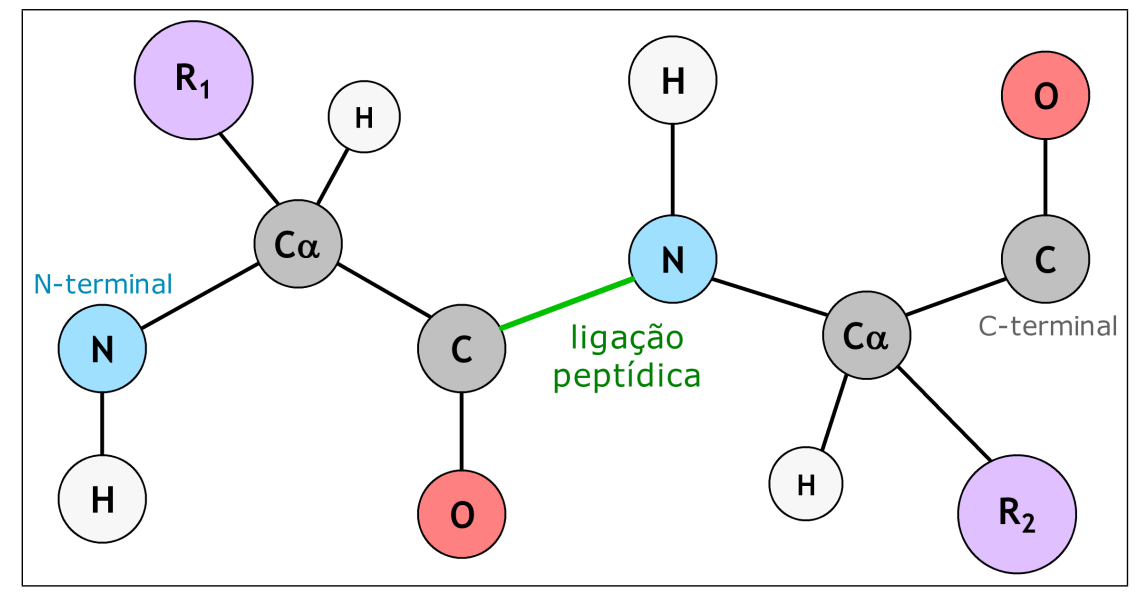

Figura 2.2: Ligação peptídica entre dois aminoácidos.

Quanto maior o número de aminoácidos que estão encadeados em uma proteína, maior é sua flexibilidade. Isso se explica devido às ligações covalentes que unem os átomos de carbono serem simples, permitindo que os átomos rotacionem livremente, assumindo várias formas. Além disso, a forma tridimensional que uma proteína pode assumir está bastante relacionada as ligações nãocovalentes, ou seja, às ligações fracas como pontes de hidrogênio, ligações iônicas e interações de 
van der Waals (Alberts et al., 2007). Outra força que determina a estrutura da proteína é o tipo da cadeia lateral $(-R)$ do aminoácido, seja polar ou apolar.

Moléculas que se dissolvem facilmente na água são chamadas hidrofílicas e podem ser compostas por íons, como $\mathrm{Na}^{+} \mathrm{Cl}^{-}$, ou por moléculas polares, assim como cadeias laterais dos aminoácidos arginina, glutamina e histidina. O motivo pelo qual essas moléculas dissolvem-se facilmente na água é que são atraídas devido aos efeitos das cargas elétricas, pois uma molécula de água tem regiões positivas e negativas. Baseado nisso, os aminoácidos que possuem afinidade com a água tendem a ficar na parte mais externa da proteína dobrada, capaz de formar pontes de hidrogênio com o meio aquoso. Por outro lado, moléculas apolares que não se dissolvem na água são chamadas de hidrofóbicas, afastando-se das moléculas de água. Por este motivo, moléculas de aminoácidos que possuem cadeias laterais hidrofóbicas, como a fenilalanina, alanina ou prolina, tendem a se agrupar no interior da proteína para tentar minimizar o contato com a água. É possível também ter aminoácidos polares no interior da proteína, porém estes, geralmente estão ligados a outros aminoácidos polares ou então à cadeia principal.

Tabela 2.1: Tabela de aminoácidos.

\begin{tabular}{c|c|c|c} 
& Aminoácido & Abreviação & Sigla \\
\hline \hline Hidrofóbico & Glicina & Gly & G \\
& Alanina & Ala & A \\
& Valina & Val & V \\
& Leucina & Leu & L \\
& Isoleucina & Ile & I \\
& Metionina & Met & M \\
& Fenilalanina & Phe & F \\
& Triptofano & Trp & W \\
& Prolina & Pro & P \\
Hidrofílico & Serina & Ser & S \\
& Treonina & Thr & T \\
& Cisteina & Cys & C \\
& Tirosina & Tyr & Y \\
& Aspartato & Asp & D \\
& Glutamato & Glu & E \\
& Lisina & Lys & K \\
& Arginina & Arg & R \\
& Histidina & His & H \\
& Asparagina & Asn & N \\
& Glutamina & Gln & Q
\end{tabular}




\subsection{Hierarquias das Estruturas das Proteínas}

A sequência de aminoácidos de uma proteína é também conhecida por estrutura primária. Ela é responsável pela forma que a proteína irá assumir (Lodish et al., 2003). Na maioria dos casos, as proteínas são escritas da direção do N-terminal (amino) para o C-terminal (carboxila). Isso significa que a cadeia polipeptídica Ala - Ser - Lys é diferente de Lys - Ser - Ala, pois no primeiro caso, o grupo livre N-terminal é da Alanina e do segundo é da Lisina (Marzzoco \& Torres, 1999).

A forma tridimensional que uma proteína pode assumir após a estabilidade de sua estrutura é também conhecida como proteína dobrada. A estrutura secundária da proteína refere-se a porções da sequência total da cadeia polipeptídica que foram dobradas isoladamente. Uma única cadeia polipeptídica pode conter vários tipos de estruturas secundárias conhecidas como $\alpha$-hélice e folha$\beta$. Elas são responsáveis por dar formas padrões às proteínas e são estabilizadas pelas ligações fracas, como energia de van der Waals, eletrostática e pontes de hidrogênio entre $N-H$ e $C=O$. Entretanto, quando não existem interações fracas estabilizadoras suficientes, podem ocorrer voltas aleatórias (Lodish et al., 2003).

Uma $\alpha$-hélice (Figura 2.3) é constituída por segmentos similares próximos uns aos outros resultando em uma hélice (Alberts et al., 2007). O arranjo estável dos aminoácidos que compõem a hélice possui uma forma cilíndrica, mantendo a cadeia lateral nas partes externas do cilindro (Lodish et al., 2003). As estruturas de hélices são mantidas por pontes de hidrogênio, entretanto, são as cadeias laterais que determinam a qualidade hidrofóbica ou hidrofílica da hélice.

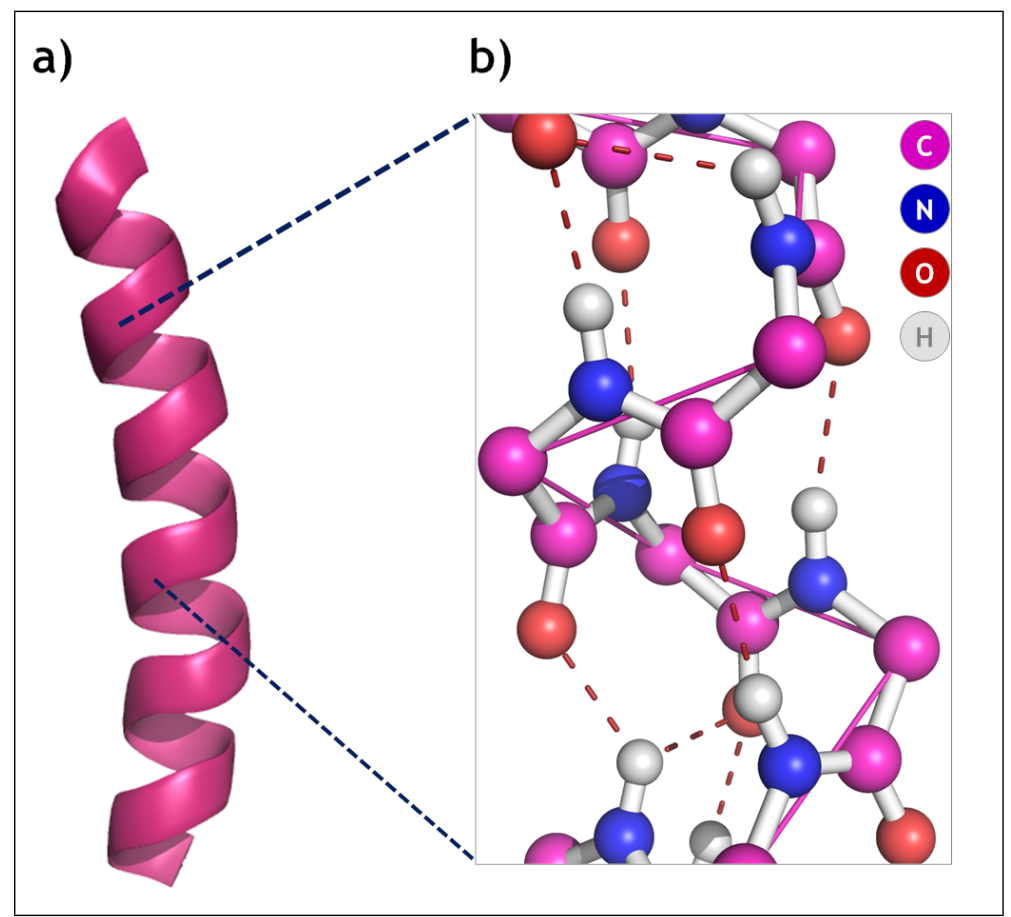

Figura 2.3: Estrutura de uma $\alpha$-hélice. a) Estrutura secundária na forma de fita. b) Posição dos átomos que formam a $\alpha$-hélice destacando a cadeia principal e algumas pontes de hidrogênio. Ocultado os átomos $C \alpha-H$ e as cadeias laterais. 
Outra forma de estrutura secundária que ocorre com frequência nas proteínas e que geralmente constituem o núcleo das proteínas são as folhas- $\beta$ (Figura 2.4). Assim como a $\alpha$-hélice, as folhas- $\beta$ possuem uma direção baseada na orientação das ligações peptídicas e são mantidas por pontes de hidrogênio. A diferença no caso das folhas- $\beta$ é que as pontes de hidrogênio são formadas entre cadeias polipeptídicas adjacentes. Quando a ponte de hidrogênio é formada entre duas cadeias polipeptídicas que estão na mesma direção, é dado o nome de folha- $\beta$ paralela e quando estão dispostas em sentidos contrários é uma folha- $\beta$ antiparalela. Conectando as folhas, têm-se as voltas.

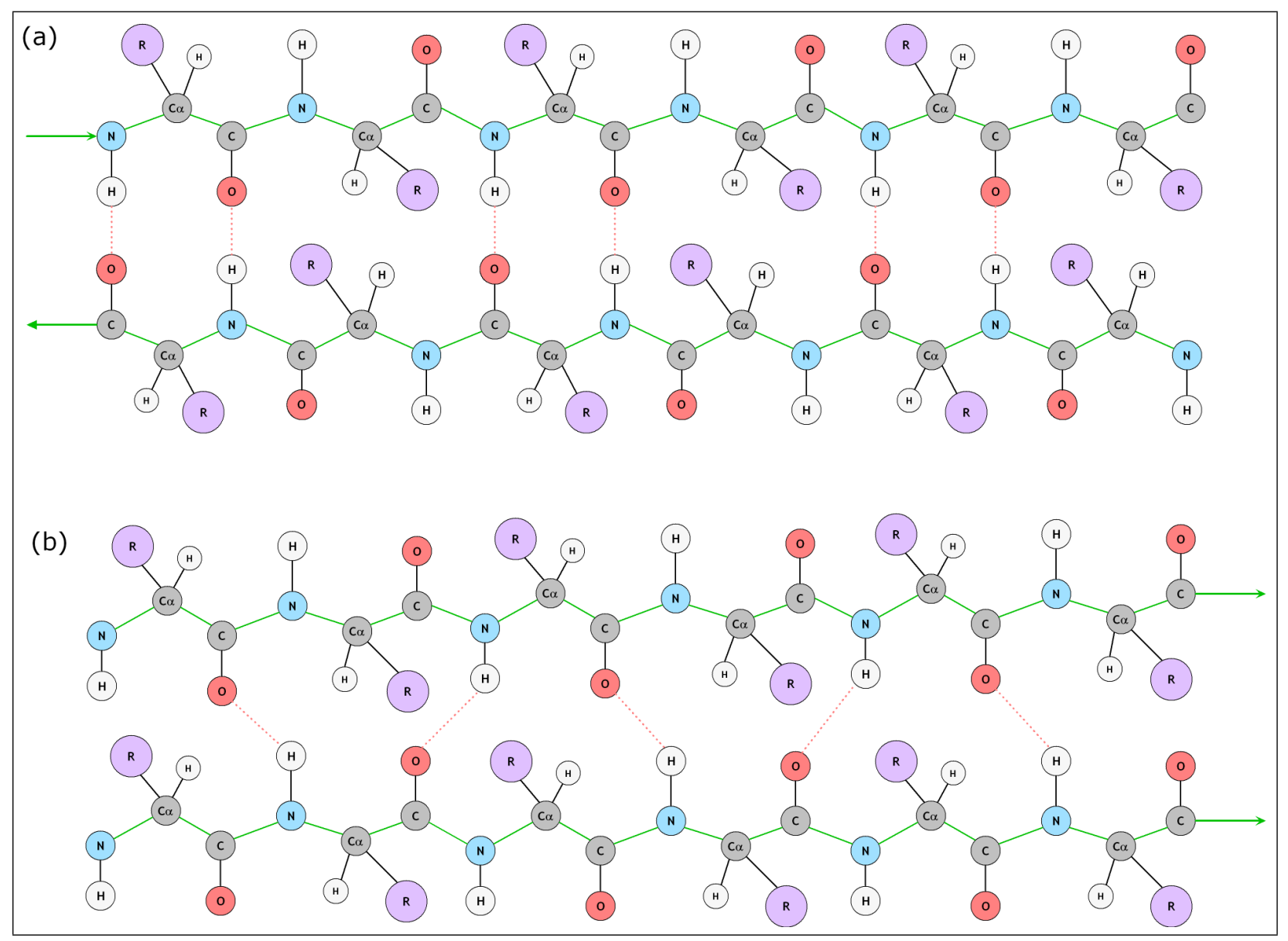

Figura 2.4: Estrutura de uma folha- $\beta$ através de pontes de hidrogênio. (a) Formação da folha- $\beta$ antiparalela. (b) Formação de uma folha- $\beta$ paralela.

As voltas, geralmente possuem de três a quatro aminoácidos formando curvas aleatórias estreitas entre a cadeia principal, redirecionando-a ao seu interior, possibilitando que grandes cadeias de aminoácidos se dobrem em estruturas pequenas. Alguns aminoácidos, como a glicina e prolina, geralmente participam dessas voltas pelo fato de suas cadeias laterais serem pequenas e terem suas estruturas estabilizadas por pontes de hidrogênio. As voltas podem variar em grau da curva ou em tamanho, resultando às vezes em looping.

A estrutura terciária de uma proteína é a forma final que o dobramento da cadeia polipeptídica poderá assumir devido à interação de todas as partes da estrutura, como $\alpha$-hélice, folha- $\beta$ e 
as voltas (Figura 2.5). Nesse modelo de estrutura, as interações fracas (ligações não-covalentes) exercem uma função importante para a estabilidade da proteína, pois segmentos que estão afastados na estrutura primária podem aparecer próximos na estrutura terciária (Marzzoco \& Torres, 1999). As estruturas são, primeiramente, estabilizadas por interações hidrofóbicas que se estabelecem entre cadeias laterais não-polares. Para aminoácidos polares, são formadas pontes de hidrogênio (Lodish et al., 2003). Outro tipo de estrutura, a estrutura quaternária, consiste em várias subunidades individuais de cadeias polipeptídicas que se unem para formar uma só proteína. Estruturas quaternárias podem conter duas subunidades semelhantes, assim como a hemoglobina (Marzzoco \& Torres, 1999), até várias subunidades diferentes. Em grande parte dos casos, essas subunidades conectam-se uma a outra por meio de ligações não-covalentes (Berg et al., 2002).

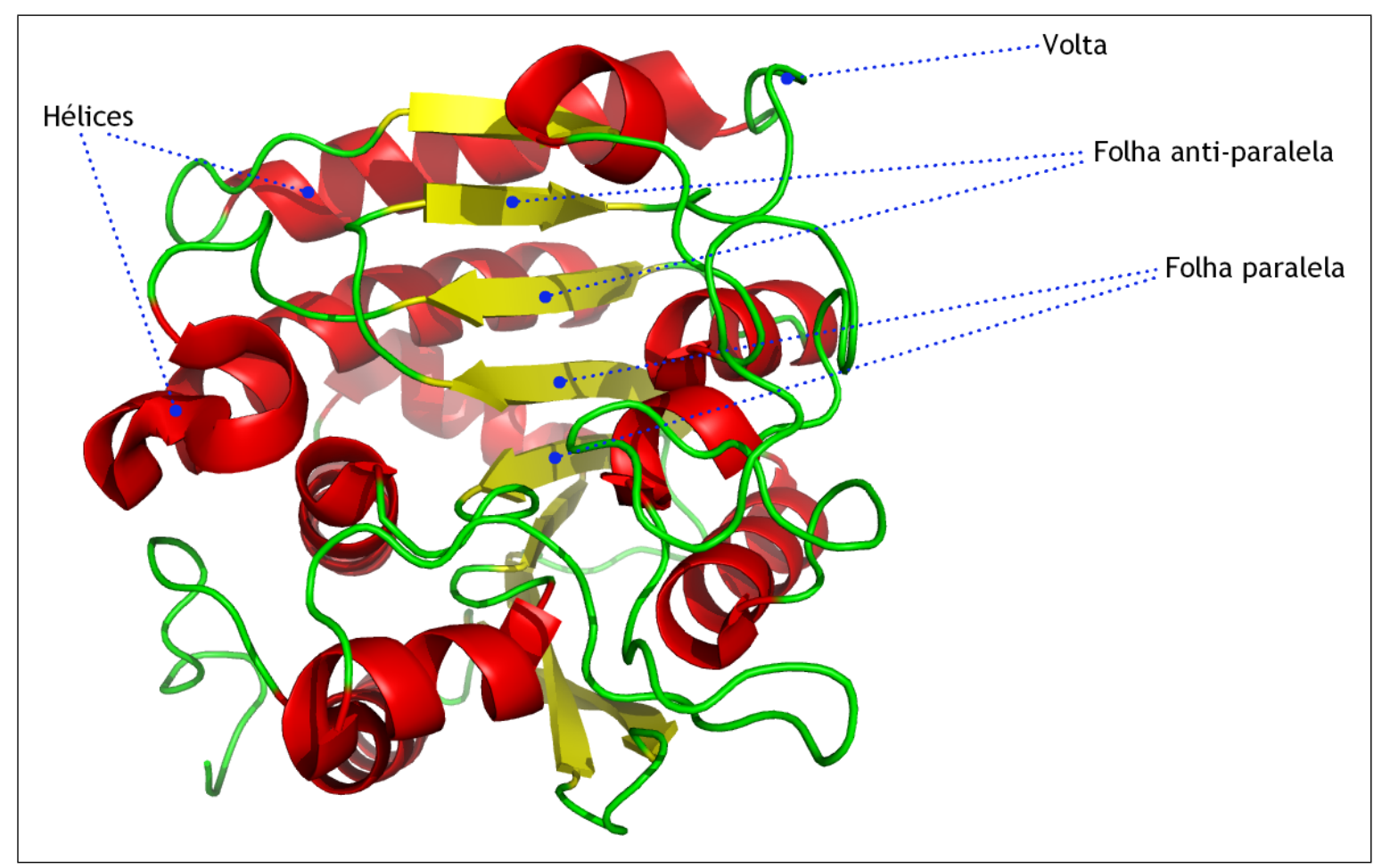

Figura 2.5: Estrutura terciária de uma proteína e suas estruturas secundárias. (Proteína ID: 1EE3 retirada do banco de dados de proteína, PDB).

\subsection{O Problema da Predição da Estrutura de Proteínas}

Toda proteína possui uma estrutura tridimensional própria formada a partir de sua sequência de aminoácidos. A estrutura da proteína dobrada, também chamada de conformação da proteína, é obtida com base em vários fatores energéticos. O conhecimento que se tem das proteínas é que elas dobram-se unicamente em uma estrutura que possui sua menor energia livre. Baseado em estudos realizados em laboratórios, sob determinadas condições ambientais, as ligações não-covalentes são 
rompidas adquirindo uma forma de proteína desnaturada ${ }^{2}$. Dependendo das mudanças, a proteína volta ao seu estado dobrado correto rapidamente. Então, pode-se concluir que a estrutura que ela irá assumir depende somente da sequência de aminoácidos. No entanto, em casos mais raros, as proteínas podem dobrar-se de forma incorreta, causando doenças no indivíduo como, o mal de Alzheimer, ou, ainda, o mal da "vaca louca" no gado (Alberts et al., 2007; Lodish et al., 2003).

O problema da predição da estrutura de proteínas é conhecer, a partir da sequência de aminoácidos, a forma dobrada da proteína em que ela está estabilizada, ou seja, a forma em que tem a energia livre minimizada. Porém, isso é um dos maiores desafios da Biologia Molecular Celular (Orengo et al., 2003) sendo que, até hoje, não existe um modelo eficiente e robusto que seja capaz, a partir da sequência de aminoácidos, de encontrar a posição espacial de cada átomo que compõe a cadeia polipeptídica. Os métodos mais utilizados para encontrar a estrutura da proteína são métodos realizados em laboratórios como a CRX e RNM. Entretanto esses métodos são complicados de reproduzir, possuem alto custo e consomem muito tempo (Baxevanis \& Ouellette, 2001). Por outro lado, métodos computacionais têm sido desenvolvidos com o objetivo de encontrar a estrutura terciária da proteína de forma mais rápida e robusta. No entanto, o PSP é um problema combinatorial de ordem exponencial, também conhecido como NP-Difícil (Fogel \& Corne, 2003). Por exemplo, utilizando um espaço de busca de apenas quatro estados no diagrama de Ramachandran (Figura 2.10) para uma proteína pequena de 100 aminoácidos, existirão $4^{100}$ conformações possíveis (Webster, 2000), ou seja, é um problema intratável. No entanto, heurísticas como os AGs (Capítulo 4), são utilizados para guiar o processo de busca. Nas Seções 2.4 e 2.5 são abordadas as técnicas utilizadas para a predição da estrutura da proteína.

\subsection{Técnicas in vitro}

Diversas técnicas para a predição da estrutura da proteína têm sido empregadas, assim como dicroísmo circular, dispersão de rotação óptica (optical rotatory dispersion), CRX e RNM (Baxevanis \& Ouellette, 2001). Elas assemelham-se por serem técnicas praticadas em laboratório, onde, ao invés dos testes serem realizados no próprio organismo vivo (in vivo), esses são feitos a partir de uma amostra em um ambiente controlado (Setubal \& Meidanis, 1997). As duas técnicas mais utilizadas são CRX e RNM e serão discutidas respectivamente nas Seções 2.4.1 e 2.4.2.

\subsubsection{Cristalografia de Raio-X}

A maioria das estruturas de proteínas determinadas utilizaram a técnica de Cristalografia de Raio- $X$. Sabe-se que mesmo utilizando um microscópio eletrônico não é possível fazer observações em nível atômico devido a sua limitação de 2nm. No entanto, o comprimento da onda do raio-x é de $0,1 \mathrm{~nm}$, próxima do diâmetro de um átomo de hidrogênio. Desta forma, permite a visualização

\footnotetext{
${ }^{2}$ Estrutura não dobrada da proteína. Isso pode ocorrer, por exemplo, adicionando compostos químicos ou provocando alterações na temperatura à solução de proteínas.
} 
de detalhes em estruturas pequenas revelando a posição dos átomos em uma proteína (Alberts et al., 2007; Berg et al., 2002). Existem três componentes da CRX:

\section{Cristalização da proteína;}

2. Fonte de raio-x;

3. Detector de padrões.

A cristalografia da proteína é um processo extremamente complicado, porém antes de chegar nessa etapa, deve-se ter uma solução pura da proteína obtida através do processo de centrifugação. Após isto, um cristal de proteína pode ser obtido adicionando, componentes químicos à solução pura de proteínas (Alberts et al., 2007; Berg et al., 2002). Isso é um dos maiores desafios dessa técnica, pois, por razões desconhecidas, certas proteínas não podem ser cristalizadas, dificultando a obtenção de um cristal de qualidade e consumindo muito tempo (Webster, 2000).

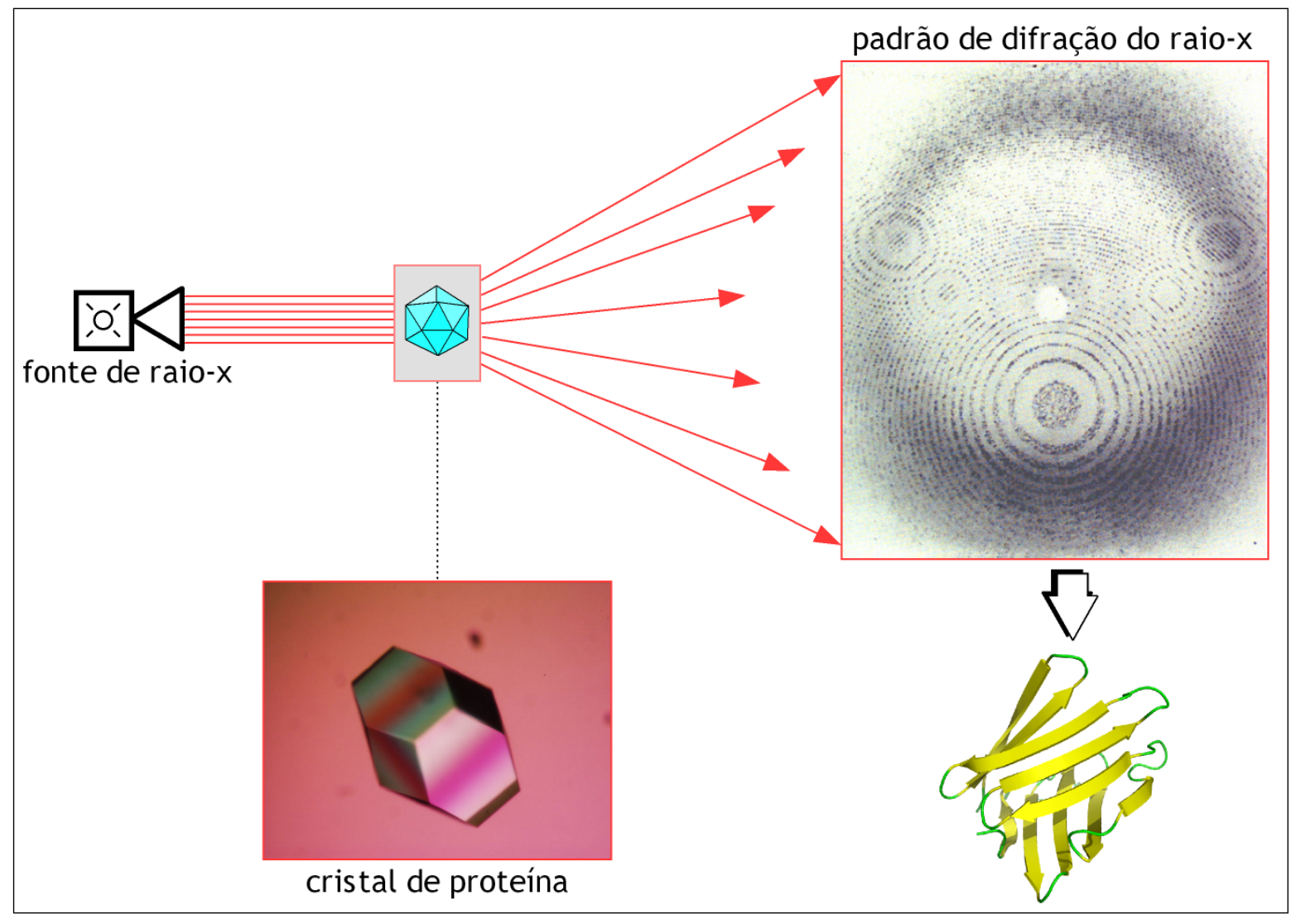

Figura 2.6: Esquema de cristalografia de raio-x.

Após a obtenção do cristal de proteína, um feixe de raio-x é emitido acelerando os elétrons contra uma placa de cobre. Parte do feixe passa direto pelo cristal de proteína. A outra parte é desviada de acordo com a quantidade de elétrons do átomo incidente do raio-x, espalhando-se em várias direções. Por exemplo, quando um feixe de raio-x incide sobre o átomo do carbono, ele é espalhado com uma intensidade seis vezes maior em relação a um átomo de hidrogênio (isso 
porque o carbono tem seis elétrons, enquanto que o hidrogênio tem apenas um). Esses raios podem ser detectados por um filme de raio-x ou eletronicamente em várias camadas (Berg et al., 2002). Mesmo uma proteína pequena pode gerar muitos pontos, precisando do auxilio de computadores, assim como a sequência de aminoácidos para a determinação de sua estrutura (Alberts et al., 2007).

É gerado um mapa de densidade eletrônica formada por várias camadas de pontos que dá a densidade de cada átomo, de forma a gerar um mapa de densidade tridimensional. Aplicando funções matemáticas, como transformada de Fourier, é possível construir a imagem da proteína (Twyman, 1998). A qualidade da imagem final está relacionada à quantidade de pontos utilizada na síntese da transformada de Fourier e no grau de perfeição do cristal da proteína (Berg et al., 2002). Apesar de todos os problemas dessa técnica, a maioria das proteínas determinadas até hoje foram obtidas utilizando a CRX (Figura 2.6).

\subsubsection{Ressonância Nuclear Magnética}

A obtenção dos cristais é uma das tarefas mais complicadas no método de CRX (Seção 2.4.1). No entanto, a técnica de RNM não necessita que cristais de proteína sejam obtidos. Os experimentos são realizados diretamente em soluções altamente concentradas de proteínas, tornando esse método muito mais rápido (Webster, 2000; Alberts et al., 2007; Berg et al., 2002). Um dos problemas desse método é que a cadeia polipeptídica não pode ultrapassar 100 aminoácidos (Webster, 2000). Em alguns casos, proteínas maiores podem ser obtidas por esse método, quebrando-a em domínios (Alberts et al., 2007).

Sabe-se que o núcleo de alguns átomos é magnético, assim como o isótopo do hidrogênio $\left({ }^{1} H\right)$, o qual possui um próton, um elétron e nenhum neutron. Quando a solução de proteínas é bombardeada com diferentes ondas de rádio, os átomos de hidrogênio movem-se, gerando um sinal de RNM. Cada núcleo tem um tipo de ressonância que também é influenciada pelos átomos que os rodeiam. Portanto, dependendo do meio que o átomo se encontra, ele gera um sinal de RNM específico. Outro fator importante é o decaimento do RNM após o bombardeamento, pois ele também depende da estrutura molecular e a forma como está disposto. Sendo assim, é possível montar um mapa bidimensional das distâncias entre os átomos (Figura 2.7). Por fim, baseado nessas informações e na sequência de aminoácidos, pode-se determinar a estrutura 3D da proteína (Twyman, 1998).

\subsection{Técnicas in silico}

Os métodos in vitro são os mais utilizados para determinar a estrutura terciária da proteína, porém todos possuem várias limitações. O crescimento de sequências de proteínas conhecidas é muito maior em relação as estruturas preditas. Em 1999, cerca de 500.000 sequências de proteínas eram conhecidas. Se apenas os métodos existentes fossem utilizados para encontrar as estruturas dessas sequências, demoraria aproximadamente 500 anos para determinar todas essas estruturas 


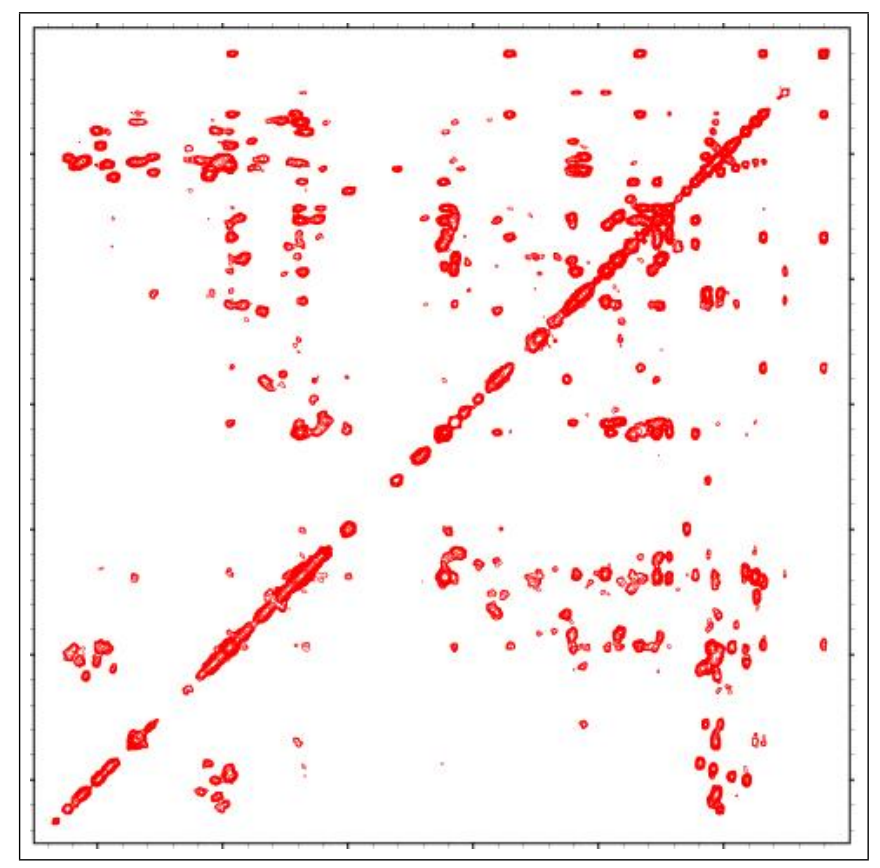

Figura 2.7: Espectro bidimensional utilizado na Ressonância Nuclear Magnética.

(Webster, 2000). Hoje, dez anos mais tarde, existem mais de sete milhões de sequências conhecidas (ExPASy Proteomics Server, 2009) e 55 mil estruturas (Berman et al., 2000), mostrando, assim, o rápido crescimento das sequências em relação às estruturas preditas.

Por esse motivo, métodos de predição da estrutura da proteína in silico têm sido intensamente pesquisados (Gibas \& Jambeck, 2001). Basicamente, os métodos computacionais são desenvolvidos para encontrar o mínimo global da energia livre da proteína, ou seja, a forma estável da proteína. Entretanto, isso ainda não foi alcançado devido às limitações da modelagem das funções de energia e também pelo fato de, em alguns casos, os algoritmos computacionais ficarem presos em ótimos locais (Lesk, 2002).

As técnicas computacionais são divididas em duas abordagens: os métodos baseados em conhecimentos e os métodos baseados em primeiros princípios (também conhecidos como ab initio ou "do início"). Os primeiros utilizam como parâmetro a estrutura de outras proteínas para compor uma nova. Os segundos são baseados em simulações de forças físicas e dinâmica molecular. Os métodos baseados em conhecimento compõem uma grande porção dos algoritmos de determinação da estrutura da proteína. No entanto, dependem da determinação da estrutura prévia de muitas outras proteínas através de outros métodos. Por outro lado os ab initio, dependem somente dos modelos computacionais que são aplicados às sequências de aminoácidos (Gibas \& Jambeck, 2001). As Seções 2.5.1 e 2.5.2 tratam dos modelos baseados em conhecimentos e a Seção 2.5.3, do ab initio. 


\subsubsection{Homologia}

A modelagem por homologia, também conhecida por modelo comparativo, possibilita construir modelos 3D para uma proteína que tenha somente sua sequência de aminoácido conhecida, baseando-se em outras estruturas de proteínas que já foram preditas e sejam semelhantes (Orengo et al., 2003; Webster, 2000; Zaki \& Bystroff, 2008; Gibas \& Jambeck, 2001; Becker et al., 2001). Para se conseguir uma estrutura a partir desse método, devem ser detectadas as reais diferenças entre a proteína conhecida e a qual está sendo predita, para que então o correto alinhamento entre as estruturas possa ser construído. Isso é possível porque pequenas alterações na sequência de aminoácidos provocam poucas alterações nas estruturas 3D. Além disso, pode-se predizer estruturas com precisão (Becker et al., 2001).

Muitas proteínas têm estruturas que se assemelham a outras proteínas e por isso são chamadas de homólogas. Devido a isso, elas podem realizar funções semelhantes podendo ser classificadas em famílias. Para certa proteína existem $40 \%$ de sequências em que o modelo comparativo pode ser aplicado. Quanto mais cresce o banco de sequências e estruturas, maior é a utilidade desse método (Becker et al., 2001). Todos os métodos comparativos consistem em quatro passos:

1. Identificar proteínas que tenham a estrutura primária semelhantes à proteína alvo;

2. Alinhar as sequências com a proteína alvo;

3. Construir um modelo para a proteína alvo a partir do alinhamento com outras estruturas;

4. Avaliar o modelo obtido.

O primeiro passo é identificar todas as estruturas das proteínas já preditas que relacionem com a proteína alvo. Este é um processo que pode ser facilitado pelos serviços de busca em banco de dados de sequências como o UniProtKB (ExPASy Proteomics Server, 2009) e de estruturas, como o PDB (Berman et al., 2000). A proteína alvo e as proteínas em que estão se baseando (proteínas modelo), geralmente pertencem à mesma família e, sendo assim, é possível organizá-las em subfamílias. Com a construção de uma árvore filogenética, o processo de decisão da escolha de uma proteína-modelo, pode ser facilitado por estarem divididas em grupos de subfamílias que estejam mais próximas à proteína alvo. Além disso, é essencial considerar o meio em que a proteína se encontra e outras propriedades bioquímicas da proteína como $\mathrm{pH}$, ligações e interações quaternárias. No caso de haver semelhanças entre proteínas modelos que foram obtidas através de métodos experimentais (CRX ou RNM), é relevante escolher aquelas que possuem maior resolução (Webster, 2000).

A segunda etapa é a mais importante e consiste no alinhamento da proteína alvo com as já existentes. Isso é essencial para se obter um bom modelo. Qualquer erro realizado nessa etapa afetará todas as posteriores, sendo que não há maneira de compensar esse erro (Webster, 2000). Quando a similaridade da sequência da proteína alvo com a proteína modelo é alta, acima de 70\%, 
então o alinhamento é, na maioria dos casos, bem simples. Entretanto, se a similaridade for menor que $40 \%$, a dificuldade de se obter um alinhamento correto cresce muito (Orengo et al., 2003; Webster, 2000). Nesses casos, quando o alinhamento das estruturas é complicado, geralmente são utilizadas várias sequências como modelo, para se ter um modelo mais preciso. Uma variação da programação dinâmica pode ser empregada para obter um alinhamento automático, mas é preciso fazer correções manuais de inserções e remoções para garantir a integridade do modelo. No caso de dúvidas sobre certas regiões obtidas é interessante gerar o modelo 3D de todas as possibilidades, avaliá-los e escolher o melhor (Orengo et al., 2003; Becker et al., 2001).

Após realizado o correto alinhamento, inicia-se a fase de construção do modelo da proteína alvo. Existem vários modelos para construção da estrutura 3D da proteína. O mais comum e utilizado deles é o agrupamento de corpos rígidos (rigid bodies assembly). Esse método constrói o modelo 3D a partir de regiões centrais da proteína, voltas e cadeias laterais obtidas por meio de partes da proteína que se relacionam. Outro método, modelagem por segment matching (ou então coordinate reconstruction), constrói o novo modelo baseado na posição dos átomos que aparecem nas proteínas utilizadas como modelo correspondentes aos átomos $C \alpha$, podendo até incluirem cadeias laterais ao modelo (Becker et al., 2001). O terceiro grupo de métodos, modelagem por satisfaction of spatial restraints, modela a representação de uma função de otimização no qual seu objetivo é minimizar as violações criadas pela função. Sua função objetivo contém restrições para as distâncias dos ângulos diedrais e estereoquímicas ${ }^{3}$ entre a proteína modelo e a proteína alvo (Sali, 1995).

O último passo da modelagem por homologia é a avaliação da qualidade do modelo 3D obtido. O RMSD (Root Mean Square Deviation) é uma medida convencional utilizada para informar quanto uma estrutura é similar a outra. O RMSD também é medido em Ångströms ${ }^{4}$ (Å) assim como geralmente utilizado nas proteínas. Para dois cristais diferentes de proteínas iguais, geralmente têm-se um RMSD de $0,6 \AA$, o que é considerado também bom para os métodos comparativos. Para proteínas grandes, podem-se assumir valores maiores: um RMSD de $4 \AA$ para uma proteína pequena de 10 aminoácidos é pior que para uma proteína com mais de 100 aminoácidos. Entretanto, o RMSD pode mascarar resultados (Figura 2.8) como, por exemplo: (1) é possível imaginar que alguns átomos estão distantes dos átomos esperados enquanto outros estão posicionados extremamente bem; (2) se uma ligação que separa duas regiões estiver errada, a região toda será mascarada. Por esse motivo fica clara a dificuldade que existe em representar coordenadas tridimensionais para dois conjuntos de proteínas através de um único número (Orengo et al., 2003). Por outro lado, existem programas que fazem análises detalhadas com a finalidade de mostrar mais precisamente se as moléculas são homólogas. Mas, apesar disso, para um modelo ser consistente, deve ser levado em consideração a estrutura da proteína e sua função (Webster, 2000).

\footnotetext{
${ }^{3}$ Ramo da química que trata das relações espaciais entre os átomos.

${ }^{4} 1 \AA$ corresponde a $10^{-10} \mathrm{~m}$ ou então $0,1 \mathrm{~nm}$.
} 


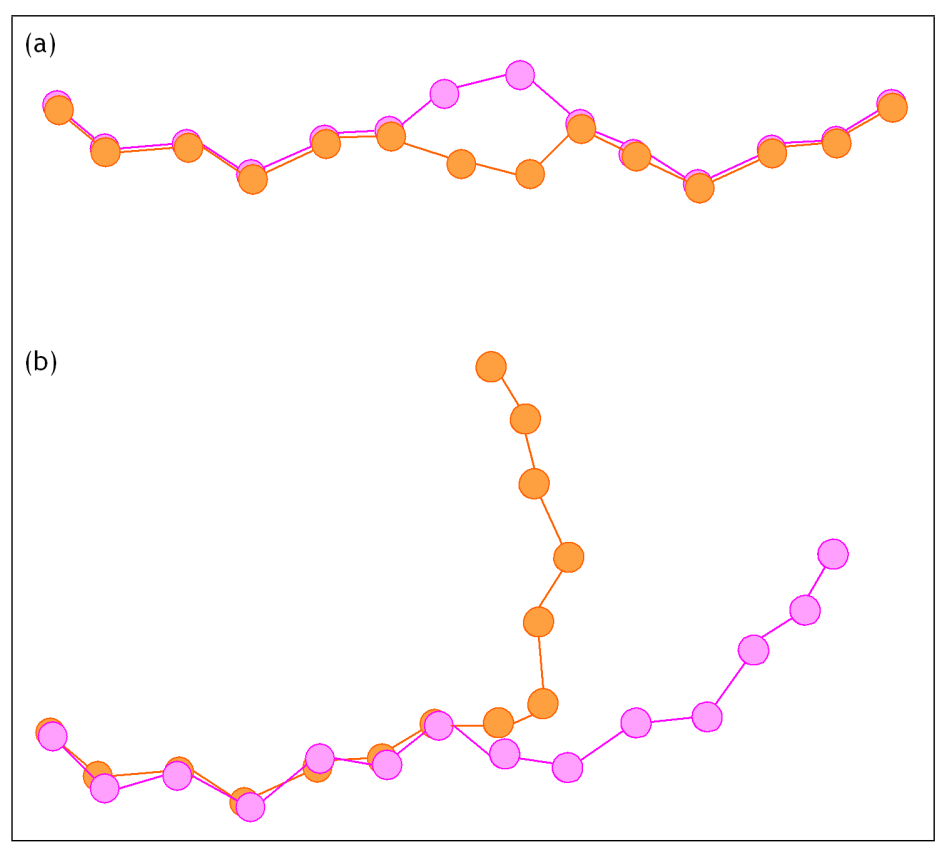

Figura 2.8: Mascaramento causado pelo RMSD. (a) A maioria dos átomos da cadeia principal estão muito bem posicionados enquanto que poucos átomos estão mal posicionados. (b) As estruturas são bem semelhantes, mas por conta de uma ligação errada, todo o restante da cadeia principal é afetado.

\subsubsection{Threading}

Outro método utilizado para a determinação de estruturas de proteínas baseada em conhecimento é o threading (também conhecido como fold recognition), introduzido inicialmente por Jones, Taylor e Thornton em 1992 (Jones et al., 1992). Quando a técnica por homologia não pode ser empregada, ou também, quando a proteína alvo não possui estruturas semelhantes para efetuar comparações (Jones, 1997a), uma alternativa é buscar por partes da sequência de aminoácidos da proteína alvo que já tiveram suas estruturas preditas através de outros métodos, como CRX e RNM. Isso permite que tais sequências, em seguida, sejam combinadas para formar uma proteína completa. Muitas proteínas adotam estruturas similares, apesar de não terem sequências ou funções relacionadas. Também supõe-se que há um número limitado de dobras existentes na natureza (Orengo et al., 2003). Existem pesquisas que procuram entender por quê sequências de aminoácidos sem muita similaridade apresentam estruturas terciárias semelhantes (Westhead et al., 1995). Diferentemente da homologia, onde as sequências são comparadas com outras sequências com a idéia de encontrar uma que seja semelhante, no threading, as sequências são comparadas com outras estruturas que já foram preditas, e devido a isso, o método também pode ser chamado de reverse protein folding (Krane \& Raymer, 2003).

Inicialmente, é escolhido um banco de dados de estruturas de proteínas distintas (como por exemplo, o PDB) e ordenadas ascendentemente pela sua energia livre, no qual as proteínas que tiverem menor energia livre irão aparecer no topo da lista (Jones et al., 1992). É então, calculado para cada par de aminoácidos da proteína alvo, sua energia livre através de algumas das mes- 
mas funções de energia utilizadas no método ab initio (Seção 2.5.3) e comparadas com a energia livre das estruturas existentes. Em seguida, são construídos modelos da estrutura da proteína alvo baseados nas energias das proteínas conhecidas. Isso resulta em um problema NP-completo, pois as combinações possíveis são exponenciais, entretanto, com a utilização de heurísticas, pode-se encontrar boas soluções, mas não necessariamente a ótima (Orengo et al., 2003). Geralmente, é utilizada a programação dinâmica. Testes mostram que é possível encontrar sequências associadas às estruturas com baixa semelhança. Desde a criação do método de threading, a predição da estrutura da proteína tem recebido progresso significativo devido ao crescimento do banco de estruturas depositadas e também por aperfeiçoamentos atribuídos à técnica de threading (Zaki \& Bystroff, 2008).

\subsubsection{Ab initio}

Diferentemente dos métodos baseados em conhecimento como a Homologia e o Threading, o $a b$ initio não utiliza nenhuma informação prévia de outras estruturas para determinar a estrutura da proteína. O ab initio, também conhecido como método baseado em primeiros princípios ou então De Novo, baseia-se somente na sequência de aminoácidos (estrutura primária) da proteína, e em cálculos físicos de dinâmica molecular para encontrar sua conformação. Muitas pesquisas estão sendo realizadas baseadas nesse método pela grande vantagem que fornece. Isso porque os métodos baseados em conhecimento, como o threading e a homologia podem apresentar certas desvantagens:

1. Grande dependência da predição da estrutura de proteínas por outros métodos;

2. Nem sempre estruturas semelhantes adotam formas parecidas;

3. Sensibilidade a proteínas grandes e ao conteúdo da estrutura secundária;

4. Dificuldade de encontrar uma proteína similar quando existem muitas inserções e remoções;

5. Os resultados nem sempre são bons.

A procura por um método ab initio que seja capaz de predizer estruturas baseando apenas no conhecimento dos aminoácidos é um dos maiores desafios da biologia computacional ainda em aberto (Gibas \& Jambeck, 2001). Parte disso deve-se aos modelos matemáticos que não estão completamente definidos (Bergeron, 2002) e também pelo espaço de busca de conformações possíveis ser enorme (Chivian et al., 2003). Quando uma proteína é submetida a altas temperaturas, ela fica desnaturada. Quando retornado ao ambiente normal, a proteína também volta ao seu estado tridimensional original, voltando a assumir sua função. Baseado nisso, determinou-se que é possível encontrar a estrutura tridimensional da proteína apenas com base na sequência de aminoácidos (Anfinsen, 1972). Também, sabe-se que ela se estabiliza no estado em que possui a menor 
energia livre. No entanto, a modelagem por ab initio pode ser dificultada, pois existem algumas proteínas que são energeticamente instáveis, não apresentando sua forma na natureza de menor energia livre. Além disso, algumas proteínas necessitam de outras, conhecidas como chaperonas, que auxiliam no processo de dobramento.

Algumas simplificações do método ab initio são feitas para reduzir a complexidade do custo computacional envolvido. Ao invés de utilizar muitas variáveis que afetam todos os átomos, com o intuito de aproximar-se ao máximo do modelo de uma proteína real, é comum o uso de representações que utilizem modelos simplificados, assim como o comprimento de ligação, ângulo de ligação e ângulo de torção (Seção 2.6) para fazer parte do cálculo da energia livre da proteína (Bergeron, 2002). Em outros casos, ao invés de adicionar milhares de moléculas que irão interagir como solvente na proteína pode-se adicionar modelos de solvente ao cálculo da função de energia. Outra representação é o modelo Lattice no qual os aminoácidos são representados por pontos adjacentes em uma malha. Esse modelo permite conformações mais rápidas pelo espaço porque representam os aminoácidos por um ponto e não por todos os átomos que estão contidos no aminoácido (modelo full-atom). No entanto, são limitados devido a seu nível de detalhamento da cadeia principal (Chivian et al., 2003).

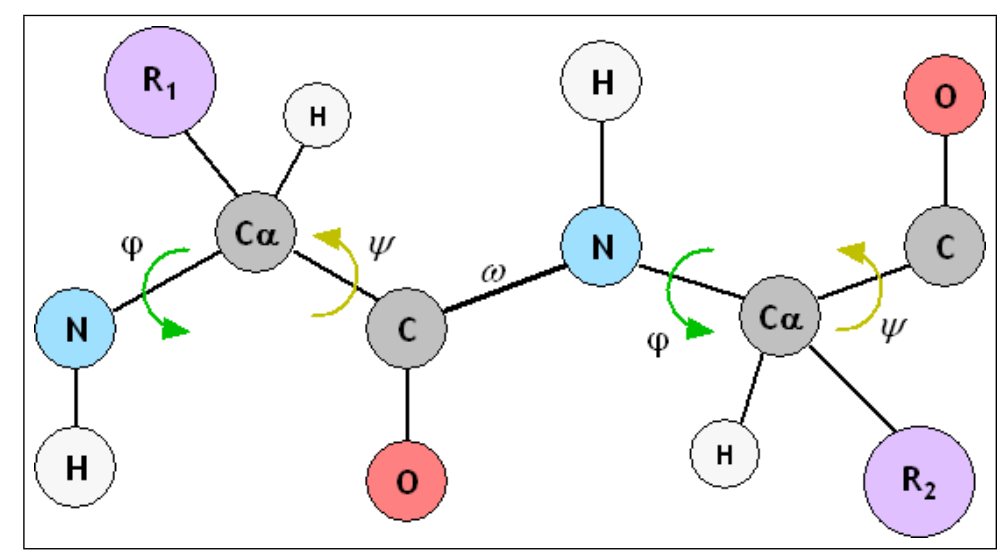

Figura 2.9: Ângulos diedrais.

Os ângulos de torção, conforme ilustrado na Figura 2.9, são uma função de quatro átomos que abrangem uma faixa de 0 a 360 graus. A cadeia principal de uma proteína é representada pelos três ângulos diedrais principais: Omega $(\omega)$, Phi $(\varphi)$ e Psi $(\psi)$. O ângulo de $C_{\beta}$ com o N é fixo em 180

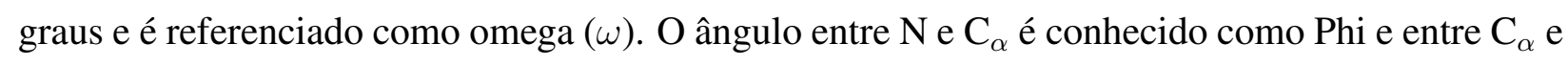
$\mathrm{C}_{\beta}$ é o Psi. Os dois ângulos diedrais, Phi e Psi são restritos pela interação de aminoácidos ligados à cadeia principal. Geralmente, os valores de phi e psi para uma $\alpha$-hélice variam de -57 a -47 graus e para folha- $\beta$ a variação é bem maior, de -119 até 113 graus. Existe um gráfico chamado Ramachandran que descreve as possíveis combinações de Phi com Psi (Figura 2.10). Uma maneira de modelar os ângulos diedrais é limitá-los no intervalo dentro do gráfico de Ramachandran.

Observando a Figura 2.9 é possível visualizar que os possíveis valores dos ângulos diedrais são muitos, mesmo para um aminoácido. Assim que mais aminoácidos são adicionados à cadeia, a quantidade de conformações possíveis com base nesses ângulos cresce exponencialmente. Por 


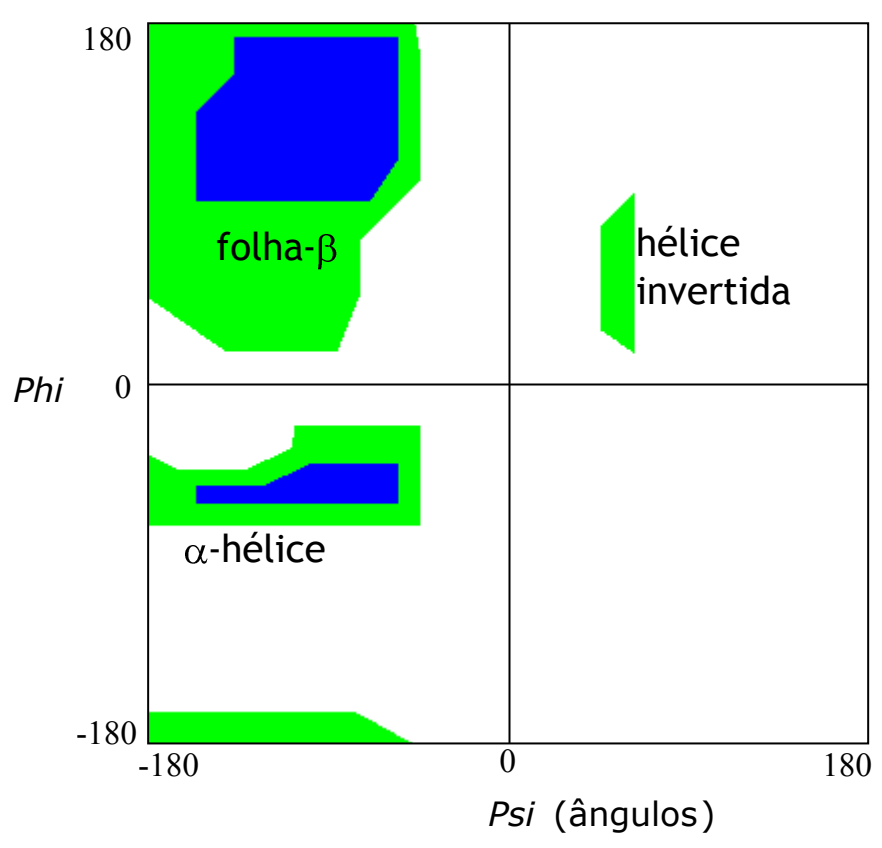

Figura 2.10: Diagrama de Ramachandran mostrando Phi e Psi.

exemplo, considerando que os ângulos que podem assumir podem formar apenas três conformações da proteína, $\alpha$-hélice, folha- $\beta$ e volta, o número de possíveis dobras que a proteína poderá assumir é de $3^{n}$, onde $n$ é o número de aminoácidos da cadeia polipeptídica. Considerando uma proteína pequena com 200 aminoácidos, o número total de conformações possíveis será de $3^{200}$, ou seja, é um problema de ordem exponencial onde mesmo utilizando os computadores mais rápidos que ainda serão inventados, não será possível encontrar uma solução em um tempo aceitável (Bergeron, 2002).

Existem alguns métodos ab initio que utilizam pouco conhecimento prévio. O método Rosetta, semi-ab initio, tem sido amplamente utilizado para se predizer a estrutura de proteínas (Chivian et al., 2003). Ele quebra a proteína em blocos de três a nove aminoácidos e compara a sequência desses fragmentos com um banco de dados de proteínas. É então utilizado o método de Monte Carlo para reconstruir os fragmentos da proteína em uma estrutura 3D.

\section{Métodos Heurísticos}

Todos os métodos computacionais utilizados no ab initio são muito custosos computacionalmente porque tentam encontrar a estrutura nativa da proteína apenas por cálculos matemáticos e, como é demonstrado nesta Seção, o problema da predição da estrutura da proteína é de ordem exponencial. Enquanto que para cristalizar uma proteína ou predizer uma estrutura com RNM continuam sendo métodos caros e demorados, a busca por métodos computacionais eficientes aplicados à predição da estrutura da proteína tem sido alvo de muitas pesquisas como o simulated anneling, simulated tempering e AGs. Esses métodos são heurísticas que procuram regiões promissoras do espaço de busca, tentando encontrar soluções cada vez melhores em pouco tempo. 
Encontrar a estrutura 3D da proteína é saber como os átomos de todos os aminoácidos estão dispostos no espaço, de tal maneira que a proteína tenha a menor energia livre. O problema de calcular a menor energia livre da proteína pode ser visto como um problema de otimização. Encontrar a posição dos átomos que represente essa configuração, geralmente, leva o processo de busca a mínimos locais. Por esse motivo, as heurísticas utilizadas nos métodos de predição devem acompanhar mecanismos para tentar sair de mínimos locais e caminhar na direção do mínimo global. Casos de sucesso do uso de AGs para encontrar a estrutura da proteína podem ser vistos em (Lima, 2006; Cui et al., 1998) e de simulated anneling em (Jones, 1997b).

\subsection{Funções de Energia}

A função básica de uma tarefa computacional em PSP é minimizar a energia da molécula, alterando a posição dos átomos e conduzindo a uma estrutura ótima. A configuração mais estável de uma molécula é encontrada com a sua menor energia livre (Figura 2.11). Pelo fato da energia zero ser arbitrária, a energia calculada é relativa a outras configurações calculadas para o mesmo componente químico. Com isso, é difícil determinar se a energia da proteína é um mínimo global ou um dos mínimos locais 5 .

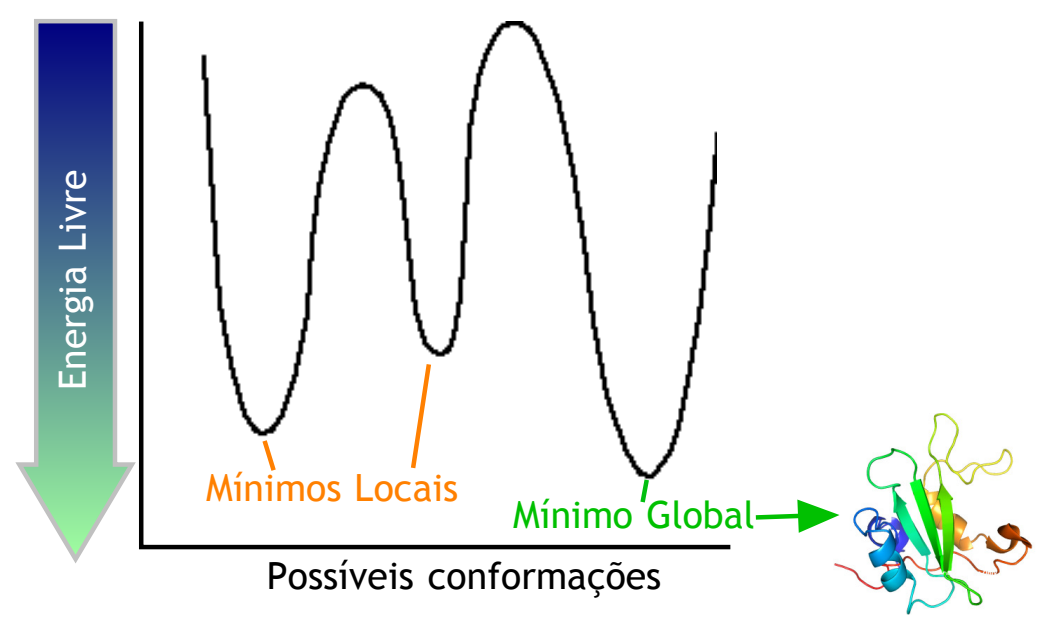

Figura 2.11: Mínimo global. Estado em que a proteína encontra-se na natureza.

Neste trabalho são utilizadas as mesmas funções de energia utilizadas pelo arquivo de parâmetros CHARMM, que acompanha o sistema de modelagem molecular TINKER (Ponder, 2001) e também duas novas formas de energia não covalente: energia de pontes de hidrogênio e energia de solvatação. Essas funções são classificadas em internas (1-5), que descrevem a energia de átomos que são ligados por ligações covalentes; e as externas (6-9), que não possui ligações entre os

\footnotetext{
${ }^{5} \mathrm{O}$ objetivo de uma função de minimização é encontrar o menor valor para um determinado tipo de entrada. No entanto, em problemas de ordem exponencial não é possível percorrer todo o espaço de busca com o objetivo de encontrar o mínimo global, ou seja, o ponto ótimo da função. Para essa classe de problemas são encontrados mínimos locais, pois não é possível determinar se o mínimo local é o mínimo global. Nesses casos, para cada problema em particular, deve-se impor uma métrica que indica se o valor mínimo atingido é suficiente para cumprir as restrições do problema.
} 
átomos (ligações não covalentes) mas que são importantes para manter a estrutura estabilizada. A energia total para um algoritmo de PSP pode ser a soma de todas as funções:

1. Energia de comprimento de ligação $\left(E_{c o m p r}\right)$;

2. Energia de ângulo de ligação $\left(E_{a n g}\right)$;

3. Energia Urey-Bradley ( $\left.E_{\text {urey }}\right)$;

4. Energia imprópria $\left(E_{i m p r}\right)$;

5. Energia de torção $\left(E_{t o r}\right)$;

6. Energia de van der Waals $\left(E_{v w d}\right)$;

7. Energia de carga ou eletrostática $\left(E_{\text {carga }}\right)$.

8. Energia de pontes de hidrogênio ( $\left.E_{h b o n d}\right)$;

9. Energia de solvatação $\left(E_{\text {sasa }}\right)$.

Dessa forma, pode-se escrever:

$$
E_{\text {total }}=E_{\text {compr }}+E_{\text {ang }}+E_{\text {urey }}+E_{\text {impr }}+E_{\text {tor }}+E_{\text {vwd }}+E_{\text {carga }}+E_{\text {hbond }}+E_{\text {sasa }} .
$$

O algoritmo deve calcular a menor soma de todas as energias para tentar encontrar a energia livre da proteína. A energia de van der Waals é uma das energias chamada de energia fraca, no entanto, tem grande influência sobre a estrutura da molécula. Em estudos realizados, mostrou-se que a energia de van der Waals contribui com até $65 \%$ do total da energia livre (Becker et al., 2001) e é um dos métodos que mais consome recursos computacionais ficando atrás apenas da energia eletrostática e solvatação. Isso porque nas energias fracas deve-se calcular a interação de todos os pares de átomos. O algoritmo de van der Waals calcula para todos os átomos que estiverem dentro do raio de $8 \AA$ do átomo em questão, enquanto que na energia eletrostática o raio é de $13 \AA ̊$. Além disso, estudos mais recentes mostraram que o parâmetro de van der Waals tem influência significante no cálculo da energia de solvatação ${ }^{6}$ (Becker et al., 2001).

\subsection{Energia de van der Waals}

A interação de van der Waals é relativamente fraca atraindo moléculas no estado sólido, líquido e gasoso. Ela faz o balanceamento da atração e repulsão entre dois átomos quando a nuvem dos

\footnotetext{
${ }^{6}$ Processo de atração e associação das moléculas do solvente com as moléculas do soluto.
} 
elétrons de cada átomo estão próximas. Em curtas distâncias, a repulsão entre os átomos é grande, pois assim que um elétron de um átomo se aproxima do elétron do outro átomo, eles acabam se repelindo. Enquanto isso, variações aleatórias na posição do elétron ao redor do núcleo, criam uma energia fraca que atrai o núcleo dos dois átomos. Quando a energia de atração está balanceada com a energia de repulsão, diz-se que os núcleos estão em contato de van der Waals. Os efeitos de atração e repulsão são iguais a zero quando a distância entre os átomos é infinita e aumentam conforme a distância diminui. Cada átomo possui uma medida que permite descrever a força que outros átomos poderão se aproximar, chamada de raio de van der Waals. A atração age em distâncias maiores enquanto que a repulsão é mais forte quando os átomos estão próximos. A estabilidade da molécula acontece quando todos os átomos estão em posições ótimas (Nelson \& Cox, 2004).

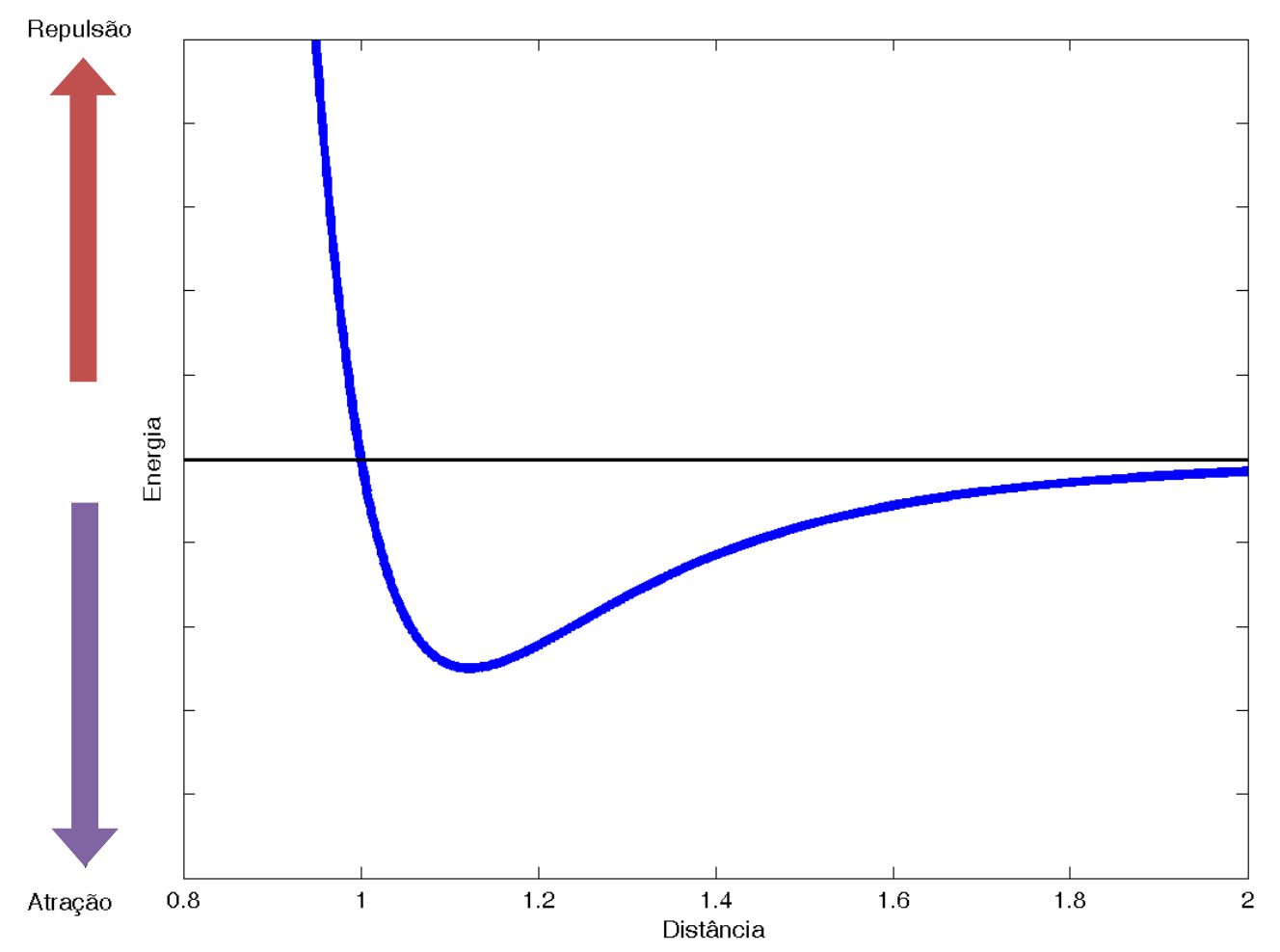

Figura 2.12: Gráfico de van der Waals na forma padrão. É possível visualizar que conforme a distância diminui a energia tende a infinito e quanto maior a distância a energia tende a zero. É mostrado também o ponto ótimo em que existe a estabilidade do sistema, chamado de contato de van der Waals.

A energia de van der Waals é geralmente descrita utilizando o potencial de Lennard-Jones. Isto porque ele reproduz muito bem as forças de van der Waals. A curtas distâncias, a repulsão é forte e a longas distâncias, a atração é fraca. O potencial de Lennard-Jones é também chamado de potencial 12-6, no qual o 12 representa a força de repulsão e o 6 a força de atração. A Equação 2.2 mostra a fórmula geral de Lennard-Jones onde os valores $A$ e $C$ podem ser determinado de várias 
maneiras, como, por exemplo, medidas de dispersão na fase gasosa e a distância dos não ligados em metais.

$$
E_{v d w}=\sum_{i j} \frac{A_{i, j}}{r^{12}}-\frac{C_{i, j}}{r^{6}} .
$$

Para o AG, utilizou-se como termo de van der Waals o potencial de Lennard-Jones. A Equação 2.3 mostra o potencial de van der Waals onde $r=\frac{d_{i, j}}{R_{i}+R_{j}}$ :

$$
f_{v d w}\left\{\begin{array}{r}
1 r^{12}-2 r^{6} \text { se } r<1,25 \\
C \text { se } r \geq 1,25
\end{array},\right.
$$

$d_{i, j}$ é a distância Euclidiana entre os átomos $i, j$ e $C$ é uma constante dada pelo valor $1 r^{12}-2 r^{6}$ onde $r=1,25$. Essa restrição impede que o potencial de van der Waals tenda a infinito quando o par de átomos estiverem próximos demais.

Por fim, a energia de van der Waals total para uma molécula de proteína é a soma da interação de todos os pares de átomos que estão dentro de um raio de $8 \AA$ calculados através de um loop duplo, como mostrado na Equação 2.4 (Cui et al., 1998; Lima, 2006):

$$
E_{v d w}=\sum_{i=1}^{n-1} \sum_{j=i+1}^{n} f_{v d w}\left(\frac{R_{i}+R_{j}}{d_{i, j}}\right) .
$$

A escolha do potencial de Lennard-Jones 12-6 para representar essa função de energia justificase porque, além de modelar a atração e repulsão produzindo bons resultados, é também eficiente. Depois de calculado $r^{6}$, somente é necessário elevar ao quadrado para encontrar $r^{12}$ (Bujnicki, 2009).

\subsection{Considerações Finais}

As proteínas exercem funções fundamentais ao processo da vida. O problema da predição da estrutura da proteína é um dos maiores desafios de toda biologia. Atualmente, as técnicas mais utilizadas para a predição da estrutura da proteína são métodos biofísicos como a CRX e RNM. No entanto, esses métodos possuem muitas limitações e, por este motivo, a predição de estrutura de proteínas utilizando métodos computacionais tem sido alvo de muitas pesquisas. Os métodos baseados em conhecimento, como a homologia e threading têm sido amplamente utilizados. Entretanto, eles dependem de estruturas de proteínas que foram preditas utilizando outros métodos. Por outro lado, o método ab initio, que não é baseado em conhecimento, tem ganhado muita atenção de pesquisadores. A precisão desse modelo em predizer estruturas está relacionada às funções de energia que são empregadas no cálculo da energia livre da proteína. A energia de van der Waals é geralmente utilizada nesses cálculos devido a sua grande influência na estabilidade de uma molécula de proteína. Devido à grande quantidade de conformações possíveis de uma proteína 
e à grande quantidade de cálculos utilizados nas funções de energia, a utilização de heurísticas é essencial no processo de busca por boas soluções. 



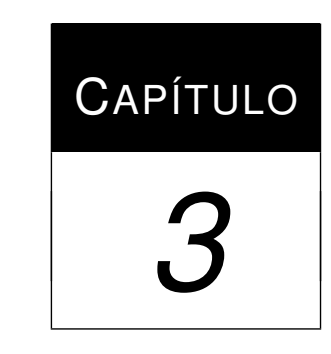

\section{Algoritmos Paralelos}

Este capítulo tem como propósito descrever as técnicas computacionais paralelas que serão utilizadas no desenvolvimento deste projeto. A Seção 3.1 mostra técnicas para construção de algoritmos paralelos. A Seção 3.2 mostra as características para o desenvolvimento de um algoritmo paralelo. A Seção 3.3 explica os dois principais paradigmas de programação paralela. A Seção 3.4 trata das métricas utilizadas para medir desempenho dos algoritmos paralelos. Por fim, a Seção 3.5 mostra as considerações finais deste capítulo.

\subsection{Técnicas de Paralelização}

O desenvolvimento de um algoritmo sequencial é uma das maneiras mais simples de se construir algoritmos. A preocupação que existe para um desenvolvedor de um algoritmo sequencial, é que, a partir de um conjunto de parâmetros de entrada, a saída esteja sempre correta. O que geralmente dá ganho de desempenho a esses algoritmos é o paralelismo implícito, presente na arquitetura dos processadores, como pipelines e superescalar (Balakrishnan, 2001), no qual o desenvolvedor de software não é capaz de gerenciar a forma que esse paralelismo é feito (Grama et al., 2003). Por outro lado, um programador de software paralelo deve ter uma visão bidimensional do algoritmo para conseguir enxergar como um problema pode ser resolvido e como vai utilizar os recursos disponíveis de forma a maximizar sua eficiência. Na Figura 3.1 é possível visualizar que, no desenvolvimento de algoritmos paralelos, o programador deve ter controle da interação dos processos em função do tempo, enquanto que, no paradigma de desenvolvimento sequencial, o controle do processo é feito utilizando a mesma linha de execução de tempo. 

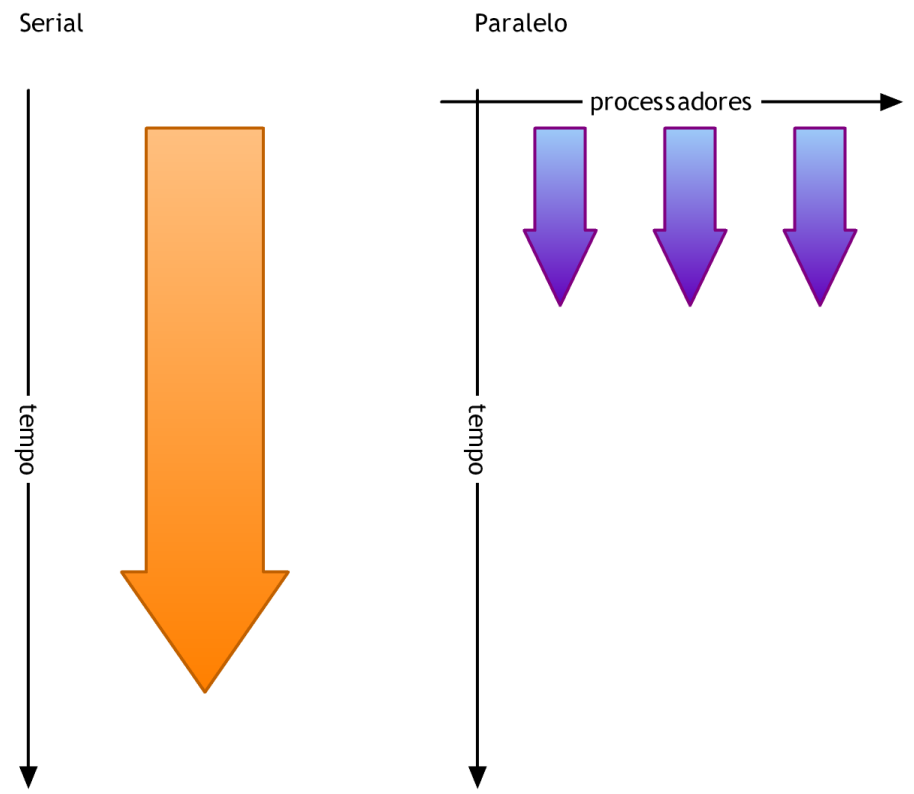

Figura 3.1: Paradigmas de programação sequencial (unidimensional) e paralelo (bidimensional).

Embora o entendimento de algoritmos paralelos seja essencial para a área da computação de alto desempenho (High Performance Computing, HPC), é necessário também entender a arquitetura dos computadores paralelos. $\mathrm{O}$ desenvolvimento de uma nova arquitetura de um computador paralelo deve ser planejado cuidadosamente. Os micro-processadores evoluem muito rapidamente, enquanto que o desenvolvimento de uma arquitetura de computador paralelo envolve muitos custos e tempo. Com isso, o lançamento de um novo computador paralelo, envolvendo várias unidades de processamento, pode já estar obsoleta em comparação com a arquitetura de um micro-processador convencional que evoluiu ao decorrer desse tempo. Isso talvez justifique o fato da maioria dos computadores mais rápidos do mundo utilizarem processadores convencionais (Quinn, 2004, 1994) em forma de clusters e grids (Bell \& Gray, 2002). No site Top500 (TOP500 Supercomputer Sites, 2009) é possível ver a lista dos 500 computadores mais rápidos do mundo, que são em sua maioria clusters de processadores convencionais.

O uso efetivo de todos os recursos disponíveis em um sistema computacional paralelo é praticamente impossível. A latência da memória é um grande limitante do desempenho do sistema (Quinn, 2004). Geralmente, o tempo de acesso à memória RAM é 100 vezes mais lento que um ciclo do processador. Isso quer dizer que, toda vez que o processador precisa de um dado que está na RAM, ele deverá aguardar 100 ciclos de clock até seu dado chegar, para que em seguida possa fazer a computação. No entanto, existem técnicas que conseguem reduzir essa latência, como a utilização de caches e multithreading. Além disso, quanto maior é o número de processadores, maior é a dificuldade em manter a uniformidade e o controle dos dados que irão trafegar pela topologia (Grama et al., 2003).

Sempre que o desempenho de um algoritmo sequencial superar qualquer implementação paralela, diz-se que o problema não pode ser paralelizado. Em alguns casos, implementações paralelas podem gerar um overhead, ou seja, um custo adicional causado pela implementação paralela, que 
impede que sua eficiência seja maior que a do algoritmo sequencial. O desenvolvimento de algoritmos paralelos, capazes de explorar eficientemente os recursos do computador paralelo, requer esforço e tempo. Algumas áreas em que a computação paralela tem sido utilizada com sucesso são: Engenharia e Desenvolvimento; Aplicações Comerciais; Aplicações Financeiras; Aplicações Geofísicas; e Aplicações Científicas. Nas seções seguintes, serão abordadas as principais técnicas para obter sucesso no desenvolvimento de um algoritmo paralelo.

\subsection{Desenvolvimento de Algoritmos Paralelos}

O desenvolvimento de um algoritmo paralelo pode começar a partir da própria implementação sequencial já existente, ou desconsiderá-la inteiramente e iniciar o desenvolvimento de forma independente. Neste caso, o tempo de elaboração do algoritmo pode ser muito maior que tentar identificar porções da versão sequencial. O ideal, no desenvolvimento de algoritmos paralelos, é pensar no paralelismo que se pode produzir em relação ao problema, ou seja, compreender inteiramente o problema e identificar as partes dele que podem ser paralelizadas. Para isso, o desenvolvimento de algoritmos paralelos requer (Grama et al., 2003):

1. Identificar porções do problema que podem ser executadas concorrentemente;

2. Mapear as partes concorrentes em múltiplos processos;

3. Gerenciar os dados que serão acessados pelos vários processadores;

4. Sincronizar os processos.

O processo de dividir a computação em pequenos conjuntos é chamado de decomposição. A decomposição pode ser feita de várias maneiras, as principais delas são: decomposição recursiva, decomposição por dados, decomposição exploratória e decomposição especulativa. A decomposição recursiva, exploratória e especulativa são geralmente utilizadas em problemas mais específicos enquanto que a decomposição por dados é amplamente empregada à maioria dos problemas (Grama et al., 2003).

Os conjuntos formados por meio da decomposição são chamados de tarefas. As tarefas são definidas pelo programador e, embora sejam de tamanho arbitrário, o tamanho de cada tarefa é relativo ao tempo necessário para completá-la. Quando o tamanho das tarefas varia pouco, então as tarefas são uniformes e, caso contrário, são chamadas de não uniformes. A geração das tarefas pode ser estática ou dinâmica. Quando todas as tarefas são conhecidas a geração de tarefas é estática como, por exemplo, em uma multiplicação de matrizes: conhecendo o tamanho das matrizes é possível conhecer o número de tarefas. Entretanto, a geração das tarefas é dinâmica quando não se tem conhecimento da criação das tarefas, ou parte delas, antes do início do algoritmo. Isso ocorre geralmente em decomposições recursivas como no algoritmo paralelo do quicksort (Cormen et al., 2002). 
As tarefas, na maioria dos casos, precisam interagir com outras tarefas, seja para compartilhar dados, computação ou informação de sincronismo. Por esse motivo, as tarefas são agrupadas de maneira abstrata, expressando a dependência que existe entre elas. Isso é feito por meio de um grafo direcionado e acíclico chamado de grafo de dependência de tarefas. Nesse grafo, os nós correspondem às tarefas e as arestas indicam a dependência que existe entre elas (Figura 3.3). Uma tarefa só pode ser executada quando todos os nós das arestas incidentes já tiverem sido executados. Existem várias classificações que caracterizam as interações de tarefas, como é possível ver na Tabela 3.1.

Tabela 3.1: Tabela de características de interação entre tarefas.

\begin{tabular}{|c|c|c|c|}
\hline Estática & Regular & Somente leitura & Unidirecional \\
\hline $\begin{array}{l}\text { O grafo de dependên- } \\
\text { cia é conhecido previa- } \\
\text { mente. } \\
\text { Dinâmica }\end{array}$ & $\begin{array}{l}\text { Possui estrutura que pode } \\
\text { ser explorado eficiente- } \\
\text { mente. } \\
\text { Irregular }\end{array}$ & $\begin{array}{l}\text { Requer somente leitura } \\
\text { ao dado compartilhado } \\
\text { entre as tarefas. } \\
\text { Leitura/Escrita }\end{array}$ & $\begin{array}{l}\text { Um par de tarefas não } \\
\text { interfere nos outros (So- } \\
\text { mente leitura). } \\
\text { Bidirecional }\end{array}$ \\
\hline $\begin{array}{l}\text { O grafo de dependência } \\
\text { não é conhecido previa- } \\
\text { mente. }\end{array}$ & $\begin{array}{l}\text { Não existe padrões regu- } \\
\text { lares entre as interações. }\end{array}$ & $\begin{array}{l}\text { Uma tarefa pode ler e es- } \\
\text { crever no mesmo local } \\
\text { de outra. }\end{array}$ & $\begin{array}{l}\text { Uma tarefa é explici- } \\
\text { tamente abastecida por } \\
\text { outra (Somente leitura e } \\
\text { Escrita/Leitura). }\end{array}$ \\
\hline
\end{tabular}

A granularidade determina o número e o tamanho das tarefas pelo qual o problema é decomposto. A granularidade é fina quando as tarefas são decompostas em grandes quantidades de pequenas tarefas e a granularidade é grossa quando a decomposição é feita por meio de poucas tarefas que são grandes. Na prática, quanto mais uma tarefa aproxima-se de uma expressão aritmética computacional, mais fina é sua granularidade e quanto maior o conjunto de operações contidas dentro de uma tarefa, mais grossa será a granularidade. A Figura 3.2 mostra um exemplo de três decomposições de tarefas distintas.

O grau de concorrência de um programa paralelo é a quantidade de tarefas que são executadas simultaneamente. O grau máximo de concorrência é o maior número de tarefas que podem ser executadas ao mesmo tempo. Em um grafo de tarefas de dependência, o caminho desde o topo até o fim do grafo, passando pelos nós com maior peso, é chamado de caminho crítico. O peso de um nó pode ser, por exemplo, o tempo de execução da tarefa ou a quantidade de operações aritméticas da tarefa. A Figura 3.3 ilustra um exemplo de grafo de dependência contendo a quantidade e o peso das tarefas, assim como também o caminho crítico e o grau de concorrência. É possível visualizar que o grau máximo de concorrência é quatro e o caminho crítico recebe o valor 45 .

Após o grafo de dependência de tarefas ter sido construído, as tarefas são associadas a processos. Esse agrupamento de tarefas em processos é chamado de mapeamento. O mapeamento é um fator determinante na redução de tempo que um programa paralelo pode atingir. Sua máxima eficiência é obtida quando existe um bom balanceamento entre a minimização de interações entre os 
A

a)

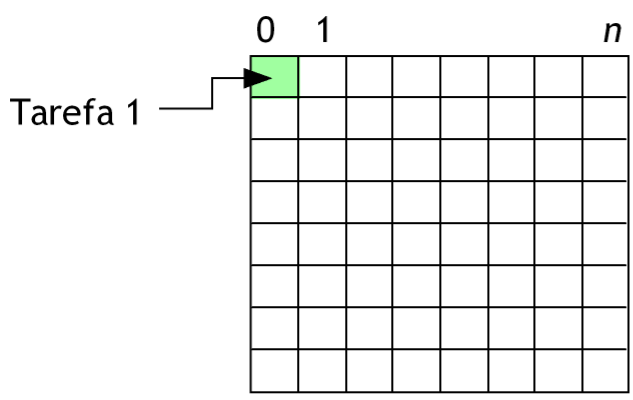

A

b)

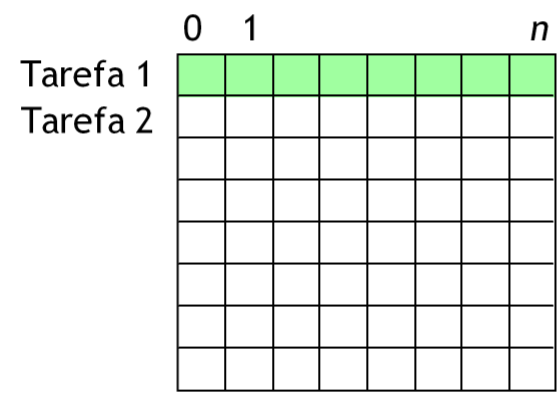

A

c)

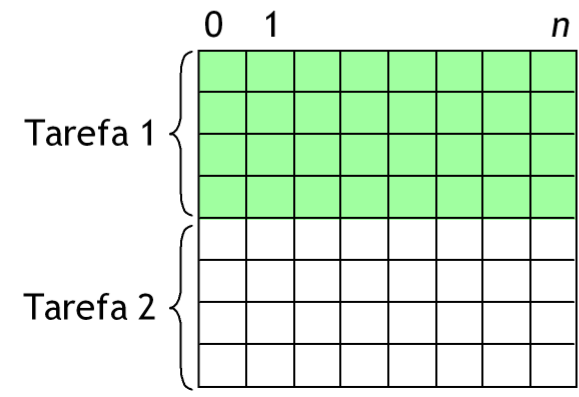

b y

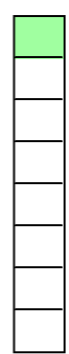

b

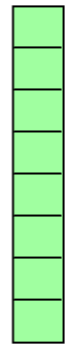

b

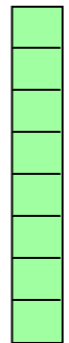

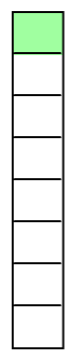

y

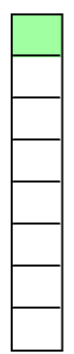

y

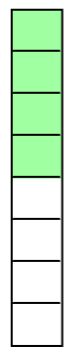

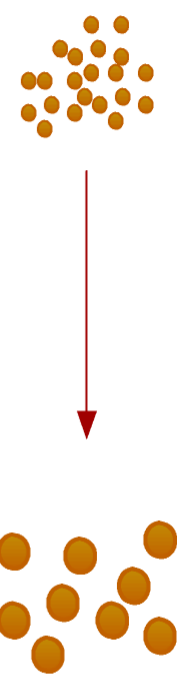

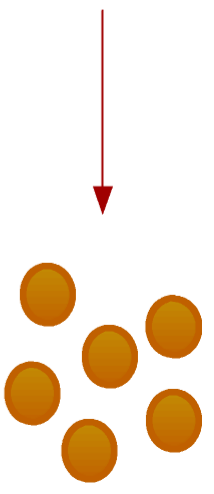

Figura 3.2: Exemplos de decomposição de tarefas e de granularidade na multiplicação de uma matriz por um vetor. a) Granularidade fina (pouca computação para cada tarefa). b) Granularidade média. c) Granularidade grossa (muita computação para cada tarefa).

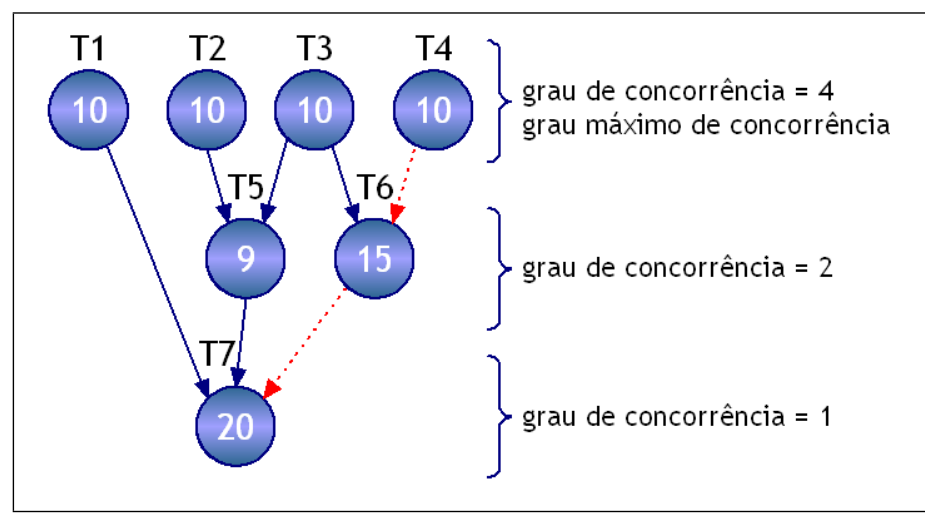

Figura 3.3: Exemplos de grafo de dependência. Cada nó é uma tarefa que contem um peso correspondente ao tamanho da computação. A linha tracejada indica o caminho crítico. 
processos e maximização do uso da concorrência. Além disso, deve existir um balanceamento de carga entre os processos, para impedir que processos fiquem ociosos. Quando é possível distribuir as tarefas aos processos antes da execução do algoritmo o mapeamento é estático e quando as tarefas são distribuídas aos processos durante a execução do algoritmo o mapeamento é dinâmico.

A interação entre os processos geram overheads devido a necessidade que os processos têm de se comunicar. No desenvolvimento de algoritmos paralelos é importante utilizar técnicas que diminuem o overhead, como:

- Minimizar o volume de troca de dados;

- Minimizar a frequência em que as interações são feitas;

- Minimizar a disputa por recursos compartilhados (para não deixar processos ociosos);

- Sobrepor interações com outras interações;

- Sobrepor computação com interação;

- Replicar dados ou computações (quando o custo de replicar é menor que o custo de interação);

- Utilizar operação de interação coletiva que são otimizadas (Grama et al., 2003) (como exemplo, tem-se algumas operações presentes no MPI, Seção 3.3);

\subsection{Modelos de Programação Paralela}

Existem diversos modelos de programação paralela disponíveis para serem utilizados nas implementações. Esses modelos baseiam-se em dois paradigmas distintos: passagem de mensagens e memória compartilhada (Grama et al., 2003). Basicamente, eles são distintos pela maneira em que os processos interagem (Figura 3.4).

\subsubsection{Programação por Passagem de Mensagens}

A programação por passagem de mensagens, também conhecida como message-passing, é caracterizada por utilizar um espaço de endereçamento particionado pertencente a cada processador, como mostrado na Figura 3.4(a). A interação entre os processos ocorre explicitamente definida pelo programador. Quando um processo precisa de um dado que não está sob seu escopo, deverá solicitar ao outro processo (que contém o dado) para que o dado seja enviado. Isso implica que, em todas as interações (leitura e escrita ou somente leitura), é indispensável a cooperação do processo que requisitou o dado e do processo que possui o dado. Essas interações são feitas através de operações básicas de comunicação ponto-a-ponto chamadas de send e receive. A grande vantagem desse paradigma de programação é que pode ser implementado na maioria das arquiteturas 
a)

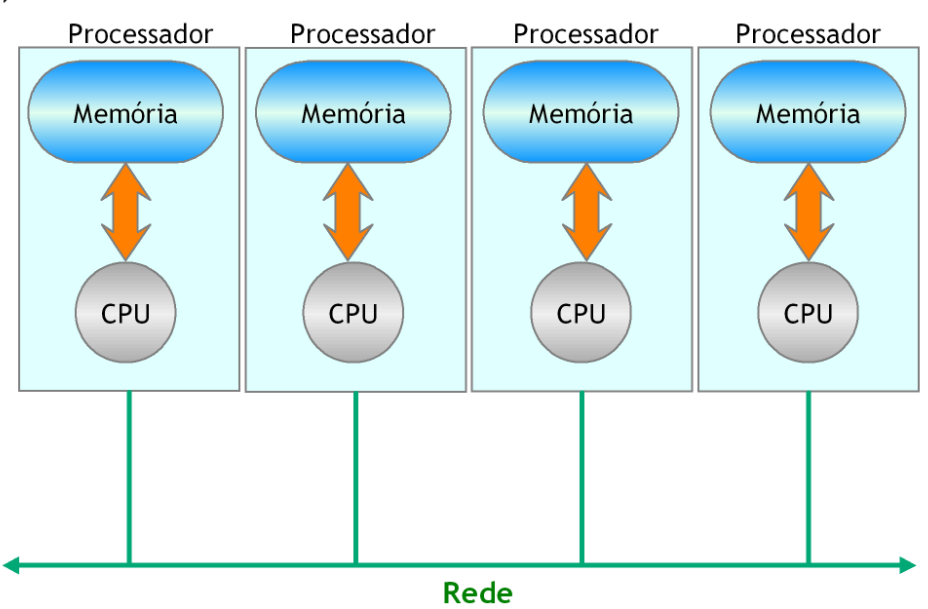

b)

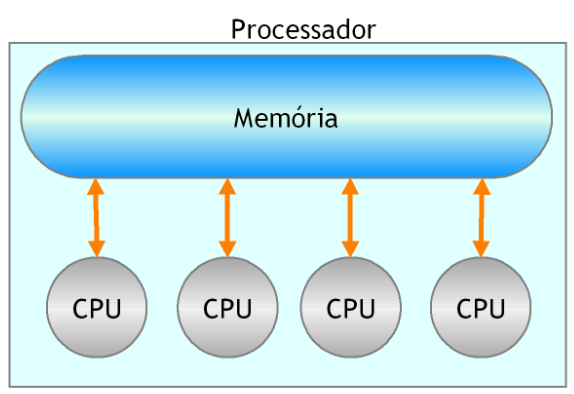

Figura 3.4: Modelos de programação paralela. a) Programação paralela utilizando passagem de mensagens. b) Programação paralela utilizando memória compartilhada.

e, na maioria dos casos, resulta em bom desempenho mesmo utilizando um grande número de processadores. Existem várias bibliotecas que implementam a abordagem de passagem de mensagens, como p4, PVM, Express e PARMACS. O MPI (Message Passing Interface) é o modelo mais comum e utilizado nas implementações atualmente (Grama et al., 2003; Foster, 1995).

\subsubsection{Programação Utilizando Memória Compartilhada}

Nesse paradigma de programação a comunicação entre os processos é implícita devido ao fato de que a mesma memória é acessada por todos processadores, como mostrado na Figura 3.4(b). Por esse motivo, o objetivo desse modelo de programação é expressar a concorrência e o sincronismo por meio de técnicas que reduzem o overhead de interação entre processos.

Apesar de todos os processos serem capazes de enxergar toda a memória, cada processo tem suas próprias variáveis privadas. Processos de aplicações distintas não têm necessidade de acessar variáveis de outros processos. No entanto, em situações em que vários processos são utilizados para resolver o mesmo problema, é interessante ter acesso a variáveis privadas de outros processos. Isso pode gerar um overhead causado pela tentativa de evitar a condição de disputa. Nesse caso, com a utilização de threads, existe uma região na memória global em que todas as threads são capazes de ler, e com isso, o acesso às variáveis são mais rápidos.

O uso de threads tem outras vantagens: (1) é possível desenvolver todo o algoritmo em um computador serial e rodá-lo em um paralelo; (2) enquanto uma thread aguarda por um dado que está na memória, outra pode fazer alguma computação; (3) o overhead de mapeamento de tarefas dinâmico é baixo e são mais simples de implementar. Existem diversas bibliotecas para threads. Os modelos mais comuns de programação paralela são PThreads (Barney, 2009) e OpenMP (Chapman et al., 2007). 
O modelo de programação paralela utilizando memória compartilhada tem a desvantagem de apresentar problemas de escalabilidade. Não é comum encontrar grandes computadores paralelos que utilizem memória compartilhada, embora atualmente a maioria dos processadores para desktop, têm sido vendidos com dois e quatro núcleos de processamento (Grama et al., 2003).

\subsection{Métricas Utilizadas nos Sistemas Paralelos}

A avaliação do desempenho de um algoritmo sequencial geralmente é feita medindo seu tempo de execução em função do tamanho da entrada. Nos algoritmos paralelos, a avaliação deve considerar também a quantidade de processadores e o tempo de overhead da interação entre processos. A maioria dos algoritmos paralelos não são inteiramente paralelos, pois possuem porções que não podem ser paralelizadas, sendo executadas sequencialmente. Na avaliação de dois algoritmos que produzem os mesmos resultados, mas um é paralelo e outro é sequencial, deve-se comparar os trechos do algoritmo paralelo com o mesmo trecho do algoritmo sequencial.

O principal objetivo do desenvolvimento de algoritmos paralelos de versões sequenciais é obter o máximo de desempenho. O tempo de execução total de um algoritmo sequencial é conhecido como $T_{s}$. O tempo total de computação de algoritmos paralelos, $T_{p}$, é computado a partir do momento que a computação paralela começou até o término do último processo. O speedup, $S$, também chamado de ganho de desempenho, é uma medida que determina o benefício de um algoritmo paralelo, como mostrado na Equação 3.1

$$
S=\frac{T_{s}}{T_{p}}
$$

O speedup ideal é igual ao número de processos $(p)$. Em alguns casos, o speedup pode ser super-linear, ou seja, maior que o número de processadores, que pode ocorrer devido à utilização de caches, à não utilização de memória virtual e também devido a algumas decomposições de tarefas para problemas específicos.

A Equação 3.2 define a eficiência $E$ de um algoritmo paralelo como sendo a razão do speedup pelo número de processadores $(p)$. O ideal é atingir 100\% $(E=1)$ de eficiência. No entanto isso dificilmente é possível, pois os processadores não podem dedicar-se inteiramente às computações, uma vez que realizam também o gerenciamento das interações com outros processos, o que não ocorre no paradigma sequencial (Grama et al., 2003).

$$
E=\frac{S}{p}
$$




\subsection{Considerações Finais}

$\mathrm{Na}$ construção de um algoritmo paralelo, é preciso identificar as porções do algoritmo que podem ser paralelizadas. Para isso, o problema deve ser dividido em tarefas e mapeado em processos. Em seguida, o programador deve ter controle dos dados que irão interagir entre os processos. A arquitetura de hardware na qual o programa paralelo irá ser executado deverá ser considerada para se determinar o paradigma de programação: memória compartilhada ou por passagem de mensagens.

O objetivo em desenvolver um algoritmo paralelo é consumir menos tempo de execução em comparação ao mesmo problema executado por um algoritmo sequencial maximizando os recursos disponíveis. Essa avaliação é feita utilizando fórmulas básicas como o speedup e o cálculo da eficiência. 



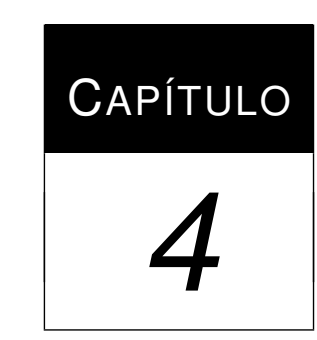

\section{Algoritmos Genéticos}

Os AGs foram inicialmente introduzidos por John Holland em 1975 (Holland, 1975) e seus alunos. Estes estudaram o processo da evolução natural, adaptando-o para ser utilizado em problemas computacionais com o objetivo de encontrar soluções para problemas complexos. Esses algoritmos pertencem a uma classe de técnicas de otimização chamada de algoritmos evolutivos que investigam um conjunto de soluções em paralelo e utilizam informações dessa investigação para gerar um novo conjunto com soluções potencialmente melhores. AGs têm sido utilizados para explorar o espaço de busca de problemas complexos utilizando o mínimo de informação (Alba, 2005). A Seção 4.1 mostra o relacionamento do AG com a Biologia, a Seção 4.2 mostra populações iniciais, a Seção 4.3 mostra algumas maneiras para representar um indivíduo, a Seção 4.4 apresenta os operadores genéticos e a Seção 4.5 detalha o algoritmo básico de um AG.

\subsection{Base Biológica}

A base dos AGs é o funcionamento do processo evolutivo. O processo evolutivo admite que os principais fatores evolutivos são a recombinação, a mutação e a seleção natural. Para isso, é necessário que exista uma população de indivíduos que competem por recursos limitados de forma a medir a habilidade deles em sobreviver e reproduzir. Além disso, deve existir a variabilidade e hereditariedade, para que os filhos tenham parte do material genético dos pais, mas não sejam cópia deles.

Os AGs possuem um conjunto de soluções formando uma população. A representação de cada solução (indivíduo) é também conhecida como cromossomo. Os cromossomos são formados por 
vários genes, que em geral correspondem às variáveis de um problema. Os diferentes valores que um gene pode assumir são chamados alelos. A posição que um determinado gene pode assumir é denominada locus. A Figura 4.1 ilustra uma representação de dados binária de 8 bits com uma população de 7 indivíduos. Cada linha dessa matriz representa um cromossomo e cada posição dessa linha representa um gene. Em comparação à Biologia, o cromossomo (por exemplo, um vetor binário $x$ ) é conhecido como o genótipo do indivíduo e a sua manifestação é chamada de fenótipo, em geral o valor de $f(x)$, onde $f$ é uma função objetivo do problema ou uma função baseada em $f$ que mede a aptidão do indivíduo. Essa função também é chamada de fitness. Quanto maior seu fitness, melhor é sua aptidão e maiores são as chances do indivíduo sobreviver para a próxima geração.

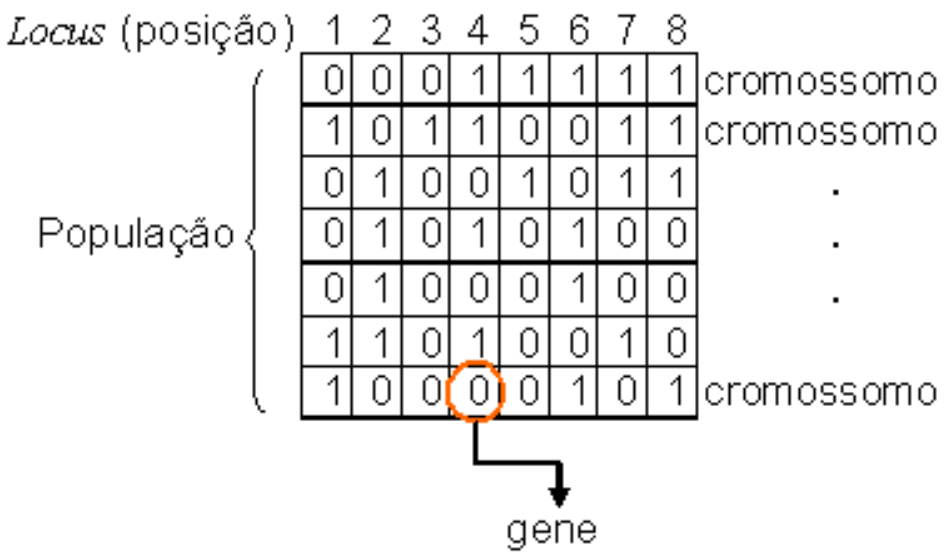

Figura 4.1: Exemplo da população de indivíduos.

Um exemplo de aplicação para os AGs é o problema de otimização combinatorial da mochila binária, o qual procura a melhor solução dentre muitas outras possíveis (Hristakeva \& Shrestha, 2004). Esse problema consiste em uma mochila, com certa capacidade e, deseja-se adicionar a maior quantidade de itens disponíveis sem exceder sua capacidade. Pode ser utilizada uma representação binária para os cromossomos, da mesma forma da Figura 4.1, onde o alelo 0 indica que o item não irá pertencer ao conjunto de solução e 1 caso pertença. Todos os cromossomos devem conter soluções factíveis para o problema, a diferença entre os indivíduos é que alguns contem soluções melhores que outros. Supondo que os pesos dos itens são: $0,5 \mathrm{~kg} ; 0,1 \mathrm{~kg} ; 1,5 \mathrm{~kg}$; 2,0kg; 1,4kg; 0,9kg; 0,2kg; $1 \mathrm{~kg}$. Para o primeiro indivíduo da Figura 4.1 seu genótipo é 00011111 , assim, seu fenótipo é $4,5 \mathrm{~kg}$.

\subsection{População Inicial}

A população é formada por um conjunto de genótipos que descrevem as possíveis soluções. Quanto maior o número de soluções diferentes, maior é a diversidade da população. Todo início de execução de um AG parte de uma população inicial. A criação dessa população inicial geralmente é feita atribuindo valores aleatórios aos indivíduos. Para problemas específicos, pode-se criar uma 
população inicial que utilize o conhecimento prévio disponível. Com isso, a aptidão dos indivíduos começa com soluções relativamente mais próximas do valor de uma solução ótima.

\subsection{Representação de Indivíduos}

Os indivíduos de uma população podem ser representados de diferentes formas. Essa representação pode ser uma estrutura de dados mais complexa que simplesmente um array de bits (ver Figura 4.2) conforme apresentado na Seção 4.1. A representação é um fator muito importante para o desempenho de um AG, principalmente para problemas mais complexos. Segundo Rothlauf (2006), o tipo mais comum de representação é a representação binária. Entretanto, a representação mais adequada depende do problema em questão. Outros tipos de representação de um cromossomo podem ser, por exemplo, variáveis contínuas ou discretas, além de representações criadas para problemas envolvendo grafos como vetor de características e número de Prüfer (Rothlauf, 2006; Lima \& Delbem, 2007).

(a)

\begin{tabular}{|l|l|l|l|l|l|l|l|}
\hline 8 & 3 & 2 & 1 & 9 & 5 & 6 & 2 \\
\hline
\end{tabular}

(b)

\begin{tabular}{|l|l|l|}
\hline 1,35 & 0,54 & $-1,89$ \\
\hline
\end{tabular}

Figura 4.2: Exemplos de representações de cromossomos: (a) Representação inteira. (b) Representação com ponto-flutuante.

\subsection{Operadores de Reprodução}

Os principais operadores envolvidos com a reprodução de um AG são: a mutação, o crossover, a seleção e o elitismo, que são descritos a seguir.

\subsubsection{Mutação}

O operador de mutação modifica aleatoriamente um ou mais genes do cromossomo. A probabilidade dessa mutação ocorrer sobre um gene é determinada por uma taxa de mutação. Isso é feito para perturbar as soluções tentando manter diversidade na população e evitar a convergência prematura, ou seja, impedir que a população perca diversidade rapidamente acabando presa em regiões não promissoras (ótimos locais). Entretanto, a taxa de mutação geralmente não é muito alta para que assim o algoritmo não se aproxime de um método de busca aleatório. A convergência prematura de uma população ocorre quando quase todos os indivíduos são iguais; em geral, nesse caso, utiliza-se o índice de 90\%. Dessa maneira, na maioria dos cruzamentos, os filhos serão iguais aos pais.

A Figura 4.3 mostra um exemplo de mutação baseado na representação binária do exemplo da Figura 4.1. O segundo bit sofreu uma mutação passando seu valor de 0 para 1. Portanto, o 
fenótipo desse indivíduo que era 4,5kg passou para 4,6kg (Exemplo da Seção 4.1) e, nesse caso, se a capacidade da mochila for maior ou igual a 4,6kg, o genótipo 01011111 é melhor que 00011111.

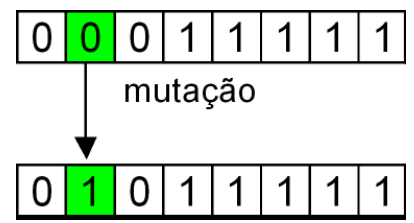

Figura 4.3: Exemplo de bit alterado pela mutação.

\subsubsection{Crossover}

O operador mais comum aplicado a dois indivíduos (pais) para gerar outros é o operador de crossover (ou recombinação). Existem vários modelos de aplicação de crossover. O mais comum é o crossover de um ponto: é escolhida uma posição aleatória de dois cromossomos pais onde será o ponto de corte separando cada cromossomo em duas partes. Um dos filhos (novos indivíduos) irá conter parte do material genético do primeiro pai e parte do segundo. O segundo filho irá conter a outra parte do segundo pai e a outra parte do primeiro pai. A quantidade de pontos de corte de um indivíduo está relacionada ao seu tamanho: como pode ser visto no cromossomo de oito genes da Figura 4.4, a quantidade máxima de pontos de corte possíveis é sete. Se o cromossomo tivesse apenas duas posições, poderia haver somente um ponto de corte. Considerando que $l$ é a quantidade de genes de um cromossomo, a quantidade máxima de pontos de corte é $l-1$.
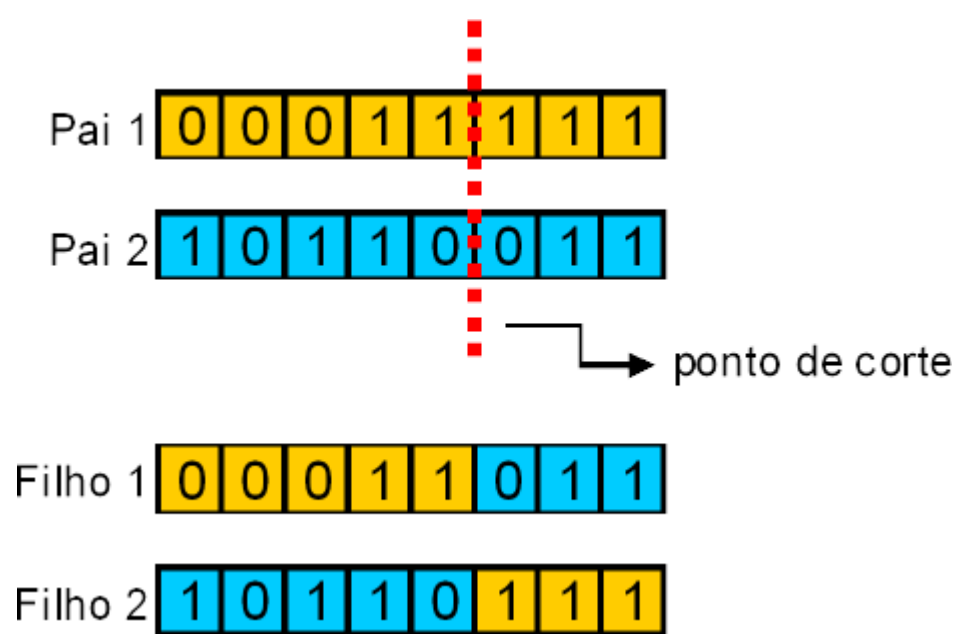

Figura 4.4: Crossover de um ponto, com corte na posição destacada pela linha tracejada.

Utilizando um crossover de dois ou mais pontos, um filho conterá mais de um trecho do cromossomo de um dos pais. É possível realizar o crossover com mais de dois pais, resultando em mais de dois filhos. Dependendo da representação e do problema relacionado, o operador de crossover pode ser diferente. Por exemplo, se ao invés de utilizar a representação de um vetor binário, um cromossomo fosse representado por um número real, o crossover de dois pais $p_{1}=1,50$ e $p_{2}=4,00$, poderia ser a média entre eles resultando em um único filho $f=2,75$. Na 
verdade, um dos crossovers mais adequados para números reais é o sorteio de um número aleatório no intervalo $\left[p_{1}-\frac{\Delta}{2}, p_{2}+\frac{\Delta}{2}\right]$, onde $\Delta=p_{2}-p_{1}$, para $p_{2}>p_{1}$ (Deb, 2001).

\subsubsection{Seleção de Indivíduos}

A cada iteração, também conhecida como geração, o algoritmo deve decidir quais indivíduos devem participar da próxima geração. Isso é feito por um dos vários esquemas de seleção existentes (Alba, 2005):

1. Baseada em Rank;

2. Roleta;

3. Torneio.

A escolha de qual método de seleção utilizar é uma das mais importantes decisões na elaboração de um AG, pois causará fortes impactos na convergência do algoritmo, podendo tornar a convergência lenta, acelerá-la ou mesmo causar convergência prematura. Um dos métodos mais simples é a seleção baseada em rank. Este ordena a população com base no fitness e seleciona um subconjunto da população com os melhores indivíduos. Esse subconjunto serão os pais da próxima geração. Outro método de seleção é o método da roleta. Este método ordena as possíveis soluções com base no fitness de cada indivíduo e atribui uma probabilidade a cada uma dessas soluções. Quanto maior o fitness do indivíduo maior é sua probabilidade de ser escolhido para ser pai. No entanto, esse método pode trazer algumas desvantagens. Se a probabilidade de escolha de alguns indivíduos for muito alta (bons indivíduos), eles provavelmente irão dominar a população causando uma convergência prematura. Além disso, se o fitness desses indivíduos forem muito próximos uns dos outros, quase não haverá pressão de seleção, ou seja, não conseguirá distinguir os indivíduos que são melhores, aproximando-se de uma busca aleatória (Eiben \& Smith, 2003).

A seleção por torneio é uma alternativa mais interessante. Essa técnica seleciona aleatoriamente um subconjunto da população de tamanho $k$, geralmente de dois indivíduos $(k=2)$. Dentre os indivíduos escolhidos, o melhor deles, baseado no fitness, é o ganhador e será um pai. Por esse motivo, a seleção por torneio não depende de um conhecimento global da população. Além disso, esse método depende diretamente do rank dos indivíduos na população, permitindo assim, uma pressão de seleção não tendenciosa e facilmente controlada somente pelo tamanho do subconjunto do torneio $(k)$ (Eiben \& Smith, 2003).

\subsubsection{Elitismo}

Em alguns casos, há o uso do elitismo impedindo que a próxima geração tenha indivíduos na população piores que o melhor indivíduo da geração atual (Alba, 2005). O grau de elitismo pode 
variar: no exemplo da Figura 4.3, após escolhido o pai e realizada a mutação nele (gerando um filho), se o filho tiver um fitness melhor que o pai então o filho vai para a próxima geração, caso contrário, o pai permanece na população.

Há também casos em que a cada geração apenas um filho é gerado para a próxima geração, podendo assim pai e filho coexistir sendo que o novo filho substituirá um indivíduo ruim, provavelmente o pior indivíduo da população. Uma estratégia sem nenhum nível de elitismo pode ser implementada gerando um número total de filhos igual ao tamanho da população e substituindo a população inteira pelos filhos na próxima geração.

\subsection{Algoritmo Base}

O Algoritmo 1 descreve o pseudo-código de um AG típico. A variável $t$ armazena o número da geração. A $P(t)$ armazena a população na geração $t$ e $P^{\prime}$ é a população temporária utilizada para geração de novos indivíduos. Ao final do algoritmo, a nova geração, ou seja, $P(t+1)$ conterá os melhores indivíduos entre as duas populações.

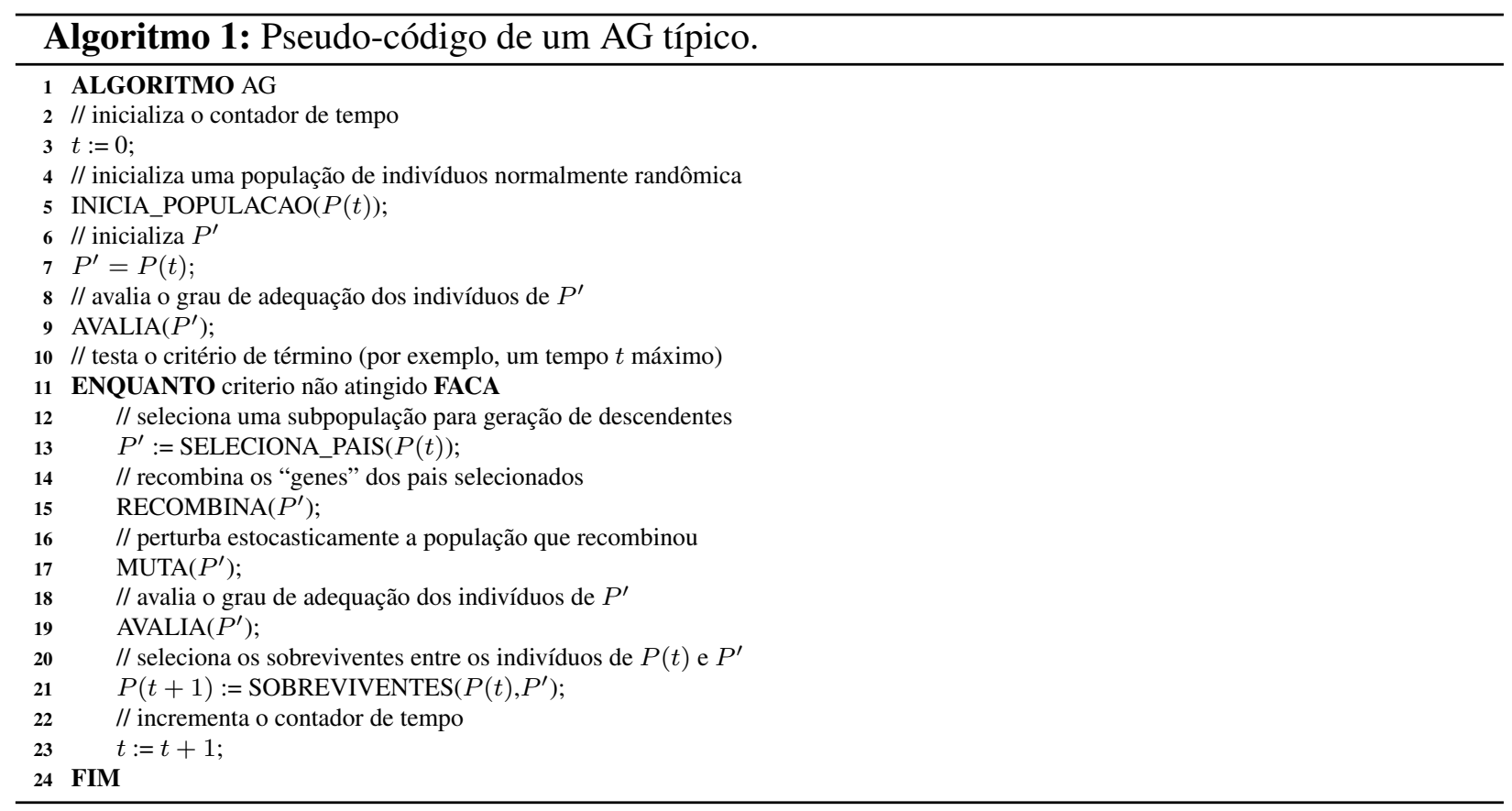

\subsection{Algoritmos Genéticos Paralelos}

Uma das mais promissoras formas de melhorar o desempenho dos AGs é por implementações paralelas (Alba, 2005), a fim de reduzir o tempo de execução do algoritmo. Os AGs paralelos não apresentam grandes dificuldades em suas implementações. Existem muitas pesquisas sobre as implementações de AGs paralelos (Cantú-Paz, 1997). 
Grande parte do tempo consumido por um AG é para o cálculo da função de avaliação de cada indivíduo. Supondo que o fitness de cada indivíduo possa ser calculado de forma independente, os AGs podem ser paralelizados nesse sentido. No entanto, os AGs paralelos são controlados por muitos parâmetros que podem significativamente alterar a qualidade da busca (Alba, 2005). O desenvolvimento de um AG paralelo envolve muitos fatores como, por exemplo, decidir se serão utilizadas populações simples ou multi-populações espalhadas nos processadores. Nos dois casos, o tamanho da população deve ser escolhido cuidadosamente e, no caso de AGs multi-populacionais, deve-se também ter cuidado na escolha do número de populações. Além disso, deve ser escolhido também se haverá troca de indivíduos entre as populações (migrações) ou se serão populações isoladas, assim como a quantidade de indivíduos que fará migrações entre as populações.

Quando se trata de computadores paralelos, existem muitos fatores que podem influenciar o desempenho final. Por exemplo, o tempo de comunicação depende bastante dos parâmetros de hardware e software, incluindo a banda da rede, topologia em que a comunicação está organizada e número de nós que participam do processo (Le \& Rejeb, 2006).

A idéia básica de um AG paralelo é dividir o problema em partes e resolvê-los utilizando múltiplos processadores (Cantú-Paz, 1997), ou seja, dividir a população em muitas subpopulações independentes uma das outras (Saroj \& Shaveta, 2004). A interação entre subpopulações ocorre por migrações onde indivíduos de uma subpopulação emigram para outra, enquanto que o indivíduo de outra subpopulação imigra para a subpopulação que teve seu indivíduo emigrado. Isso é feito para garantir uma maior diversidade entre as subpopulações. Há várias classificações de AGs paralelos. Alba (2005) considera quatro classes principais:

1. Single-population master-slave [global parallelization (Rivera, 2001)];

2. Multiple-population [coarse-grained parallel GAs (Cantú-Paz, 1997)];

3. Celular [fine-grained parallel GAs (Cantú-Paz, 1997)];

4. Hierarchical hybrids.

\subsubsection{Single-population master-slave}

A maneira mais simples de implementar um AG paralelo é distribuir a função de cálculo do fitness em vários processadores escravos (slaves) enquanto o mestre (master) executa as operações genéticas básicas como crossover, mutação e seleção (Figura 4.5). Essa classificação possui alguns pontos importantes: 1) o espaço de busca explorado pelo algoritmo é o mesmo que o serial; 2) implementação é simples; 3) em geral, as vantagens são significativas.

O desempenho dessa classificação está fortemente relacionado ao tempo de computação necessário para a função de cálculo do fitness, as quais são realizadas nos escravos. Quanto maior for o tempo utilizado pela função do cálculo do fitness, melhor será o speedup dessa técnica. No entanto, 


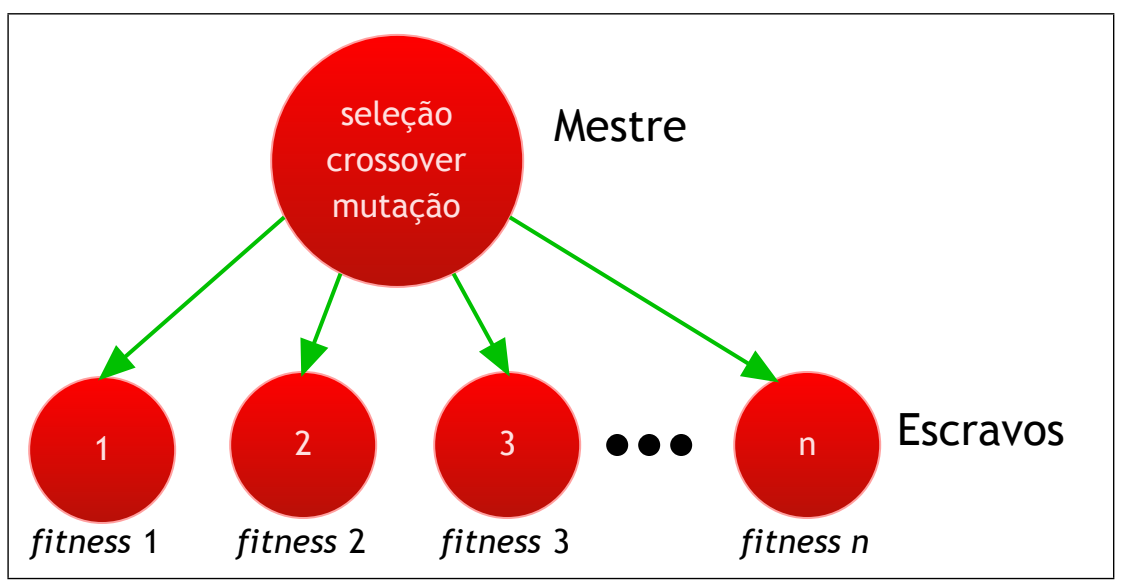

Figura 4.5: Classificação de AG paralelo Mestre-Escravo. O mestre armazena a população, executa as operações genéticas e distribui os indivíduos para os escravos calcularem o fitness.

se o tempo de cálculo do fitness para toda a população em um AG serial for menor que o tempo de comunicação total mestre-escravo, então o AG serial deve ser melhor, pois a comunicação passou a ser o gargalo. Se o tempo de comunicação somado ao tempo de computação do escravo for menor que o tempo de calcular o fitness de toda população no AG serial, então o AG paralelo deve apresentar um desempenho melhor.

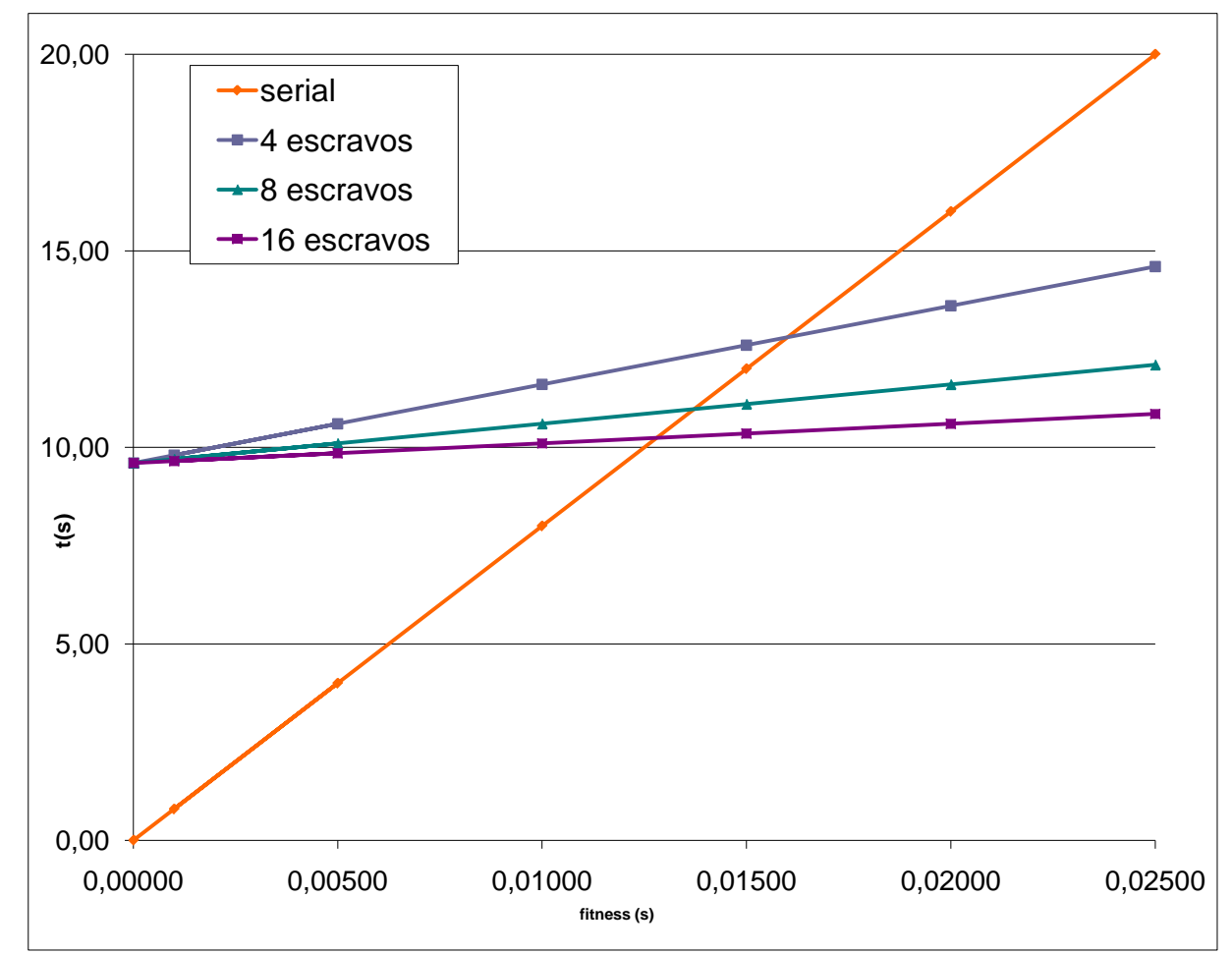

Figura 4.6: Gráfico comparativo Mestre-Escravo que mostra o ponto em que as linhas se cruzam. $\mathrm{Na}$ abscissa tem-se o tempo de cálculo da função de fitness em segundos. Na ordenada tem o tempo total de computação para uma geração.

A Figura 4.6, ilustra o funcionamento do AG mestre-escravo. Os cálculos foram realizados utilizando uma população de 800 indivíduos e tempo de comunicação total (send + receive) de 12 
milissegundos. Nesse exemplo, assumiram-se dados teóricos para o tempo de cálculo do fitness. Para enviar os indivíduos do mestre para o escravo foi levado em consideração um send bloqueante (Grama et al., 2003), isto é, o mestre apenas envia os dados para o próximo escravo somente quando o send anterior acabar. Percebe-se então que para problemas onde o cálculo da função de fitness é pequeno, o speedup é baixo. Mas, na medida em que a função de fitness aumenta, nota-se que as linhas dos algoritmos sequencial e paralelos mestre-escravo começam a distanciar, aumentando linearmente o speedup. Por outro lado, se ao invés de utilizar o send bloqueante, fosse utilizado o send não-bloqueante ${ }^{1}$, os resultados para a classificação mestre-escravo poderiam ser melhores (Figura 4.7).

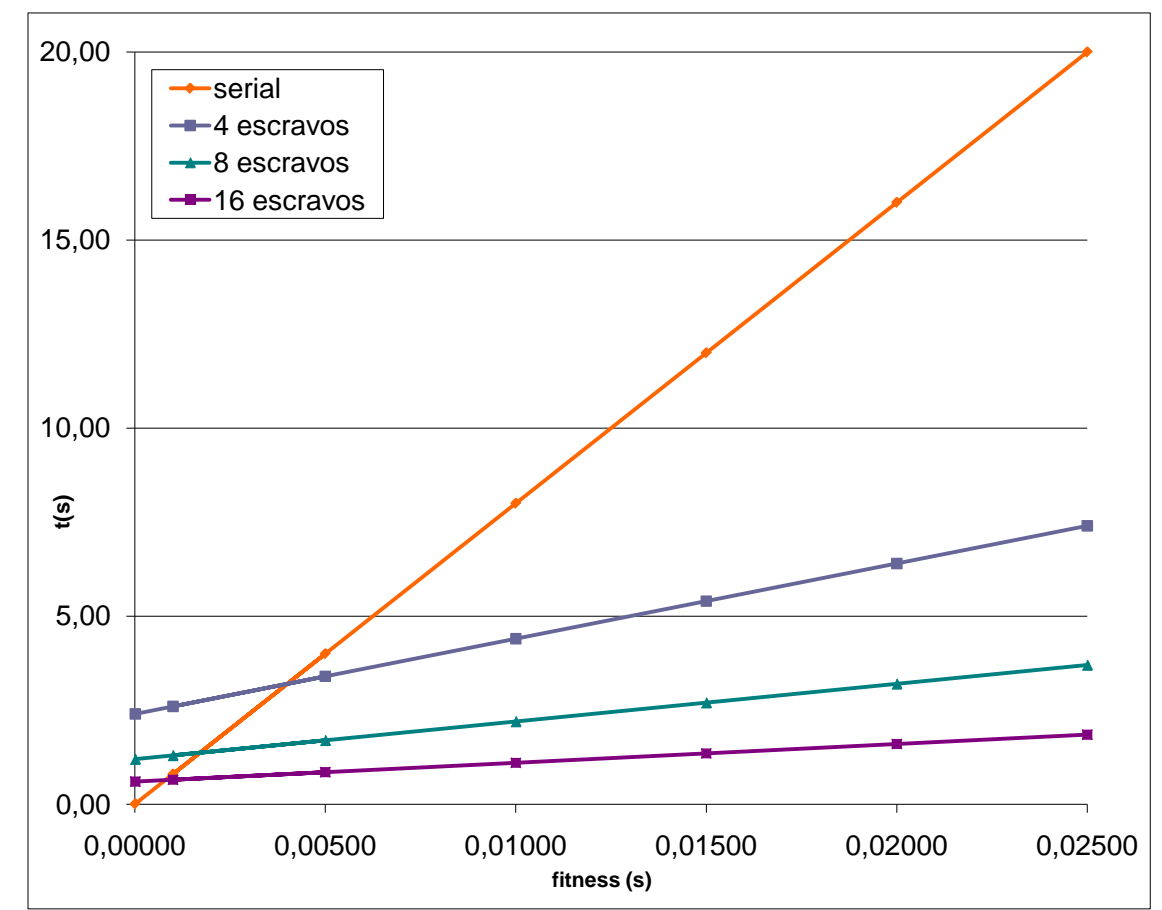

Figura 4.7: Gráfico Mestre-Escravo com Send não-bloqueante.

\subsubsection{Multiple-population}

Também chamado de Coarse Grained (Saroj \& Shaveta, 2004), o AG paralelo multiple-population é o tipo mais sofisticado e comum, possuindo vários conjuntos de subpopulações que interagem. Essas interações são chamadas de migrações e são controladas por vários parâmetros como frequência, número de imigrantes e método de seleção (Alba, 2005). A Figura 4.8 ilustra interações entre populações dos AGs, realizadas por meio de migração dos indivíduos.

Existem dois principais fatores que se relacionam: o tamanho de cada população e os efeitos da migração. Um dos casos mais simples de multi-população é a execução de AGs independentes e a escolha da melhor solução de todas as possíveis. Essa estratégia é interessante, pois os AGs são métodos estocásticos e, assim, ocorre variação de qualidade entre os resultados, isto é, a qualidade

\footnotetext{
${ }^{1}$ Para a realização desses cálculos, desconsiderou-se o tempo para enchimento do buffer antes de enviar.
} 


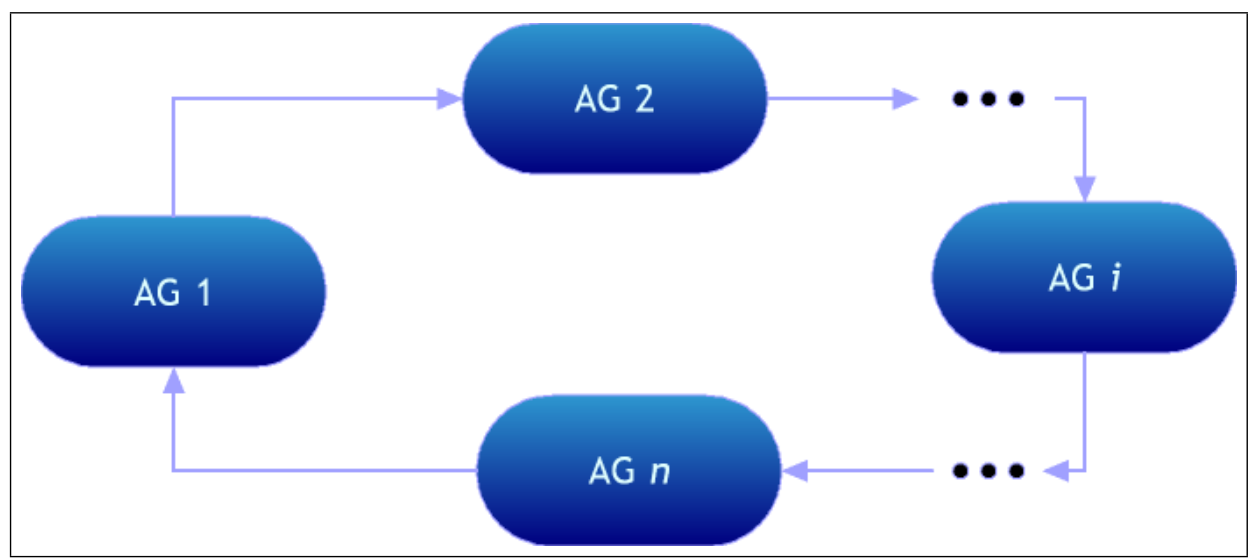

Figura 4.8: Conjunto de subpopulações utilizados na classificação de múltipla-população.

do resultado esperado da execução de vários AGs pode ser melhor que apenas a execução de um AG. Deve-se observar que é importante executar várias vezes os AGs independentes com fim de comparação estatística de resultados. Alba (2005) indica que é possível manter a qualidade da solução reduzindo o tamanho da população com a execução de AGs independentes (com populações reduzidas) em paralelo, alcançando a solução ótima mais rapidamente que um AG simples. No entanto, isso nem sempre é muito eficiente, pois a pequena redução no tamanho da população, não causará impacto significativo na comparação com um AG simples.

A partir de resultados empíricos, Alba (2005) confirma que utilizar populações isoladas não é uma abordagem eficiente. A maioria das implementações de AGs paralelos com multi-população possuem mecanismos de troca de indivíduos entre as populações (migrações). Entretanto, isso causa grande dificuldade em modelar o algoritmo.

Utilizando AGs paralelos multi-populacionais, existe a possibilidade de uma grande redução do tamanho da população em comparação com o AG serial. Para se manter a qualidade da solução, a população inicial deve conter alguns building blocks, ou seja, agrupamento de genes que se relacionam (Goldberg, 2002). Com essa garantia, mesmo utilizando taxas de migrações pequenas, é possível a solução ótima ser migrada para outras populações. Porém, o conhecimento prévio de building blocks não é possível para problemas mais complexos ou de larga-escala.

Outro ponto importante a ser considerado, é escolher quais indivíduos devem migrar. Até este ponto, discutiu-se somente de migrações após a convergência da população, ou seja, não existe diferença na escolha de uma solução imigrante, pois todas são iguais. Mas em uma população com muita diversidade, escolher os imigrantes e como eles serão incorporados na população receptora é um fator importante.

A pressão de seleção de um AG influencia na velocidade de convergência de uma população. Uma convergência muito lenta ou rápida pode fazer o algoritmo falhar (Alba, 2005). Isso ocorre porque as migrações influenciam na pressão de seleção (Alba, 2005; Goldberg, 2002). A escolha dos imigrantes pode ser aleatória ou baseada no fitness deles. Assim, como a escolha dos emi- 
grantes (indivíduos receptores) também pode ser aleatória ou baseada em seu fitness. De forma geral, existem quatro maneiras de fazer as migrações.

1. Bom $\rightarrow$ Ruim. Um bom indivíduo imigrante substitui um indivíduo ruim da população receptora;

2. Bom $\rightarrow$ Aleatório. Um bom indivíduo imigrante substitui aleatoriamente qualquer indivíduo da população receptora;

3. Aleatório $\rightarrow$ Ruim. Um indivíduo imigrante aleatório substitui um indivíduo ruim da população receptora;

4. Aleatório $\rightarrow$ Aleatório. Um indivíduo aleatório da população receptora é substituído por um imigrante aleatório.

Pode-se então concluir que dependendo da política de migração, a convergência do AG pode ser lenta ou rápida. Se for adotada a política de que sempre o bom substitui o ruim, então a convergência será rápida. Por outro lado, se for adotada a migração aleatória para ambos os lados, a convergência será relativamente lenta, semelhante à convergência de um AG com uma única população. Isso mostra como a escolha dos migrantes influencia no tempo de convergência do AG. Além disso, a quantidade de migrantes também é responsável pelo tempo de convergência do AG.

A topologia é outro fator importante que está relacionada ao tempo de convergência. Em uma topologia em que existem muitos vizinhos é provável que a convergência seja mais rápida (Alba, 2005).

\subsubsection{AG Paralelo Celular}

Também chamado de Fine-Grained Parallel GAs (Cantú-Paz, 1997), o AG Paralelo Celular consiste em uma única população com uma estrutura espalhada geralmente em uma grade 2-D (Figura 4.9), onde cada nó tem um ou pouco mais de um indivíduo. Os operadores genéticos são restritos ao pequeno número de vizinhos e pela utilização das melhores vizinhanças que essas soluções começam a se espalhar pelas populações.

Alba (2005) considera que existem muitos trabalhos teóricos e poucas aplicações sobre os AGs Paralelos Celulares. Isso pode acontecer porque essa classificação de AG paralelo é bem aceita em computadores SIMD ${ }^{2}$, exigindo assim hardware especializado; ao contrário das outras duas classificações anteriores (Seções 4.6.2 e 4.6.1), em que um cluster da classe Beowulf (Dongarra et al., 2005) é suficiente. Entretanto, utilizando uma granularidade mais grossa é possível implementar eficientemente em computadores MIMD $^{3}$

\footnotetext{
${ }^{2}$ Single Instruction, Multiple Data. Aplica a mesma instrução a múltiplos dados.

${ }^{3}$ Multiple Instruction, Multiple Data. Aplica várias instruções independentes a dados diferentes.
} 


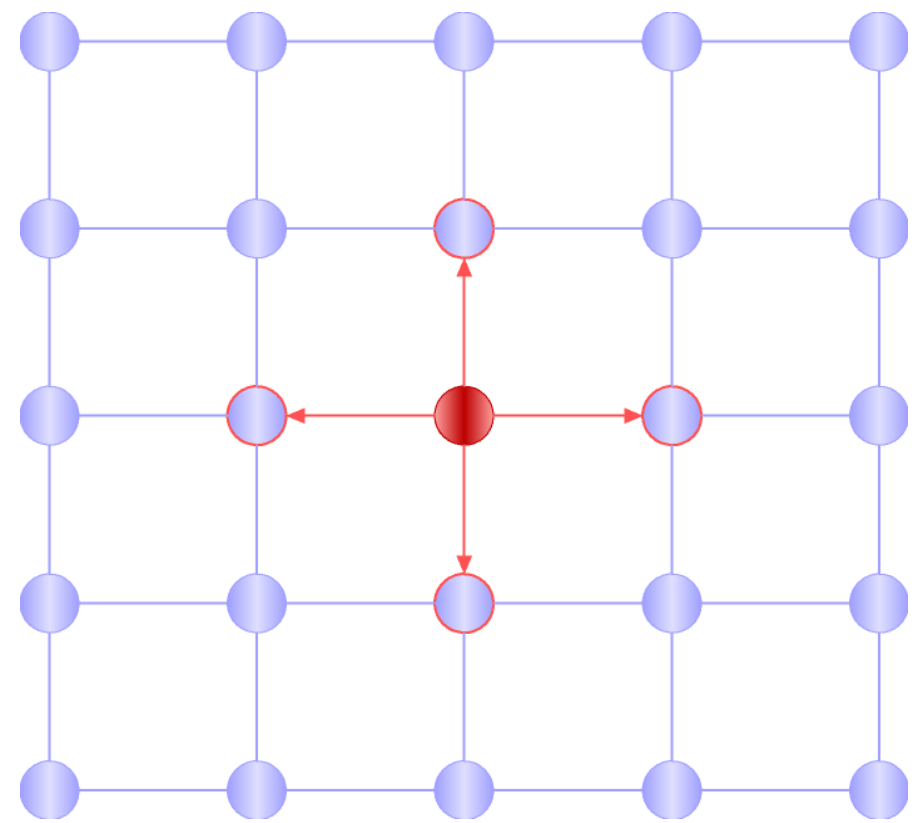

Figura 4.9: Esquema de um AG Paralelo Celular. A interação ocorre somente com os vizinhos próximos.

Uma vez que o AG Paralelo Celular interage somente com seus vizinhos, a qualidade e a eficiência do algoritmo dependem fortemente dessa interação. Cantú-Paz (1997) apresenta uma análise feita por Manderick e Spiessens, onde verificou-se que o aumento do número de vizinhos, faz o desempenho do algoritmo piorar. Por outro lado, se o número de vizinhos não for grande o suficiente, o algoritmo aproxima-se de uma única população. Por esse motivo deve-se usar uma quantidade de vizinhos moderada. Mais adiante, Sarma e De Jong (Cantú-Paz, 1997) analisaram os efeitos da quantidade de vizinhos e da topologia empregada no processo de seleção, concluindo que a razão do raio da vizinhança para o raio total da grade 2-D deve ser um parâmetro crítico que determina a pressão de seleção sobre toda a população.

Em alguns casos, é possível aproveitar a topologia existente de processadores para criar a mesma topologia nos AGs Paralelos Celulares. Muitos computadores massivamente paralelos utilizam uma grade 2-D que pode ser aproveitada para se criar a vizinhança do AG Paralelo Celular (Cantú-Paz, 1997). Além disso, pode-se testar outras topologias, pois geralmente esses computadores têm um roteador global que pode comunicar-se com qualquer processador (talvez com alto custo).

O AG Paralelo Celular tem respostas melhores comparado aos AGs multi-populacionais. No entanto, isso não é uma regra, pois o oposto também pode ocorrer. Cantú-Paz (1997) destaca um ponto importante: o caminho crítico (do grafo de dependência, discutido na Seção 3.2) de um AG Paralelo Celular é sempre menor que um multi-populacional, podendo assim atribuir a computação a mais processadores gastando menos tempo. Deve-se observar que esse é um resultado de um estudo analítico, assim, ao considerar-se a comunicação o resultado pode não ser o mesmo. 
Para Alba (2005) as células podem ser atualizadas paralelamente de modo síncrono, ou seja, são atualizadas simultaneamente a cada geração. No entanto, a atualização das células pode ser serial e de modo assíncrono. Os testes apresentados em Alba (2005), mostram que, mesmo utilizando o modelo assíncrono, as soluções são alcançadas rapidamente, porém de forma mais lentas que as síncronas.

\subsubsection{AG Paralelo Híbrido}

Combinando características de AGs paralelos, os sistemas híbridos podem ser construídos (Figura 4.10). Esses AGs Paralelos Híbridos são também chamados de hierárquicos, pois em um nível mais alto, tem-se um algoritmo como, por exemplo, o multi-populacional e, em um nível mais baixo tem-se outro modelo, como o celular (Figura 4.9). É comum o uso do multi-populacional em alto nível. Um AG Paralelo Hierárquico combina as melhores qualidades disponíveis desses modelos para se obter um melhor desempenho (Alba, 2005). No entanto, na união de dois algoritmos, a complexidade, que já era grande devido aos modelos paralelos, torna-se ainda maior.

Os indivíduos podem migrar para outras populações tentando melhorar a qualidade das soluções. Cantú-Paz (1997) afirma que com essa hierarquia pode-se conseguir resultados relevantes. Outro tipo de AG Paralelo Hierárquico é a combinação do mestre-escravo com o multi-populacional. A migração é feita entre as ilhas e a avaliação dos indivíduos é feita em paralelo. Essa estratégia é mais adequada se o cálculo do fitness é muito custoso. Um terceiro método de construção AGs Paralelos Híbridos é pela utilização de multi-populações de multi-populações. Entretanto, esse método ainda não foi implementado (Cantú-Paz, 1997).

a)

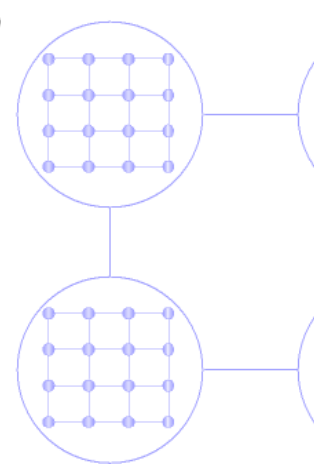

b)

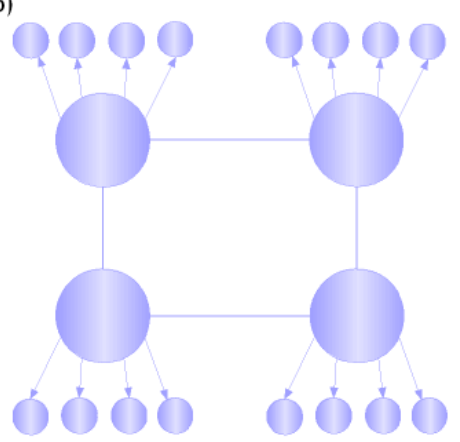

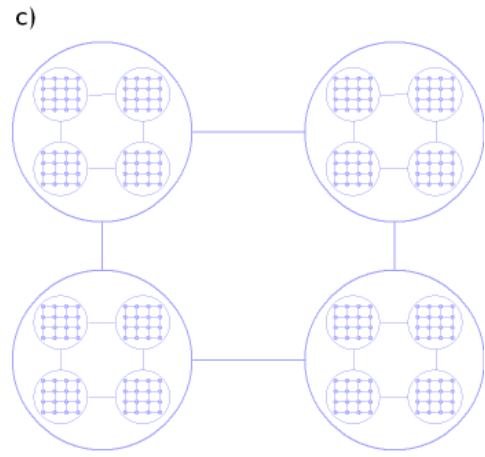

Figura 4.10: Exemplo de AG Paralelo Híbrido. a) Um AG Paralelo Hierárquico que combina multi-população (alto nível) e Celular (baixo nível). b) Esquema de AG Paralelo Híbrido. No nível mais alto, o multi-populacional e no nível mais baixo, mestre-escravo. c) Multi-população em dois níveis e o Celular no nível mais baixo.

Quando forem utilizadas implementações hierárquicas, a quantidade de tempo gasta para executar o algoritmo pode ser menor que a soma dos dois algoritmos isolados. Por exemplo, considerando que existe um ótimo speedup para as duas implementações, mestre-escravo $\left(S_{m s}\right)$ e o speedup para a implementação multi-populacional $\left(S_{\text {mpop }}\right)$, o speedup geral combinado das duas implementações esperado deverá ser $S_{m s} \times S_{m p o p}$ (Cantú-Paz, 1997). 


\subsection{Considerações Finais}

Os AGs são técnicas de otimização populacionais que se baseiam no processo da evolução natural para encontrar regiões promissoras no espaço de busca que contenham soluções relevantes. As soluções são os indivíduos do AG, que são representados por uma estrutura de dados que pode ser particular para certo problema buscando o aumento da eficiência. Cada representação tem seus próprios operadores gênicos para o crossover e mutação. Existem vários parâmetros que influenciam a qualidade da solução que pode ser obtida, assim como o tamanho da população, tipo de representação e método de seleção. Os AGs são aplicados às classes de problemas que são de ordem não polinomial, assim como o problema de predição de estrutura de proteínas. A função de avaliação é a operação mais demorada de um AG. O ganho da eficiência de um AG pode ser realizado paralelizando sua função de avaliação ou então utilizando AGs paralelos. No entanto, para ambos os casos, é necessário conhecimento de técnicas de paralelização, descritas no Capítulo 3. O desenvolvimento de AGs Paralelos é uma maneira eficiente de diminuir o tempo de execução de um AG. Existem vários modelos de AGs Paralelos, e, a idéia básica deles é a divisão da população em subpopulações para que os indivíduos possam ser avaliados simultaneamente. Na maioria dos casos, além de reduzir o tempo de execução de um AG, podem também encontrar soluções melhores. É interessante observar que a paralelização de AGs não é o foco deste trabalho. Tal tarefa fica para trabalhos futuros. 


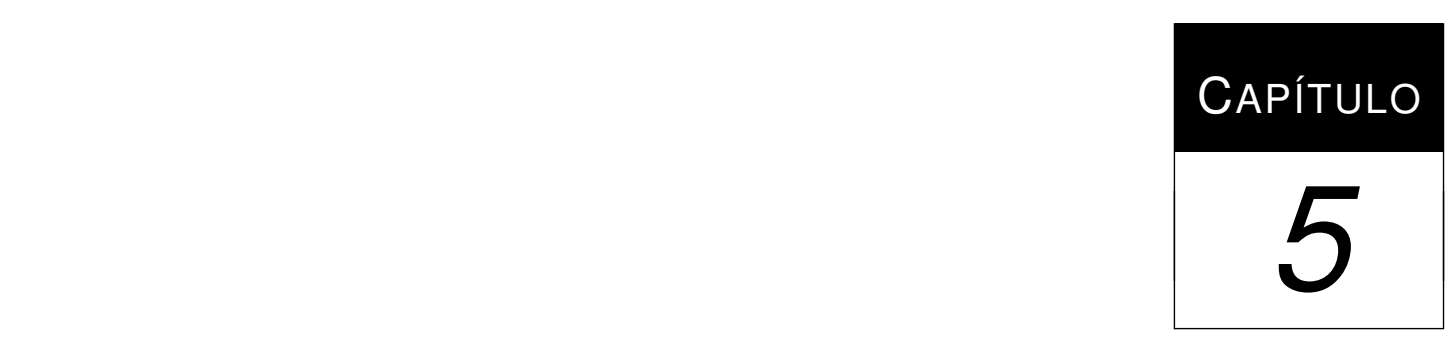

\section{Van der Waals e AGs para PSP}

A energia de van der Waals é amplamente utilizada em softwares de dinâmica e modelagem molecular, pois a partir dessa energia, tem-se um modelo do comportamento da interação entre pares de átomos de uma molécula. Com isso, é possível simular o comportamento de moléculas sob temperaturas e pressões, verificando se a mesma é capaz de manter sua estrutura estável. Por outro lado, o emprego da energia de van der Waals em AGs tem como objetivo determinar a qualidade dos indivíduos diferenciando soluções boas (que tem a estrutura semelhante ao de moléculas estudado na natureza) e soluções ruins (que não estão na forma mais estável de energia, apresentando estruturas que dificilmente são encontradas na natureza). Dessa forma, utilizado a energia de van der Waals na função de avaliação do AG, capacitando o AG a encontrar estruturas de proteínas próximas as encontradas na natureza.

A Seção 5.1 descreve o aplicativo capaz de predizer estruturas de proteínas desenvolvido pelo grupo de pesquisa SEER ${ }^{1}$. A Seção 5.2 faz uma apresentação do pacote de modelagem molecular Tinker. A Seção 5.4 mostra a versão mais simples de um algoritmo que calcula a energia de van der Waals. Por fim, a Seção 5.5 apresenta as considerações finais deste capítulo.

\subsection{O ProtPred}

O ProtPred é um aplicativo desenvolvido inicialmente por Lima (2006) em seu mestrado. É um AG capaz de predizer estruturas de proteínas relativamente pequenas. Desde seu desenvolvimento, vários refinamentos foram introduzidos para melhorar a qualidade das soluções obtidas. Brasil

\footnotetext{
${ }^{1}$ Sistemas Embarcados, Evolutivos e Robóticos
} 
(2010) em seu doutorado (em andamento), adicionou as energias de pontes de hidrogênio e solvatação à função de avaliação, aumentando a qualidade das soluções (Brasil et al., 2009a). Outras funções de energia como a energia eletrostática, energia de van der Waals, energia Urey-Bradley, energia de ligação, energia de torção, energia de comprimento de ligação e energia imprópria foram adquiridas do pacote de modelagem molecular Tinker (Seção 5.2).

O ProtPred é um AG específico para o problema de PSP ab initio full-atom que possui uma representação própria de dados, operadores de recombinação (crossover) e mutação. A função de avaliação é composta pelas funções que calculam a energia da proteína descritas na Seção 2.6. Além dos trabalhos já citados aqui, o ProtPred tem sido o ambiente de experimentos de várias publicações como (Santos, 2009) e (Brasil et al., 2009b).

Os indivíduos são selecionados pelo método do torneio (Goldberg, 2002) para compor os pais que serão cruzados. São aplicados três tipos diferentes de operadores de recombinação aos pais de acordo com uma probabilidade pré-definida para a aplicação de cada operador. O primeiro operador de recombinação é um operador desenvolvido especificamente para cromossomos representados por números reais, chamado de BLX- $\alpha$ (Eshelman \& Schaffer, 1993). Outro operador utilizado é o crossover de um ponto (ou multi-pontos) (Sywerda, 1989) onde a cada dois pais escolhidos são gerados apenas um novo indivíduo filho. O terceiro operador aplica o crossover de dois pontos em dois pais gerando dois novos indivíduos. Os pontos de corte desses operadores são selecionados de tal maneira a preservar a restrição imposta pelos ângulos $\Phi$ e $\Psi$.

Assim como os operadores de recombinação, o ProtPred utiliza três tipos de mutação. Antes de iniciar o processo de mutação dos indivíduos são feitas duas cópias dos pais. Na primeira cópia de indivíduos é alterado somente um resíduo alterando os ângulos de torção da cadeia principal e da cadeia lateral com novos ângulos obtidos de suas correspondentes regiões de restrição, podendo o mesmo indivíduo ser selecionado mais de uma vez para ter outro resíduo mutado. O segundo e terceiro operadores de mutação provocam uma perturbação nos ângulos de torção da cadeia principal e da cadeia lateral. Esses operadores são similares e distinguem-se somente pelo fato de um ter impacto maior sobre o ângulo, pois ambos se aplicam à segunda cópia de indivíduos pais. Para evitar a convergência prematura é definido, a partir do número da geração, o número de vezes que cada operador de mutação será aplicado.

Por fim, tem-se um total de quatro vezes o número de indivíduos da população: o conjunto de indivíduos pais, o conjunto de indivíduos gerados pelo operador de crossover, o conjunto de indivíduos gerados pelo primeiro operador de mutação e o conjunto gerado pelo segundo e terceiro operadores de mutação. Em seguida, é calculado o fitness de cada indivíduo ordenando crescentemente com base no fitness e o conjunto dos primeiros indivíduos que representam o tamanho da população é selecionado para compor os pais da próxima geração (Lima, 2006; Cui et al., 1998).

O processo de avaliação dos indivíduos (cálculo do fitness) é o processo mais caro do ponto de vista computacional. A energia de van der Waals, que representa grande influência nas soluções obtidas pelo ProtPred, tem custo computacional $O\left(n^{2}\right)$. Isso representa o gargalo do algoritmo, e, considerando que mesmo para pequenas proteínas (até 50 aminoácidos ou 1.000 átomos) o tempo 
computacional é grande, torna-se impraticável para outras classes de tamanhos de proteínas. A Seção 5.2 mostra um método existente utilizado para o aumento da eficiência do cálculo da energia de van der Waals utilizado no software de modelagem molecular Tinker.

\subsection{O software de modelagem molecular Tinker}

O Tinker é um pacote geral e completo de modelagem molecular para dinâmica e mecânica molecular, com algumas características especiais para biopolímeros ${ }^{2}$. O Tinker tem a habilidade de usar vários conjuntos de parâmetros como Amber, CHARMM, OPLS e AMOEBA (Ponder, 2001).

O Tinker foi implementado em Fortran e possui uma variedade de algoritmos modularizados que dão flexibilidade à implementação. Atualmente, o Tinker conta com a versão 5 utilizando linha de execução sequencial. No entanto, a partir da versão 6, espera-se obter melhor eficiência com o emprego de programação paralela, como o uso de OpenMP (ver Seção 3.3).

A energia de van der Waals, bem como outras funções de energia que calculam a interação de pares de átomos sem ligação covalente, podem ser calculadas mais rapidamente utilizando algoritmos que procurem por átomos que interajam somente com seus vizinhos mais próximos, ou seja, que estão próximos ao cutoff (ver Seção 2.6). O Tinker utiliza um algoritmo chamado Método das Luzes (do inglês, method of lights) que será descrito a seguir.

\subsection{Método das Luzes}

O Tinker utiliza o método das luzes para acelerar a computação da interação entre pares de átomos da molécula que está sendo analisada. O método das luzes (LUZ) se baseia na ordenação do valor das coordenadas das partículas para formar a lista de vizinhos. O procedimento para determinar a lista de vizinhos é independente dos valores de cada coordenada ( $x y z)$. As informações das listas ordenadas são utilizadas para obter faixas nos eixos $x, y, \mathrm{e} z$ que, combinadas, geram uma lista de vizinhos. Para facilitar o entendimento, será adotado um exemplo de espaço 2D.

O primeiro passo a fazer é ordenar o vetor $x$ independente dos valores de $y$ mantendo os valores do índice de $x$. Depois, fazer o mesmo para $y$. Os valores da chave são chamados de locx e locy. O desempenho do método das luzes está fortemente relacionado ao método de ordenação adotado. Em geral, os métodos de ordenação eficientes são da ordem de $O(n \log n)$, limitando o desempenho do método das luzes. No caso do Tinker e da implementação realizada neste projeto (ver Seção 8.7), é utilizado o método de ordenação heapsort, com complexidade média de $O(n \log n)$ (Cormen et al., 2002).

Em seguida, é definida uma vizinhança quadrada descrita por pares de ponteiros para cada partícula que indicam faixas na lista de partículas ordenadas, ou seja, os limites superior e inferior.

\footnotetext{
${ }^{2}$ Polímeros produzidos por organismos vivos como, por exemplo, DNA, RNA e proteínas.
} 
Para determinas esses limites, chamados de $k b x, k b y$ (inferior) e $k e x, k e y$ (superior) é preciso varrer os vetores das partículas utilizando os vetores locx e locy. Depois de montado todos os vetores de limites superiores e inferiores, as interações entre pares de átomos são realizadas varrendo a lista de chaves de átomos que estão dentro dos limites de sua faixa.

Apesar de o método das luzes evitar vários cálculos desnecessários utilizando a lista de vizinhança, a complexidade do algoritmo é $O\left(n^{3 / 2}\right)$ para o problema em duas dimensões e $O\left(n^{5 / 3}\right)$ para três dimensões (Sullivan et al., 1985).

\subsection{Algoritmo Base de van der Waals}

Para reduzir o tempo de computação do AG do ProtPred, este trabalho propõe que isso seja realizado focando na redução do tempo computacional da energia de van der Waals. No entanto, a função de van der Waals implementada possui características específicas para o ProtPred, relacionando a estrutura de dados e a integração com outras funções. Para se obter um controle absoluto da energia de van der Waals, decidiu-se implementar um algoritmo básico que somente faça o cálculo da energia de van der Waals para diferentes moléculas de proteínas. Isso facilita determinar quais são os pontos que realmente interferem no desempenho do cálculo de van der Waals, isolando trechos do algoritmo que são mais custosos computacionalmente. Além disso, a utilização de diversos paradigmas de programação se torna mais simples, sendo assim, capaz de determinar as características dos métodos com mais precisão (ver propostas no Capítulo 6).

O Algoritmo Base Sequencial (ABS) foi implementado somente a partir dos princípios físicos do cálculo da energia de van der Waals (Seção 2.7), sem qualquer tipo de aperfeiçoamento computacional. Para construir o arquivo de entrada utilizado no ABS é escolhido uma proteína já existente no PDB e convertida para extensão .XYZ, pois o PDB possui informação dos ângulos diedrais dos aminoácidos enquanto que arquivos .XYZ contém a posição espacial de cada átomo, o tipo e os átomos que fazem ligação covalente (Figura 5.1). O Tinker possui um conversor de PDB para XYZ, mas limita-se a 10.000 átomos, número baixo para os experimentos deste projeto. Assim, alterou-se o limite para 200.000, recompilando apenas bibliotecas relacionadas ao programa de conversão, habilitando assim mais experimentos para cadeias gigantes de proteínas (centenas de milhares de átomos).

\subsection{Considerações Finais}

Neste capítulo foi abordado o uso da energia de van der Waals no ProtPred, Tinker e em sua forma mais básica (ABS). A energia de van der Waals contribui fortemente na qualidade das soluções obtidas no ProtPred. No entanto, o algoritmo não é eficiente, pois apresenta complexidade $O\left(n^{2}\right)$. Essa eficiência pode ser melhorada empregando métodos existentes, como o método das luzes, atualmente utilizado no Tinker. Primeiramente, foi desenvolvido um algoritmo base 


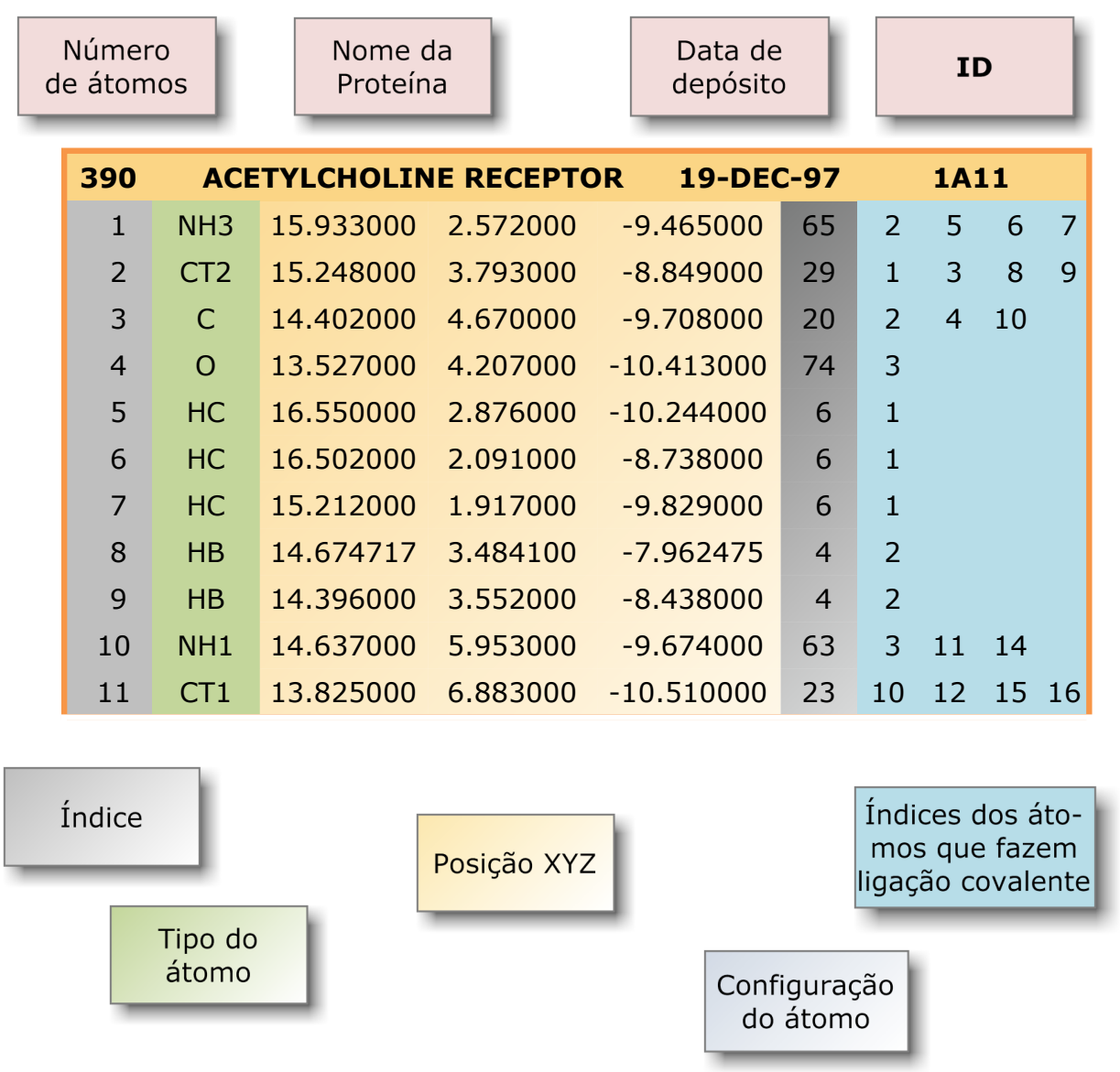

Figura 5.1: Exemplo de arquivo XYZ.

com finalidade de testar o desempenho das técnicas de aumento de eficiência empregadas, bem como facilitar a construção das novas técnicas. Dessa forma, será possível detectar quais técnicas geraram resultados mais relevantes para que posteriormente sejam incorporadas ao ProtPred. 



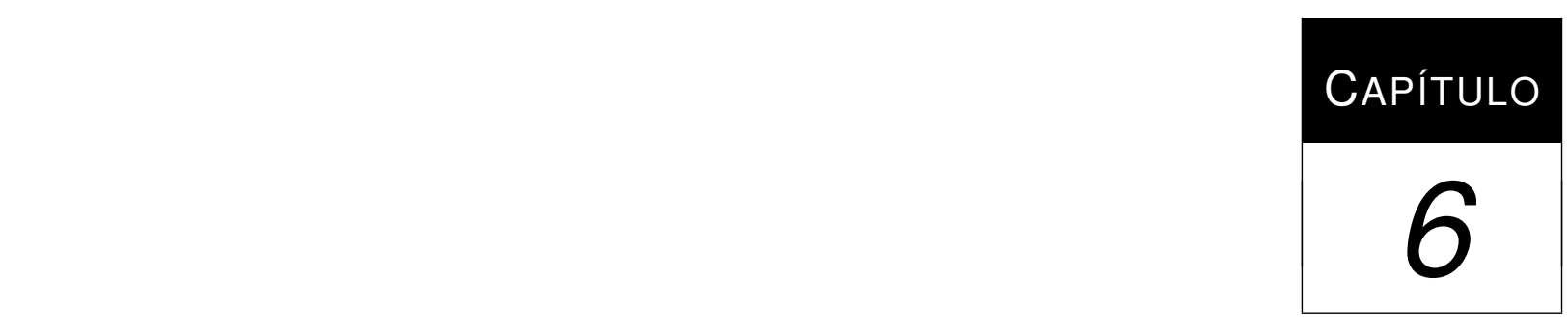

\section{Propostas para Aumento da Eficiência}

O Capítulo 5 mostrou o comportamento da energia de van der Waals no ProtPred e Tinker. Para capacitar programas, como o ProtPred, a trabalharem com proteína de vários tamanhos, é necessário desenvolver e aplicar técnicas que reduzam a complexidade do cálculo para van der Waals. Este capítulo apresenta técnicas de redução do custo computacional que podem ser aplicadas ao cálculo da energia de van der Waals, especificamente para uso em AGs, capazes de diminuir significativamente o tempo de computação.

A Seção 6.1 mostra uma versão otimizada do ABS. A Seção 6.2 ilustra uma maneira de acelerar o cálculo utilizando características dos AGs. A Seção 6.3 discute o cálculo da energia de van der Waals por meio de tabelas. A Seção 6.4 aborda o uso de lista de células para construir a vizinhança de interações. Por fim, a Seção 6.6 apresenta as considerações finais deste capítulo.

\subsection{Algoritmo Básico Sequencial Otimizado}

A primeira forma de melhorar a eficiência do ABS foi com o uso de técnicas que otimizassem o algoritmo, mas que também não alterasse sua estrutura. Para determinar quais trechos do algoritmo eram mais custosos computacionalmente, utilizou-se o GNU Profiler (gprof) ${ }^{1}$. No entanto, os resultados revelados pelo gprof não foram animadores, pois o algoritmo é pequeno e o gargalo acusado foi na função que faz a interação entre todos os pares de átomos. Para uma inspeção mais detalhada, seria necessário saber se existe alguma linha específica da execução responsável pelo gargalo.

\footnotetext{
${ }^{1}$ http://www.cs.utah.edu/dept/old/texinfo/as/gproftoc.html
} 
Por esse motivo, foi necessário empregar uma medida de análise fina de inspeção. Para cada linha do algoritmo, mediu-se o tempo necessário de execução de cada uma separadamente. Dessa forma, foi possível detectar onde estava o principal gargalo para o algoritmo: na função de potência (função pow da biblioteca GNU C math library) (Overflow, 2009). Essa função é chamada em todas as interações entre pares de átomos para calcular a distância Euclidiana

$$
d=\sqrt{\left(x_{i}-x_{j}\right)^{2}+\left(y_{i}-y_{j}\right)^{2}+\left(z_{i}-z_{j}\right)^{2}},
$$

e para calcular $r^{6} \mathrm{e} r^{12}$. A substituição da função de potência por composições de produtos simples tornou o algoritmo mais eficiente. Devido ao fato de não ser possível obter resultados melhores com a versão básica do algoritmo, a versão de composição de produtos simples é chamada de Algoritmo Básico Sequencial Otimizado, ABSO.

\subsection{Aproveitamento do cálculo pela recombinação}

A utilização de um método de otimização populacional, como os AGs, pode significar uma vantagem para o cálculo da energia de van der Waals. Outra técnica para aumentar o desempenho do AG pode ainda ser o emprego como, por exemplo, da economia de processamento pelo Aproveitamento do Cálculo pela Recombinação (ACR). Toda vez que dois indivíduos se cruzam, geram um novo indivíduo. Pelo fato do indivíduo conter parte do material genético de cada pai, é provável que muitas interações do cálculo da energia de van der Waals não precisem ser refeitas. Bastam apenas utilizar as mesmas interações calculadas para os pais, exceto em regiões do ponto de corte do crossover (ver Seção 4.4). No entanto, isso pode causar um overhead para recalcular a área quebrada pelo operador de recombinação. Por isso, foi verificado experimentalmente para moléculas com tamanhos que variam em escala se esse overhead é menor que o ganho de desempenho (Figura 6.1).

Outro problema enfrentado nessa técnica é o uso de memória necessária, que cresce quadraticamente de acordo com o número de átomos da proteína. Isso porque para armazenar estaticamente todas as interações, são necessários

$$
\frac{n^{2}-n}{2} \times\left(n_{\text {pais }}+n_{\text {filhos }}\right)
$$

onde $n$ é o número de átomos e $n_{\text {pais }}+n_{\text {filhos }}$ é a soma de duas vezes o tamanho da população, permitindo armazenar os pais e os filhos na memória. No entanto, um estudo sobre como os átomos da proteína interagem, mostrou que a maioria dos átomos da proteína não interagem com os outros, ou seja, a matriz na memória que representa a interação entre os átomos da proteína é esparsa. A Seção 6.2.1 mostra alguns exemplos de matriz esparsa e de representação esparsa. 
(a)

Pai 1

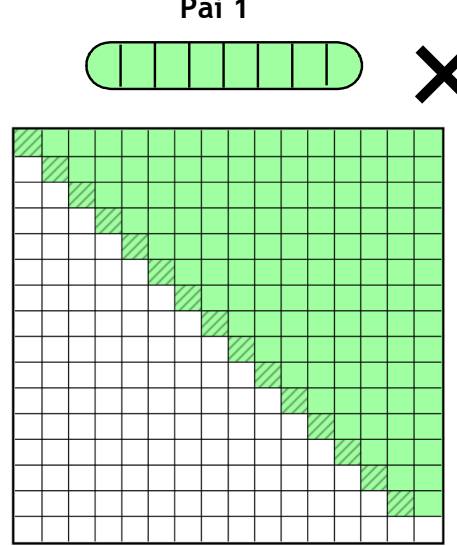

Pai 2

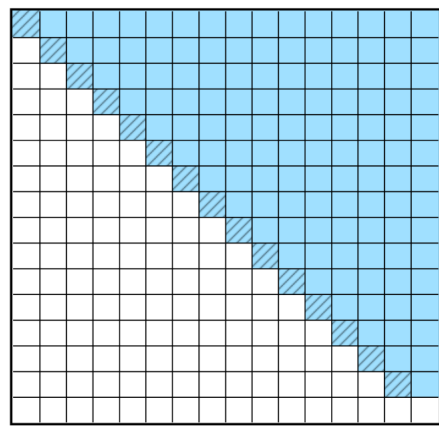

(b)

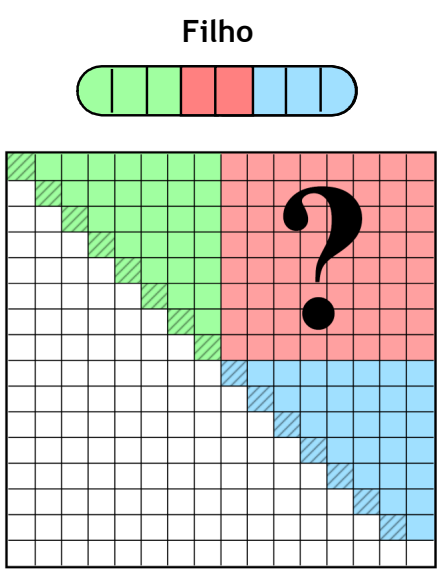

Figura 6.1: Aproveitamento do cálculo pela recombinação. (a) Pais utilizados na geração do filho. (b) Filho gerado pelo cruzamento dos pais. A região marcada pela interrogação é onde os cálculos devem ser refeitos.

\subsubsection{Representação esparsa da memória}

A esparsidade da matriz foi determinada graficamente utilizando o ABSO. Porém, ao invés do algoritmo calcular a interação de van der Waals para o par de átomos, apenas é verificado se a distância é inferior que o cutoff e, em caso positivo, a posição da matriz referente a interação desses pares de átomos é destacada pintando um pixel da matriz, caso contrário o pixel recebe cor branca. Para visualizar o arquivo, a matriz de interação precisa ser salva no formato PGM.

O PGM, (do inglês, Portable Gray Map) (Poskanzer, 2003), é um formato de arquivo de imagem sem compressão simples. Os pixels no sentido horizontal são separados por tabulações e no sentido vertical são separados por linhas. É possível até construir imagens coloridas RGB utilizando esse formato de arquivo, onde cada pixel é representado por uma tripla na linha horizontal. Nos arquivo PGM, é definida a dimensão do arquivo, a escala de cores e o restante são valores que estão dentro da escala de cores, que representam cada pixel individual da própria figura. Uma amostra de utilização do formato PGM é exemplificada na Figura 6.2

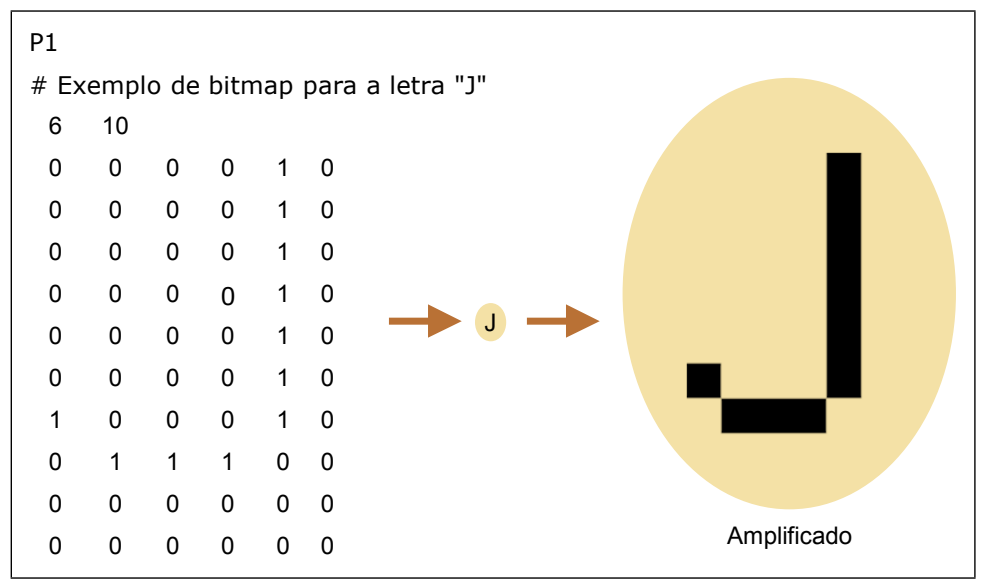

Figura 6.2: Exemplo de utilização do PGM. 
Utilizando arquivos PGM de saída para o ABSO determinou-se a esparsidade de várias moléculas. O tamanho das imagens é respectivo ao número de átomos, isto é, uma proteína com 390 átomos tem dimensão $390 \times 390$ pixels e uma proteína com 2.000 átomos tem dimensão $2.000 \times 2.000$. Pelo fato de não haver compressão nesses arquivos, limitou-se à proteína 1W1I, com no máximo 11.671 átomos (ver Seção 8.2), que corresponde a uma figura de 340 MB. A Figura 6.3 ilustra a comparação de várias proteínas com tamanho e topologia diferentes. Notou-se que quanto maior é a molécula, mais esparsa é a matriz. Isso ocorre porque as interações possuem um raio de corte que limita a interação dos átomos somente àqueles que estão próximos uns aos outros. Conforme cresce o número de átomos da molécula, menos interações ocorrem, pois a maioria dos átomos não interagem porque a grande parte das distâncias entre os átomos é superior ao raio de corte.

Dessa forma, fica claro que armazenando os dados do cálculo em uma matriz quadrada consome memória em excesso, pois a maioria das posições da memória recebe o valor zero. Por esse motivo, adotou-se representação esparsa da memória. A cada interação de dois átomos, somente é instanciada uma nova posição de memória quando dois pares de átomos estiverem dentro do cutoff. O gráfico da Figura 6.4 mostra como o consumo de memória cresce linear de acordo com número de átomos.

Apesar de solucionado o problema do crescimento quadrático da memória, essa técnica pode ficar restrita ao tamanho da população. Considerando uma proteína com, em média, $m$ interações, são necessárias $m \times\left(n_{\text {pais }}+n_{\text {filhos }}\right)$ unidades de alocação de memória. A Tabela 6.1 mostra o exemplo de um AG e a memória necessária para diversos tamanhos de proteínas utilizando uma população de 400 indivíduos. O desempenho adquirido com essa técnica é mostrado na Seção 8.5.

Tabela 6.1: Tabela do uso de memória utilizando ACR.

\begin{tabular}{c|r|r|r|r|r|r} 
Proteína & Núm. Átomos & Qtde. iterações & Pais & Filhos & Tam. Float & MB RAM \\
\hline \hline 1A11 & 390 & 19.840 & 400 & 400 & 4 bytes & 61 \\
1BFI & 1.753 & 125.337 & 400 & 400 & 4 bytes & 382 \\
1AI0 & 4.728 & 321.009 & 400 & 400 & 4 bytes & 980 \\
4HHB & 8.804 & 711.298 & 400 & 400 & 4 bytes & 2.171 \\
1W1I & 11.671 & 976.815 & 400 & 400 & 4 bytes & 2.981
\end{tabular}

\subsection{Cálculo off-line}

Toda operação aritmética consome tempo da CPU. Enquanto algumas delas são feitas rapidamente em um ciclo de clock, outras consomem mais por serem um processo iterativo. Um exemplo de operação aritmética que só pode ser resolvida iterativamente é a operação de divisão. Isso significa que operações de divisão geralmente são gargalos em um algoritmo. No cálculo da energia de van der Waals, para calcular a distância relativa $r$ (Equação 2.4) é necessário fazer uma divisão. 


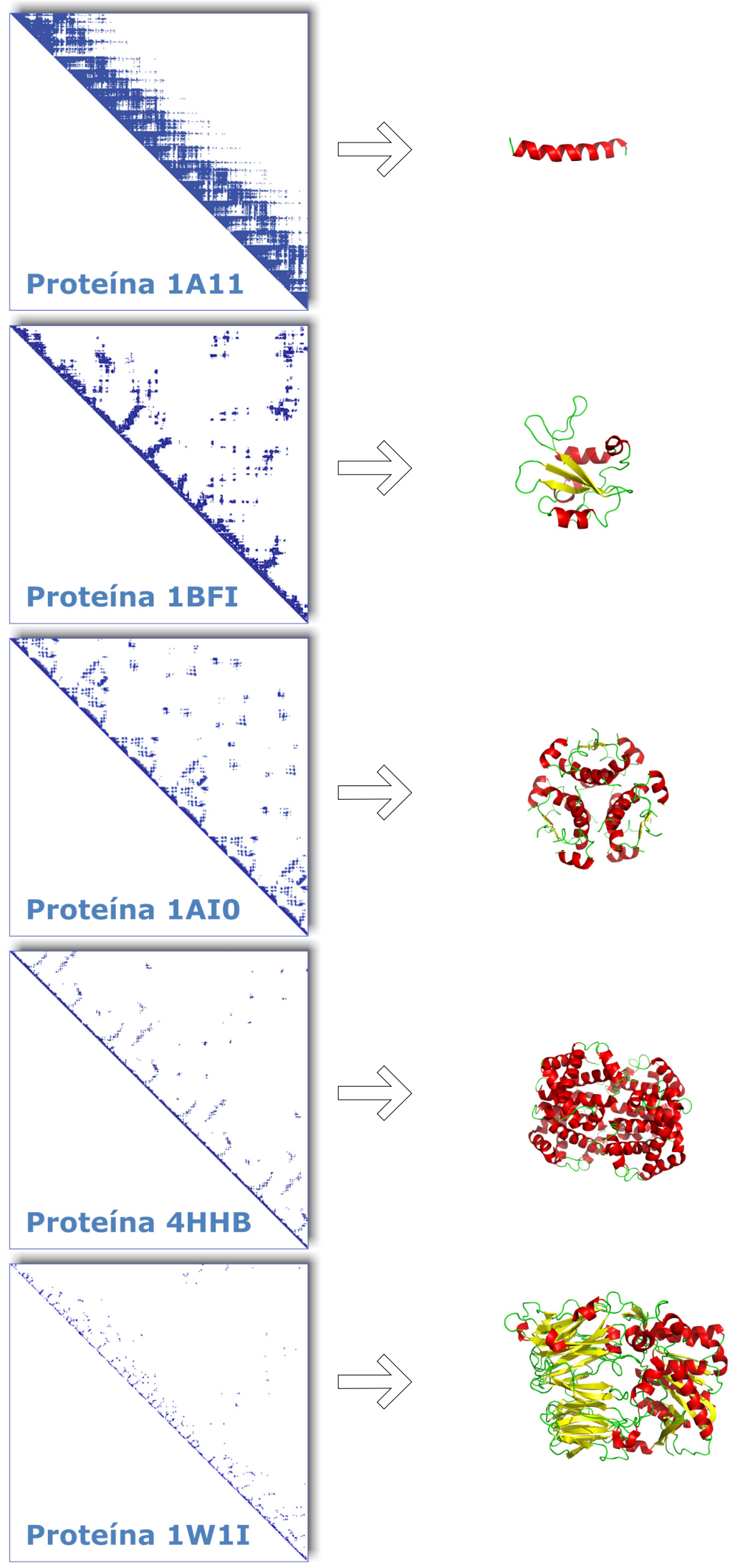

Figura 6.3: Matriz de bitmap gerada para cinco proteínas. Quanto maior a proteína mais esparsa é a matriz. 


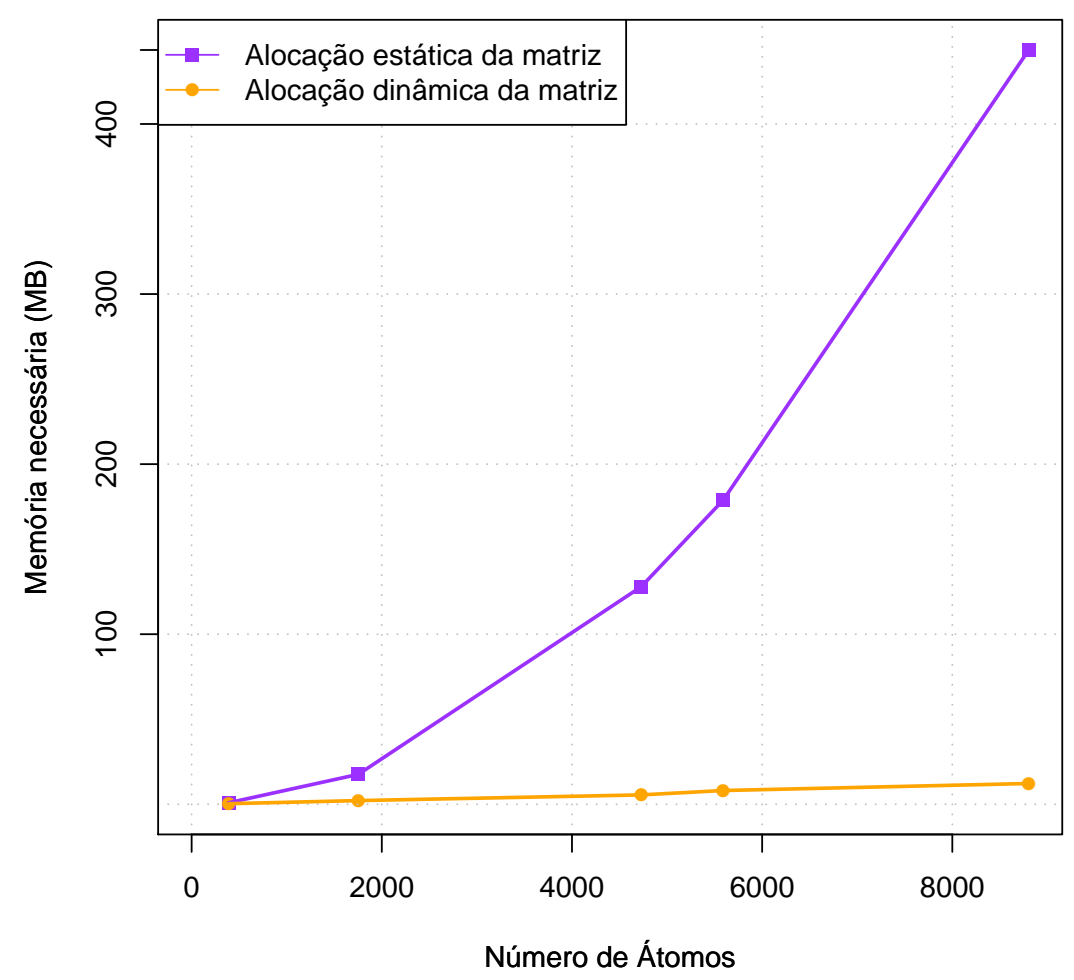

Figura 6.4: Aproveitamento do cálculo pela recombinação.

Além disso, como mostra a Equação 2.3 é necessário fazer duas potências, uma multiplicação e uma subtração.

A proposta da técnica para o Cálculo Off-Line (COF) é evitar que esses cálculos sejam executados no processador para cada interação de par de átomos (Allen \& Tildesley, 1987). É possível calcular a energia de van der Waals para um par de átomos conhecendo a distância $d_{i j}$ e o tipo dos átomos $i$ e $j$ como, carbono, nitrogênio, oxigênio, hidrogênio e enxofre ${ }^{2}$. Baseado nesse conhecimento, é possível gerar tabelas para todos os tipos de parâmetros. Devem ser geradas 15 tabelas referente às combinações dos tipos de átomos: $\mathrm{CC}, \mathrm{CH}, \mathrm{CO}, \mathrm{CN}, \mathrm{CS}, \mathrm{HH}, \mathrm{HO}, \mathrm{HN}, \mathrm{HS}, \mathrm{OO}, \mathrm{ON}$, OS, NN, NS e SS. O número de linhas de cada tabela determina a precisão desse método. Quanto maior for o número de linhas, menor será o erro do cálculo. A energia referente à interação de dois átomos na tabela é o valor que corresponde a uma aproximação dada pela precisão da tabela. A Figura 6.5 ilustra um exemplo de utilização dessa técnica.

\subsection{Lista de Células}

A técnica de COF é interessante no sentido de que grande parte da computação é economizada por meio das tabelas. Mas um fator agravante em termos de tempo computacional são as verificações que o algoritmo realiza para saber qual interação deve ser calculada, isto é, a maioria dos

\footnotetext{
${ }^{2}$ Tipos dos átomos que constituem as proteínas.
} 


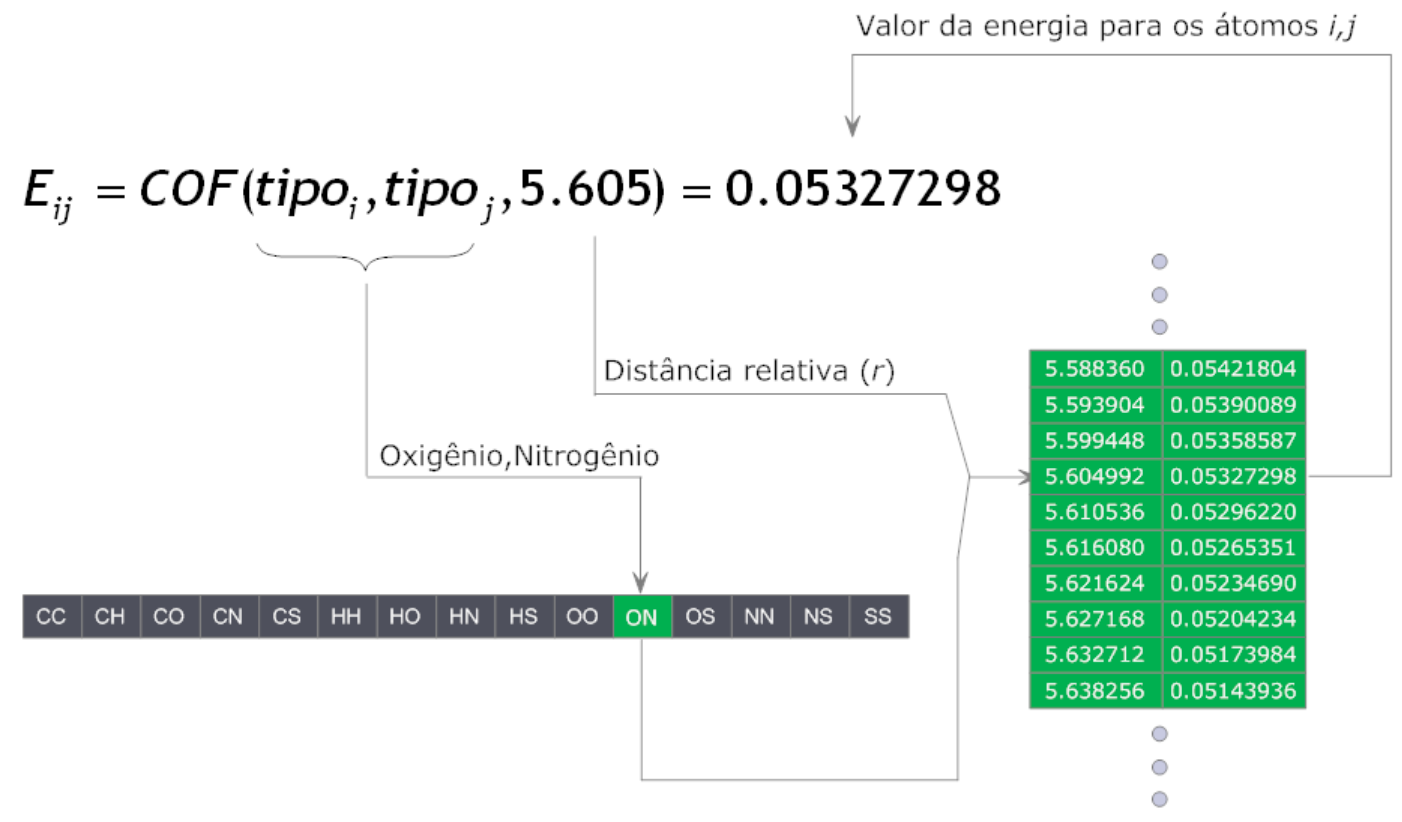

Figura 6.5: Exemplo do cálculo da energia utilizando COF.

átomos estão a mais de $8 \AA ̊$ de distância e mesmo que a energia de van der Waals não seja calculada esse tipo de verificação não é evitado. Isso resulta em um algoritmo quadrático de interações e, como mostrado na Seção 6.2, a maioria dos átomos da proteínas não interagem com todos os outros, o que resulta na matriz esparsa de interações.

Para que um algoritmo que calcule a energia de van der Waals seja eficiente, precisa ser capaz de calcular a energia somente para pares de átomos que possuem um fator energético, desconsiderando aqueles que não contribuem com a energia. Como foi visto até agora, as técnicas apresentadas mostraram formas de obter melhor desempenho, mas para que um AG consiga trabalhar corretamente com moléculas de qualquer tamanho, isso só é possível se a complexidade do cálculo for reduzida.

A Lista de Células (do inglês, cell-lists) foi proposta inicialmente em (Schofield, 1973; Hockney et al., 1974), com o objetivo de reduzir a complexidade de algoritmos utilizados no cálculo da interação de partículas que se interagem dentro de um raio determinado pelo cutoff. Para isso, o algoritmo de lista de células (LC), por meio de um mecanismo de busca eficiente, armazena em listas distintas somente átomos que estão próximos ao raio de corte. Dessa forma, o algoritmo garante que o número de interações necessárias para uma molécula com $n$ átomos será de complexidade $O(n)$. A técnica de LC pode ser empregada em diversas funções de energia, como no caso da energia de van der Waals, que possui as características necessárias para aplicação do método (assim como a energia eletrostática) e possui a mesma qualidade que as técnicas convencionais de complexidade $O\left(n^{2}\right)$ (Allen \& Tildesley, 1987).

Primeiramente, a molécula de proteína é carregada em um espaço de dimensões $\left(L_{x}, L_{y}, L_{z}\right)$. O comprimento desse espaço é determinado pela diferença entre o maior valor e o menor valor da coordenada do átomo da mesma direção, e para garantir que o último átomo esteja dentro da 
última célula é adicionado um valor de folga de 0,1 . Assim, tem-se $L_{x}=\left(\max _{x}-\min _{x}\right)+0,1$ para o eixo $x$, por exemplo.

Conhecendo o tamanho total do espaço nos três eixos e o raio de corte é possível determinar o número de células em cada eixo em uma grade de $n_{x} \times n_{y} \times n_{z}$ células, onde

$$
n_{x}=\left\lfloor\frac{L_{x}}{r_{c}}\right\rfloor, n_{y}=\left\lfloor\frac{L_{y}}{r_{c}}\right\rfloor, n_{z}=\left\lfloor\frac{L_{z}}{r_{c}}\right\rfloor
$$

e $r_{c}$ é o radio de corte. O número de células deve ser sempre arredondado para o inteiro inferior para que o tamanho das células seja igual ou maior ao raio de corte. Essas células são fixadas no espaço, sendo assim, possível determinar aonde começam e terminam dividindo o espaço total pelo número de células, $c_{x}=\frac{L_{x}}{n_{x}}, c_{y}=\frac{L_{y}}{n_{y}}$ e $c_{z}=\frac{L_{z}}{n_{z}}$.

Em seguida, a lista de átomos é percorrida para encontrar os índices $i_{x}, i_{y}, i_{z}$ de cada átomo para sua respectiva célula. Assim, é possível determinar que átomo corresponde a qual célula. Os índices dos átomos são encontrados utilizando $i_{x}=\frac{\operatorname{atom}(i)_{x}-\min _{x}}{c_{x}}$, repetindo o mesmo para $i_{y} \mathrm{e} i_{z}$, onde atom $(i)_{x}$ é a coordenada no eixo $x$ referente ao átomo $i$. Após o preenchimento das células com todos os átomos é iniciada a varredura na qual se pretende calcular a interação entre os átomos da mesma célula e das células vizinhas. Esse é ponto do algoritmo que caracteriza a complexidade como $O(n)$, pois átomos que estão em células distantes em relação à célula em questão não passam pelo processo de interação.

Por fim, as células são percorridas uma a uma e, para cada dessas células, é calculada a interação entre os átomos que estão dentro da mesma célula e com todos os átomos das células vizinhas. Pelo fato do tamanho da célula ser maior ou igual ao raio de corte, se uma partícula estiver praticamente encostada na parede de uma célula, essa partícula nunca iria interagir com nenhuma outra da célula que está separada por dois vizinhos, mesmo que no outro vizinho a partícula esteja praticamente no lado oposto, encostada na parede. Isso garante que a técnica de LC tem a mesma força de interação que um método $O\left(n^{2}\right)$.

Para facilitar o entendimento, a Figura 6.6 ilustra uma abordagem de LC com duas dimensões. Nesse exemplo é utilizado uma grade de células de dimensão $n x \times n y=3 \times 3$. O átomo indicado no centro da circunferência tracejada da célula $i, j$ tem interação somente com aqueles que estão dentro da circunferência. Entretanto, na abordagem de LC, embora tenha dois átomos nas células vizinhas fora do seu raio de corte, a interação não será calculada, somente será consumido processamento realizando a verificação do raio de corte. Dessa forma, ganha-se tempo computacional evitando calcular a energia de van de Waals para os átomos que não são vizinhos, pois se não são vizinhos certamente estarão mais longe que o raio de corte.

Deve ser tomado um certo cuidado no momento de escolher as células vizinhas devido ao fato do cálculo da interação para pares de átomos serem simétricas, isto é, a energia entre dois átomos $E_{i, j}$ é a mesma energia para os átomos $E_{j, i}$. Dessa forma, calculando a interação entre as células cell $_{i, j, k}$ e $c e l l_{i+1, j, k}$ não deve ser calculada a interação $c e l l_{i+1, j, k}$ e $c e l l_{i, j, k}$. No caso do espaço 3D, os vizinhos possíveis da célula $(i, j, k)$ são: $(i, j, k+1),(i, j+1, k-1),(i, j+1, k),(i, j+1, k+1)$, 


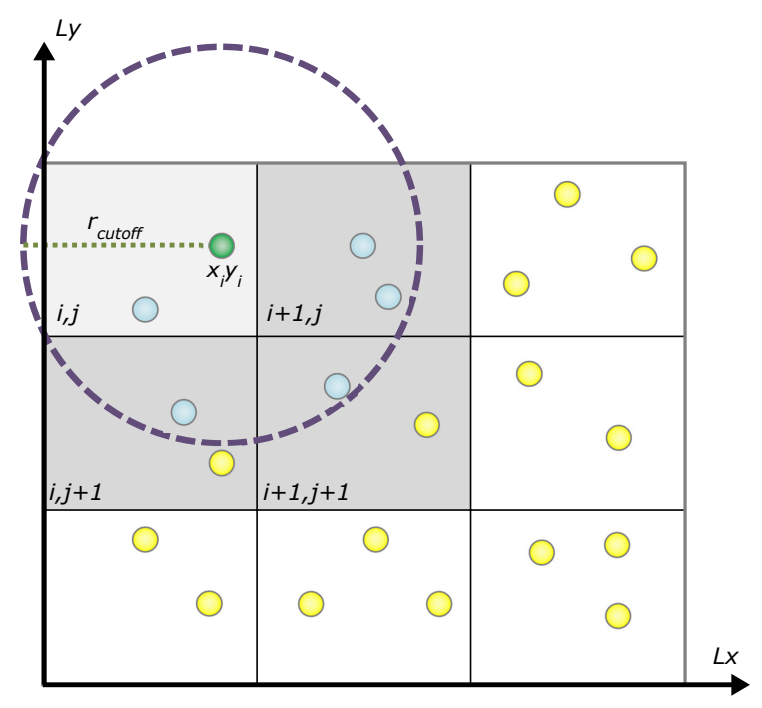

Figura 6.6: Abordagem de LC com grade $3 \times 3$.

$(i+1, j-1, k-1),(i+1, j-1, k),(i+1, j-1, k+1),(i+1, j, k-1),(i+1, j, k),(i+1, j, k+1)$, $(i+1, j+1, k-1),(i+1, j+1, k),(i+1, j+1, k+1)$.

\subsection{AGs para PSP com Lista de Células}

Os softwares de Dinâmica Molecular (DM) envolvem um grande número de computação e, por essa razão, precisam de métodos eficientes que sejam capazes de acelerar as simulações. O método de LC é amplamente utilizado nos programas de DM como, por exemplo, Gromacs (van der Spoel et al., 2004), LAMMPS (Corporation, 2003), Amber (Case et al., 2004) e CHARMM (Stote et al., 1999). Esses programas de DM são utilizados para descobrir o comportamento de proteínas e outras moléculas por meio de simulações computacionais. Na DM, o sistema (ambiente da simulação) é inicializado com uma molécula obtida por meio de métodos experimentais como, CRX e RNM. Cada átomo assume uma posição no espaço 3D e sua posição é levemente alterada, para dar uma pequena minimização na energia. Os átomos recebem uma velocidade inicial e o sistema é aquecido e submetido a uma pressão. Em seguida, a simulação é iniciada e continua até atingir uma temperatura de equilíbrio ou algum outro critério adotado pelo usuário. Ao final da simulação, as trajetórias dos átomos são salvas possibilitando que sejam analisadas pelos usuários. Dessa forma, é possível submeter proteínas a várias condições de temperatura e pressão a fim de estudar seu comportamento como, por exemplo, testar os limites de temperatura suportados por certa proteína antes que se desestabilize.

Em contraste com os pacotes de DM, em que os cálculos das energias são utilizados nas simulações para determinar comportamentos de moléculas, os cálculos de energia são utilizados na função de avaliação de AGs para PSP para distinguir a qualidade dos indivíduos. Dessa forma, há uma diferença do método de LC quando aplicado para softwares de DM e AGs para PSP. Quando a posição dos átomos é inicializada na DM, a grade de células é criada somente uma vez. Após o 
início da simulação, os átomos podem sofrer uma pequena variação na posição. Essas pequenas variações podem fazer o átomo pular para uma célula vizinha, por exemplo, certo átomo que está na célula $i, j, k$ pode passar para a célula $i+1, j, k$. Para garantir a que a informação da célula dos átomos esteja sempre correta, os pacotes de DM adotam estratégias semelhantes. Alguns atualizam a lista que contém as células a cada 10 passos de simulação, enquanto outros atualizam em todos os passos. É possível também utilizar células um pouco maiores que o raio de corte e evitar a atualização das células durante a simulação, mas o usuário deve estar ciente que os átomos não sofrerão grande alteração em suas posições.

Por outro lado, para avaliar a energia em AGs para PSP usando LC, é necessário fazer todo o processo de criação e varredura do método para cada conformação. Em AGs, os indivíduos (as conformações de uma proteína) podem ser alterados significativamente a cada nova solução investigada o tempo todo por meio dos operadores genéticos (recombinação, mutação e seleção). Por exemplo, para calcular a energia de van der Waals utilizando LC para dois pais, é necessário realizar todas as etapas do método de LC para cada um dos indivíduos, assim como também deverá acontecer o mesmo para os filhos gerados. Dessa forma, o método de LC quando aplicados a AGs para PSP tem um gasto alto de computação em relação aos softwares de DM (Figura 6.7).

(a)

Passo 1

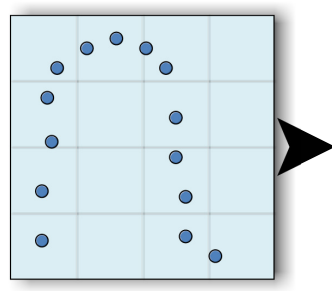

Indivíduo 1

(b)

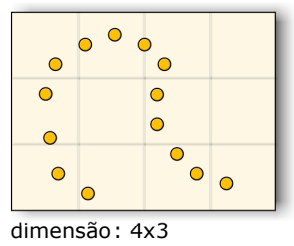

Passo 2

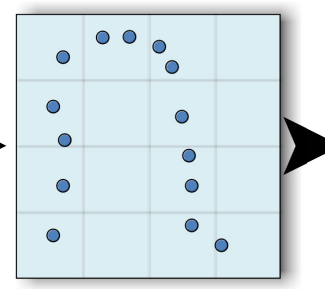

Indivíduo 2

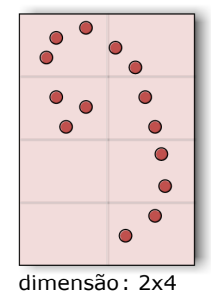

Passo 3

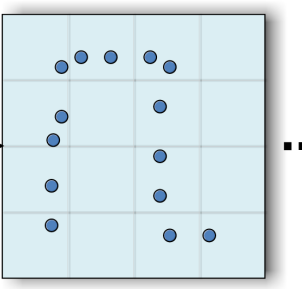

Indivíduo 3

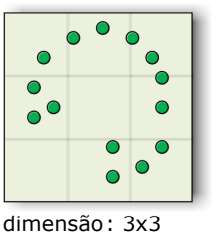

Passo $i$

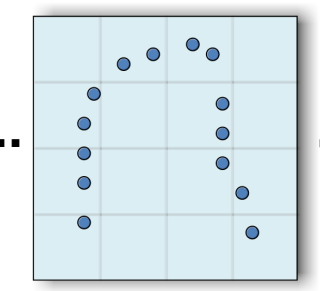

Indivíduo $i$

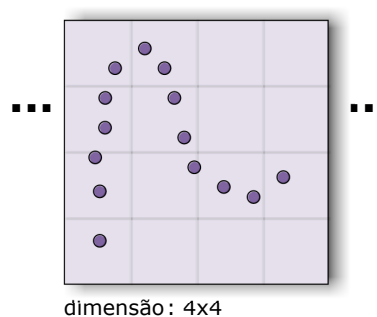

Passo $n$

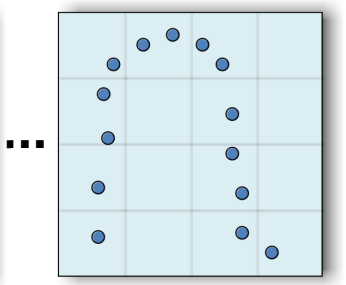

Indivíduo $n$

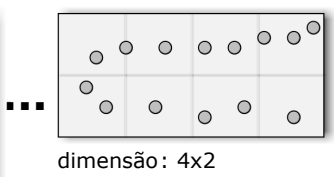

Figura 6.7: Exemplo do uso de LC para DM e em AGs. (a) Na DM a mesma célula é aproveitada durante a simulação. (b) Em AGs, é realizado todo o processo de criação de célula para cada avaliação de indivíduo.

\subsection{Considerações Finais}

Este capítulo mostrou técnicas que podem ser utilizadas para o aumento da eficiência computacional do cálculo da energia de van der Waals utilizada em AGs para PSP. O ABSO foi a primeira versão desenvolvida com o objetivo de melhorar o desempenho do algoritmo no nível 
mais baixo possível, permitindo que outras técnicas combinassem suas características às otimizações do ABSO. A técnica de ACR se aproveita do operador de recombinação dos AGs para aumentar a eficiência do cálculo no filho e, nesse sentido, fica restrita ao uso com AGs. O COF é capaz de aumentar a eficiência do cálculo evitando que operações aritméticas sejam executadas durante o processo de interação entre os átomos. A energia de van der Waals, possui um número relativamente pequeno de operações aritméticas tornando a técnica do COF pouco eficiente. Além disso, o desempenho dessa técnica está proporcionalmente relacionada à precisão da mesma. Entretanto, podem ser combinadas outras técnicas. Considerando que a maior parte dos átomos de uma proteína não interagem uns com os outros e sim somente com seus vizinhos próximos, foi também abordado o método de LC, o qual é capaz de reduzir a complexidade do algoritmo para $O(n)$ garantindo que os átomos somente irão interagir com átomos que estejam próximos, sendo assim o mais eficiente. A técnica de LC também pode também ser combinada como, por exemplo, ao ABSO e COF. 



\section{CAPÍTULO 7 \\ Propostas de implementações paralelas}

O Capítulo 6 mostrou técnicas de programação sequencial que podem ser aplicadas ao cálculo da energia de van der Waals utilizando AGs para PSP. Neste capítulo, serão abordadas técnicas de paralelização para os métodos ABS (Seção 7.1) e LC (Seção 7.2) para que assim, seja reduzido o tempo de computação dessas técnicas quando utilizados vários processadores.

\subsection{Algoritmo Básico Paralelo}

O Algoritmo Básico Paralelo (ABP) é uma implementação paralela em MPI do ABS. Inicialmente, as operações aritméticas envolvidas no cálculo da energia de van der Waals foram divididas em tarefas de granularidade fina. Em seguida, foi elaborado um mapa de dependência de tarefas e, dessa forma, tornando possível visualizar trechos do algoritmo que estavam sujeitos à execução em paralelo. Com o agrupamento de tarefas em processos, verificou que utilizando passagem de mensagens não era viável paralelizar o algoritmo nesse nível de granularidade, pois o custo de comunicação seria elevado em relação à computação, sendo necessário gerar tarefas de tamanho maior, deixando de utilizar a granularidade mais fina (Figura 7.1).

Nesse sentido, aproveitando o grafo de dependência, é possível visualizar que cada interação entre pares de átomos não tem relação com nenhum outro par de átomos, ou seja, é possível calcular a energia $E_{1,2}$ e $E_{1,3}$ ao mesmo tempo, pois o resultado de um $E$ qualquer não interfere no cálculo da interação de nenhum outro par de átomos (Figura 7.1(b)). Baseando-se na função da energia de van der Waals, 


$$
E_{v d w}=\sum_{i=1}^{n-1} \sum_{j=i+1}^{n} f_{v d w}\left(\frac{R_{i}+R_{j}}{d_{i, j}}\right),
$$

as tarefas podem ser geradas a partir do somatório de $j$, onde cada tarefa tem tamanho da iteração 1 (granularidade mais fina) ou do somatório de $i$, onde cada tarefa tem tamanho $1 \times j$ (granularidade mais grossa). Devido ao fato da computação realizada no laço mais interno ser relativamente pequena, o tamanho da tarefa utilizada no ABP é correspondente a uma iteração do laço mais externo. Assim, as tarefas podem ser geradas de maneira estática a partir do tamanho da proteína, porém não é garantido que o tamanho de cada tarefa seja o mesmo porque o cálculo da interação depende da posição espacial de cada átomo e se o par de átomos distam mais de $8 \AA$, o cálculo de van der Waals não é realizado, tornando a computação mais rápida. No entanto, como todas as tarefas estão sujeitas a esse tipo comportamento, o tamanho das tarefas é considerado uniforme.

Depois que a computação foi dividida em tarefas, é necessário mapear as tarefas em processos. Cada processador irá executar um conjunto de processos baseado no número de átomos de proteína e na quantidade de processadores. Mas, para garantir o balanceamento de carga é necessário que todos os processos tenham o mesmo tamanho, pois a interação entre pares de átomos da energia de van der Waals gera uma matriz triangular superior de interações. Por exemplo, a tarefa 1 do somatório em $i$ tem tamanho $n-1$, a tarefa 2 tem tamanho $n-2$, até a tarefa $n-1$ que tem tamanho $n-(n-1)$. Para compensar esse desbalanceamento de carga são mapeadas duas tarefas em um mesmo processo: $P_{1}=T_{1}, T_{(n-1)} ; P_{2}=T_{2}, T_{(n-2)} ; P_{3}=T_{3}, T_{(n-3)} ; P_{n / 2}=T_{(n / 2)}, T_{(n-(n / 2))}$.

Isso garante que, apesar do total do número de processos ser $n / 2$, todos os processos têm o mesmo tamanho (Figura 7.2). Com isso, a interação entre os pares de átomos da energia de van der Waals pode ser visto como uma matriz densa de interações. Para que o algoritmo seja adequado a matriz densa de interações é necessário atribuir novos índices para as posições $i$ e $j$. Os índices modificados são chamados de $x$ e $y$, e são determinados utilizando as posições de $i$ e $j$, como mostrado no Algoritmo 2.

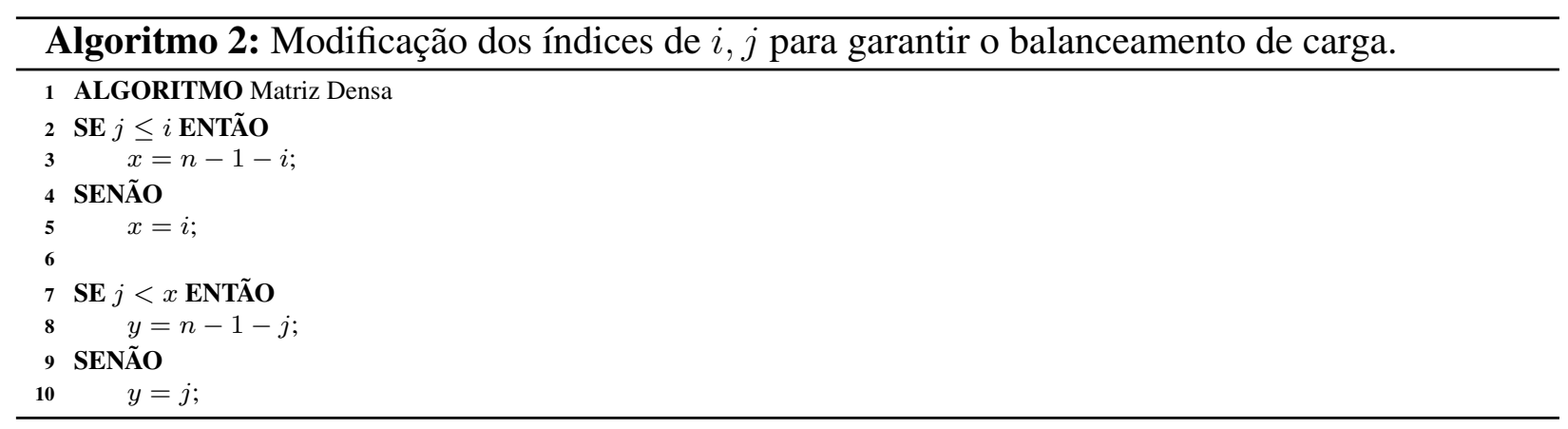

Os processos são mapeados nos processadores utilizando o número de identificação do processador $(r a n k)$, a quantidade de átomos da proteína $(n)$ e o número total de processadores $(p)$. Para determinar qual processador será responsável por computar qual índice do somatório mais externo, 
o somatório é alterado para

$$
E_{v d w}=\sum_{i=\text { rank }}^{n / 2} \sum_{j=0}^{n-1} f_{v d w}\left(\frac{R_{x}+R_{y}}{d_{x, y}}\right)
$$

onde o incremento de $i$ é dado por $i=i+p$ e $i \neq j$.

\subsubsection{MPI sem enviar átomos}

Baseado nos conceitos de programação paralela, foi desenvolvida a versão mais simples de um algoritmo paralelo em MPI, chamado de ABP-1 (Algoritmo Básico Paralelo 1). Nesse algoritmo, todos os processadores contém os dados necessários para iniciar a computação, sem depender da necessidade do mestre ou algum outro processador ter que enviar algum dado. Isso ocorre, pois as coordenadas dos átomos $x y z$ são lidas do disco por todos os processadores ao mesmo tempo, considerando que o sistema de arquivos permite esse tipo de acesso. Dessa forma, o algoritmo não precisa aguardar pelas coordenadas dos átomos antes de iniciar a computação das tarefas.

Cada processador tem uma variável própria correspondente ao resultado parcial da soma da energia que é encarregado de computar. Conforme os processadores terminam suas tarefas, eles enviam o resultado parcial da energia para o mestre (processador com rank $=0$ ). Após o recebimento da energia parcial de todos os processadores, o mestre realiza a soma dessas energias e compõe a energia total de van der Waals para a molécula. O mestre também executa o cálculo parcial da energia para suas respectivas tarefas, porém, já possui acesso ao valor parcial calculado, tendo somente que incrementar ao valor das energias parciais recebidas.

Esse tipo de algoritmo que não envia as coordenadas dos átomos para os processadores é o melhor algoritmo que se pode criar para obter desempenho, pois o envio de grandes matrizes por passagem de mensagens gera um alto custo de comunicação, mesmo utilizando redes gigabit. No ABP-1, isso é evitado lendo as grandes matrizes de coordenadas diretamente do disco. No entanto, esse tipo de algoritmo não pode ser aplicado a AGs, pois nos AGs, as coordenadas $x y z$ dos átomos são alteradas constantemente pelos operadores genéticos. A cada nova geração de um AG, os novos indivíduos gerados têm coordenadas diferentes dos indivíduos da geração anterior. Assim, é necessário que, no momento do cálculo da energia de van der Waals, os processos tenham a informação atualiza da posição de cada átomo.

\subsubsection{MPI enviando átomos}

Para garantir que os processadores tenham a informação atualizada das coordenadas dos átomos é necessário enviar as coordenadas para os processadores antes do início do cálculo. Isso cria um efeito de "simulação" do emprego da técnica para poder ser aplicado a AGs. Por esse motivo, o ABP-2 (Algoritmo Básico Paralelo 2) considera que as coordenadas dos átomos $x y z$ sejam enviadas para todos os processadores. Baseado no ABP-1 (Seção 7.1.1), o ABP-2 possui a 


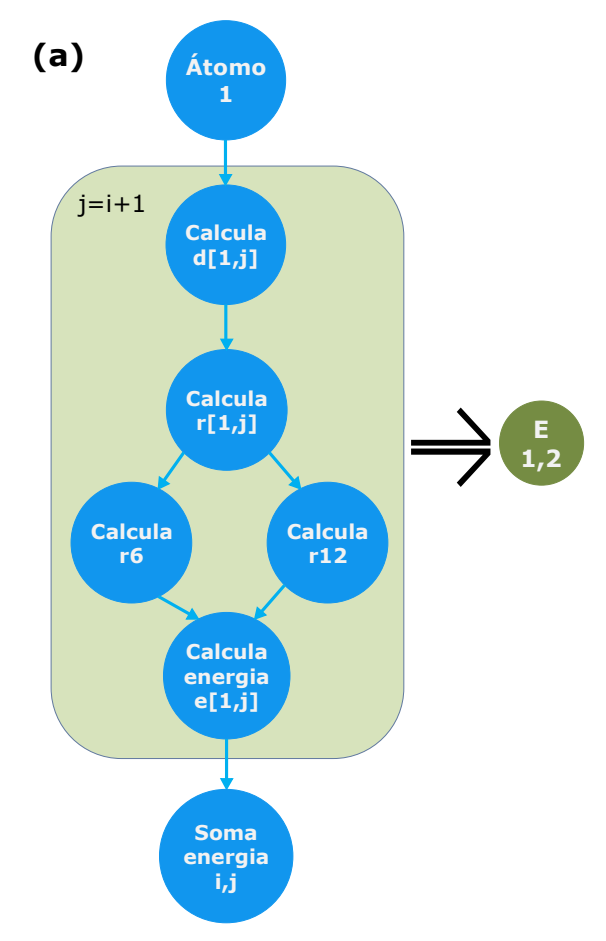

(b)

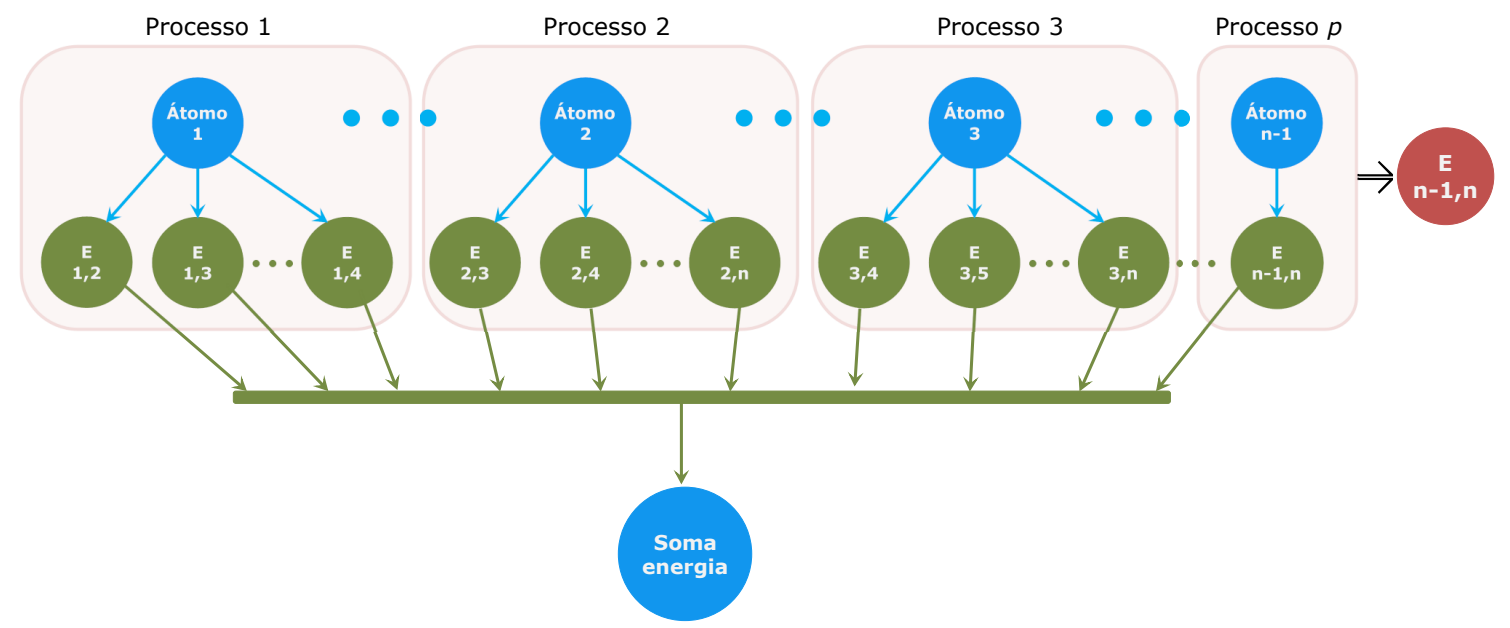

(c)

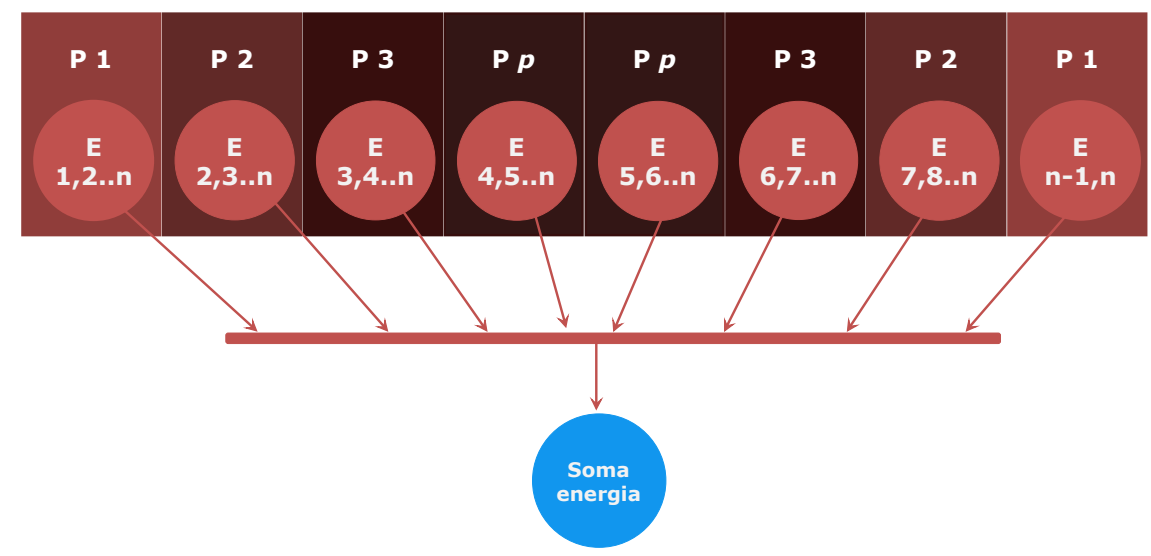

Figura 7.1: Dependência de tarefas para o cálculo da energia de van der Waals. (a) O grafo de dependência com granularidade fina. (b) Mapeamento das tarefas em processos. (c) Mapeamento com balanceamento de carga. 

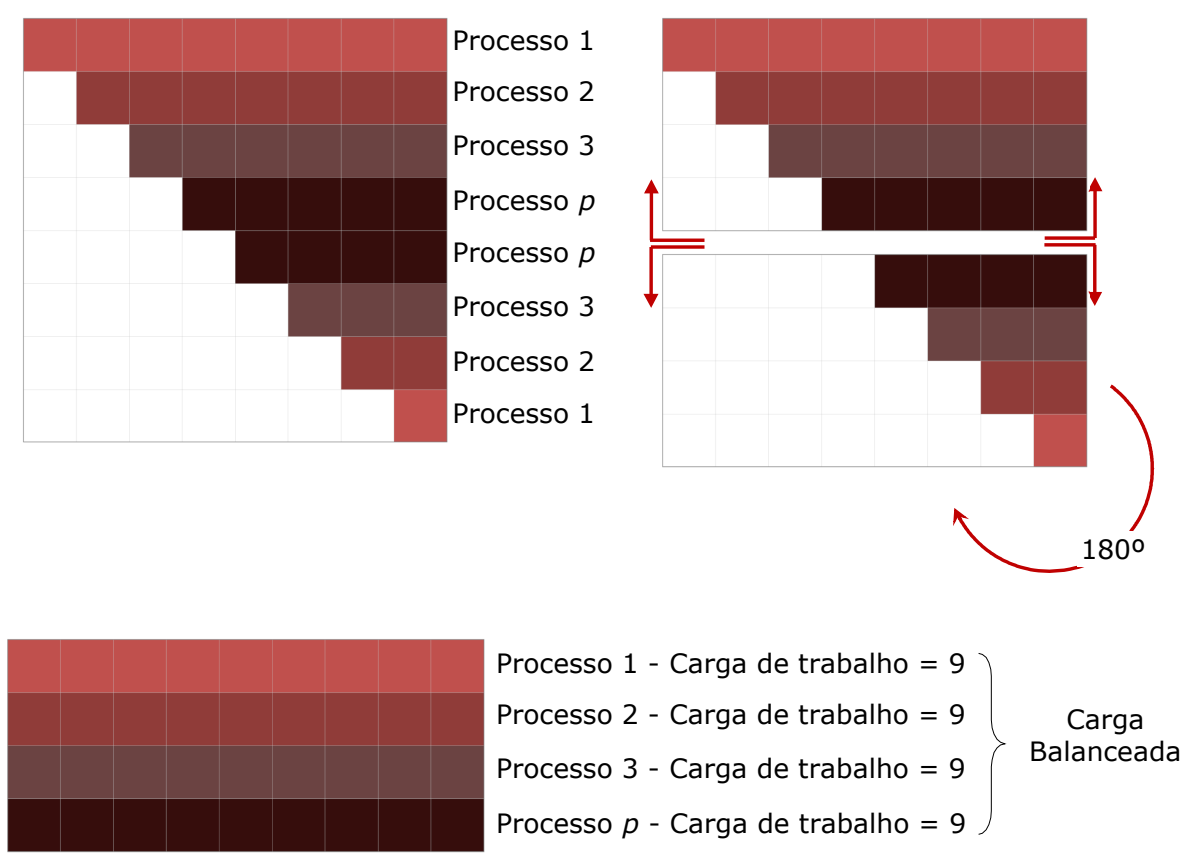

Figura 7.2: Balanceamento de carga para a matriz triangular superior.

característica de poder enviar uma estrutura de dados própria, chamada de MPI_Pos para os processadores escravos. Essa estrutura de dados armazena os vetores $x, y \mathrm{e} z$ de coordenadas, pois, por padrão em MPI, somente é permitido enviar dados para outros processadores que sejam do tipo básico como, por exemplo, float, int e char. Utilizando a forma de envio tradicional, seriam necessárias três interações de tarefas entre o mestre e todos os escravos: um para envio do vetor de coordenadas $x$, um para $y$ e outro para $z$. Por outro lado, com o uso da estrutura de dados personalizada é possível economizar o overhead gerado pelas interações de tarefas agrupando todos os dados da coordenadas $x y z$ em um único comando de envio. Assim, utilizando a estrutura de dados MPI_Pos é enviada a mesma quantidade de dados para todos os processadores, porém com um overhead menor.

Os parâmetros necessários para o cálculo da energia de van der Waals são as posições das coordenadas e também o tipo de cada átomo ( $\mathrm{C}, \mathrm{H}, \mathrm{O}, \mathrm{N}$ ou S). No início do algoritmo é lido do disco e armazenado na memória o índice do átomo e seu respectivo tipo. Isso ocorre em todos os processadores, sendo assim possível saber o tipo dos átomos $i, j$ utilizando o índice do átomo. Embora os átomos possam ter suas posições alteradas o tempo todo, o átomo de índice 1, por exemplo, será carbono durante toda a execução do algoritmo. Isso evita o envio de mais uma informação para os processadores, economizando tempo.

\subsection{Lista de Células em Paralelo}

As Listas de Células em Paralelo, LCP, são utilizadas para reduzir o tempo computacional do cálculo da técnica de LC. Diferentemente do ABP, a LCP não pode ser dividida nas mesmas tarefas porque em ABP existe um número quadrático de interações que são divididos entre em 
tarefas, enquanto que em LCP o número de interações é linear. Sendo assim, LCP requer uma nova geração de tarefas. Observando a Figura 7.3 foi notado que o trecho do algoritmo que faz a varredura das células pode calcular independentemente o valor da energia entre qualquer átomo de qualquer célula. No algoritmo padrão de LC, o cálculo da energia pode ser visto como:

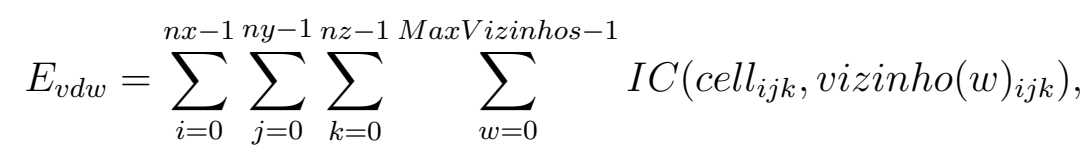

onde $c e l l_{i j k}$ é a célula referente à célula na posição $i j k$, vizinho $(w)_{i j k}$ é o vizinho $w$ da célula $i j k$ e $I C$ é a função que calcula a interação dos átomos da célula com os átomos do vizinho.

O algoritmo de LCP foi elaborado utilizando o nível do laço mais externo para compor as tarefas, garantindo uma granularidade mais grossa. Nesse caso, o tamanho de cada tarefa é $1 \times$ $n y \times n z \times w$ para todos os processadores e, em geral, de tamanho regular. Além disso, é possível fazer mapeamento estático conhecendo o tamanho de $n y$ e $n z$. Pode-se também gerar tarefas menores de tamanho $1 \times n z \times w$ ou $1 \times w$, porém há um maior custo de comunicação. As tarefas são mapeadas em processos de mesmo tamanho. Os processos são agrupados nos processadores de acordo com o tamanho de $n x$ e do número de processadores. A versão modificada de LC é:

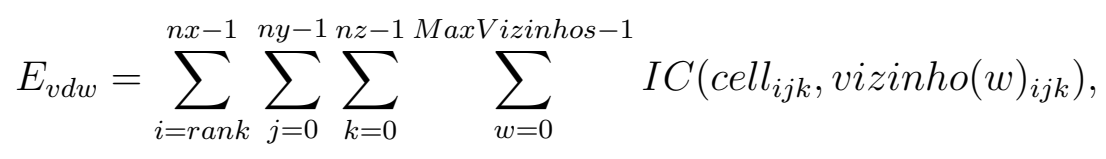

onde o incremento de $i$ é dado por $i=i+p$.

A Figura 7.3 ilustra um exemplo do mapeamento de processos utilizando células de dimensão $8 \times 8 \times 8$. O número total de tarefas é o número de células na direção de $\mathrm{x}(n x=8)$ e os processos têm o mesmo tamanho das tarefas. Considerando que os processos são do mesmo tamanho, podem ser mapeados em $p$ processadores, que nesse caso é igual a dois. Assim, o processador 1 e o processador 2 serão responsáveis por computar 4 blocos de $n x$ cada um, gerando uma carga total de trabalho de $n y \times n z \times(n x / p)$ para cada processador, resultando em $8 \times 8 \times 4=256$ células de computação para cada processador. Se houvessem 9 processadores no exemplo, os 8 primeiros processadores teriam carga de 64 enquanto que o processador 9 ficaria ocioso. Da mesma forma, se houvessem 7 processadores a carga de trabalho do processador 1 seria de 128 enquanto que para os processadores restantes a carga seria de 64. Para que houvesse melhor balanceamento de carga a divisão das tarefas deveria ser realizada, por exemplo, baseando-se nas direções $n x, n y, n z$, onde a carga de trabalho de cada processador seria dada por $\left\lceil\frac{n \times \times n y \times n z}{p}\right\rceil$ que nesse caso seria $\lceil 512 / 7\rceil=74$ e, apesar desse número ser um pouco maior que o total de células, a carga de trabalho estaria balanceada entre os processadores. No entanto, a estrutura de mapeamento pelos três eixos não foi utilizada neste trabalho, pois isso tornaria a granularidade mais fina e aumentaria o custo de comunicação em relação à computação.

De forma semelhante ao ABP, a LCP computa os resultados parciais nos escravos e por fim retorna esses valores para o mestre. O mestre, por sua vez, além de ser encarregado de calcular 
(a)
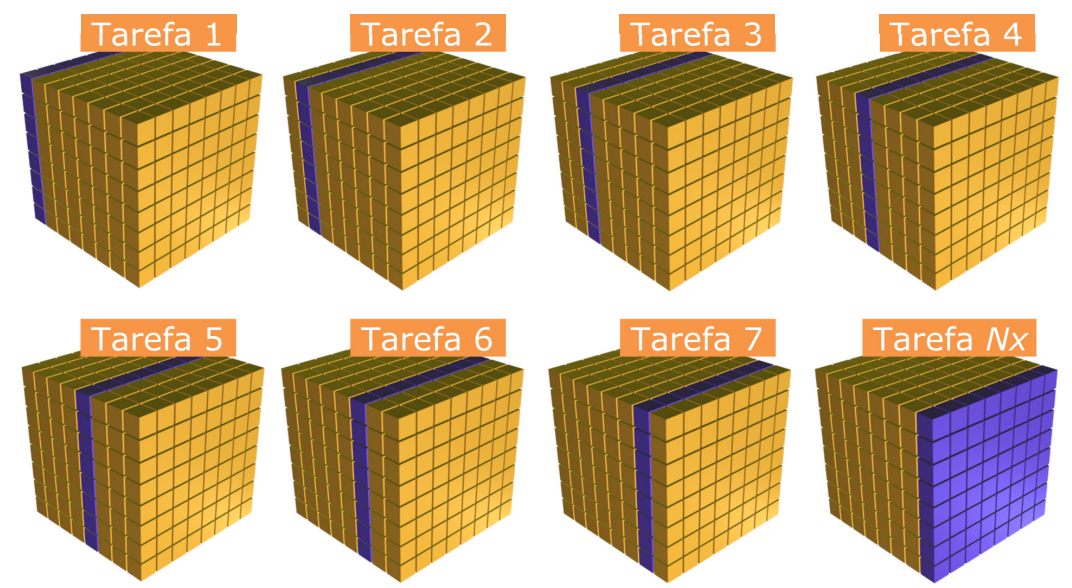

(b)

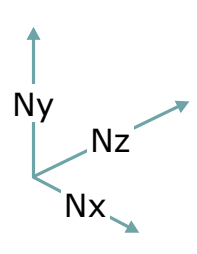

\section{Processador $p$}

Figura 7.3: Mapeamento de processos para LCP. (a) Divisão das tarefas por $n x$. (b) Mapeamento dos processos em processadores.

sua fatia de processos, faz o recebimento e a soma do valor das energias parciais vindas dos outros processos. A Seção 7.2.1 trata o algoritmo de células em MPI sem computar o tempo de enviar os átomos aos processadores enquanto que na Seção 7.2.2, esse tempo é considerado. A Seção 7.2.3 descreve um algoritmo em OpenMP para LC. Por fim, a Seção 7.2.4 faz uma combinação dos paradigmas MPI e OpenMP para LC.

\subsubsection{MPI sem enviar átomos}

A versão em MPI mais eficiente para o cálculo da energia de van der Waals paralelo utilizando LC é chamado de LCP-1 (Lista de Células em Paralelo 1). De forma semelhante ao ABP-1 (Seção 7.1.1), a LCP-1 não considera o tempo necessário gasto para enviar as coordenadas dos átomos $(x y z)$ para todos os processadores. É assumido que todos os processos são capazes de ler as coordenadas diretamente do disco, sem necessidade de aguardar o envio por outro processo. Dessa forma, cada processador é encarregado apenas de computar suas tarefas independente do tamanho da proteína. Após a conclusão das tarefas pelos processadores, os valores parciais das energias são enviados para o processador mestre. Cada processador escravo envia apenas um valor de energia para o mestre, tornando esse procedimento rápido em comparação à execução das tarefas. Assim, é possível obter o cálculo da energia de van der Waals utilizando vários processadores da maneira mais eficiente possível.

No entanto, esse tipo de algoritmo não pode ser aplicado em AGs porque é necessário que todos os processadores tenham a informação da posição espacial dos átomos antes de iniciar as 
tarefas, tornando necessário o envio das coordenadas $x y z$ para todos os processos. A idéia do desenvolvimento do algoritmo de LCP-1 é para determinar o limite de desempenho que será possível alcançar utilizando essa técnica quando for empregada em AGs.

\subsubsection{MPI enviando átomos}

O correto funcionamento de um AG que utiliza LCP precisa garantir que a cada avaliação de indivíduo, os processadores tenham a informação atualizada das coordenadas dos átomos. É preciso que o processador responsável pelos operadores genéticos envie a informação aos processadores escravos antes da avaliação do indivíduo. Para imitar esse procedimento utilizando o algoritmo de LCP, criaram-se dois algoritmos baseados no LCP-1: (1) LCP-2a, onde o processador mestre envia as coordenadas de todos os átomos para todos os processadores; (2) LCP-2b, onde o processador mestre envia somente as coordenadas referentes às tarefas que os processadores escravos irão precisar.

\section{Replicação de computação e comunicação}

Após a leitura das coordenadas pelo mestre, o algoritmo de LCP-2a envia imediatamente as coordenadas dos $n$ átomos da proteína para os $p$ processadores. Nesse algoritmo, todos os processadores têm a informação das coordenadas dos átomos, o que geralmente é desnecessário, pois, um processador somente irá calcular uma parte do espaço total que contém as células.

Com o recebimento de todas as coordenadas pelos processadores escravos, os próprios processadores fazem a montagem do espaço 3D e alocação dos átomos às células, apesar de que somente irão executar as tarefas que foram associadas. O envio de todas as coordenadas dos átomos da proteína para todos os processadores tem a vantagem de que qualquer processador é capaz de montar o espaço 3D das células, pois tem o conhecimento do espaço $L x, L y, L z$. Aliando essa informação ao raio de corte é possível encontrar qual átomo pertence a qual célula e, embora esse algoritmo coloque todos os átomos nas posições de células corretas, ele não irá utilizar toda essa informação.

Nesse sentido, o algoritmo de LCP-2a replica computação para reduzir o overhead da montagem das células. Além disso, a implementação desse algoritmo é relativamente simples pois tem a mesma estrutura do algoritmo de LCP-1. No entanto, para o caso de proteínas gigantes (com centenas de milhares de átomos) o custo de replicação de comunicação pode significar um problema.

\section{Minimização da comunicação}

Para reduzir o custo de comunicação, foi desenvolvida a versão LCP-2b, onde o processador mestre envia as coordenadas específicas para os processadores escravos utilizando a estrutura de dados MPI_Pos apresentada na Seção 7.1.2, sem replicar comunicação. No entanto, isso exige maior carga de trabalho para o mestre. 
Encontrar os átomos específicos que serão utilizados pelos processadores escravos exige que o processador mestre faça todo o processo de criação de células. Depois de calculado os valores de $n x, n y, n x, l x, l y, l z, \min _{x}, \min _{y}, \min _{z}$ pelo mestre esses valores são enviados para os processadores escravos. Para reduzir o overhead de comunicação, as informações de características das células são empacotadas em um único vetor de nove posições e enviadas, pois o custo gerado por uma comunicação que utiliza um vetor de uma posição e outro que utiliza um vetor de 10 posições é praticamente o mesmo. No entanto, o custo de enviar 10 vezes um vetor de uma posição é grande.

Com as informações recebidas pelos processadores escravos é necessário primeiramente determinar o espaço 3D, como $n x, n y, n x, l x, l y, l z, \min _{x}, \min _{y}, \min _{z}$ para que posteriormente, o mestre possa enviar os átomos. Com esses valores, é possível determinar a dimensão das células $(c x, c y, c z)$ nos escravos e, posteriormente, no momento de receber as coordenadas dos átomos, os escravos poderão saber em qual célula o átomo deverá ser alocado.

Em seguida, o mestre calcula quantos e quais átomos deverão ser enviados para qual processador. Com essa informação, o mestre precisa enviar a quantidade de átomos antes de enviar as coordenadas dos átomos para os escravos. Caso contrário os escravos não saberão qual é o tamanho da mensagem que estão recebendo. A partir disso, os escravos são capazes de determinar qual átomo pertence a qual célula de forma independente. A escolha de qual processador irá computar qual tarefa é realizada modificando o valor de $i$ :

$$
E_{v d w}=\sum_{i=0}^{\lceil n x / p\rceil} \sum_{j=0}^{n y-1} \sum_{k=0}^{n z-1} \sum_{w=0}^{M a x V i z i n h o s-1} I C\left(\operatorname{cell} l_{(p \times r a n k+i) j k}, \operatorname{vizinho}(w)_{(p \times r a n k+i) j k}\right) .
$$

De forma semelhante aos outros métodos paralelos, a energia total é computada pelo mestre a partir das energias parciais calculadas pelos escravos. O algoritmo de LCP-2b apresenta um menor custo na quantidade de dados na comunicação. No entanto, custos são adicionados como, por exemplo, o envio dos dados para construção do espaço 3D e da quantidade de átomos. Custos que devem ser ponderados, pois para que o método seja vantajoso a soma desses dois overheads deve ser menor que o custo de enviar todos as coordenadas dos átomos para todos os processadores. Além disso, a implementação torna-se complicada devido ao gerenciamento da interação das tarefas e ao trabalho excessivo do mestre. No entanto, tanto em LCP-2a quanto em LCP-2b, o custo de comunicação poderia deixar de ser um gargalo se todos os processadores tivessem acesso a mesma memória.

\subsubsection{Memória Compartilhada}

As implementações em MPI dos algoritmos de LC têm a vantagem de serem extensíveis a uma grande quantidade de processadores, dependendo basicamente da quantidade de processadores disponíveis para serem ligados à rede. Mas o custo de comunicação entre os processadores é alto em comparação ao custo de comunicação entre processadores que acessam a mesma memória 
global, isto é, utilizam memória compartilhada. A desvantagem desse paradigma é o limite de processadores, que está relacionado à própria arquitetura. Com a modernização dos processadores, está ficando cada vez mais fácil ter acesso a computadores com várias unidades de processamento que acessam a mesma memória como, por exemplo, o processador $i 7 \mathrm{da}$ Intel, que possui quatro processadores físicos e tecnologia hyper threading, dando visibilidade de oito processadores para o usuário.

Assim, o algoritmo de Lista de Células em Paralelo 3 (LCP-3) foi desenvolvido em OpenMP para ser executado em ambientes que utilizam vários processadores com memória compartilhada. Esse algoritmo baseia-se no algoritmo padrão de LC, utilizando as mesmas tarefas geradas para LCP. O processo que é executado no processador principal é dividido em várias threads. O sistema operacional, responsável por gerenciar em qual processador as threads serão executadas, faz um escalonamento para maximizar o uso de computação.

O algoritmo de LCP-3 deve, então, somente indicar a porção do algoritmo que deverá ser executado em paralelo. No caso do OpenMP, com apenas uma linha a mais no código-fonte, adicionada no algoritmo de LC sequencial, foi possível produzir um algoritmo que executasse em paralelo utilizando memória compartilhada. Como em outras plataformas de programação paralela, o OpenMP possui um conjunto de operações coletivas. Em comparação às variáveis que acumulavam os valores parciais das energias calculadas nos escravos dos algoritmos de LCP-1 e LCP-2, em LCP-3 é utilizada a operação de redução com adição à variável que contem o valor parcial das energias. Além disso, em LCP-3 é preciso informar que os índices dos somatórios para o cálculo da energia de van der Waals somente é visível para a thread que está executando.

Utilizando o algoritmo de LCP-3 é possível reduzir significativamente o tempo do cálculo da energia de van der Waals com uma implementação relativamente simples, pois o processo principal é dividido em threads na quantidade de processadores que a máquina paralela possui. No entanto, o desempenho dessa técnica fica restrito ao número de processadores que essa máquina paralela possui.

\subsubsection{Híbrido}

Para vencer a limitação do número de processadores imposta pela técnica LCP-3 e do custo de comunicação da técnica LCP-2, foi desenvolvido o algoritmo de Lista de Células em Paralelo 4 (LCP-4). O algoritmo de LCP-4 reúne características do algoritmo de LCP-2 e LCP-3 para compor um híbrido. Dessa maneira, é possível aproveitar o máximo de paralelismo disponível em computadores paralelos com vários processadores bem como uma grande quantidade deles interconectados por uma rede.

No algoritmo de LCP-4, o conjunto de tarefas atribuídas ao processador é dividido em threads que são executados em paralelo. No MPI, é possível especificar a quantidade de processos $p$ e o nome das máquinas que irão executar o algoritmo. A criação dos processos em MPI ocorre na sequência em que os nomes das máquinas aparecem. Se o número de processos for maior que o 
número de máquinas, o processo $m+1$ é executado na primeira máquina, onde $m$ é o número de máquinas. Por exemplo, utilizando um cluster com 10 máquinas (maq1, maq2, maq3, maq4, maq5, maq6, maq7, maq8, maq9, maq10) e 20 processos $(p=20)$, os processos 1 e 11 serão executados em maq1 enquanto que os processos 2 e 12 serão executados em maq2. Se cada máquina tem dois processadores, os 20 processos irão ocupar os 20 processadores, ou seja, não haverá perda de eficiência, pois os 20 processadores foram ocupados. No entanto, considerando que maq1 é o mestre, ele deverá comunicar-se com cada escravo duas vezes como, por exemplo, maq2, que recebeu as coordenadas dos átomos para o processo número 2 e também para o processo número 12.

Uma maneira de aumentar a eficiência desse método é iniciar 10 processos, um em cada máquina. Cada processo é dotado de uma diretiva de código paralelo (LCP-3) que sabe quantos processadores cada máquina possui. Dessa forma, quando o processo número 2 for iniciado em maq2, não haverá necessidade de criar um novo processo para ocupar o outro processador, reduzindo a comunicação, pois os dois processadores de maq2 serão ocupados por duas threads, melhorando a eficiência do algoritmo.

A Figura 7.4 ilustra um exemplo da técnica LCP-4 com duas máquinas com quatro processadores cada uma. No início do programa, é criado um processo em cada uma das máquinas por MPI que são encarregadas de computar as células $n x=i \times p+r a n k$. Em seguida, cada processo é dividido em threads por OpenMP pela quantidade total de processadores que cada máquina possui.

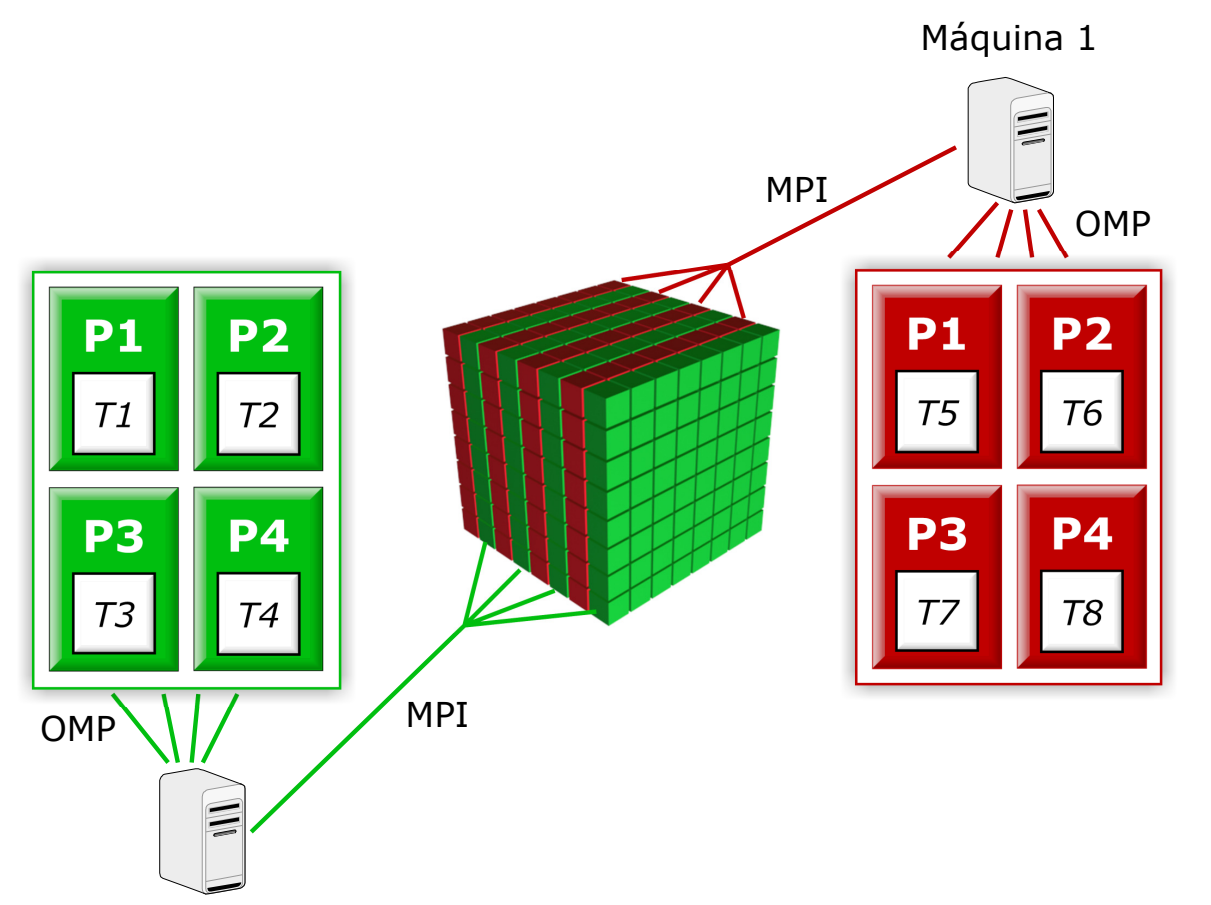

Máquina 2

Figura 7.4: Modelo híbrido de varrer as células.

A técnica do algoritmo com LCP-4 apresenta resultados melhores quando utilizados em clusters com várias máquinas que possuam muitos processadores (quatro ou mais). A LCP-4 pode 
apresentar resultados iguais ou semelhantes a LCP-2 se utilizada em um cluster com várias máquinas com apenas um processador cada e, do mesmo modo, pode apresentar resultados semelhantes a LCP-3 quando executada em uma máquina paralela com vários processadores. Nesse sentido, a decisão da escolha de um algoritmo que utilize LCP-2, LCP-3 ou LCP-4 está diretamente relacionada ao ambiente aonde serão empregadas.

\subsection{Considerações Finais}

Neste capítulo foram abordadas técnicas paralelas que podem ser empregadas no cálculo da energia de van der Waals para PSP. O algoritmo do cálculo da energia de van der Waals pode ser altamente paralelizado, pois é possível calcular a interação de todos os pares de átomos da proteína simultaneamente, ou seja, a interação entre um par de átomos no cálculo da energia de van der Waals não interfere no resultado de nenhuma outra interação. Mas, o desenvolvimento de um algoritmo paralelo requer passos importantes para construção de um algoritmo eficiente e escalável.

Primeiramente foi desenvolvido um algoritmo paralelo a partir do ABS capaz de ser executado em vários processadores. Embora a versão inicial, chamada de ABP-1, não pode ser utilizada em AGs, ela tem como objetivo encontrar a eficiência máxima servindo de limitante superior para a técnica ABP-2, que pode ser aplicada a AGs. Além disso, é possível fazer comparações entre as duas técnicas e verificar a influência do custo de comunicação.

Apesar da eficiência das técnicas ABP-1 e ABP-2, é interessante investigar as técnicas de paralelização para o algoritmo de LC, que reduz a complexidade do algoritmo para $O(n)$. Assim, ao contrário dos ABPs onde a complexidade é $O\left(n^{2} / p\right)$, a complexidade dos algoritmos de LCP são de complexidade $O(n / p)$, ou seja, mesmo utilizando um número gigante de processadores, a técnica de LC sequencial provavelmente seria mais eficiente que os ABPs.

Por esse motivo, investigaram-se várias técnicas de paralelização do algoritmo de LC. A LCP-1 não pode ser aplicada a AGs, mas serve de limitante superior para as técnicas LCP-2a e LCP-2b. A técnica de LCP-3 explora o paralelismo presente nas máquinas atuais bem como uma implementação relativamente simples. Já a técnica de LCP-4 combina as melhores características de LCP-2 e LCP-3. A intenção de investigar técnicas diferentes de paralelização para LC é apresentar resultados que indiquem a influência que cada fator exerce sobre a técnica.

Por fim, os resultados atingidos por cada técnica abordada neste capítulo são apresentados no Capítulo 8. 


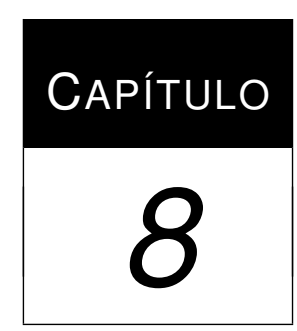

\section{Resultados Experimentais}

Os Capítulos 6 e 7 abordaram as técnicas propostas para o aumento da eficiência para o cálculo da energia de van de Waals utilizado em AGs para PSP. Essas técnicas foram avaliadas experimentalmente e os resultados obtidos são apresentados neste capítulo.

A Seção 8.1 apresenta a metodologia utilizada para avaliar o tempo dos experimentos e o cluster que foi utilizado. A Seção 8.2 introduz as proteínas que foram utilizadas nos experimentos. As Seções 8.3, 8.4, 8.5, 8.6, 8.7, 8.8, 8.9, 8.10, 8.11, 8.12, 8.13 e 8.14, mostram os resultados obtidos para as técnicas ABS, ABSO, ACR, COF, LUZ, ABP-1, ABP-2, LC, LCP-1, LCP-2, LCP-3 e LCP-4, respectivamente. A Seção 8.15 faz uma comparação entre as técnicas. A Seção 8.16 mostra um breve resultado da técnica LCP-3 empregada no ProtPred. Por fim, a Seção 8.17 apresenta as considerações finais deste capítulo.

\subsection{Avaliação de Desempenho}

Esta seção aborda a metodologia adotada para a avaliação de desempenho dos experimentos realizados. Cada experimento foi repetido 100 vezes com o propósito de obter amostras significativas, do ponto de vista estatístico. Foram removidos os pontos espúrios ${ }^{1}$ que estavam fora do conjunto representado por três vezes a mais e a menos a variância da média da amostragem. Por fim, é calculada a mediana da nova amostragem, que é o valor utilizado nos resultados.

Para realização desses procedimentos, utilizou-se a linguagem R, ambiente de programação científica para análise de dados e gráficos. Todo experimento executado gerou arquivos de saída

\footnotetext{
${ }^{1}$ Pontos que estão distantes do resto dos dados, também chamados de outliers.
} 
contendo os tempos de execução, visto que cada arquivo de saída contém 100 linhas referente a 100 medidas de tempo diferente. Para cada experimento foi criado um script em R capaz de ler os arquivos de saída dos experimentos, remover os pontos espúrios e gerar gráficos.

A Seção 8.1.1 explica como foi realizada a medição de tempo. A Seção 8.1.2 faz uma apresentação do cluster onde os experimentos foram executados. Por fim, a Seção 8.1.3 mostra uma avaliação de desempenho alcançado pelo cluster.

\subsubsection{Medição de Tempo}

A função de medição de tempo incorporada nos experimentos foi retirada da ferramenta de benchmark de sistemas de arquivos IOZone (IOzone, 2009). Essa função é capaz de medir o tempo com precisão de picossegundos $\left(10^{-12}\right)$, ideal para medir o tempo de operações rápidas, como a utilizada na Seção 6.1 para o cálculo do tempo de execução de cada linha do algoritmo. Em todas as técnicas é utilizada a mesma estrutura para medir o tempo, que é basicamente apresentada no Algoritmo 3.

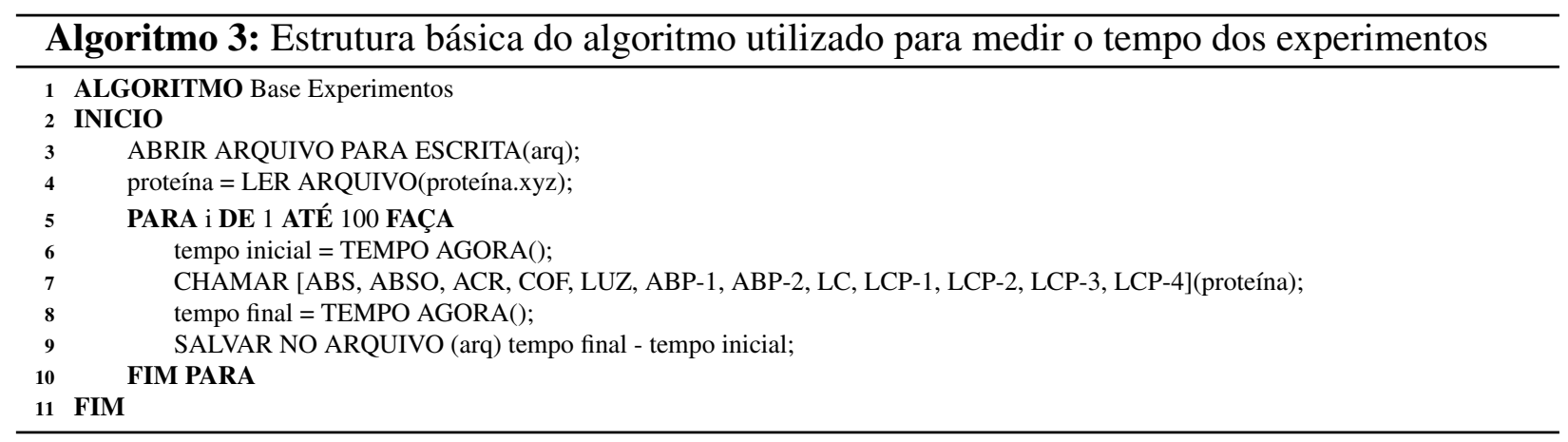

\subsubsection{Características do Cluster}

Os experimentos foram executados no cluster, com 14 nós (máquinas), pertencente ao próprio laboratório de pesquisa do grupo SEER, o LCR. Os nós são divididos em dois grupos com base nas características de cada processador. O primeiro grupo de nós (G1) é formado por 10 nós com processador AMD Dual Core 64 bits 2.8GHz e 4GB de memória RAM cada. O segundo grupo (G2) é formado pelos 4 nós restantes e possuem o processador Intel Core $i 764$ bits $2.67 \mathrm{GHz}$ com $12 \mathrm{~GB}$ RAM cada (Figura 8.1). O processador da Intel com tecnologia $i 7$ permite a visualização de oito núcleos pelo sistema operacional, onde quatro são núcleos físicos e os outros quatro são simulados pela tecnologia hyper threading. O processador AMD possui apenas dois núcleos físicos. No total, o cluster possui 52 processadores. Nos resultados obtidos pelas técnicas por MPI é considerado que é executado um processo por processador.

O sistema operacional do cluster é o GNU/Linux Ubuntu 64 com kernel versão 2.6.26-2. Embora todos os nós tenham disco rígido, os dados são apenas armazenados no mestre (nó 1) e são 
compartilhados entre os nós pelo Network File System (Linux NFS). Para garantir a eficiência do acesso ao sistema de arquivos pelos nós e pelas mensagens que são transmitidas por MPI, cada nó tem duas placas de rede onde a primeira é utilizada especificamente para o NFS e a segunda exclusivamente para mensagens em MPI. Ambas as placas de rede são conectadas em dois switches independentes $3 \mathrm{Com} 1 \mathrm{~Gb}$.

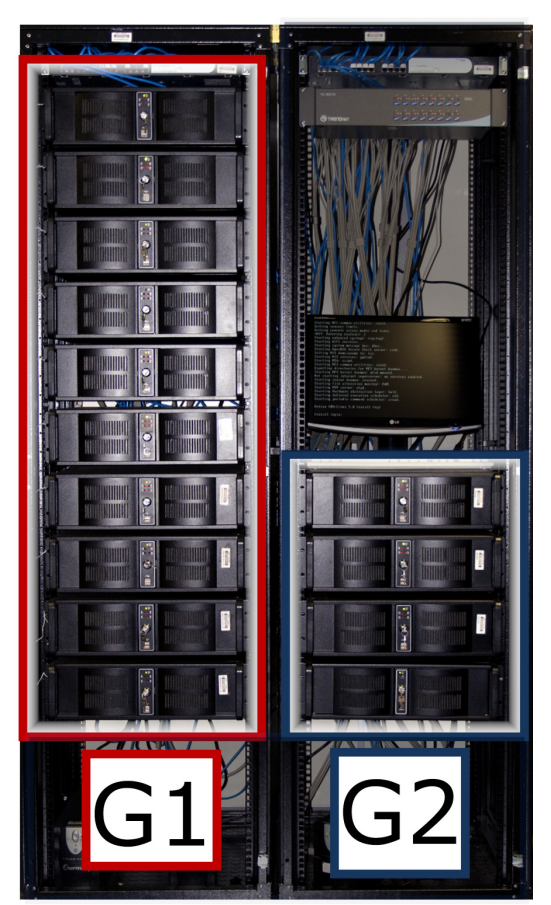

Figura 8.1: Imagem do cluster com identificação dos grupos G1 e G2.

\subsubsection{Teste de Desempenho}

O desenvolvimento de um algoritmo paralelo que utilize passagem de mensagem pode ser impraticável se o fluxo de banda da rede é inferior ao mínimo necessário para se obter ganho de desempenho em relação a um algoritmo sequencial. Dessa forma, conhecendo o volume de dados a ser transmitido e a capacidade do desempenho da rede do cluster é possível pré-determinar a eficiência de uma implementação paralela com passagem de mensagens, bem como a escalabilidade do algoritmo.

A avaliação de desempenho da rede do cluster foi obtida utilizando a implementação livre da biblioteca de passagem de mensagens chamada $\mathrm{MPICH}^{2}$. Primeiramente, foram analisadas duas maneiras de enviar dados, send e broadcast, para determinar a eficiência de cada uma delas. Foi verificado que o broadcast consumiu menos tempo para enviar os dados quando utilizado para mais de dois processadores. O tempo foi medido colocando um cronômetro no início da primeira mensagem para o primeiro nó (mestre). Na medida em que os nós terminam de receber os dados,

\footnotetext{
${ }^{2}$ http://www.mcs.anl.gov/research/projects/mpi/mpich1/.
} 
eles enviam um comando de $o k$ para o nó mestre. O cronômetro pára de correr quando o primeiro nó receber o $o k$ do último nó escravo.

Para esse experimento, utilizou-se a mesma estrutura de dados criada para os algoritmos de implementações paralelas, MPI_Pos, que representa as coordenadas dos átomos, descrito no Capítulo 7. Para 2 processadores, o desempenho de ambos os métodos de comunicação são praticamente idênticos. No entanto, com o crescimento do número de processadores o método de comunicação coletiva broadcast mostrou ser mais eficiente (Figura 8.2). Dessa forma, é possível pré-determinar o custo de comunicação para proteínas de vários tamanhos e, aliado ao custo de computação de um algoritmo sequencial, pode-se encontrar a eficiência esperada.

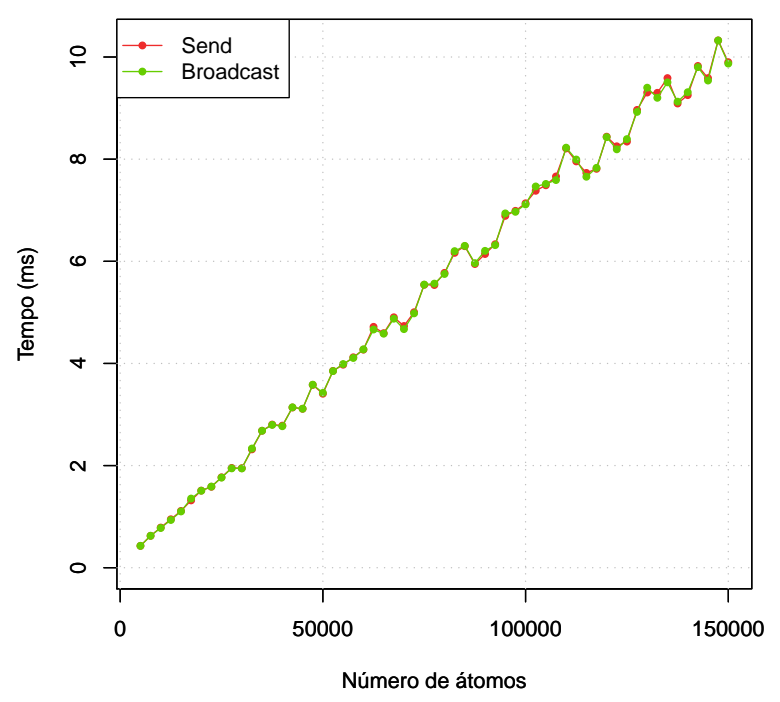

(a) Para 2 processadores

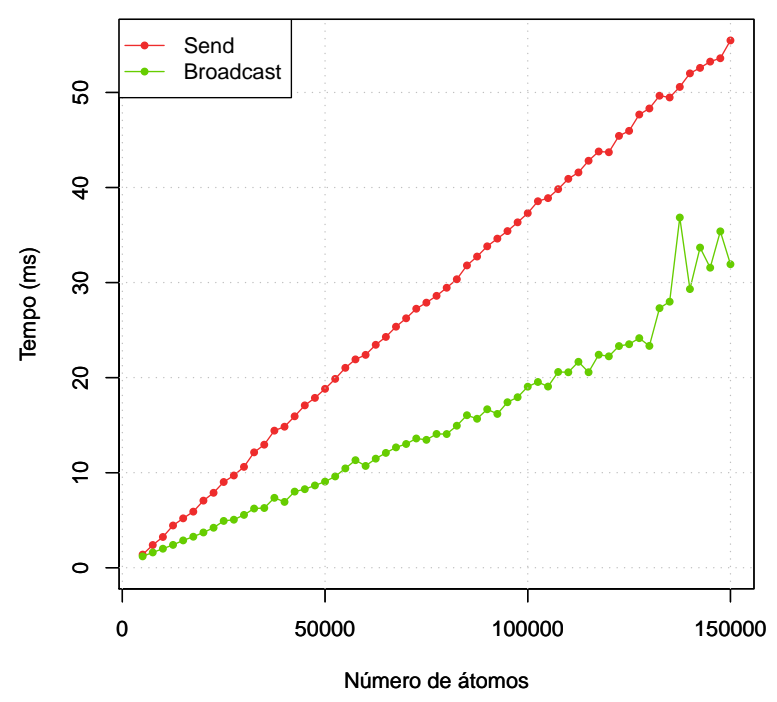

(b) Para 8 processadores

Figura 8.2: Tempo para enviar as coordenadas dos átomos.

\subsection{Proteínas selecionadas}

Os experimentos utilizaram estruturas terciárias e quaternárias de proteínas armazenadas no banco de dados de estruturas de proteínas, PDB. Partindo do princípio de que a quantidade de átomos da maior parte das proteínas encontradas na natureza varia entre alguns milhares de átomos até algumas centenas de milhares de átomos, foram selecionadas oito proteínas, determinada por métodos experimentais como, CRX e RNM, para cobrir a faixa de intervalo com proteínas pequenas, médias e grandes. Sendo assim, cada experimento tem a possibilidade de ser executado com oito tamanhos diferentes de entrada, dependendo do tamanho das proteínas. A proteína 1A11, com 390 átomos é a menor proteína do conjunto de proteínas selecionadas e faz um papel de limitante inferior. Enquanto que a estrutura quaternária de proteína 1HTO, com 147.900 átomos é o limitante superior para os experimentos. A Tabela 8.1 mostra o número de átomos e a principal função de cada proteína e a Figura 8.3 mostra as estruturas de cada proteína. 
Tabela 8.1: Tabela de proteínas selecionadas.

\begin{tabular}{l|l|r|l} 
ID & Descrição & Átomos & Função \\
\hline \hline 1A11 & Acetilcolina & 390 & Age como neurotransmissor \\
1BFI & Phosphoinositide & 1.753 & Proteína reguladora \\
1AI0 & Insulina & 4.728 & Regula a absorção de glicose \\
4HHB & Hemoglobina & 8.804 & Transporte de oxigênio \\
1W1I & Célula T (cadeia 1) & 11.671 & Proteína reguladora \\
1RUZ & Hemaglutinina & 22.380 & Agrega o vírus à célula (H1 da gripe suína) \\
2BGN & Célula T & 69.448 & Defesa do organismo \\
1HTO & Glutamina synthetase & 147.980 & Metaboliza o nitrogênio
\end{tabular}

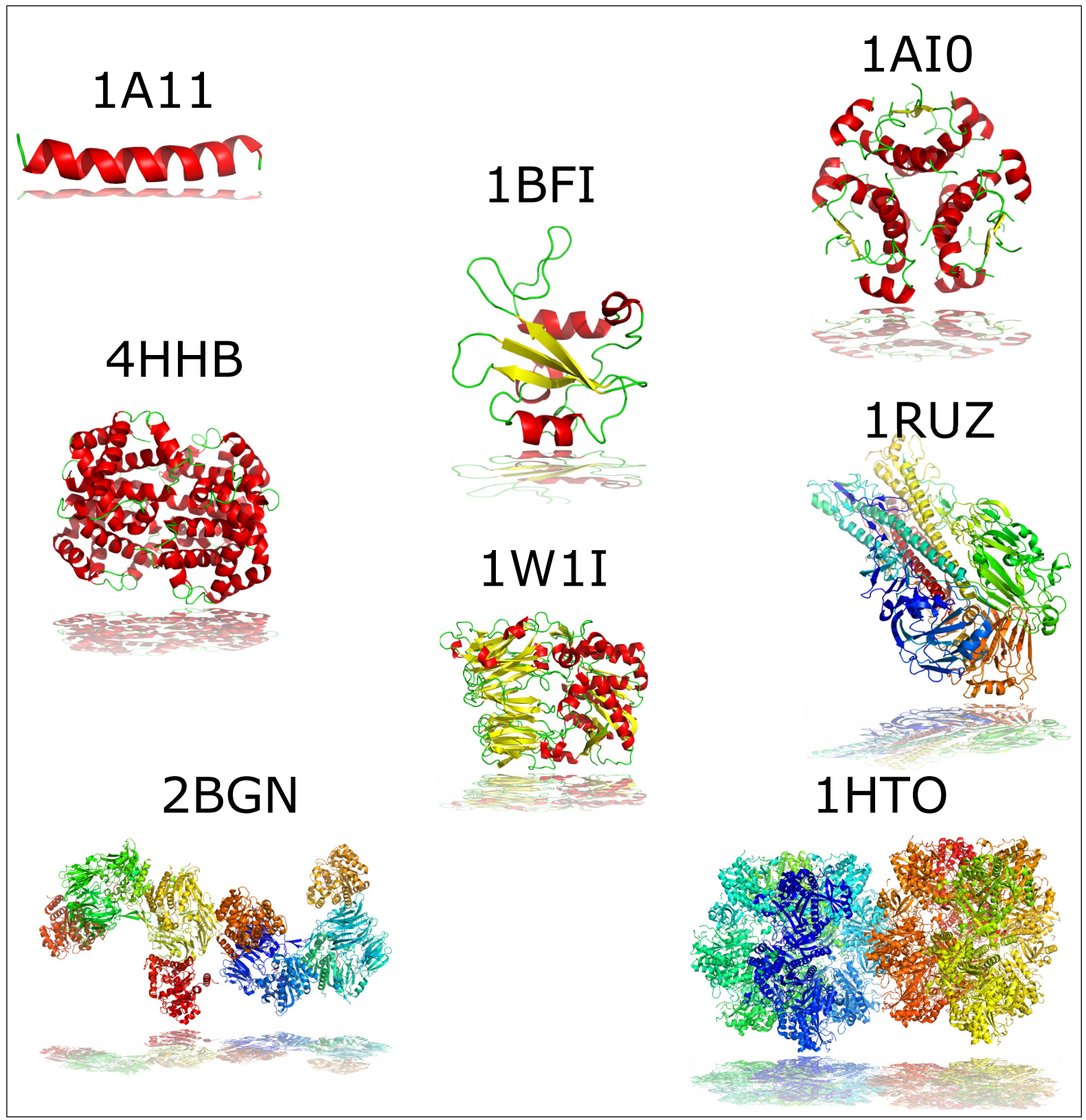

Figura 8.3: Estruturas de proteínas selecionadas. 


\subsection{Algoritmo Base Sequencial}

Os experimentos iniciaram-se com a execução do algoritmo mais simplista para o cálculo da energia de van der Waals, o ABS. Para cada uma das proteínas selecionadas, o tempo foi medido e gerado um ponto no gráfico da Figura 8.4 utilizando um processador AMD (do agrupamento G1) e outro Intel (do agrupamento G2). Pelo fato do ABS ser um algoritmo sequencial, foi executado utilizando apenas um processador.

Tanto no processador de G1 quanto no processador de G2 os resultados foram os mesmos, apesar de que em G2 o cálculo gastou menos tempo por conta das características da arquitetura do processador, tornando aproximadamente 2,5 vezes mais rápido, como mostra a Figura 8.5. É possível notar isso observando a diferença das escalas no eixo y da Figura 8.4. Contudo, no ABS, assim como descrito na Seção 5.4, é possível observar que houve um crescimento quadrático de acordo com o número de átomos, pois é de ordem $O\left(n^{2}\right)$.

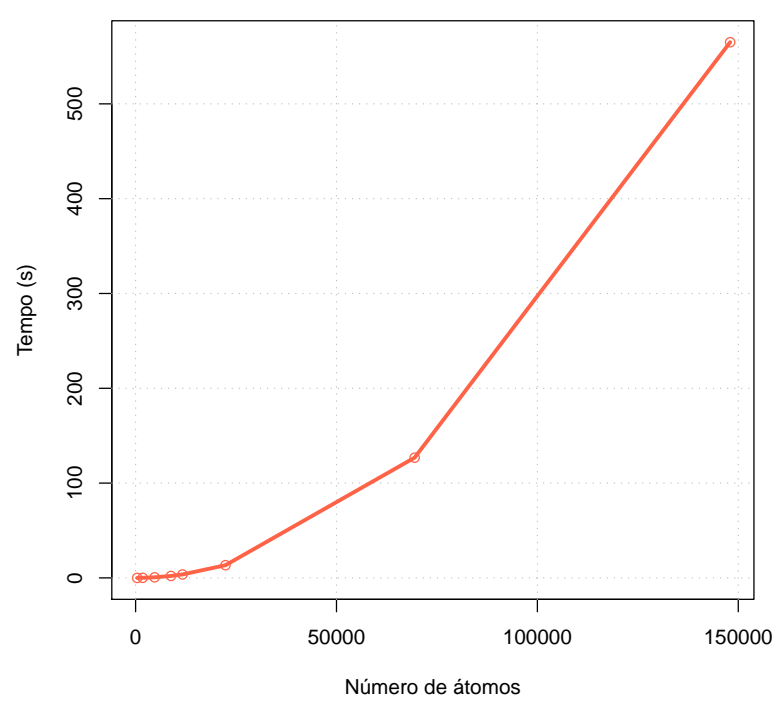

(a) Processador de G1

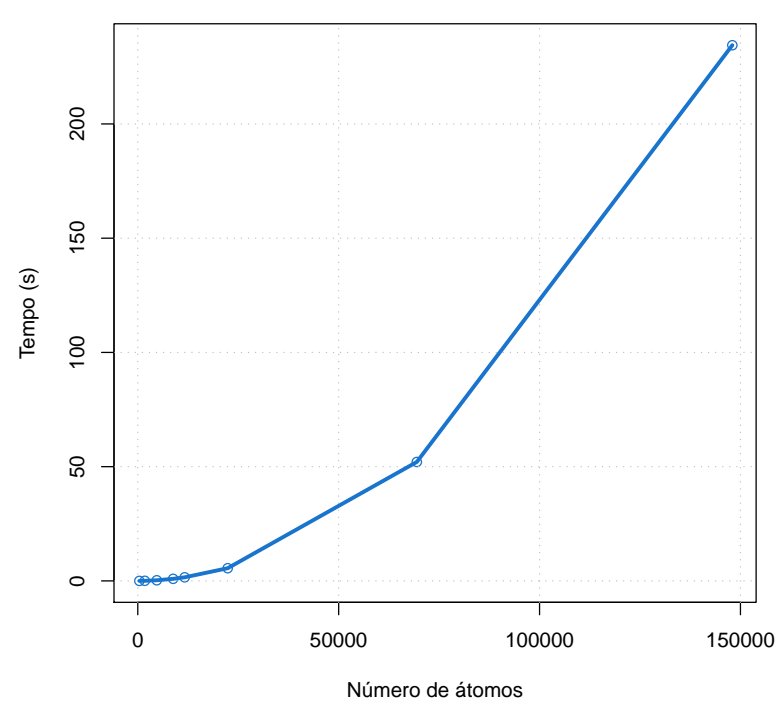

(b) Processador de G2

Figura 8.4: ABS executado em dois processadores diferentes

\subsection{Algoritmo Base Sequencial Otimizado}

A segunda execução dos experimentos foi do ABSO (Seção 6.1) com o objetivo de determinar a influência da substituição do operador de potência da biblioteca matemática por composições de produtos simples. O procedimento de montagem do gráfico foi semelhante ao adotado na Seção 8.3.

Os tipos de processadores não influenciaram no ganho de desempenho obtido, pois, como é possível ver na Figura 8.6, as curvas são semelhantes. Esse algoritmo, foi capaz de acelerar em 


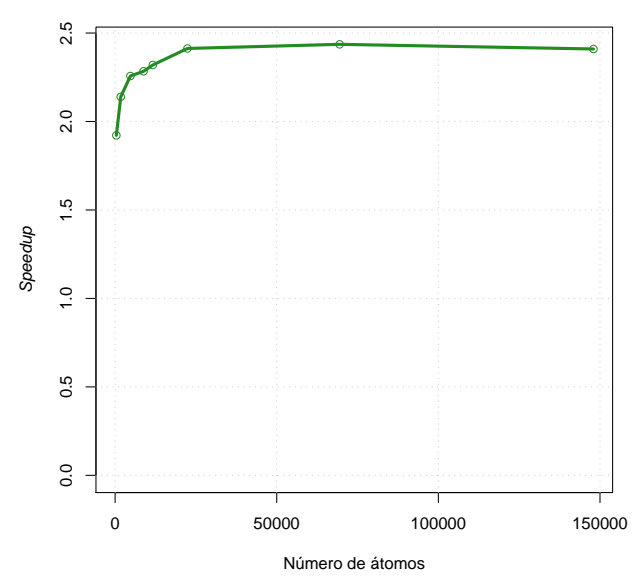

Figura 8.5: Speedup de um processador de G1 sobre G2.

quase 3 vezes o algoritmo do cálculo da energia de van der Waals para proteínas pequenas sem alterar sua estrutura.

É interessante notar que para proteínas acima de 4000 átomos o ganho de desempenho dessa técnica é semelhante a proteínas gigantes acelerando o cálculo em 1,5 vezes. No entanto, para as proteínas pequenas o ganho de desempenho foi quase o dobro das proteínas grandes. Isso ocorre porque em proteínas pequenas a relação de esparsidade da matriz de interações é mais baixa, ou seja, do total de interação que o algoritmo tem que percorrer o cálculo da energia de van der Waals (que teve sua função de potência otimizada) é executada muito mais vezes em comparação com proteínas gigantes, na qual a maior parte do algoritmo não passa pelo trecho que foi otimizado.

Foi determinado que, se fosse necessário calcular a energia de van der Waals para todas as interações de par de átomos, o speedup utilizando a técnica ABSO seria de 8 vezes. Isso porque a substituição da função de potência por produtos simples é $80 \%$ mais rápido. Isso significa que se essa técnica fosse empregada em um algoritmo mais eficiente do cálculo da energia de van der Waals, o ganho pode ser superior a 2,5, como obtido nos experimentos.

\subsection{Aproveitamento do cálculo pela recombinação}

A técnica de ACR, Seção 6.2, utiliza valores calculados previamente nos pais para compor a energia dos filhos, evitando que seja invocado o cálculo da energia de van der Waals. Após o cruzamento de dois indivíduos no AG, a região próxima ao ponto de corte cria um local onde o cálculo deve ser refeito. Para essa técnica, quanto mais próximo das extremidades do indivíduo for o ponto de corte melhor será a eficiência. O pior caso é quando o ponto de corte ocorre exatamente na metade do cromossomo, tendo que executar o cálculo de van der Waals para $50 \%$ do indivíduo.

É possível verificar que o overhead adicionado nessa técnica por conta do armazenamento dos valores calculado nos pais é baixo. Tomando como exemplo a proteína 1RUZ do gráfico da Figura 8.7, gastou-se pouco mais que 50\% do tempo do cálculo do pai para gerar o filho. A porcentagem 


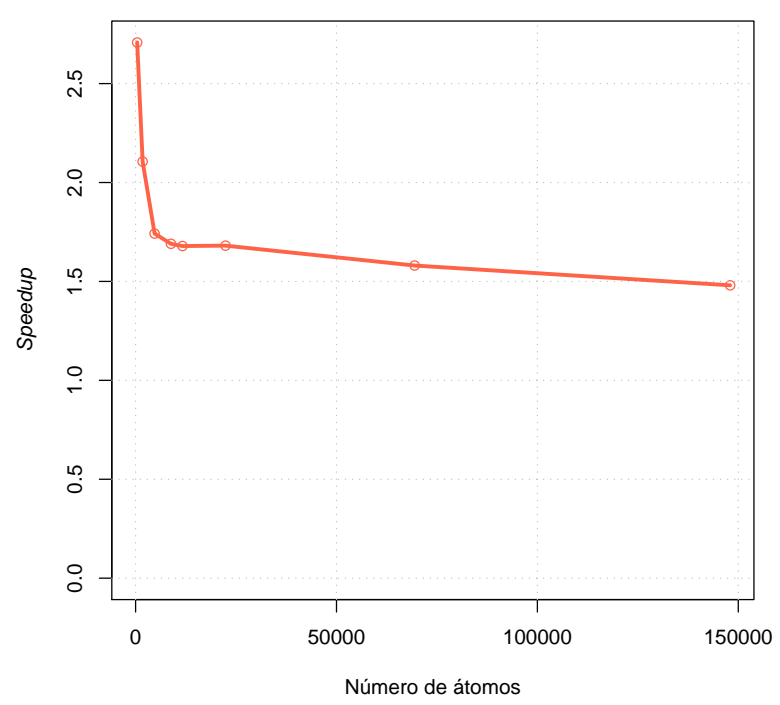

(a) Processador de G1

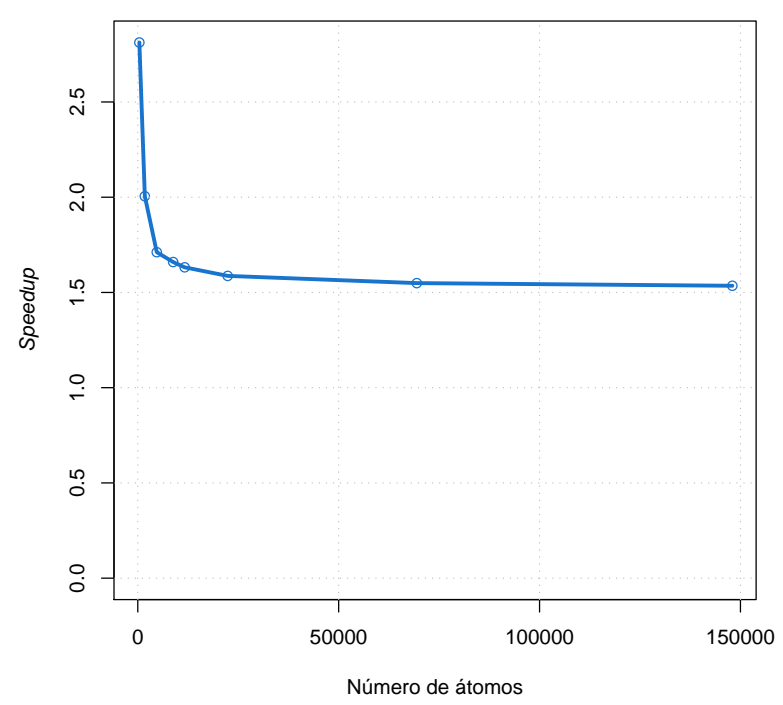

(b) Processador de G2

Figura 8.6: Speedup de ABSO em relação ao ABS executado em dois processadores diferentes.

excedente pode significar o overhead enquanto que os $50 \%$ se refere a parte do cálculo que precisou ser refeita.

Há outro fator que é possível observar no gráfico da Figura 8.7: quanto menor é a proteína, mais rápido é o cálculo principalmente nas regiões de pior caso, onde o ponto de corte do crossover ocorre no meio do cromossomo. Isso ocorre porque enquanto o cálculo está sendo refeito pelo filho, este provavelmente será pai da próxima geração, portanto, deve armazenar as informações das interações que veio do pai 1 , do pai 2 e também da região que está sendo calculada, aumentando o overhead. Observando as quatro curvas das proteínas, nota-se que com o aumento do número de átomos da proteína a distância entre os pontos do eixo $y$ diminuem. Assim, mesmo utilizando proteínas maiores que 20.000 átomos, os resultados serão bem semelhantes à proteína 1RUZ.

Essa técnica somente funciona quando empregada em AGs e, apesar do ganho de eficiência ser relativamente baixo, é possível reduzir o tempo total do AG pela metade considerando que a cada vez que a função for chamada, ela irá retornar o resultado na metade do tempo. Além disso, embora técnicas mais eficientes para o cálculo de van der Waals serão abordadas, a idéia de ACR pode ser utilizada para reduzir o tempo de computação de outros algoritmos aplicados à AGs.

Dos dois paradigmas de uso de memória abordados na Seção 6.2, ambos foram testados para proteínas pequenas como a 1A11 (390 átomos) e apresentaram desempenho semelhante. Assim, optou-se somente por utilizar alocação esparsa das matrizes de interação porque mesmo para a proteína relativamente pequena $1 \mathrm{AI} 0$, com 4.728 átomos, seriam necessários $42 \mathrm{~GB}$ de memória RAM somente para armazenar as interações de um indivíduo, o que não é plausível do ponto de vista prático. 


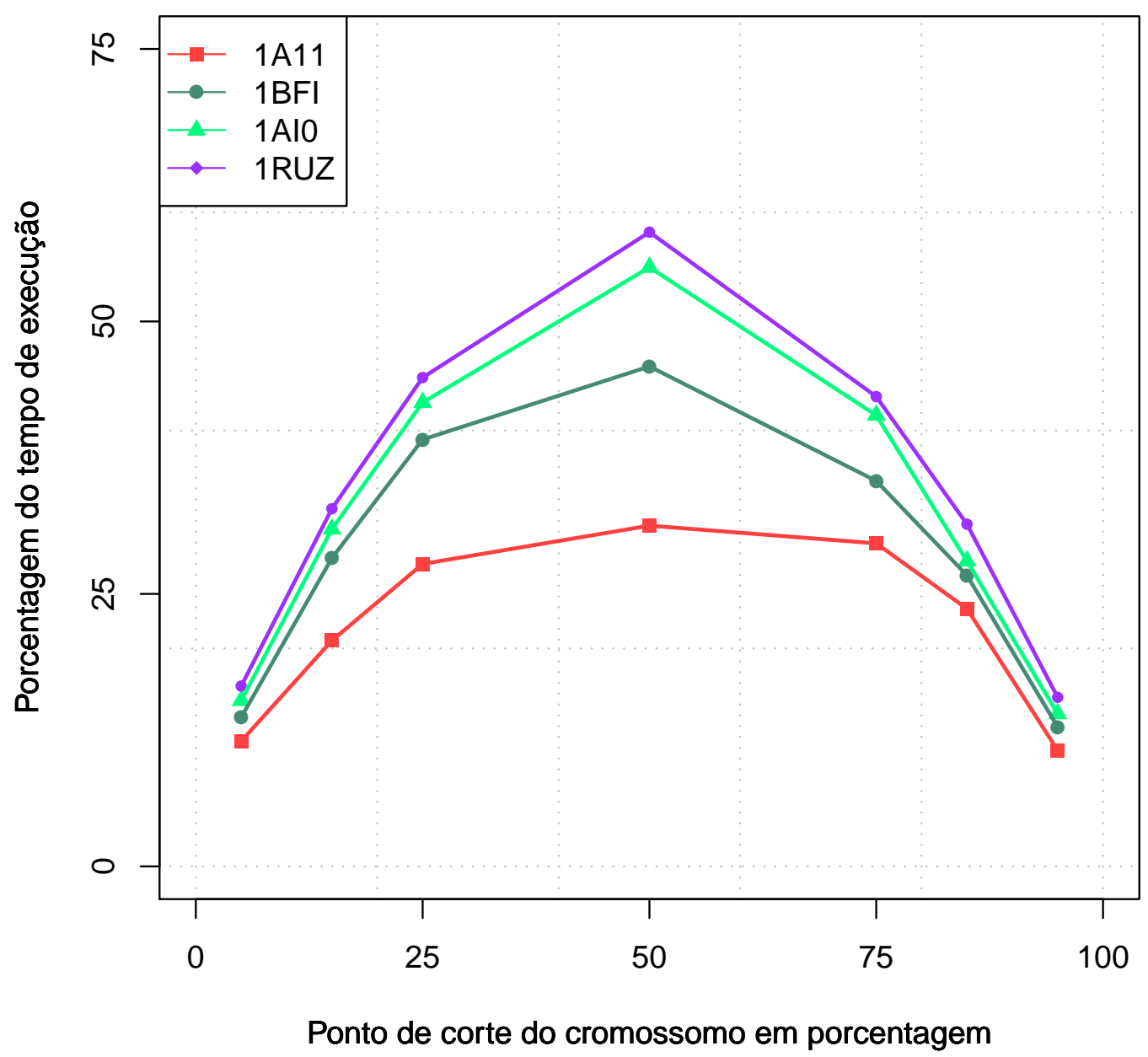

Figura 8.7: Gráfico do ganho de eficiência utilizando ACR.

\subsection{Cálculo off-line}

O método de COF, descrito na Seção 6.3, evita a chamada do cálculo da energia de van der Waals toda vez que o par de átomos estiver em uma distância menor que $8 \AA$, procurando em tabelas calculadas previamente, pelo valor mais próximo correspondente àquela interação. A precisão desse método depende da quantidade de linhas utilizadas nas tabelas.

Com um maior número de linhas em cada tabela, mais preciso é o método. No entanto, isso requer mais memória e o algoritmo tende a ficar mais lento no momento de fazer buscas na tabela, apesar de utilizar tabelas indexadas e conseguir fazer a busca em $O(1)$. Isso é possível realizando a razão entre o número de linhas e a distância, retornando um índice. Em seguida, é verificado uma posição acima e outra abaixo desse índice na tabela para determinar quais valores produzem menor diferença com a distância e, por fim, é retornado o valor da energia.

Para determinar a precisão desse método, foram escolhidos quatro valores para serem empregados nos experimentos: 10, 100, 1.000 e 10.000 número de linhas, com o objetivo de balancear 
os fatores precisão e custo computacional. A Tabela 8.2 mostra a precisão obtida para as oito proteínas calculando precisao $=e v d w / e v d w_{l}$, onde evdw é o valor da energia calculada utilizando métodos convencionais e $e v d w_{l}$ é a energia de van de Waals calculada utilizando COF e $l=10,100,1000,10000$. Para validar os quatro tipos de precisão empregados, utilizou o student $t$-test ${ }^{3}$ com teste de hipótese nula e intervalo de confiança de $95 \%$. É possível verificar que para as colunas referentes às precisões 10 e 100 a hipótese foi rejeitada porque utilizando o intervalo de confiança de $95 \%$, o p-valor foi menor que 0,05 . Isso significa que calcular a energia de van der Waals utilizando o COF com precisão de 10 e 100 linhas nas tabelas deverá produzir resultados inconsistentes. Por outro lado, como mostrado nas colunas de precisão 1.000 e 10.000, o p-valor é maior que 0,05 e, portanto, a hipótese é aceita. Isso mostra que não há diferença em termos do valor da energia de van der Waals entre um método convencional (como um ABSO) e o COF com precisão de 1.000 ou 10.000 linhas nas tabelas. Nesse sentido, o uso do COF com precisão de 1.000 linhas será vantajoso em relação ao COF 10.000, pois além de consumir menos memória e tempo computacional deverá também produzir os mesmos resultados.

A Figura 8.9 mostra o tempo de execução necessário para as quatro variações de precisão para oito proteínas diferentes. O tempo computacional entre as precisões 10, 100 e 1.000 são semelhantes. Já a precisão com 10.000 linhas apresentou o pior tempo para todas as proteínas. Contando com o teste de hipótese, as precisões aceitáveis são 1.000 e 10.000 , e considerando que 1.000 é mais rápido que 10.000, os gráficos da Figura 8.8 foram gerados utilizando precisão 1.000 .

Essa técnica pode apresentar resultados melhores modificando a escala graduada de valores da precisão uniforme para uma distribuição não uniforme. Ao invés de dividir a função em 1.000 partes iguais, o gráfico da função da energia de van der Waals (Seção 2.7) poderia ser dividido em 100 partes iguais, a partir do tapering off até o contato de van der Waals. Depois, mais 100 partes entre o contato de van der Waals até uma distância de $4 \AA$. Por fim, de $4 \AA$ até o cutoff poderia ser dividido em mais 50 partes. Isso iria garantir um valor da energia de van der Waals mais preciso. Além disso, com a redução do número de linhas de precisão, o algoritmo iria consumir menos tempo, pois como pode ser visto nos gráficos da Figura 8.9, mesmo o tempo de acesso às tabelas sendo de $O(1)$, o tamanho delas influencia no tempo de computação. O gráfico da Figura 8.8 mostra que o desempenho obtido em relação ao ABSO foi de aproximadamente 1,5 vezes e, especificamente para proteínas muito pequenas o ganho dessa técnica é baixo. Isso pode ocorrer pelo fato de que no COF a verificação de distância (se os átomos estão mais distante que $8 \AA$ ) é mais rápido que no $\mathrm{ABSO}$, pois com os valores das energias em tabelas, se o valor não estiver na tabela é imediatamente retornado o valor zero àquela interação.

Resultados bons para o valor da energia e redução de tempo computacional podem ser alcançados com essa técnica. Apesar da implementação exigir um certo esforço, é um código bem

\footnotetext{
${ }^{3}$ Teste de hipóteses que segue uma distribuição de probabilidades. Na comparação de médias de dois conjuntos de dados, se a hipótese for nula significa que a diferença da média entre os dois conjuntos é zero, ou seja, não há diferença entre os dois conjuntos.
} 
estruturado. Outra vantagem desse método é que pode ser utilizado em AGs. Em geral, a qualidade real dos indivíduos deverá depender da precisão empregada no cálculo

Tabela 8.2: Tabela de precisão por proteína.

\begin{tabular}{c|c|c|c|c} 
Precisão & $\mathbf{1 0}$ & $\mathbf{1 0 0}$ & $\mathbf{1 . 0 0 0}$ & $\mathbf{1 0 . 0 0 0}$ \\
\hline \hline & 0,758303845 & 0,996438292 & 0,999950889 & 1,000006801 \\
& 0,779396563 & 0,997213988 & 0,999534787 & 0,999504670 \\
& 0,789328111 & 0,997802790 & 0,999951475 & 1,000000333 \\
& 0,794847524 & 0,997320564 & 0,999979405 & 1,000005993 \\
& 0,806361564 & 0,998971186 & 0,999977819 & 0,999974502 \\
& 0,811558506 & 0,998668289 & 0,999978841 & 0,999997994 \\
& 0,810507052 & 0,998724800 & 0,999974764 & 0,999999268 \\
& 0,814124792 & 0,998548387 & 0,999982590 & 0,999999674 \\
\hline \hline p-valor & 0,000000001 & 0,000382647 & 0,169835700 & 0,335506200
\end{tabular}

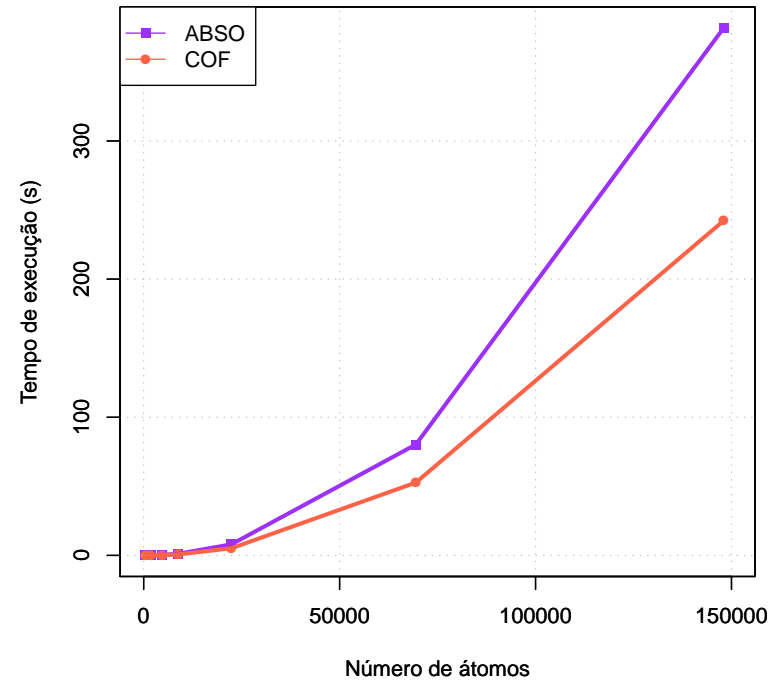

(a) Comparação entre ABSO e COF executado em G1.

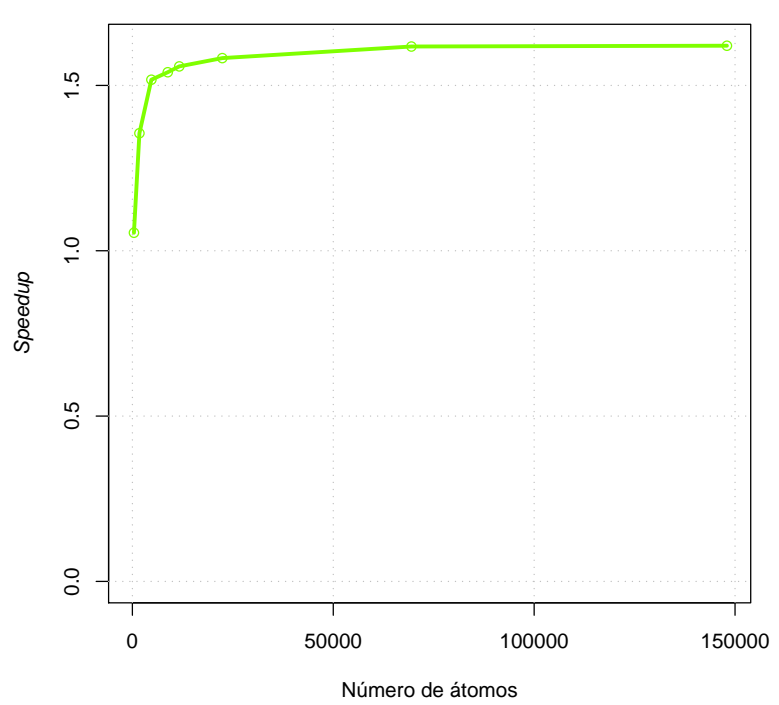

(b) Speedup de COF alcançado em relação ao ABSO.

Figura 8.8: Desempenho obtido pelo método COF 


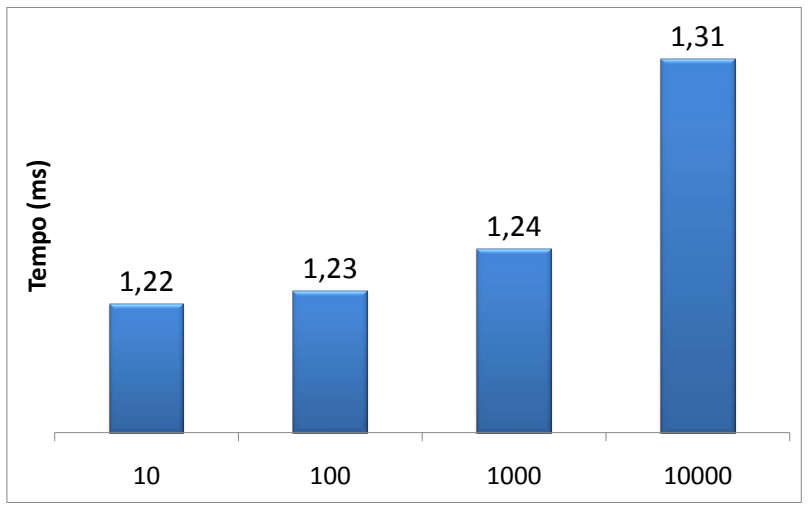

(a) Proteína 1A11.

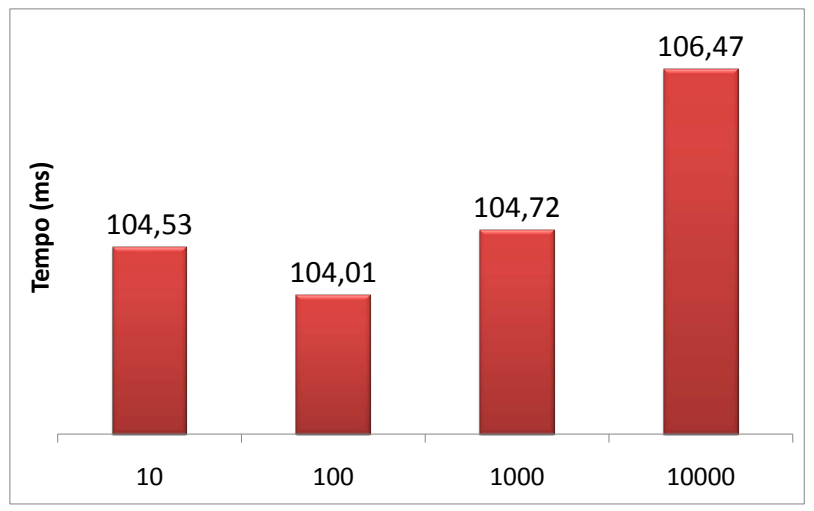

(c) Proteína 1AI0.

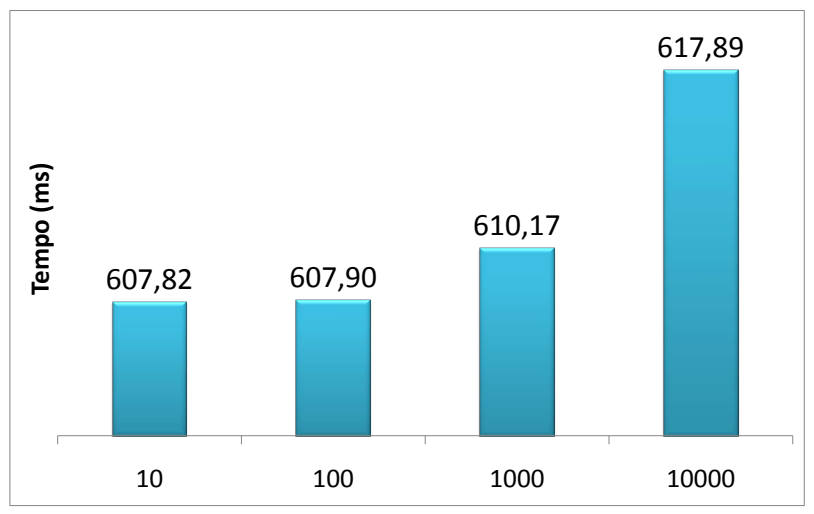

(e) Proteína 1W1I.

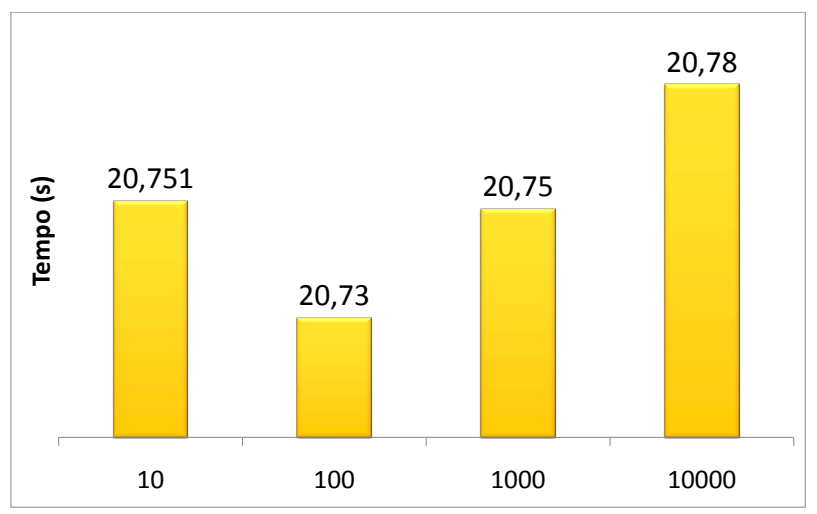

(g) Proteína 2BGN.

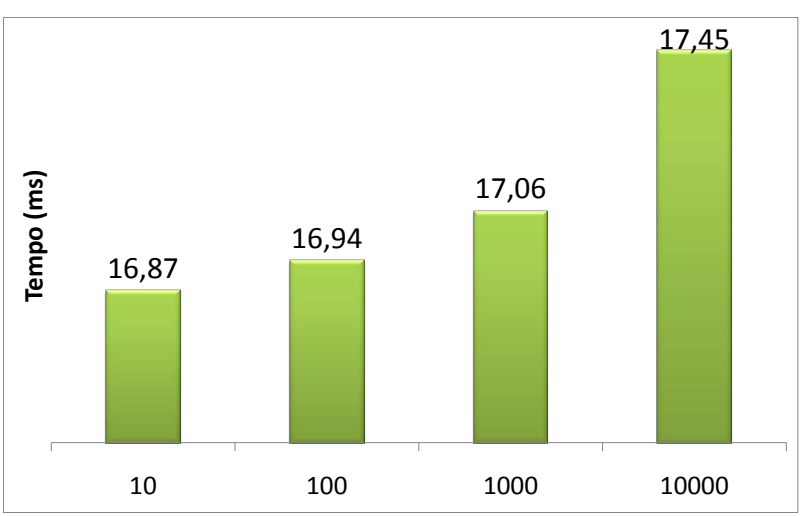

(b) Proteína 1BFI.

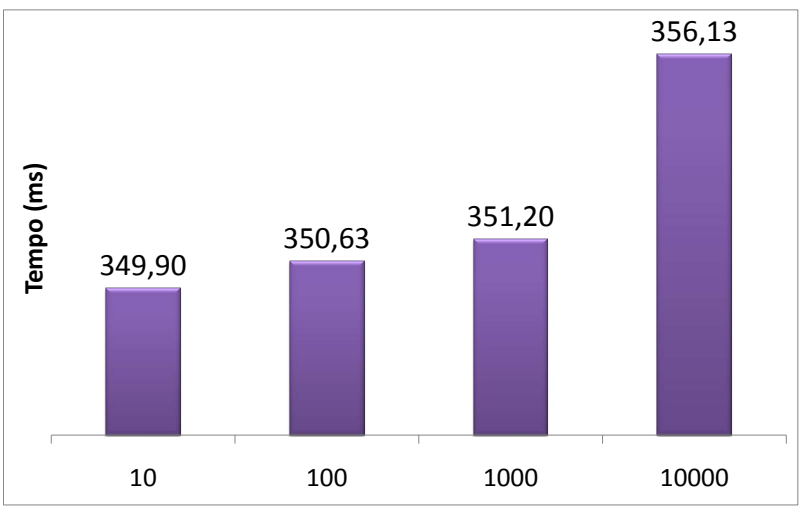

(d) Proteína 4HHB.

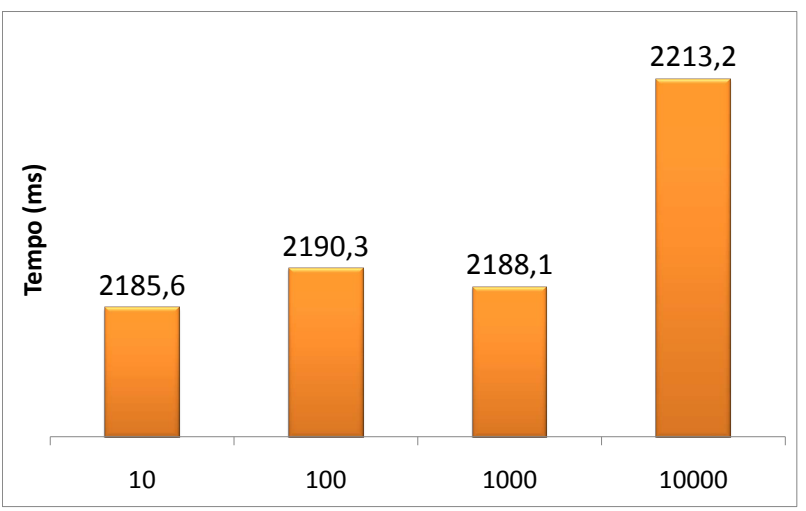

(f) Proteína 1RUZ.

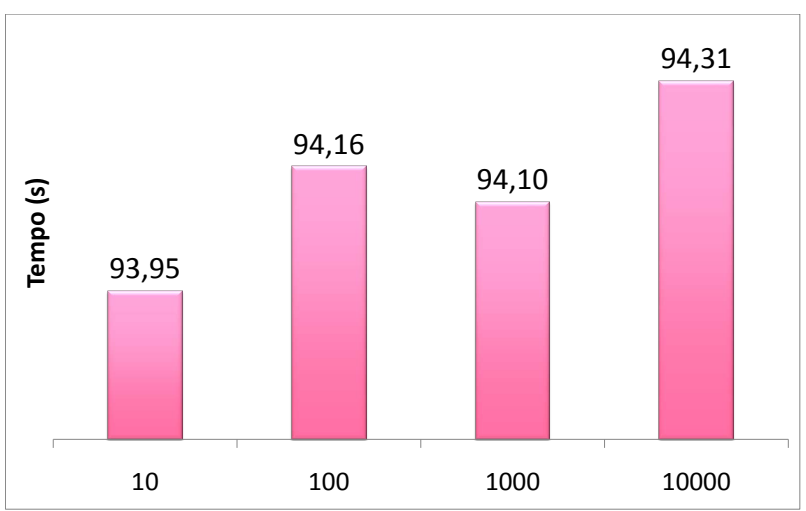

(h) Proteína 1 HTO.

Figura 8.9: Comparação do tempo computacional para quatro tipos de precisão. 


\subsection{Método das Luzes}

O métodos das luzes, descrito na Seção 5.3, é o método otimizado do pacote de modelagem molecular Tinker para acelerar a computação da interação da energia de van der Waals. A eficiência desse método está restrita aos métodos de ordenação utilizados para ordenar $x, y, z$ onde sua complexidade é de $O(n \log (n))$. Dessa forma, o método das luzes é mais eficiente que os algoritmos básicos, no entanto, o tempo necessário para calcular a energia aumenta quase quadraticamente de acordo com o tamanho da proteína.

É possível ver no gráfico da Figura 8.10 que, apesar da curva do método das luzes ter crescimento mais sutil, ainda não seria praticável o emprego da técnica para proteínas grandes. O desempenho está relacionado ao uso de métodos de ordenação eficientes, assim, é possível paralelizar a ordenação em dois sentidos: utilizando métodos de ordenação paralelizáveis e também executar a ordenação dos vetores $x, y, z$ simultaneamente, pois são tarefas independentes. Com isso, pode-se ganhar desempenho, mas o tamanho do problema (número de átomos da proteína) estaria relacionado ao número de processadores disponíveis.

O speedup foi calculado e mostrado no gráfico da Figura 8.20. É interessante notar que para ambos os tipos de processadores, o speedup da proteína 1W1I (quinto ponto do gráfico) foi inferior às proteínas 1AI0 e 4HHB, que são menores. Esse experimento, em especial para a proteína 1W1I, ao invés de 100 execuções foi executado 2.000 vezes com a finalidade de gerar dados mais precisos do ponto de vista estatístico. No entanto, o resultado de 2.000 execuções foi semelhante a 100 execuções, permanecendo uma queda na curva de ambos os tipos de processadores. Isso pode ter ocorrido pelo fato da estrutura 1W1I ser uma estrutura muito compacta. Observando a reta gerada pelos três últimos pontos do gráfico, em 8.11(a) a reta é descendente enquanto que em 8.11(b) a reta é ascendente. Para determinar se realmente houve influência no tipo de processador empregado nessa técnica, seria necessário executar o método das luzes para proteínas com 300.000 ou mais átomos, o que ainda não é possível, pois a maior estrutura conhecida hoje tem cerca de 150.000 átomos.

O ganho de desempenho dessa técnica em comparação ao ABSO foi de aproximadamente 2 vezes (Figura 8.20). Se considerar o impacto de modificações necessárias realizadas no ABSO para se adequar ao método das luzes, o speedup pode ser considerado baixo. O processo de implementação exige um esforço considerável e, além disso, é um algoritmo pouco estruturado e difícil de compreender. 


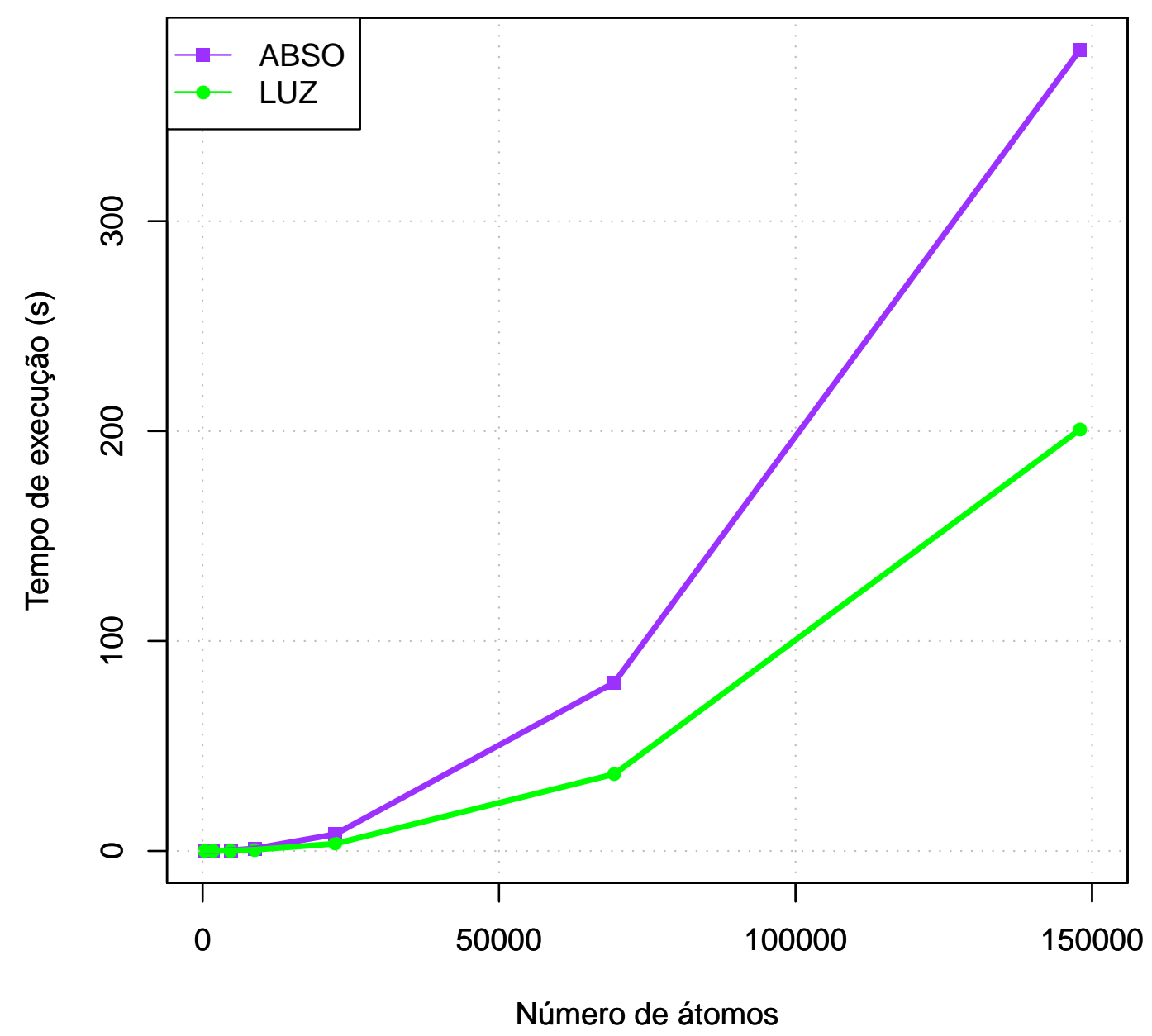

Figura 8.10: Gráfico da comparação entre ABSO e LUZ executado em G1.

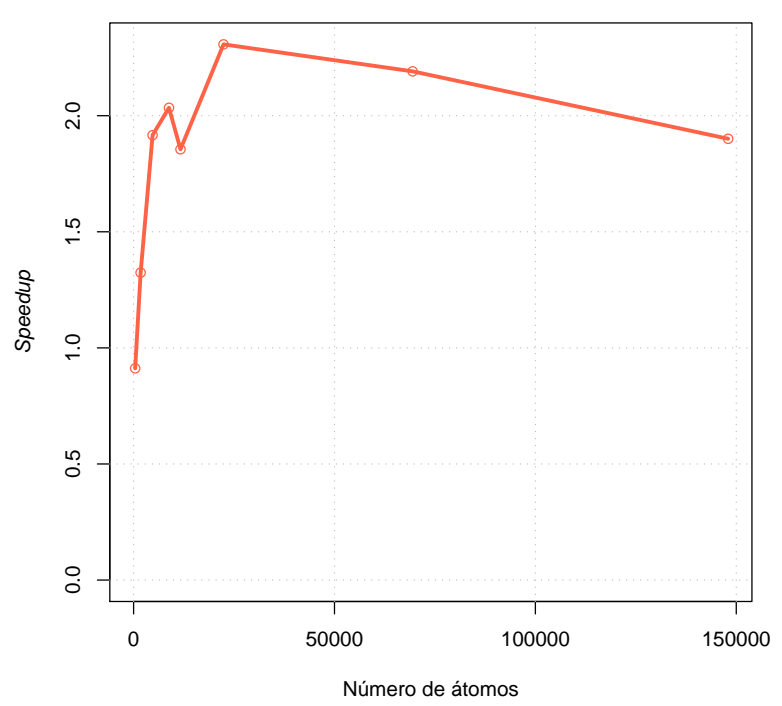

(a) Processador de G1

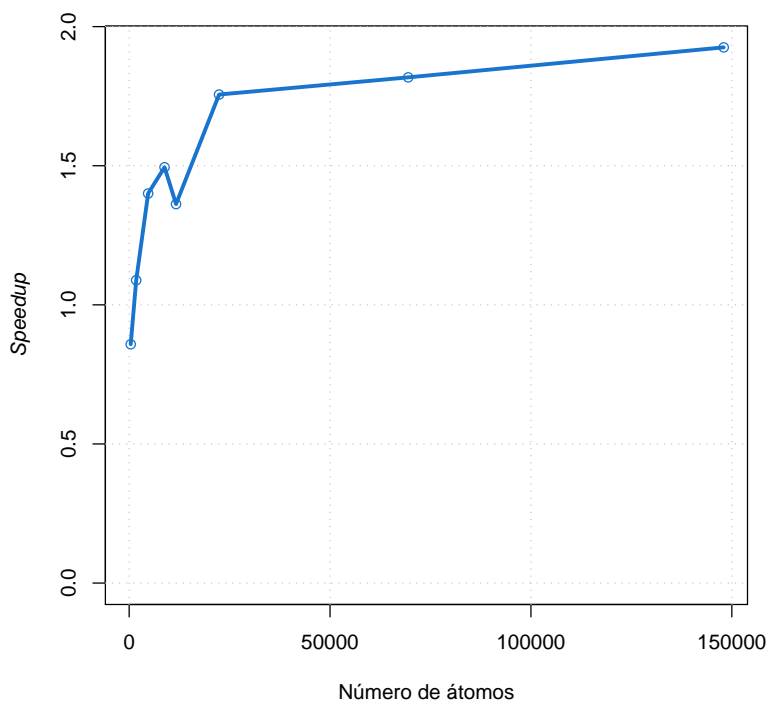

(b) Processador de G2

Figura 8.11: Speedup de LUZ executado em dois processadores diferentes. 


\subsection{Algoritmo Base MPI sem enviar átomos}

O ABP-1, descrito na Seção 7.1.1, calcula a energia de van der Waals utilizando o paradigma de programação por passagem de mensagens para reduzir o tempo do cálculo. Nessa técnica, é desconsiderado o tempo de enviar as coordenadas dos átomos somente para servir de referência. Esse experimento foi executado no G1 para verificar o comportamento da técnica quando utilizado um maior número de máquinas, pois G1 tem 10 máquinas e G2 tem quatro. Apesar das 10 máquinas disponíveis para realização desse experimento, optou-se por não utilizar o primeiro nó, pois ele contém toda a estrutura de controle do cluster e caso ele parasse de responder, todos os outros 13 nós também deixariam de funcionar. Por esse motivo, os experimentos envolvendo passagem de mensagens limitou-se a utilizar 9 nós do G1, no total de 18 processadores.

O gráfico da Figura 8.12 mostra que o speedup foi super linear para todos os tamanhos de proteínas, exceto para a 1A11, com 390 átomos, que se manteve super linear até 6 processadores (Figura 8.14(b)). Com esse gráfico, pode-se concluir que para proteínas acima de cerca de 1.500 átomos, o método ABP-1 é eficiente e, apesar do gráfico mostrar apenas o máximo de 18 processadores, as linhas indicam que seria possível manter a eficiência por mais processadores, pois a comunicação é extremamente pequena em relação à computação.

O fato pelo qual o speedup foi super linear não pode ser explicado com tanta facilidade. Em geral, isso ocorre quando é utilizado um computador com menos memória que o programa exige tendo que fazer swap. Quando esgota a memória física do computador o sistema operacional pode optar por utilizar meios de armazenamento secundários, como discos rígidos, para armazenar os dados da memória. No entanto o acesso a meios de armazenamento secundários é lento e considerando que o processador somente consegue ler dados da memória física, o sistema operacional deve gerenciar a troca dos dados entre a memória física e meios de armazenamento secundário. Assim, quando um problema é paralelizado e executado em diferentes máquinas, cada máquina possui memória própria e se por esse motivo não ocorrer swap o speedup poderá ser super linear, pois utilizando a memória de vários computadores não há a necessidade de fazer swap.

O ABS consome no máximo 10MB RAM para cadeias de proteínas gigantes, como a 1HTO e, considerando que cada máquina de G1 tem 4GB RAM, é descartado a possibilidade de fazer swap. Há outras formas de se obter speedup super linear como, por exemplo, o aproveitamento da memória cache pelo processador, resultado da redução da quantidade de dados que transita na memória num programa paralelo. Se o volume de dados, que inicialmente permanecia na memória RAM em um programa sequencial, for dividido para a memória de vários computadores, pode ser possível que toda ou quase toda parte da memória utilizada em um computador paralelo seja ajustada ao tamanho da memória cache, aumentando a eficiência do algoritmo devido ao fato do acesso da memória cache ser mais veloz. Essa é uma explicação plausível para o ABP-1 ser super linear pois, considerando que cada processador de G1 tem $512 \mathrm{~KB}$ de memória cache e, utilizando 18 processadores totalizando 9MB de memória cache, um programa que ocupa no 
máximo 10MB de memória pode ter pedaços ajustados individualmente em suas memórias caches de cada processador, diminuindo o acesso a memória RAM.

Por outro lado, o overhead gerado pela modificação do ABS para garantir o balanceamento de carga (Seção 7.1) não foi perceptível aos resultados. Ao contrário disso, ele pode ter contribuído com o speedup super linear. Isso foi testado executando a versão ABS comum e outra utilizando a mesma matriz densa de interações utilizada em ABP-1. Assim, foi comprovado que há um ganho de desempenho no cálculo da energia de van der Waals quando utilizado uma matriz densa de interações. O gráfico da Figura 8.13(a) mostra um pequeno ganho de desempenho de ABS utilizando a matriz densa de interações em relação a ABS utilizando a convencional matriz triangular superior de interações. Dessa forma, calculando a eficiência entre o ABS utilizando matriz densa de interações e o ABP-1, o speedup deixa de ser super linear, exceto para os primeiros pontos da proteína com 390 átomos (Figura 8.13).

Em geral, a eficiência dessa técnica está relacionada ao tamanho da proteína e do número de processadores. No entanto, esse tipo de algoritmo não pode ser utilizado em metaheurísticas populacionais, como no caso de AGs. Os gráficos apresentados nesta seção servem de limitantes superiores para os resultados alcançados para ABP-2, pois no ABP-2 há comunicação com transmissão da matriz de coordenadas.

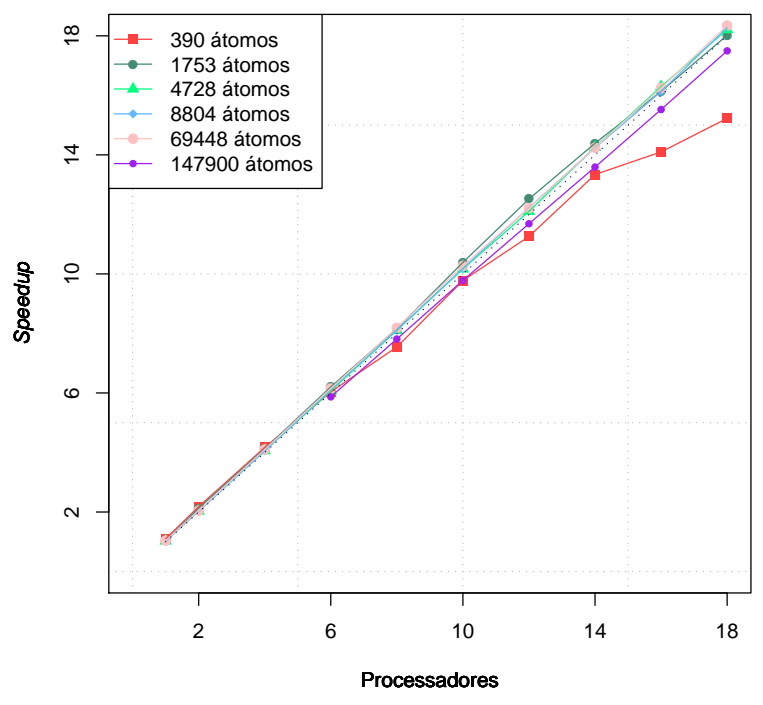

(a) Speedup alcançado com 18 processadores.

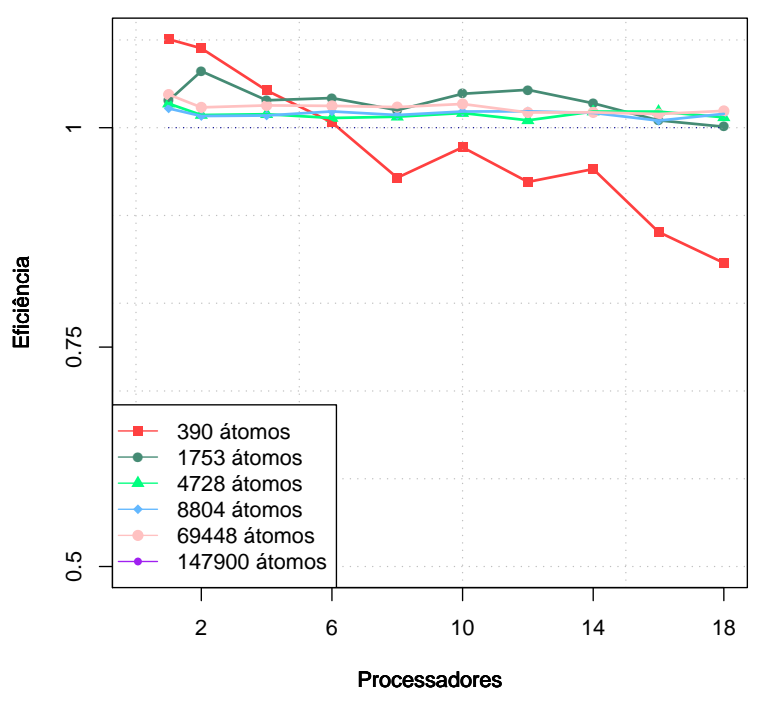

(b) Eficiência com 18 processadores.

Figura 8.12: Ganho de desempenho para ABP-1 utilizando 18 processadores.

\subsection{Algoritmo Base MPI enviando átomos}

Para que a técnica seja capaz de trabalhar em AGs é necessário garantir que todos os processadores tenham a informação atualizada das coordenadas $x y z$ dos átomos, pois os operadores 


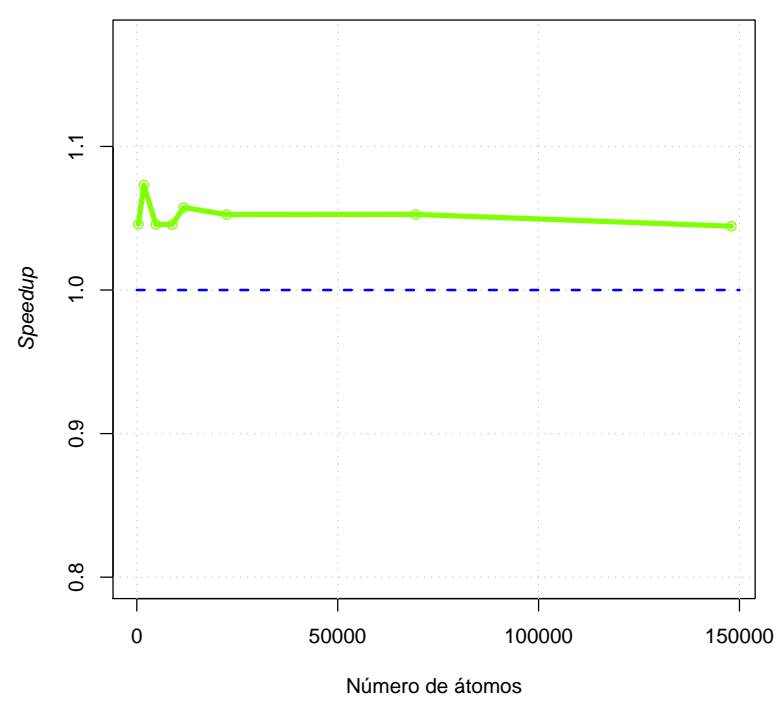

(a) Speedup alcançado entre ABS e ABS utilizando matriz (b) Eficiência alcançada de ABP-1 em relação a ABS utidensa.

Figura 8.13: Comparação de desempenho entre ABS e ABP-1 com matriz densa de interações. Para um algoritmo paralelo, isso significa que antes de iniciar o cálculo da energia todos os processadores devem possuir o valor das coordenadas sendo necessária a transmissão desses dados pelo mestre.

O custo de comunicação varia de acordo com o tamanho da proteína. Por exemplo, para uma proteína de tamanho médio, com 70.000 átomos o tamanho do pacote a ser enviado é de aproximadamente $900 \mathrm{~KB}$. Assim, deve ser levado em consideração o tempo do cálculo utilizando um algoritmo sequencial e o tempo necessário para enviar 900KB. Se o tempo de enviar 900KB para os outros nós for maior que o tempo de computação de um algoritmo sequencial, pode-se dizer que a implementação paralela não é viável para esse problema. A Seção 8.1.3 fez medições de desempenho para o problema específico de enviar átomos para justificar se é possível ou não aplicar as técnicas de ABP-2.

Observando o gráfico da Figura 8.2 é possível verificar que o tempo necessário para enviar uma proteína com 70.000 átomos para outro processador é de aproximadamente 5 milissegundos e o tempo de computação para essa proteína é de aproximadamente 33 segundos (Tabela 8.3). Nesse caso, 5 milissegundos representa uma porção insignificante no tempo do cálculo. Considerando que o tempo de comunicação cresce linear e o tempo de computação da técnica ABSO cresce quadraticamente, o tempo de transmissão das coordenadas dos átomos será cada vez mais insignificante em comparação ao tempo de computação.

Por outro lado, para proteínas relativamente pequenas, como a 1A11 (Tabela 8.3), o tempo de computação é próximo ao tempo de comunicação. Arredondando o tempo de computação para 1,3 milissegundos e o tempo de comunicação para 0,2 milissegundos, utilizando dois processadores 
haverá ganho de desempenho. Mas se utilizado 8 processadores o tempo de comunicação subiria para 1,6 milissegundos, tornando impraticável o uso desse algoritmo para esse tamanho de proteína e número de processadores. No gráfico da Figura 8.14 há uma queda brusca na eficiência quando utilizado mais de 8 processadores.

Além disso, é possível observar também que o speedup para as proteínas menores (390, 1753, 4728 e 8804 átomos) foi mais baixo que as outras maiores devido ao alto custo da comunicação. Com isso, fica claro o efeito de Amdahl, no qual aumentando o tamanho do problema, que nesse caso é o número de átomos, o speedup aproxima-se do speedup perfeito.

O aumento da eficiência dessa técnica está relacionado ao tamanho da proteína, do número de processadores e também do tempo que o algoritmo sequencial é capaz de resolver o mesmo problema utilizando um processador. Apesar de ser relativamente simples de implementar e aplicável em AGs, esse método traz resultados interessantes do ponto de vista de computação paralela. No entanto, mesmo com o bom speedup alcançado, o cálculo da energia de van der Waals continuará sendo o gargalo do AG, pois tem um crescimento quadrático do tempo de computação em relação ao tamanho da proteína.

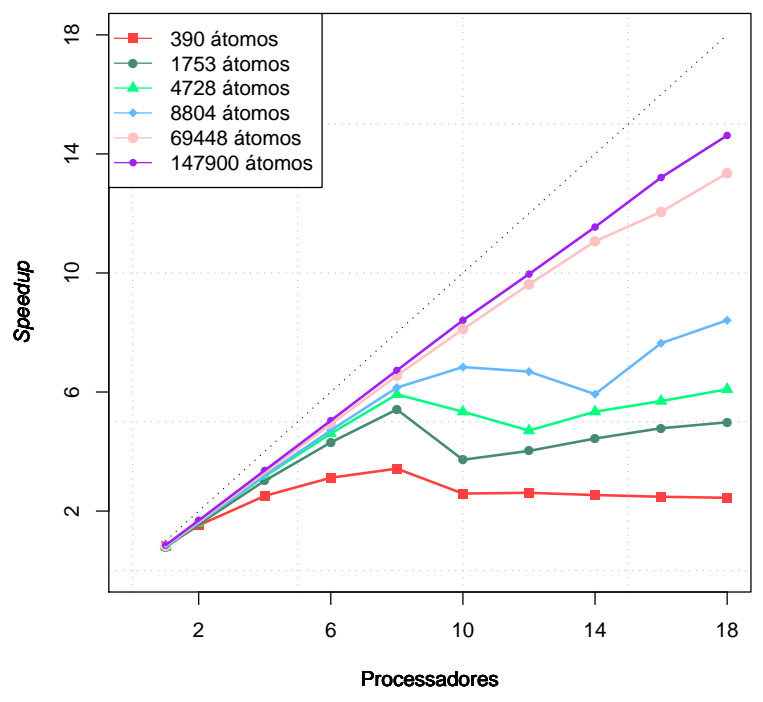

(a) Speedup alcançado com até 18 processadores.

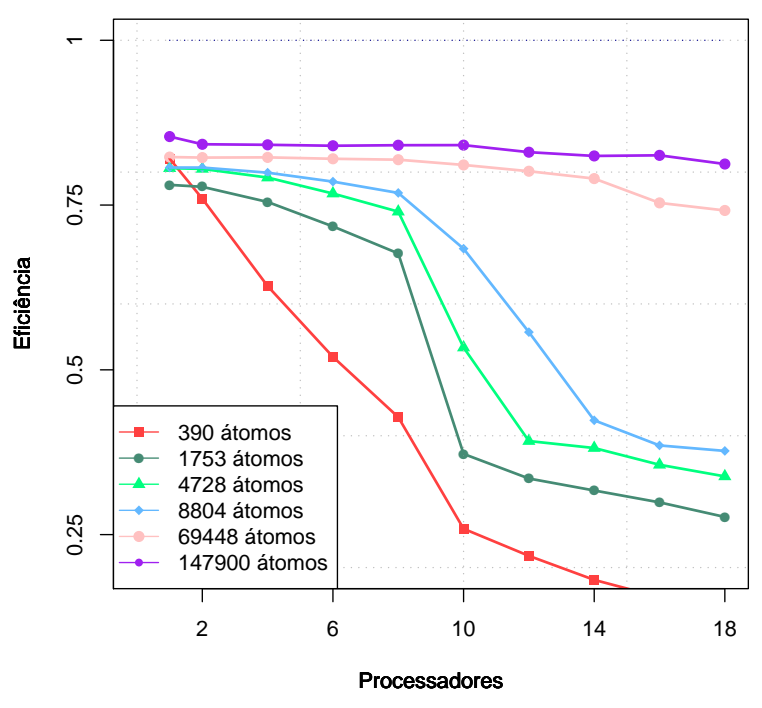

(b) Eficiência com até 18 processadores.

Figura 8.14: Ganho de desempenho para ABP-2 utilizando 18 processadores.

\subsection{Lista de Células}

Até este ponto, todos os experimentos executados foram de complexidade quadrática ou subquadrática. Mesmo reduzindo o tempo de computação utilizando vários processadores, a maior parte dessa computação é desnecessária pois, como visto na Seção 6.2.1, a maioria dos átomos apenas interagem com aqueles que estão na vizinhança próxima. Dessa forma, a técnica de LC traz novos resultados por conta da redução da complexidade do algoritmo para linear. 
Tabela 8.3: Tabela com o tempo de ABSO e o custo de comunicação.

\begin{tabular}{c|r|c} 
Proteína & ABSO (s) & Comunicação (ms) \\
\hline \hline 1A11 & 0,001375 & 0,000214 \\
1BFI & 0,023645 & 0,000306 \\
1AI0 & 0,161527 & 0,000508 \\
4HHB & 0,548372 & 0,000784 \\
1W1I & 0,962386 & 0,000979 \\
1RUZ & 3,502444 & 0,001705 \\
2BGN & 33,603360 & 0,004931 \\
1HTO & 152,738100 & 0,010222 \\
\hline \hline
\end{tabular}

$\mathrm{O}$ algoritmo de LC tem um overhead adicionado pela montagem da lista de vizinhança realizado antes de iniciar a interação entre os átomos (Seção 6.4). Esse overhead foi levado em consideração no momento de gerar os resultados, pois diferentemente do uso de LC em programas de DM, onde a LC é montada apenas uma vez, em AGs, a LC é montada sempre que um indivíduo é avaliado. No entanto, o custo adicional pela montagem das células toda vez que for avaliar um indivíduo é praticamente insignificante.

Isso pode ser visto no gráfico da Figura 8.15(a). Mesmo para a menor proteína do conjunto de proteínas selecionadas houve um pequeno ganho para a técnica de LC, pois o primeiro ponto desse gráfico está levemente acima da linha do speedup $=1$. Se fosse igual a um significaria que seriam idênticos. Nos gráficos da Figura 8.15 foram adicionados linhas de modelo para que fosse possível notar que o ganho de desempenho cresce linear de acordo com o tamanho da proteína. Essa é uma grande vantagem da técnica de LC, visto que está utilizando apenas um processador.

No gráfico da Figura 8.16 é possível verificar que o tempo de execução necessário para a técnica de LC é insignificante em relação ao tempo de outros métodos. Visualizando a curva do ABS, que é utilizado na função de avaliação para o cálculo da energia de van der Waals no AG do ProtPred e também da curva do método das luzes, utilizado no Tinker, é possível notar que esses dois métodos não são adequados para serem utilizados com a maioria dos tamanhos de proteínas.

O COF é um algoritmo que pode ser utilizando em qualquer um dos outros métodos, pois a estrutura do algoritmo atinge somente o trecho do algoritmo que faz a chamada para a função de van der Waals e sendo assim, pode ser utilizado também em LUZ e LC. O gráfico da Figura 8.16(b) mostra que utilizando o COF junto com LC é possível obter um desempenho sutilmente melhor. O ganho de desempenho obtido utilizando LC + COF seria significativo se LC fosse baseado em ABS, e não em ABSO, pois em ABS é utilizado a função de potência (Seção 6.1). Se LC evitasse o uso dessa potência o ganho de desempenho seria melhor. No entanto, como LC já foi desenvolvido sobre o algoritmo otimizado, o ganho de desempenho para LC + COF é baixo.

O algoritmo de LC reduz a complexidade de computação de $O\left(n^{2}\right)$ para $O(n)$. Isso pode ser visto experimentalmente por meio dos resultados obtidos nesta seção. Além disso, com uma 
complexidade relativamente baixa de implementar esse algoritmo é o mais promissor para ser utilizado no ProtPred (e também no Tinker). No entanto, durante o processo evolutivo de um AG são realizadas dezenas de milhares de avaliações, dependendo do tamanho da população e número de gerações. Isso significa que mesmo utilizando o algoritmo de LC para uma proteína gigante e considerando o tempo de computação de 1 segundo (Figura 8.16(a)), o processo evolutivo total pode durar muitas horas. Nesse sentido, é interessante investigar técnicas paralelas para LC.

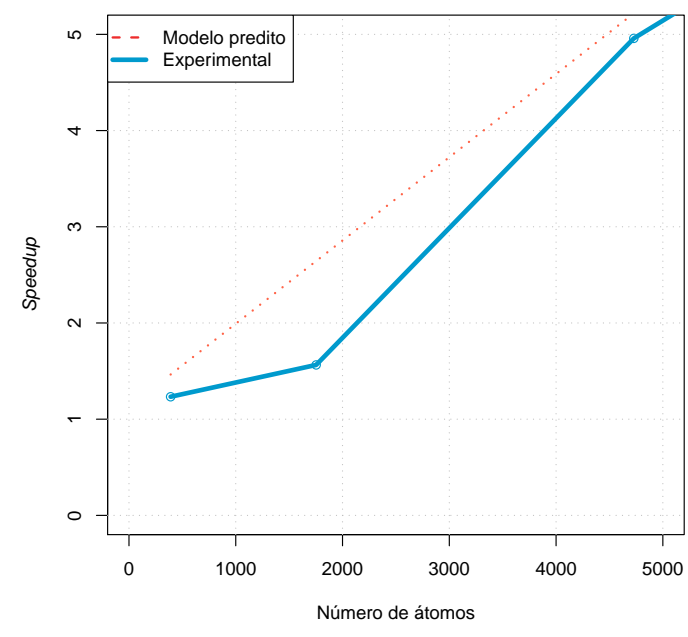

(a) Speedup para proteínas pequenas.

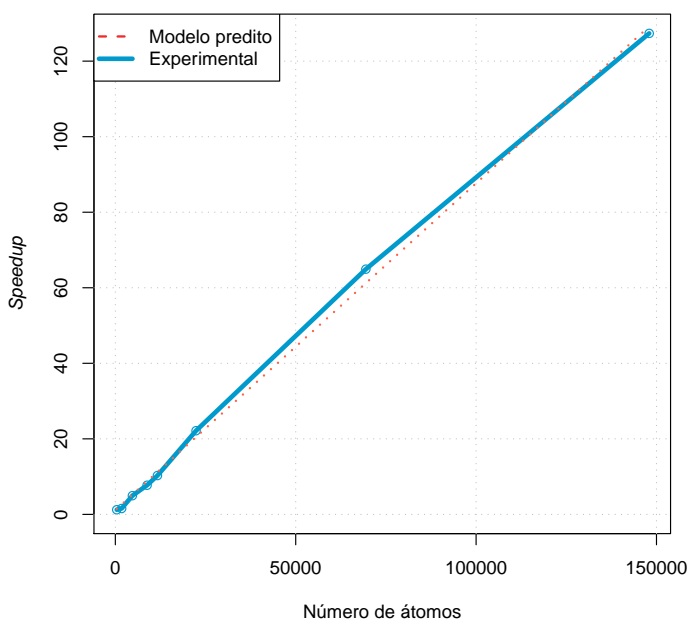

(b) Speedup para vários tamanhos de proteínas.

Figura 8.15: Ganho de desempenho para LC em relação ao ABSO.

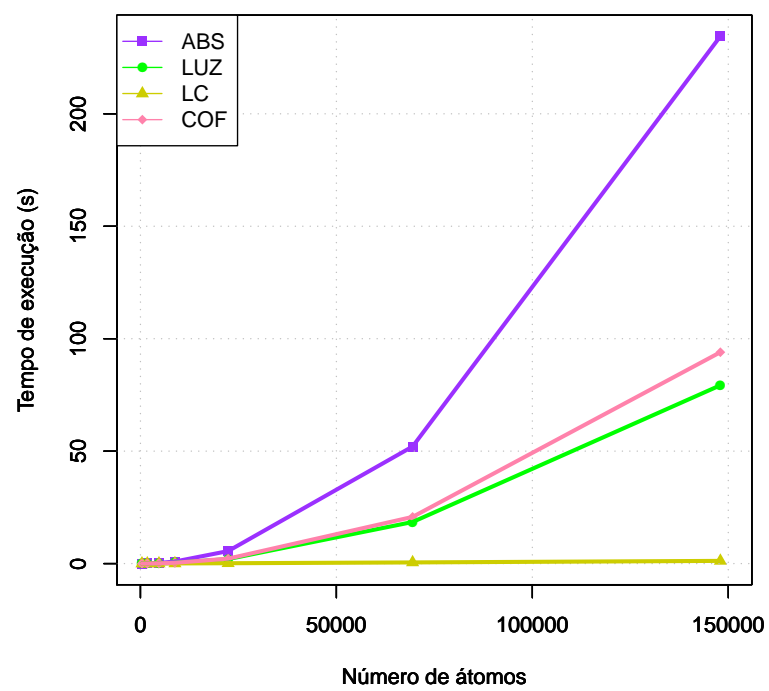

(a) Gráfico da comparação do tempo de execução entre ABS, LUZ, COF e LC utilizando processador de G2.

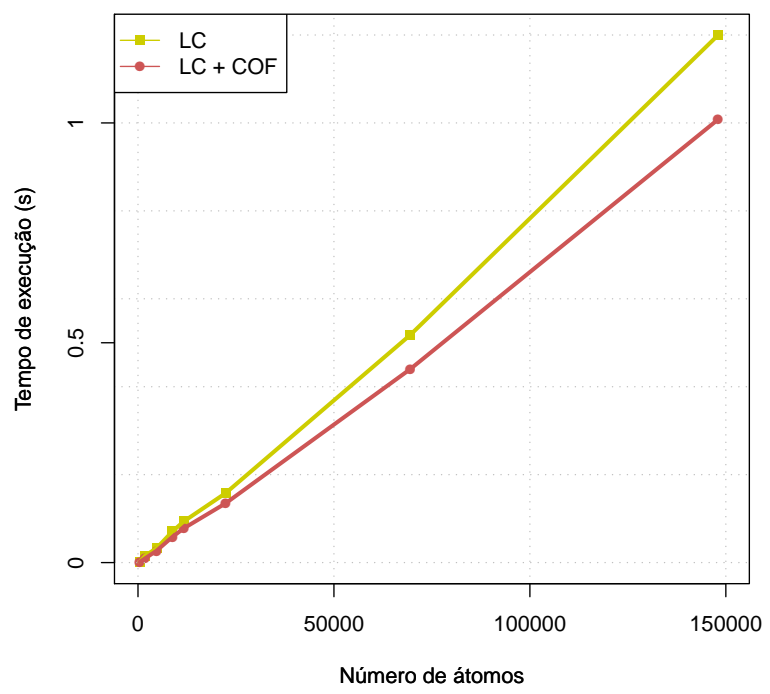

(b) Influência do uso do COF em LC executado em G2.

Figura 8.16: Ganho de desempenho para LC. 


\subsection{Lista de Células MPI sem enviar átomos}

A técnica de LC reduziu significativamente o tempo do cálculo para a energia de van der Waals. A fim de conseguir calcular a energia mais rapidamente, esta seção mostra os resultados obtidos da técnica LCP-1 (Seção 7.2.1). O objetivo é conseguir os melhores resultados de paralelização para LC desconsiderando o tempo de envio dos átomos do mestre para os escravos. Assim, espera-se conseguir determinar o limitante superior de ganho de desempenho para o uso de LC com vários processadores, de forma semelhante à Seção 8.8 .

Nessa técnica, há dois fatores que influenciam diretamente a qualidade dos resultados: (1) a forma como o mapeamento de processos é realizado e (2) o tempo de enviar os valores parciais da energia para o mestre. Observando o gráfico da Figura 8.17 é possível notar que o ganho de desempenho foi levemente superior a cinco vezes, mesmo para as maiores proteínas. Para proteínas pequenas quase não houve ganho de desempenho.

O tempo de envio de um resultado parcial do valor da energia é muito rápido. Para compor o valor da energia final o mestre deve somar os valores parciais que recebeu dos escravos. No entanto, se um dos escravos tem carga de trabalho um pouco superior aos outros escravos, o algoritmo todo é prejudicado esperando pelo resultado parcial "atrasado". Isso pode ocorrer em algoritmos que tenham o tempo de computação muito rápido, como no caso de LCP-1.

Outro fator influente nos resultados é a forma como o mapeamento de processos é realizado. Os algoritmos de LCPs foram projetados de forma a distribuir a carga de trabalho entre os processadores pela divisão no eixo $x$ do espaço 3D. Mas, observando a Tabela 8.4 é possível verificar que o número de células $\left(n_{x}, n_{y}, n_{z}\right)$ é pequeno. Tomando como exemplo a primeira proteína dessa tabela, a quantidade máxima de processadores permitidos é três, pois se utilizado mais que isso, eles ficarão ociosos. Com 1 processador, a carga de trabalho dele é de $3 \times 2 \times 3$; com 2 processadores, a carga de trabalho do processador 1 é $2 \times 2 \times 3$ e do processador $2,1 \times 2 \times 3$; com 3 processadores a carga de trabalho de cada um dos três processadores será de $1 \times 2 \times 3$; e por fim, com 4 ou mais processadores a carga de trabalho dos três primeiros processadores será a mesma para 3 processadores enquanto que do processador número 4 para frente a carga de trabalho será zero. Nesse sentido, o número máximo de processadores para uma proteína é do tamanho de $n_{x}$.

A técnica de LCP-1 determinou o limitante superior que um AG poderá obter, por desconsiderar o tempo de enviar os átomos. Foi verificado que a quantidade de células $\left(n_{x}, n_{y}, n_{z}\right)$ para uma proteína é pequena. Na Tabela 8.4 é possível encontrar a quantidade de células para a estrutura nativa dessas proteínas e mesmo para proteínas gigantes o número de células é pequeno. Poderia-se conseguir melhores resultados utilizando um mapeamento dos processos não somente na direção de $n_{x}$, mas também por $n_{x}, n_{y}$ ou por $n_{x}, n_{y}, n_{z}$. Dessa forma, seria possível garantir um melhor balanceamento de carga e utilizar um maior número de processadores. 


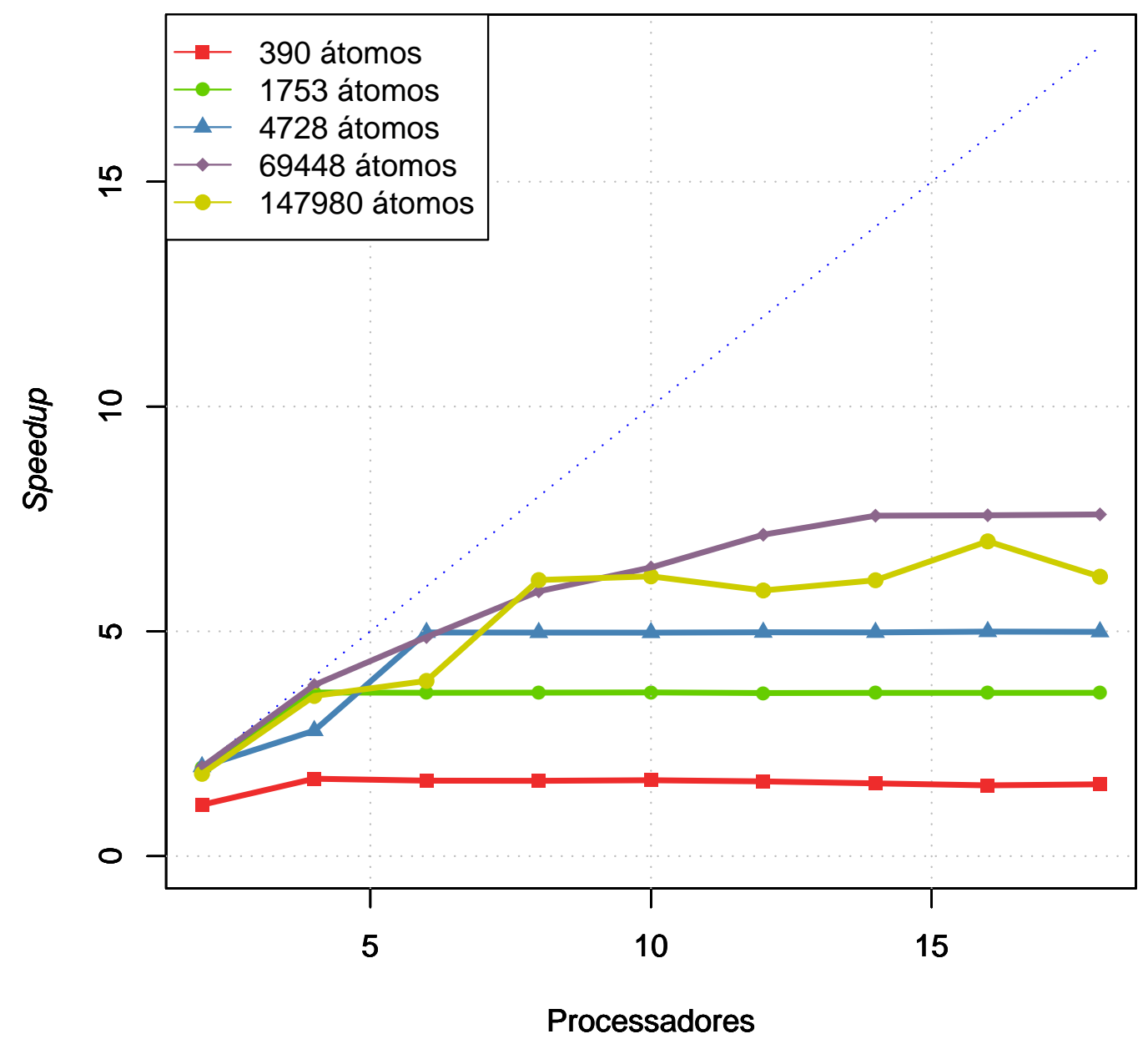

Figura 8.17: Gráfico do speedup de LCP-1 para 5 proteínas diferentes em G1.

Tabela 8.4: Tabela de dimensões do espaço para estruturas de proteínas nativa.

\begin{tabular}{c|r|c} 
Proteína & Núm. átomos & Células $\left(n_{x} \times n_{y} \times n_{z}\right)$ \\
\hline \hline 1A11 & 390 & $3 \times 2 \times 3$ \\
1BFI & 1.753 & $4 \times 5 \times 4$ \\
1AI0 & 4.728 & $6 \times 6 \times 5$ \\
4HHB & 8.804 & $8 \times 6 \times 7$ \\
1W1I & 11.671 & $9 \times 8 \times 8$ \\
1RUZ & 22.380 & $13 \times 14 \times 14$ \\
2BGN & 69.448 & $14 \times 14 \times 32$ \\
1HTO & 147.980 & $27 \times 18 \times 16$
\end{tabular}

\subsection{Lista de Células MPI enviando átomos}

A técnica de LCP-2, descrita na Seção 7.2.2, considera o envio dos átomos do mestre aos processadores escravos para que seja adequado a trabalhar em AGs. Dessa forma, o tempo de 
envio dos átomos é considerado no cálculo dos resultados. Foram propostas duas formas de fazer o envio desse átomos: replicando comunicação e computação e minimizando comunicação (Seção 7.2.2).

Observando os gráficos da Figura 8.18 é possível visualizar que o ganho de desempenho entre LC e os algoritmos LCP-2a e LCP-2b não foram significativos. O melhor speedup alcançado foi de 4 a 5 vezes para proteínas grandes. Isso ocorre porque mesmo para as proteínas grandes o tempo de comunicação é próximo ao tempo de computação pelo método de LC sequencial (Tabela 8.5), pois além do tempo de enviar as coordenadas dos átomos, o mestre precisa receber os valores parciais calculados pelos escravos, aumentando o overhead (assim como descrito na Seção 8.11).

Considerando o pequeno número de células na direção $x\left(n_{x}\right)$ das proteínas nativas, nos AGs, esse número também deverá ser pequeno, porque os indivíduos nos AGs possuem conformação aleatória podendo causar variações na quantidade de células. Assim, a eficiência desse método depende também do indivíduo. Embora a eficiência da técnica de LCP-2a e LCP-2b tenham várias restrições, ela ainda é capaz de reduzir o tempo do cálculo da energia de van der Waals. No entanto, com o custo de computação se aproximando do custo de comunicação, pode-se afirmar que a comunicação é o gargalo.

Tabela 8.5: Tabela do tempo de LC e tempo de transmissão.

\begin{tabular}{r|r|r} 
Núm. átomos & LC (s) & Comunicação (ms) \\
\hline \hline 390 & 0,001115 & 0,000214 \\
1.753 & 0,015119 & 0,000306 \\
4.728 & 0,032576 & 0,000508 \\
8.804 & 0,070993 & 0,000784 \\
11.671 & 0,093590 & 0,000979 \\
22.380 & 0,158053 & 0,001705 \\
69.448 & 0,517549 & 0,004931 \\
147.980 & 1,199322 & 0,010222 \\
\hline \hline
\end{tabular}

\subsection{Lista de Células e OpenMP}

A relação de custo de comunicação pelo tempo de computação das técnicas que utilizam passagem de mensagens mostrou problemas de eficiência. Portanto, para vencer esse obstáculo serão apresentados nesta seção os resultados da técnica LCP-3, descrito na Seção 7.2.3. O custo da comunicação inter-processo utilizando memória compartilhada é muito baixo em relação ao tempo de computação do método de LC, tornando viável o uso de vários processadores.

Os experimentos dessa técnica foram executados no processador de G2 pelo fato de possuir 4 núcleos. Assim, para cada proteína esse método foi executado utilizando 1, 2, 3, 4, 8 e 16 


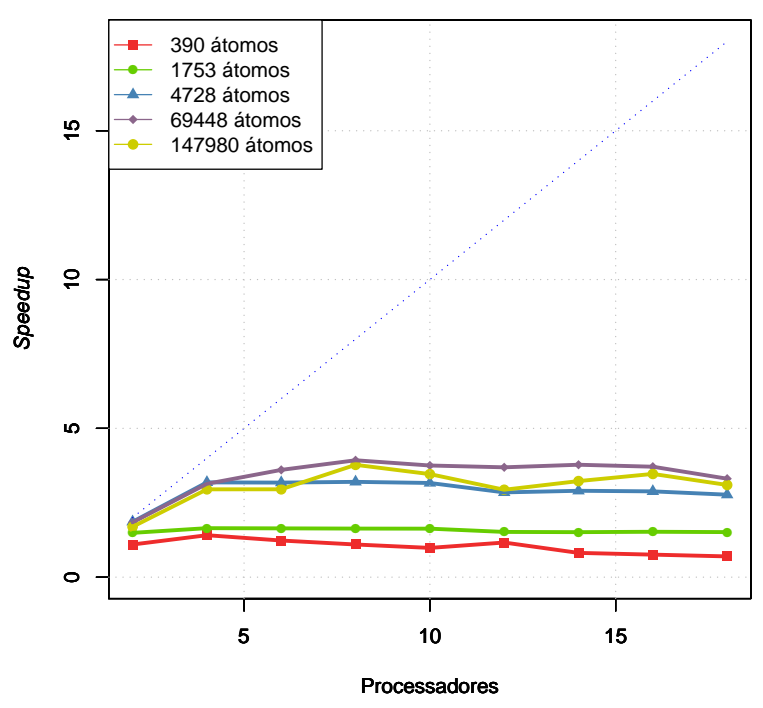

(a) Speedup de LCP-2a para 5 proteínas.

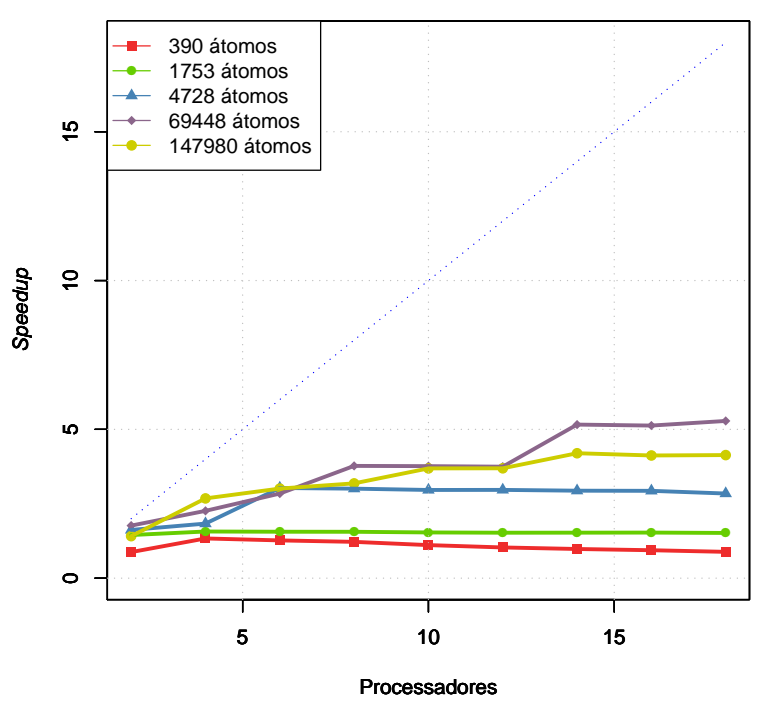

(b) Speedup de LCP-2b para 5 proteínas.

Figura 8.18: Speedup de LCP-2a e LCP-2b em relação a LC (executados em G1).

processos. Esse método foi capaz de reduzir significamente o tempo de computação para todos os tamanhos de proteínas. Observando o gráfico da Figura 8.21 é possível observar que quanto maior é a proteína melhor é a eficiência com relação ao ABSO. O terceiro ponto do gráfico, isto é, utilizando 3 processadores o método apresentou uma anormalidade para a proteína 2BGN, com 69.448 átomos, pois o ponto deveria seguir uma linha entre os pontos referente à execução com 2 e 4 processos. Isso pode ter ocorrido pelo modo como o mapeamento foi realizado. Para a proteína 1HTO, com 147.980 átomos, houve um ganho incomum no ponto 3, mas isso pode ter sido causado pelo fato do mapeamento ser feito por $n_{x}$ o qual contem 27 células nessa direção, ou seja, sendo múltiplo de 3 processadores pode ter se ajustado de forma a otimizar o escalonamento. Embora o processador i7 de G2 tenha apenas 4 núcleos físicos, mas que simula 8 pelo hyper threading, mostrou ser mais eficiente utilizando 8 processos. $\mathrm{O}$ chaveamento entre processos nesse processador é muito veloz e, fazendo com que as proteínas 1RUZ e 2BGN com 16 processos apresentassem ganho de desempenho superior a 8 processos. Mesmo para proteínas muito pequenas o algoritmo de LCP-3 teve um ganho considerável em relação ao ABSO (Figura 8.19(b)) e à LC e LCP-2a (Figura 8.20).

No gráfico da Figura 8.19(a) é possível verificar que o primeiro ponto já inicia com aproximadamente de 2,5 vezes de ganho de desempenho. Para as proteínas maiores o speedup permanece com crescimento linear da mesma maneira que a Figura 8.15(b), porém com um speedup maior por utilizar vários processadores. Na comparação com o algoritmo padrão de LC, o speedup foi de aproximadamente 4 vezes, ou seja, o número total de núcleos físico do processador.

Os dados de LCP-2a da Figura 8.20(b) foram obtidos executando de 2 a 18 processos no G2 e recolhido o melhor tempo de execução para cada proteína, para servir de referência ao LCP-3. Em relação ao LCP-2a, o algoritmo de LCP-3 foi melhor para proteínas muito pequenas enquanto 
que para todo o resto das proteínas o speedup foi praticamente o mesmo. Isso mostra a eficácia do método de LCP-3, pois utilizando apenas uma máquina foi obtido o mesmo desempenho de 4 máquinas e 18 processos utilizando passagem de mensagens. Esse gráfico apresentou um pequeno pico de perda de desempenho para a proteína 1W1I, com 11.671 átomos, causado provavelmente para estrutura da topologia da proteína.

O algoritmo de LCP-3 pode aumentar a eficiência do algoritmo utilizando máquinas com processamento paralelo e acesso à memória compartilhada. Esse algoritmo é relativamente simples de implementar e pode aumentar o desempenho do cálculo da energia de van der Waals em até 4 vezes em relação ao algoritmo sequencial. Com praticamente uma linha de código adicionada ao algoritmo de LC, foi transformado na sua versão paralela para memória compartilhada, o LCP-3, que é aproximadamente 450 vezes mais rápido que o ABSO. Pela alta redução do custo de comunicação com o uso de memória compartilhada, essa técnica é interessante ser utilizada em máquinas paralelas com vários núcleos ou processadores. No entanto, por uma limitação de tecnologia e custo operacional, o número de unidades de processamento de uma máquina paralela não é grande. Uma solução para isso é o uso de memória compartilhada e passagem de mensagens no qual cada uma das técnicas irá explorar de forma maximizada os recursos disponíveis.

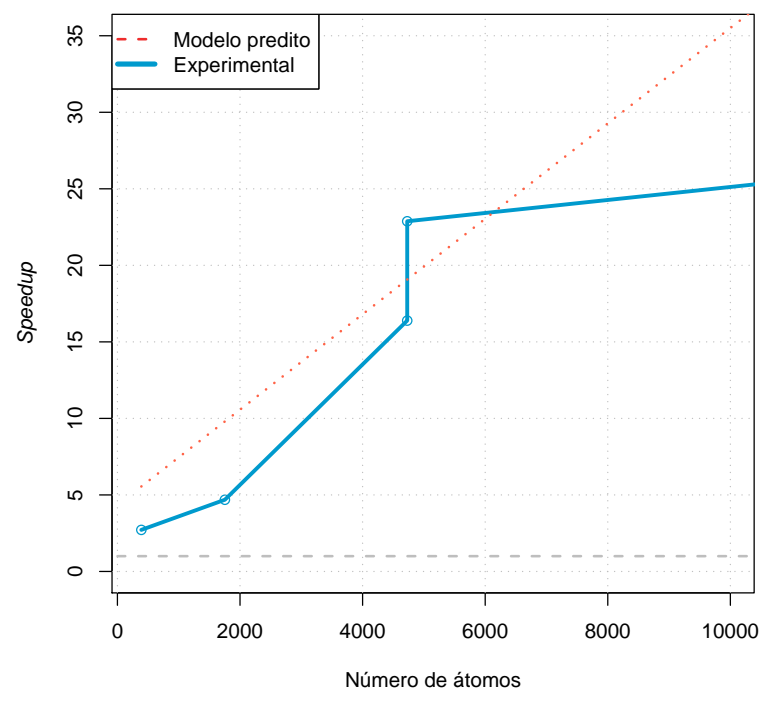

(a) Speedup para proteínas pequenas.

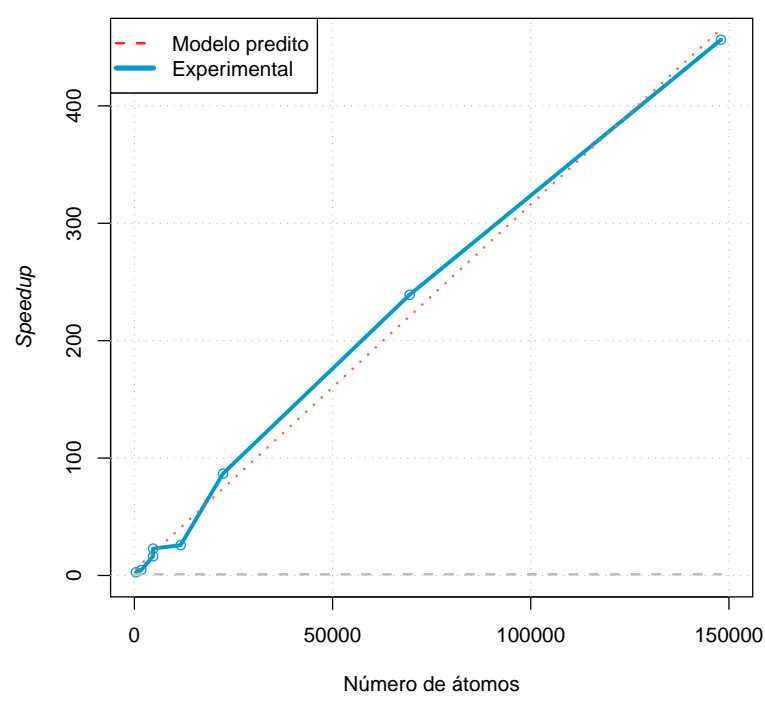

(b) Speedup para vários tamanhos de proteínas.

Figura 8.19: Ganho de desempenho para LCP-3 em relação ao ABSO executados no G2. 


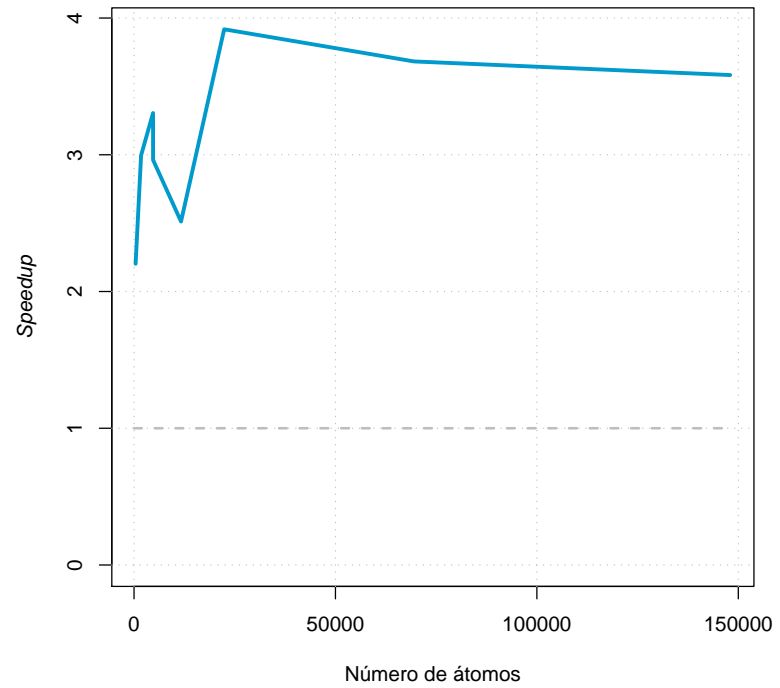

(a) Speedup obtido de LCP-3 em relação a LC.

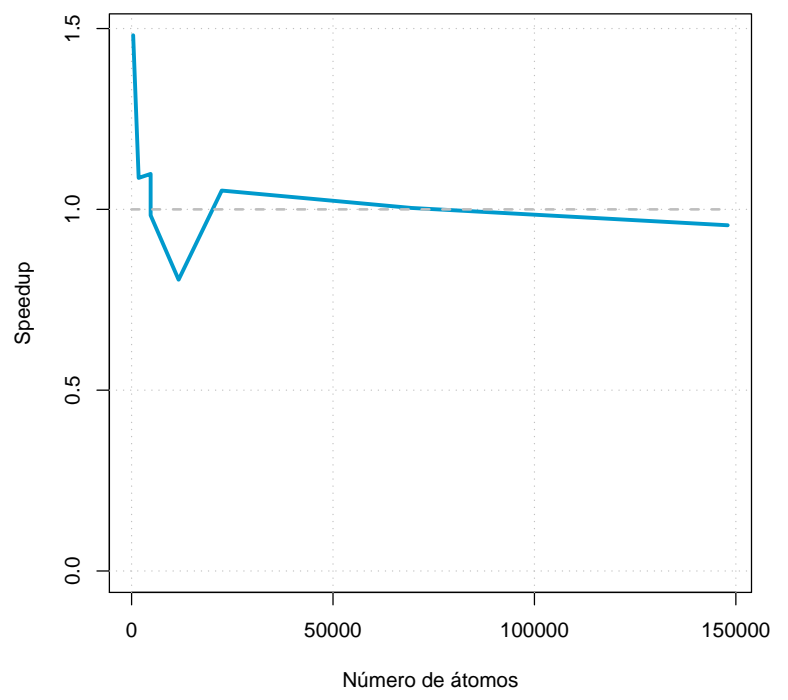

(b) Speedup obtido de LCP-3 em relação a LCP-2a.

Figura 8.20: Comparação do speedup entre LCP-3 com LC e LCP-2a executados no G2.

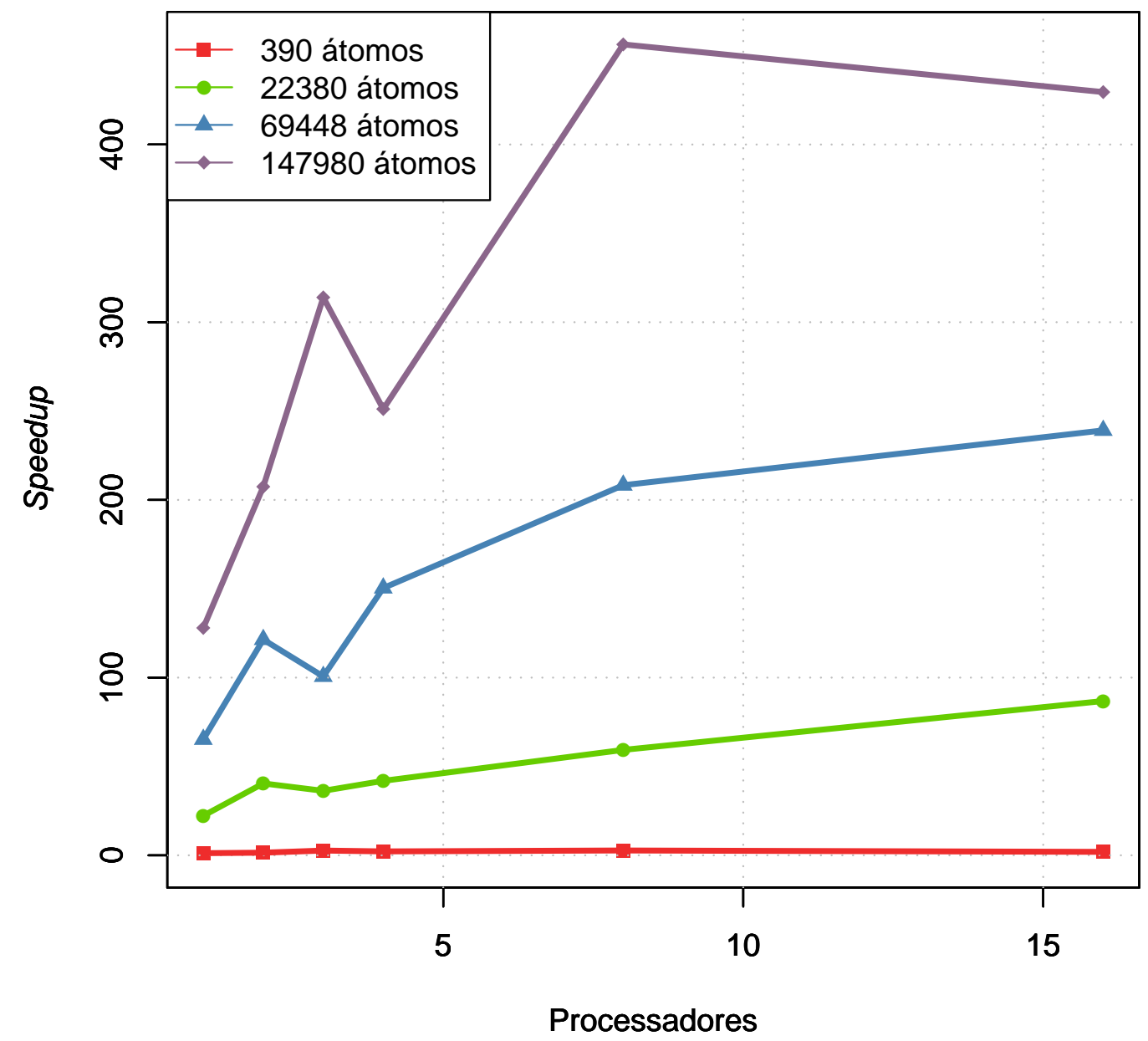

Figura 8.21: Gráfico do speedup obtido de LCP-3 em relação a ABSO utilizando G2. 


\subsection{Lista de Células Híbrido}

O algoritmo de LCP-4, descrito na Seção 7.2.4, é uma implementação combinada de LCP2a e LCP-3 realizada para que seja possível explorar o paralelismo nos níveis de quantidade de máquinas paralelas e número de processadores de cada máquina paralela. Dessa forma, espera-se reduzir a comunicação na passagem de mensagens aumentando a eficiência. Nesta seção, serão mostrados os resultados obtidos para execuções no G1 e G2, pois G1 tem 10 máquinas paralelas com 2 núcleos cada e G2 tem 4 máquinas paralelas com 8 núcleos cada uma. Para cada proteína do conjunto das proteínas selecionadas, o algoritmo LCP-4 e LCP-2a foram executados utilizando 8, 16, 24 e 32 processos em G2 e 2, 4, 6, 8, 10, 12, 14, 16 e 18 processos em G1.

Os gráficos da Figura 8.22 mostram o ganho de desempenho para oito proteínas utilizando o LCP-4 em relação ao algoritmo de LC comum. Foi adicionado também nesses gráficos o desempenho obtido para as técnicas LCP-2a e LCP-3 para efeito de comparação. Para proteínas muito pequenas o ganho de desempenho para as três técnicas foi baixo, pois, como descrito na Seção 8.11 o mapeamento realizado não é capaz de aproveitar todos os processadores para essas proteínas. No entanto, com o aumento do tamanho da proteína o speedup fica cada vez melhor. Observando esses gráficos individualmente o speedup aproximado é de 3 vezes para 1BFI e 1AI0, 4 vezes para 4HHB e $1 \mathrm{~W} 1 \mathrm{I} ; 5$ vezes para $1 \mathrm{RUZ}$; 6 vezes para $2 \mathrm{BGN}$ e 7 vezes para $1 \mathrm{HTO}$.

Por outro lado, observando a Figura 8.23(a) o speedup é em média constante de 5 vezes para G1. É interessante observar nessa figura que o modelo híbrido foi capaz de combinar o desempenho das técnicas LCP-2a e LCP-3 obtendo ganho de desempenho tanto no G1 quanto no G2. O algoritmo de LCP-3 obteve mais desempenho em G2 enquanto que o LCP-2a foi melhor em G1. Isso ocorre porque em G1 existe apenas 2 núcleos em cada máquina tornando a porção que contém OpenMP no LCP-4 menos eficiente, mas em G2 cada máquina tem 4 núcleos, privilegiando o trecho do algoritmo que utiliza OpenMP, isto é, a parte "LCP-3" do algoritmo de LCP-4.

A aplicação do modelo híbrido é capaz de reduzir significativamente o tempo do cálculo da energia de van der Waals utilizado no ProtPred. Para efeito de comparação, a Figura 8.25 mostra o ganho de desempenho de LCP-4 em relação a ABS. Isso significa que esse seria o ganho de desempenho se a técnica de LCP-4 fosse empregada na função de avaliação do AG que faz o cálculo da energia de van der Waals, ou seja, 1.500 vezes para longas cadeias de proteínas. Nesse gráfico, é possível verificar que a relação desempenho por número de átomos aumenta uma vez para cada 100 átomos da proteína. Assim, se fosse possível executar os experimentos com proteínas com um milhão de átomos o speedup seria de aproximadamente 10.000 vezes. 


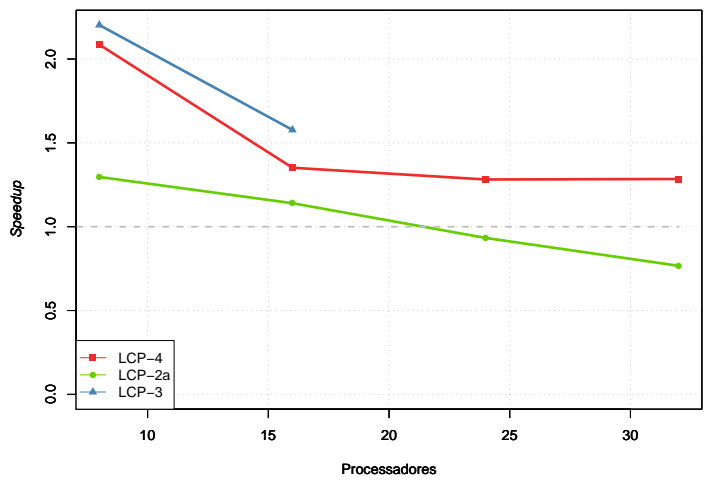

(a) Proteína 1A11.

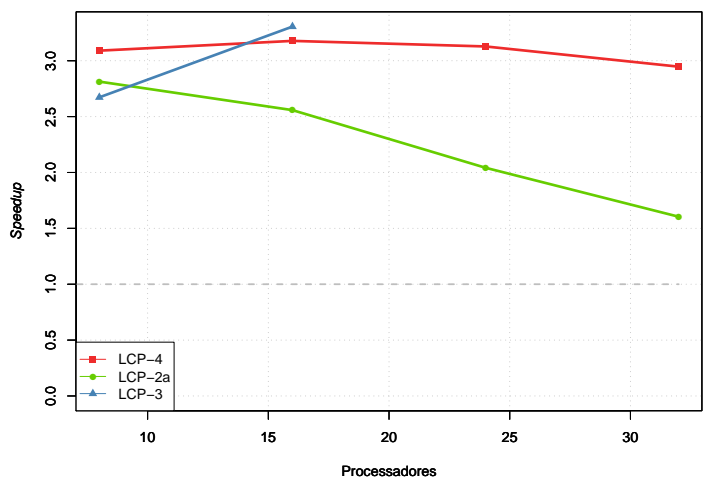

(c) Proteína 1AI0.

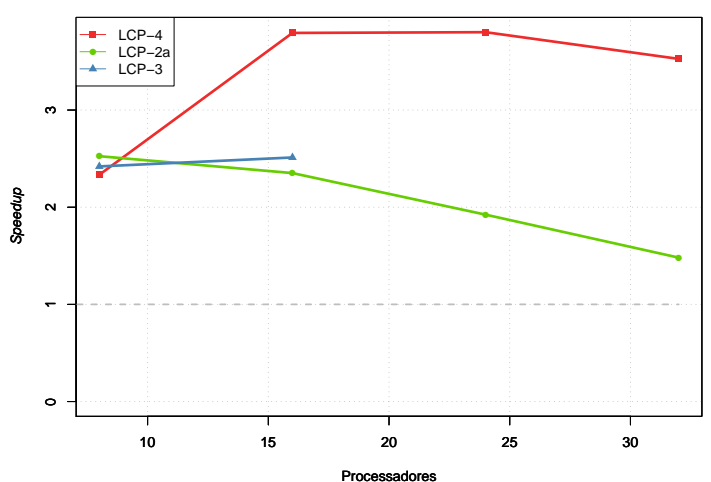

(e) Proteína 1W1I.

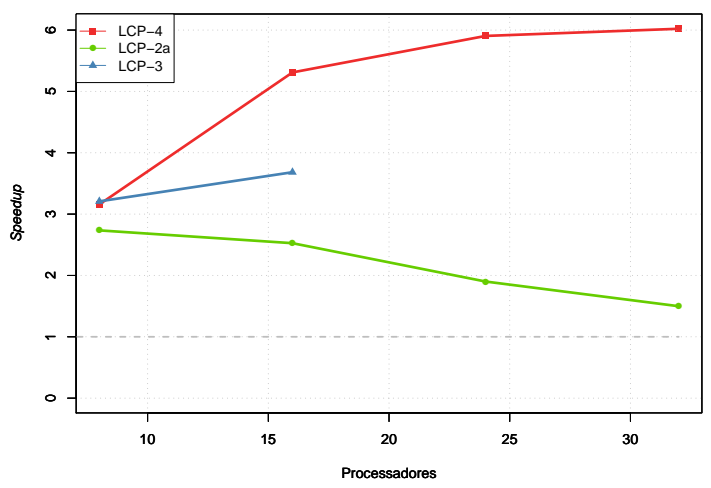

(g) Proteína 2BGN.

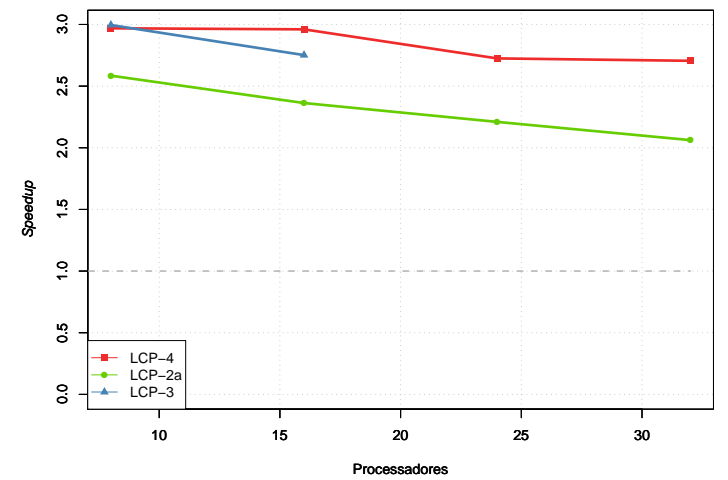

(b) Proteína 1BFI.

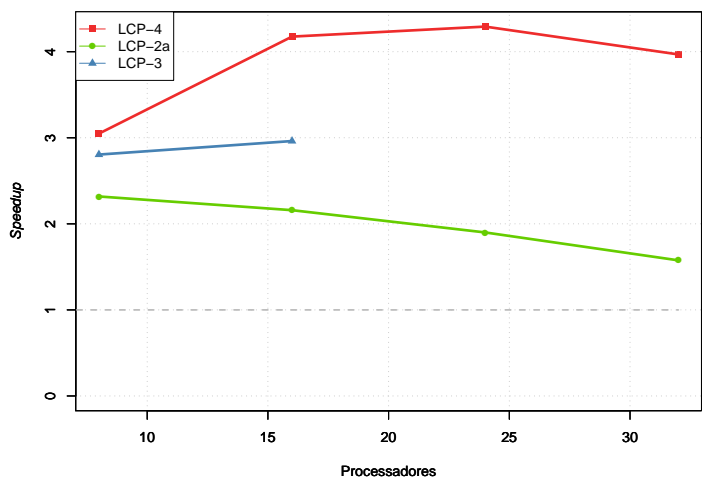

(d) Proteína 4HHB.

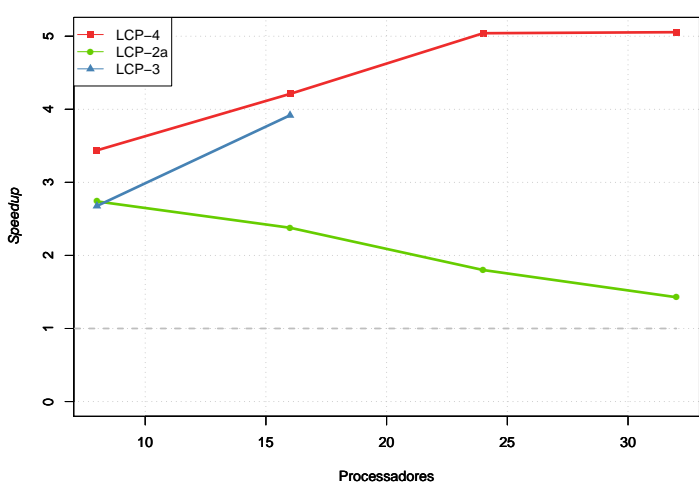

(f) Proteína 1RUZ.

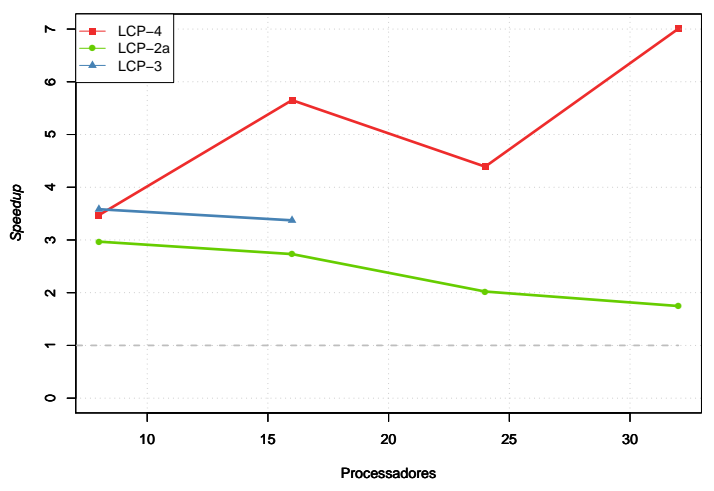

(h) Proteína 1HTO.

Figura 8.22: Comparação do speedup de LCP-4, LCP-2a e LCP-3 em relação a LC para 8 proteínas executadas em G2. 
A técnica de algoritmos de LCP-4 pode ser mais bem aproveitada fazendo um balanceamento entre máquinas e processadores. Observando a Figura 8.24 é possível verificar que apesar da técnica ter sido capaz de reduzir o tempo de computação a eficiência é baixa, pois para o G2 utilizando 32 processadores, o speedup está longe do speedup perfeito mesmo para vários tamanhos de proteínas, ou seja, há vários processadores ociosos. Por fim, a escolha de um método de aumento da eficiência do tempo do cálculo da energia de van der Waals deve levar em consideração o total de ganho desejado e os impactos que a técnica poderá gerar.

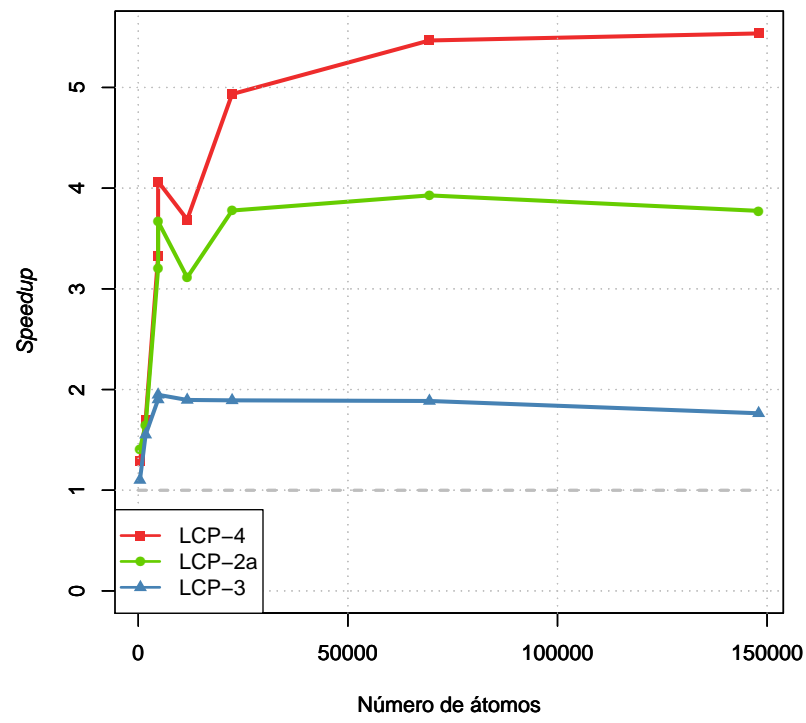

(a) Processador de G1

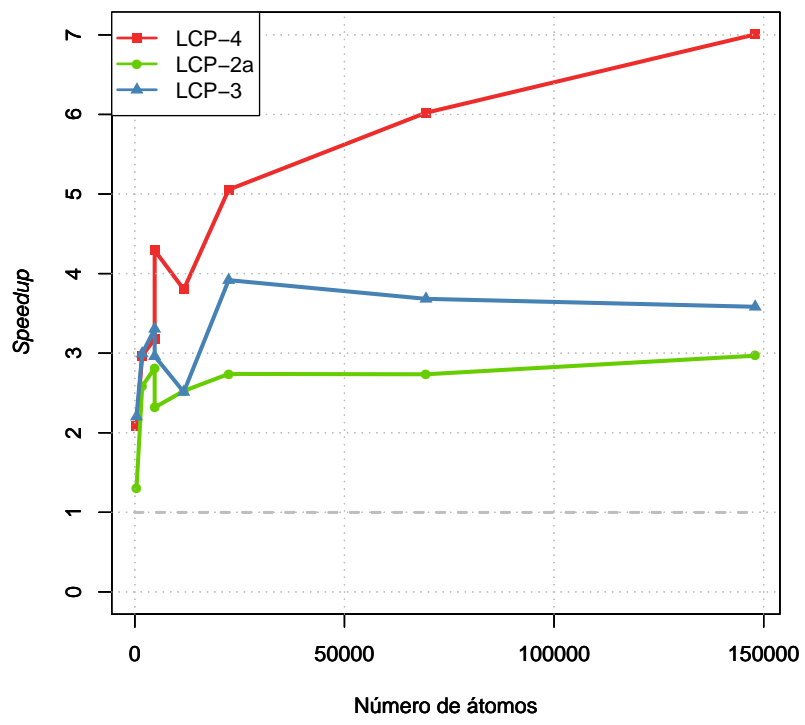

(b) Processador de G2

Figura 8.23: Speedup de LCP4, LCP-2a e LCP-3 em relação ao LC variando o número de átomos.

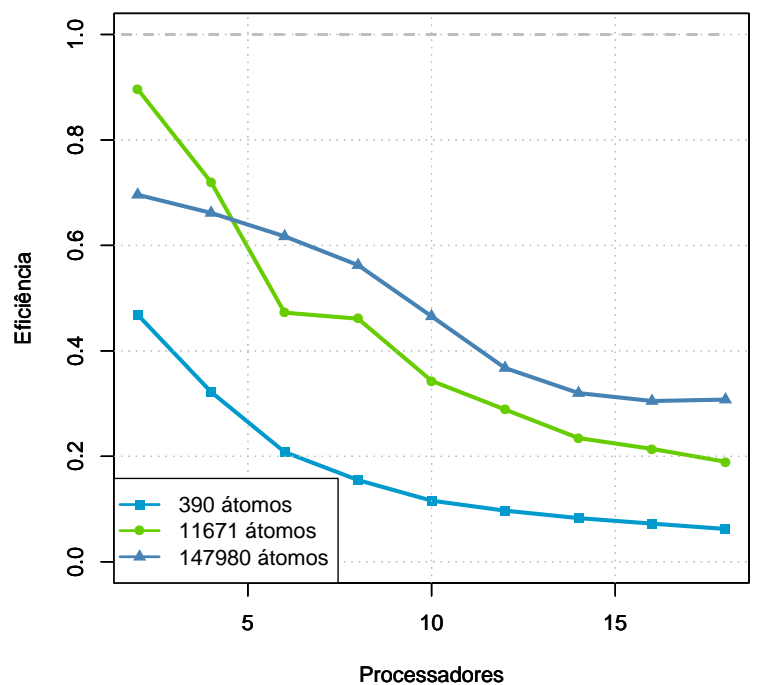

(a) Processador de G1

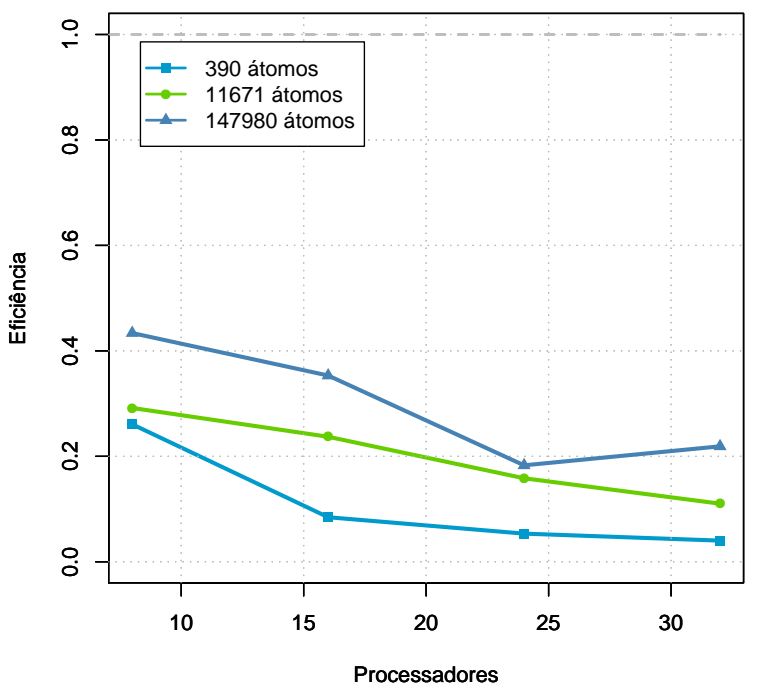

(b) Processador de G2

Figura 8.24: Eficiência de LCP-4 em relação ao algoritmo de LC. 


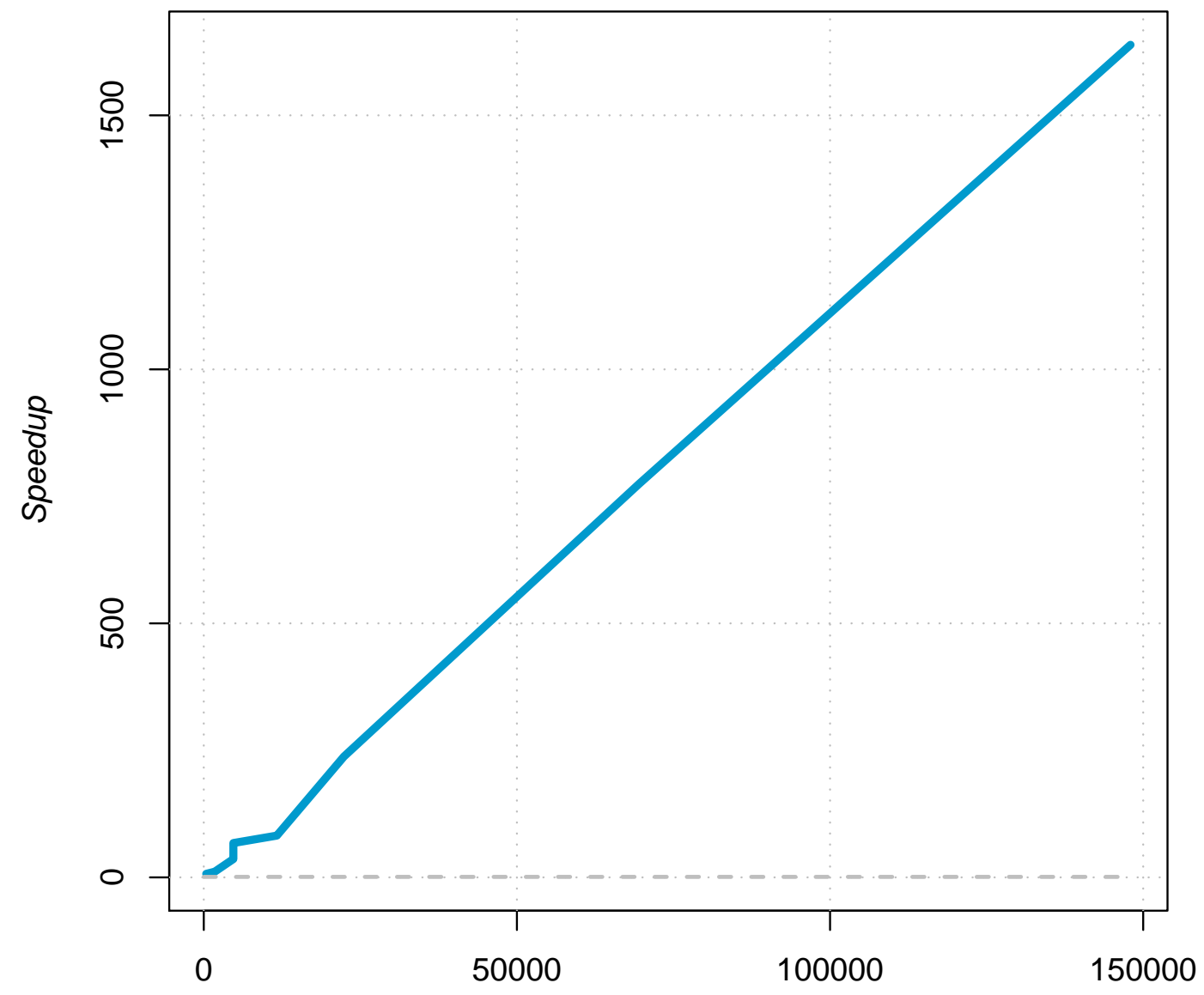

Número de átomos

Figura 8.25: Ganho de desempenho de LCP-4 em relação ao ABS executado em G1.

\subsection{Comparação entre as técnicas}

Nesta seção é exibida uma relação de todas as técnicas executadas em G1 e G2 para o conjunto de proteínas selecionadas. Dessa forma, conhecendo as características das técnicas é possível antecipar algumas conclusões. O G1 foi utilizado para expressar o comportamento das técnicas utilizando muitas máquinas com pouco processador. Ao contrário disso, o G2 foi utilizado para medir a influência das técnicas utilizando poucas máquinas paralelas, mas com muitos processadores cada uma.

A Figura 8.26 faz um comparativo de eficiência para o G1 entre as técnicas para oito proteínas. Os valores utilizados nesse gráfico é o speedup que cada uma das técnicas alcançou em relação ao algoritmo mais básico de todos, o ABS. Esses valores são mostrados na tabela incorporada ao gráfico. A técnica LCP-1 obteve speedup superior para $75 \%$ proteínas atingido um speedup de 2.000 vezes para a proteína 1 HTO. Os outros $25 \%$ foram conseguidos pelo algoritmo ABP1, para as menores proteínas, 1A11 e 1BFI. Embora essas técnicas tenham atingido os melhores resultados, elas serviram apenas de limitante superiores para outras técnicas, pois não podem ser aplicadas em AGs. Isso significa que houvesse uma comunicação entre mestre/escravo muito mais 
veloz, os algoritmos de LCP-2a ou LCP-2b poderiam atingir no máximo os resultados de LCP-1, assim como também ABP-2 pode atingir no máximo a speedup de ABP-1. Se considerado somente as técnicas que podem ser aplicadas em AGs, o LCP-4 obteve o melhor desempenho em 7 das 8 proteínas, pois a proteína 1A11 é muito pequena para esse tipo de algoritmo.

De forma semelhante, a Figura 8.27 faz um comparativo de eficiência entre as técnicas executadas em G2, o speedup mostrado na tabela de valores é calculado em relação ao ABS. É possível visualizar que o algoritmo LCP-4 possui a maior fatia de área da figura. Esse algoritmo obteve o melhor speedup para 7 das 8 proteínas mesmo considerando as técnicas ABP-1 e LCP-1. Além disso, o LCP-4 obteve quase o dobro de desempenho obtido por LCP-1. Em segundo lugar, ficou o LCP-3 que, dentre os algoritmos que são aplicáveis à AGs, conseguiu o melhor speedup para $75 \%$ das proteínas. A característica principal desse algoritmo é ganho de desempenho especialmente para proteínas pequenas e médias (até 20.000 átomos) enquanto que o LCP-4 obteve os melhores resultados para as maiores proteínas. A porção do gráfico das técnicas que não utilizam LC consegue ser visualizada até proteínas de tamanho médio. Depois disso, essas técnicas são impraticáveis, considerando o tempo de computação.

Por fim, os resultados experimentais revelaram que é possível reduzir significativamente o tempo do cálculo para a energia de van der Waals de várias maneiras. A escolha de uma técnica deve levar em consideração os benefícios que oferece como, por exemplo, o ganho do desempenho, facilidade de implementação, extensibilidade, portabilidade, flexibilidade, bem como outros fatores oferecidos pela configuração do ambiente de execução como, velocidade da rede de comunicação, número de máquinas, velocidade e quantidade de processador por máquina, sistema operacional e o tamanho do problema. Por esse motivo, a comparação entre as técnicas descritas nesta seção tem o objetivo de mostrar a relação do ganho de eficiência entre elas auxiliando no processo de escolha da técnica a ser implementada em um algoritmo. 


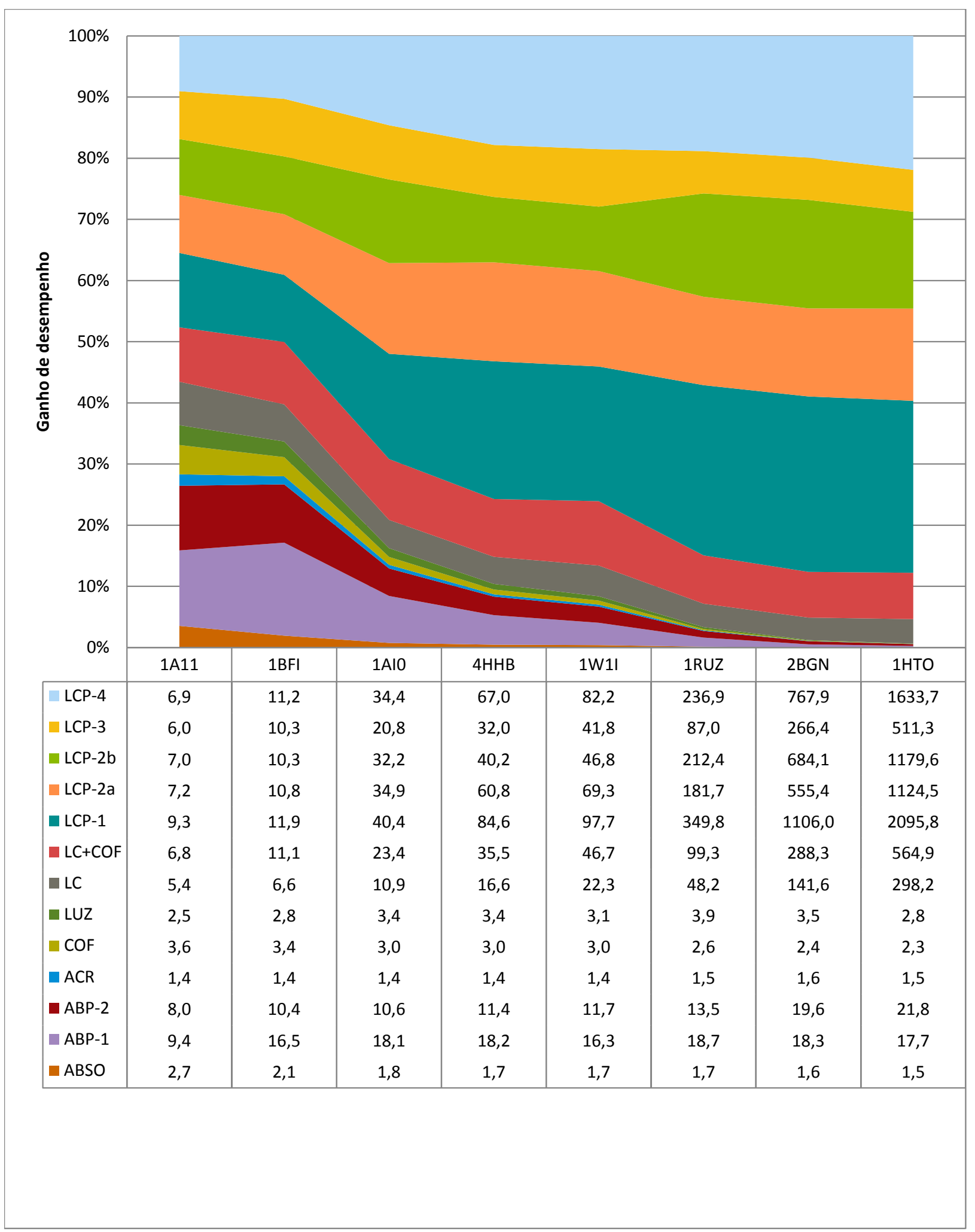

Figura 8.26: Ganho de desempenho por técnica executado em G1. 


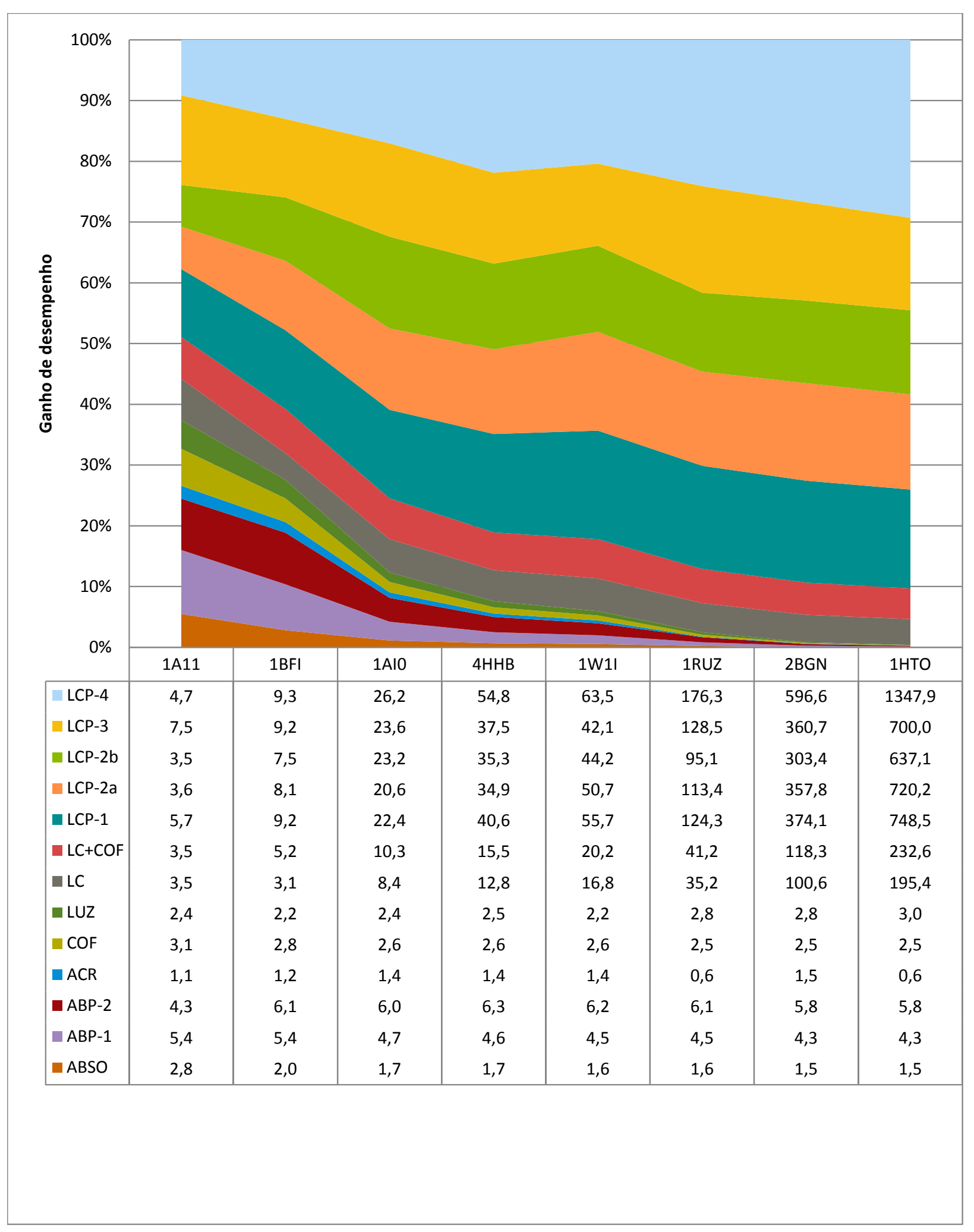

Figura 8.27: Ganho de desempenho por técnica executado em G2. 


\subsection{Desempenho do ProtPred}

Baseado nos resultados oferecidos pelas técnicas estudadas, a técnica mais promissora em termos de desempenho computacional para ser implementado no ProtPred é o algoritmo de LCP4. Para adequar o ProtPred ao LCP-4 deve ser necessário a implementação de LCP-2a ou LCP-2b para que seja capaz de trabalhar com passagem de mensagens, bem como o LCP-3, para que faça o uso dos núcleos das máquinas pelo uso de memória compartilhada.

Por outro lado, considerando que a maioria das proteínas preditas no ProtPred tem menos que 10.000 átomos e, em geral, é executado em processadores do tipo do G2, a técnica do algoritmo de LCP-3 é também uma maneira promissora de se reduzir o tempo do cálculo da energia de van der Waals. O que realmente causa uma explosão no desempenho dessas técnicas é o uso de LC, e com uso de LC no ProtPred, já haveria um ganho significativo de desempenho, pois permitiria ao ProtPred trabalhar com qualquer tamanho de proteína. No entanto, esse desempenho pode se triplicado se utilizado a implementação paralela com OpenMP sem causar esforços de implementação, o LCP-3.

\subsubsection{Lista de Células e OpenMP}

Apesar de ser possível reduzir o tempo do cálculo com LC para proteínas de qualquer tamanho, esse tempo pode significar várias horas para o ProtPred, pois nos AGs, são realizadas dezenas de milhares de avaliações durante o processo evolutivo. Assim, é interessante utilizar técnicas paralelas para que, ao invés de horas, permita a execução do processo evolutivo em minutos mesmo para proteínas não pequenas.

O processo de adequação para permitir o uso de LC no ProtPred foi iniciado com a cópia do algoritmo de LC em substituição ao cálculo padrão. No entanto, a função que faz o cálculo da interação de van der Waals (Equação 2.3) foi mantida a mesma, pois haviam detalhes de implementação derivados do pacote Tinker que garantiam um cálculo da energia mais refinado com baixo custo computacional. Depois de adequado o cálculo da energia de van der Waals do ProtPred para utilizar o algoritmo de LC, foi adicionado o trecho que permitiria executar em paralelo utilizando memória compartilhada, ou seja, transformar o LC em LCP-3. Além de garantir um melhor desempenho, isso pôde ser realizado com um baixo nível de dificuldade de implementação.

Nesse sentido, buscando antecipar os resultados pelo ProtPred, foi montada a Tabela 8.6 de estimativa de tempo necessário para a execução do AG utilizando uma população de 400 indivíduos e 200 gerações, resultando num total de 80 mil conformações, ou seja, durante o processo evolutivo o AG deverá chamar a função do cálculo da energia de van der Waals 80 mil vezes. Isso enfatiza mais ainda os algoritmos lentos para o cálculo da energia. Se no ProtPred a função padrão do cálculo da energia de van der Waals utiliza um algoritmo do tipo ABS, a estimativa de tempo necessário de execução é impraticável para proteínas não pequenas. Por outro lado, é possível 
executar o ProtPred com LCP-3 mesmo para proteínas gigantes em pouco tempo, permitindo até aumentar o número de gerações ou o tamanho da população.

Tabela 8.6: Tabela de estimativa do tempo de execução para um AG com 80 mil conformações utilizando a técnica de LCP-3.

\begin{tabular}{c|r|c|r|c} 
Proteína & ABS (s) & ProtPred com ABS & Speedup de LCP-3 & ProtPred com LCP-3 \\
\hline \hline 1A11 & 0,003867 & 5 minutos & 7,5 & 41 segundos \\
1BFI & 0,047410 & 1 hora & 9,2 & 7 minutos \\
1AI0 & 0,276436 & 6 horas & 23,6 & 16 minutos \\
4HHB & 0,910104 & 20 horas & 37,5 & 32 minutos \\
1W1I & 1,570561 & 35 horas & 42,1 & 50 minutos \\
1RUZ & 5,557874 & 5 dias & 128,5 & 58 minutos \\
2BGN & 52,057972 & 48 dias & 360,7 & 3 horas \\
1HTO & 234,463864 & 217 dias & 700,0 & 7 horas
\end{tabular}

\subsubsection{Resultados com o ProtPred}

Alguns resultados foram obtidos experimentalmente pelo ProtPred para mostrar a eficácia do método de LCP-3. Ao invés de realizar 100 execuções para determinar cada ponto do gráfico, por se tratar de várias horas de processamento, nesse experimento utilizou 10 execuções. O gráfico da Figura 8.29 mostra a explosão do tempo do cálculo do ProtPred utilizando o algoritmo padrão, tornando inadequado a execução de experimentos para proteínas maiores que 10 mil átomos. Esse gráfico mostra que os experimentos executados para os algoritmos de LC tiveram o mesmo comportamento quando utilizados em AGs, onde mesmo incrementando o tamanho da proteína o tempo de execução permanece quase o mesmo.

Assim como foi descrito na Seção 6.5, o overhead gerado pela montagem das células na avaliação de cada indivíduo foi insignificante, pois mesmo para proteínas muito pequenas, como a 1A11 com 390 átomos, o ProtPred com LCP-3 consumiu menos tempo que o algoritmo padrão. A Figura 8.28 mostra que além do desempenho significativo do ProtPred com LCP-3, a qualidade das soluções permanecem as mesmas, pois essa figura mostra que a estrutura predita da proteína 1A11 ficou semelhante a estrutura nativa apenas utilizando a energia de van de Waals.

Isso foi obtido em apenas dois minutos de execução do AG e, considerando que o ProtPred é um AG do tipo full-atom ab initio, esse tempo é consideravelmente baixo. Sem a implementação de LCP-3 no ProtPred a energia de van der Waals seria o gargalo do AG. No entanto, utilizando essa técnica o tempo do cálculo da energia de van de Waals deixa de ser o gargalo. Se considerar o tempo total de dois minutos do AG para predizer a proteína 1A11 e o tempo cálculo da energia de van der Waals para 80 mil conformações de aproximadamente 41 segundos (Tabela 8.6), significa que o AG gastou o outro um minuto realizando operações do próprio AG como, por exemplo, tarefas dos operadores genéticos e leitura das configurações. 
Esses resultados são bem animadores para o ProtPred. A energia eletrostática poderia também ser adequada ao algoritmo de LCP-3 trazendo resultados similares da energia de van der Waals. Dessa forma, seria possível executar o ProtPred não apenas para proteínas maiores, mas também poderia ser executado muitas vezes para qualquer tipo de proteína para fins estatísticos, bem como para ajuste de parâmetros como, por exemplo, aumento do tamanho da população e número de gerações, aumentando a probabilidade de obter estruturas de proteínas de boa qualidade.

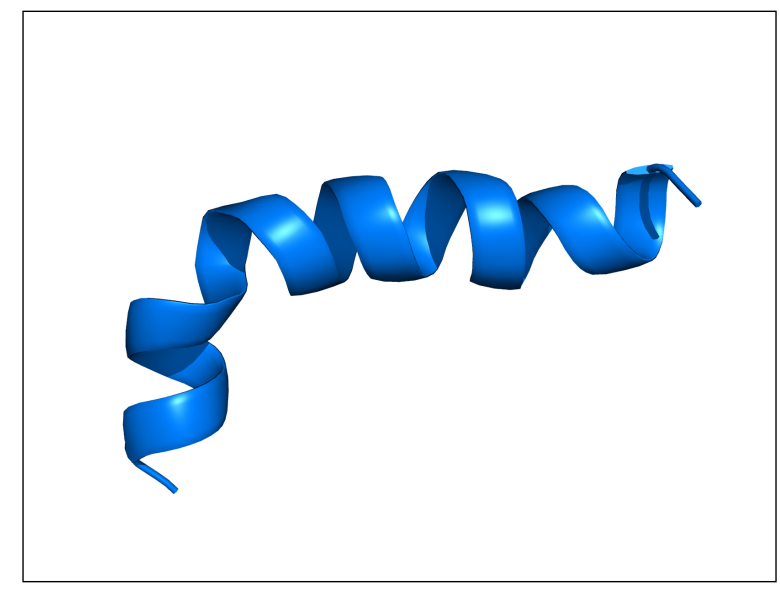

(a) Proteína 1A11 predita em 2 minutos com o ProtPred e LCP-3.

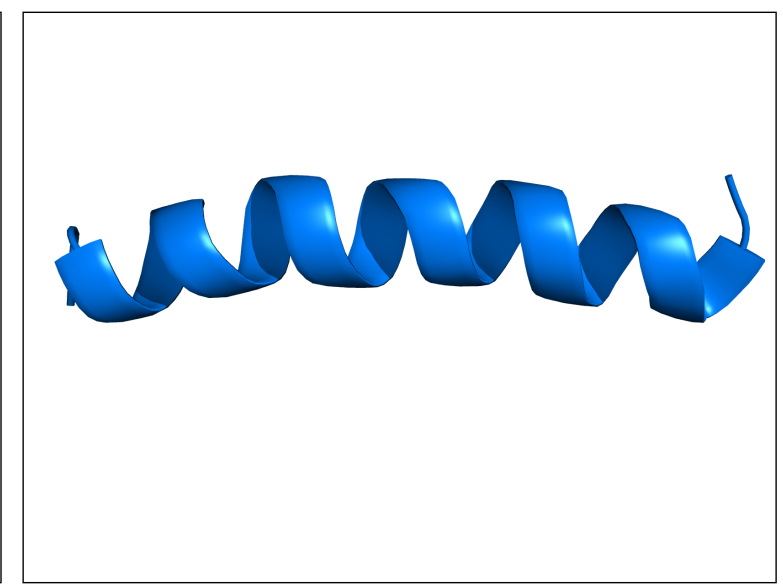

(b) Estrutura nativa da proteína 1A11.

Figura 8.28: Comparação entre a proteína 1A11 predita e a nativa.

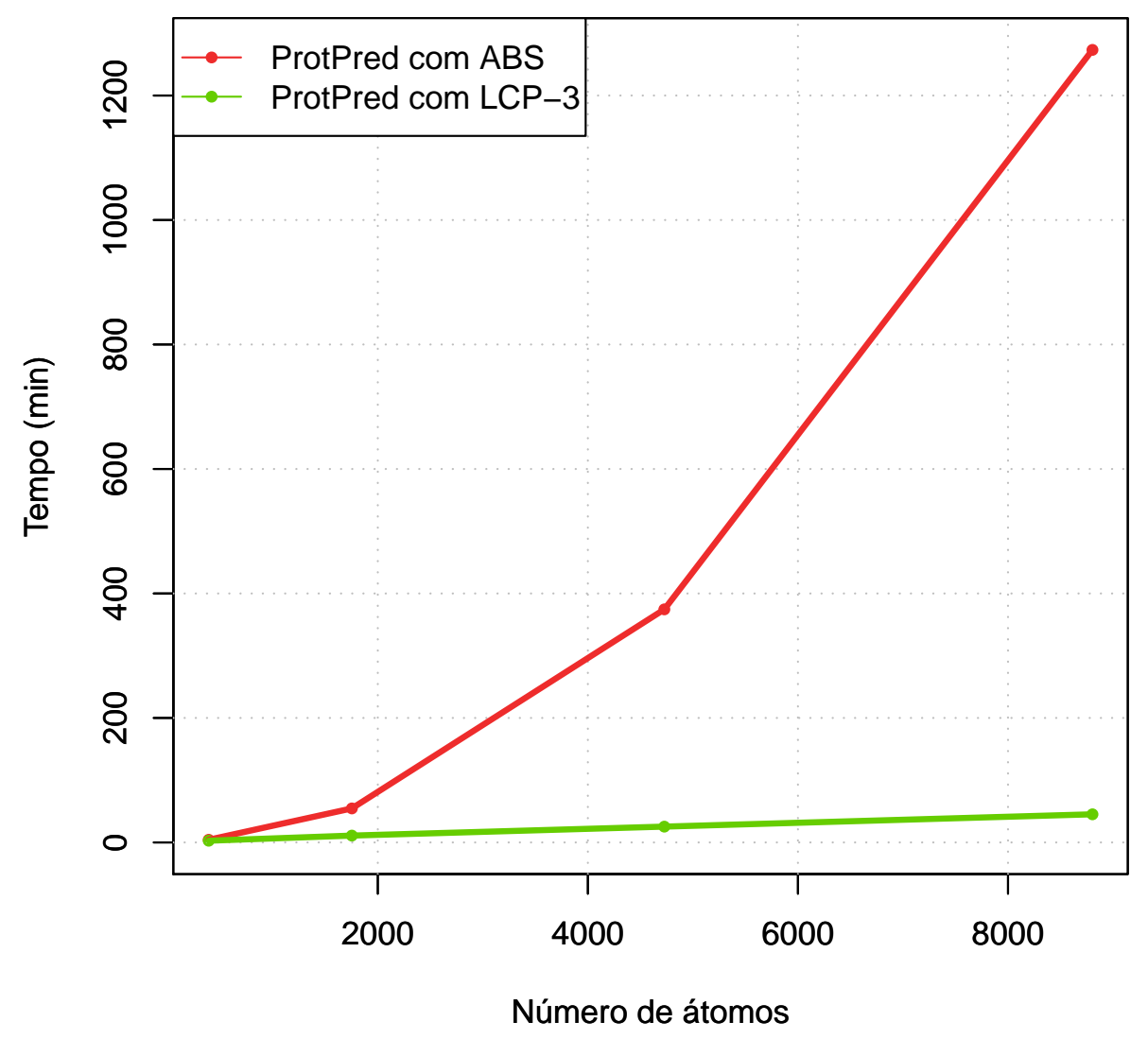

Figura 8.29: Tempo de execução do ProtPred com ABS e LCP-3 


\subsection{Considerações Finais}

Este capítulo mostrou os resultados obtidos pelas técnicas propostas utilizando algoritmos sequenciais, descritas no Capítulo 6 e por técnicas paralelas, descritas no Capítulo 7, executadas em dois tipos diferentes de máquinas. Por meio dos resultados experimentais foi mostrado que é possível reduzir consideravelmente o tempo do cálculo da energia de van der Waals aplicada em AGs para PSP.

O principal ponto deste capítulo são os resultados experimentais para LC que comprovam a redução da complexidade do algoritmo de $O\left(n^{2}\right)$ para $O(n)$. Com isso, o tamanho da proteína deixou de ser o problema para o cálculo da energia de van de Waals. No entanto, para acelerar ainda mais o cálculo, foram propostas técnicas para o cálculo em paralelo dessa energia, capaz de reduzir mais ainda o tempo de computação. Acredita-se que poderia haver maior redução do tempo de computação das implementações paralelas de LC se fosse utilizado um mapeamento que privilegiasse a maximização dos recursos computacionais como, por exemplo, a distribuição dos processos por $n_{x}, n_{y}$ ou $n_{x}, n_{y}, n_{z}$

Por fim, o objetivo da utilização de várias técnicas onde algumas delas têm poucas variações é determinar e isolar experimentalmente os efeitos que cada fator exerce em relação ao tempo do cálculo e os impactos gerados pela técnica. Assim, foi possível partir de uma das técnicas (LCP-3) e implementar o protótipo em uma aplicação real, como o ProtPred, sem muito esforço. 



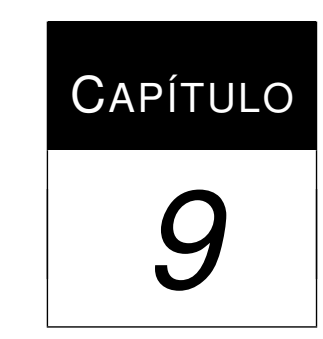

\section{Conclusões}

Este trabalho propõe a investigação de métodos computacionais para o aumento da eficiência do cálculo da energia de van der Waals utilizado em AGs para PSP. O uso da energia de van der Waals é essencial para compor a função de avaliação do indivíduo de um AG para PSP, pois é entendido que essa energia contribui com a maior parte para a estabilidade de uma proteína. Dessa forma, foram desenvolvidas e analisadas várias técnicas capazes de reduzir o tempo do cálculo da energia de van der Waals que pode ser aplicada à AGs. Além disso, foi escolhido uma das técnicas para verificar experimentalmente o comportamento em um AG para PSP.

Entre todas as técnicas investigadas neste trabalho, o algoritmo de lista de células foi essencial para obtenção dos resultados alcançados. É importante ressaltar que o algoritmo de lista de células, apesar de reduzir a complexidade do algoritmo de quadrático para linear, produz os mesmos resultados que os algoritmos quadráticos, em termos de energia. Ou seja, utilizando um algoritmo quadrático e um linear, ambos os algoritmos irão encontrar a mesma energia, a diferença é que os algoritmos que utilizam a lista de células fazem isso em tempo linear. Dessa forma, fica claro que o uso de lista de células é essencial quando se tratar de funções como cálculo da energia de van der Waals (ou outras funções que possuam um raio de corte de interação). Para ganhar ainda mais eficiência nessa técnica, foram investigadas formas de paralelizar o algoritmo de lista de células. Com isso, é possível concluir que o algoritmo de lista de células paralelo híbrido (LCP-4) foi o algoritmo que obteve melhor desempenho, pois explora muito bem o paralelismo, principalmente para proteínas gigantes, quando executados em clusters com vários processadores e vários nós.

O AG para PSP utilizado pelo grupo de pesquisa, o ProtPred, é, atualmente, somente capaz de predizer estruturas de proteínas relativamente pequenas, com até 5.000 átomos. Embora a técnica 
LCP-4 seja a mais eficiente de todas, se observar o ganho de desempenho para proteínas com até 5.000 átomos no gráfico da comparação das técnicas (Figura 8.27) o ganho de desempenho para a técnica LCP-3 é bem semelhante a LCP-4. No entanto, para a classe de proteínas pequenas, a técnica LCP-4 é menos eficiente que LCP-3, considerando que utiliza 32 processadores e tem um desempenho semelhante a LCP-3, que invés de 32 utiliza 8 processadores. Dessa forma, é possível fazer 4 execuções independentes do ProtPred com LCP-3 (um em cada nó de G2) com muito mais eficiência que o LCP-4 faria com os 32 processadores, para uma única proteína. Ou seja, enquanto que o ProtPred com LCP-4 seria capaz de predizer apenas uma estrutura de proteína com 32 processadores, o ProtPred com LCP-3 seria capaz de predizer 4 estruturas diferentes utilizando praticamente o mesmo tempo. Considerando que AGs, como o do ProtPred, produzem soluções diferentes a cada execução (que dependem da semente que é utilizada no gerador de números aleatório), fica mais fácil encontrar boas soluções aumentando a quantidade de proteínas preditas, inclusive para fins estatísticos.

Além disso, observando os resultados obtidos em G1 (Figura 8.26), pode-se perceber que a técnica LCP-2a teve um desempenho bem semelhante a LCP-4 para as proteínas pequenas. No entanto, como o resultado final esperado é a redução do tempo computacional, é melhor otimizar o ProtPred de maneira que seja utilizado a técnica que produza os melhores resultados nos computadores mais rápidos. Isso justifica a escolha da técnica LCP-3 e o G2 como sendo o caminho mais promissor para obter melhor desempenho com o ProtPred.

Em geral, os resultados de desempenho apresentaram benefícios para todas as técnicas propostas, pois todas foram capazes de reduzir o tempo do cálculo. Embora algumas tenham apresentado resultados mais relevantes é importante considerar os vários fatores que envolvem a decisão por uma dessas técnicas para a aplicação em um sistema real. Como no caso do AG do ProtPred, o qual teve seu tempo execução significativamente reduzido. O propósito do uso de algoritmos como o ProtPred é obter estruturas de proteínas a partir da sequência de aminoácidos que ainda não tenham a estrutura conhecida. Entretanto, o ProtPred deve receber refinamentos para que, uma vez capaz de predizer estruturas conhecidas também será capaz de encontrar novas estruturas. Para isso, são necessários utilizar funções refinadas de cálculo inter-atômico para que a avaliação dos indivíduos do AG seja mais próxima possível dos modelos na vida real. Mas o desempenho do AG diminui de acordo com a quantidade de funções que são utilizadas para avaliar um indivíduo.

Portanto, a contribuição deste trabalho foi, de certa forma, significativa para redução do tempo do cálculo do AG, pois seus resultados também podem ser extendidos à energia eletrostática, tornando possível a predição de estruturas de proteínas com mais qualidade e menor tempo. Além disso, o uso das energias de solvatação e de pontes de hidrogênio tem mostrado ser de grande importância para a qualidade das proteínas preditas, porém são funções caras computacionalmente. Por fim, este trabalho permitiu que surgissem novos objetos de pesquisa para serem investigados tanto no aspecto de eficiência computacional como na utilização de modelos mais refinados de avaliação dos indivíduos. 


\subsection{Trabalhos Futuros}

Foi abordado no Capítulo 4 que é possível explorar o paralelismo de metaheurísticas como, por exemplo, os AGs, avaliando os indivíduos simultaneamente. Esse tipo de paralelismo certamente poderá ser utilizado em conjunto com as técnicas abordadas neste trabalho e poderá trazer resultados satisfatórios. No entanto, em primeiro lugar, busca-se encontrar as melhores técnicas de aumento da eficiência no nível mais baixo de programação, ou seja, no cálculo da função da energia contida na função de avaliação. Assim, é interessante esgotar as formas de contribuição para o aumento da eficiência do cálculo da energia de van der Waals antes de subir no nível de paralelismo dos AGs paralelos. Para isso, é necessário investigar novas formas de aumentar a eficiência do cálculo da energia de van der Waals, bem como refinar as técnicas existentes, aumentando mais ainda a eficiência da função de avaliação do AG, e, com esse aumento, o paralelismo fornecido pelo AG paralelo será melhor aproveitado.

A implementação da versão LCP-3 para a energia eletrostática pode ser uma tarefa relativamente simples dado que já foi utilizada para a energia de van der Waals. A técnica LCP-3 poderia ainda ser melhorada se fosse elaborado um novo mapeamento de processos, para garantir o balanceamento de carga. Com essas duas formas de energias otimizadas, no sentido de eficiência computacional, o ProtPred seria capaz de predizer estruturas com mais qualidade e velocidade. Além disso, deveria ser estudado formas de aumentar a eficiência para o cálculo da energia de solvatação, incorporada recentemente ao ProtPred e que tem mostrado ser importante. Embora essa energia seja mais cara computacionalmente que as energias de van der Waals e eletrostática, é possível obter predições de boa qualidade com menor número de avaliações, ou seja, reduzindo o tempo do cálculo dessa função e, com a redução do número de avaliações do AG, as predições seriam mais rápidas.

Por conta de ambas as energias, van de Waals e eletrostática, necessitarem calcular a interação dos átomos vizinhos, essas duas etapas poderiam ser vistas como uma só. Primeiramente, montase as LCs utilizando o raio de corte da energia com interação mais longa, ou seja, da eletrostática que é de $13 \AA$ A. Em seguida, a cada interação deve ser verificado se a distância entre o par de átomos é menor que $8 \AA$ e, caso positivo, é calculado a energia de van der Waals e também eletrostática. Caso a distância seja maior que $8 \AA$ é calculado somente a interação para a energia eletrostática. Deve-se medir o desempenho para van der Waals e eletrostática separadamente e verificar se a aplicação dessa técnica é viável, pois apenas poderá apresentar benefícios quando um AG utilizar as duas formas de energia em sua função de avaliação, isto é, aplicaria as duas formas de energia a cada indivíduo. Poderia, então, construir três funções de energia: para van der Waals somente; para eletrostática somente; e para van der Waals e eletrostática juntas.

Há outras formas de paralelismo como, o uso de GPUs e FPGAs, que também constituem os trabalhos futuros. Considerando que nas GPUs o processamento paralelo é realizado rapidamente por muitas threads, poderia realizar o processo de montagem das células em CPU e, em seguida, ao invés de transmitir as coordenadas dos átomos pela rede de inter-conexão das máquinas para- 
lelas, esses dados seriam copiados para a memória da GPU. A GPU seria responsável por executar a interação de todos átomos com todos átomos das células em diferentes threads e todas ao mesmo tempo. Espera-se com isso realizar o cálculo da energia de van der Waals com apenas uma varredura. Entretanto, dado que os processadores modernos possuem um clock muito alto, seria necessário investigar técnicas eficientes para o uso de van der Waals com GPUs, pois dependendo do grau de paralelismo o uso de GPUs não é viável.

O uso de FPGAs também é promissor para a redução do tempo do cálculo da energia de van der Waals. Os FPGAs são capazes de fazer acessos à memória com muita velocidade. Baseando-se na técnica do COF onde as tabelas de interações entre todos os átomos estão alocados na memória principal da CPU, poderia ser transportada para a memória de FPGAs para serem armazenadas em lookup tables permitindo que fosse possível fazer o cálculo da interação de van der Waals de vários pares de átomos ao mesmo tempo.

Outra abordagem futura no sentido de metaheurística é explorar o uso de Algoritmos de Estimação de Distribuição (AED) no lugar do AG do ProtPred. O AED é uma classe de AGs que não utiliza operadores genéticos para produzir novos indivíduos e sim modelos probabilísticos que baseiam na qualidade dos indivíduos da população. Os AEDs estão ganhando cada vez mais espaço entre os pesquisadores, pois têm apresentados resultados promissores para os mais variados tipos de problemas. Com um AED, o ProtPred seria capaz de encontrar soluções boas com um menor número de avaliações. Além disso, com a utilização de agrupamento de genes do cromossomo (do inglês, building blocks) o AED seria capaz de evitar que soluções promissoras fossem perdidas por conta dos operadores genéticos. 


\section{Referências Bibliográficas}

AlBA, E. Parallel metaheuristics a new class of algorithms. Wiley Interscience, 2005.

Alberts, B.; Bray, D.; Hopkin, K.; Johnson, A.; Lewis, J.; RAFF, M.; Roberts, K.; WALter, P. Fundamentos da biologia celular. Artmed Editora, 2007.

Allen, M. P.; Tildesley, D. J. Computer simulation of liquids. Oxford University Press, 1987.

Anfinsen, C. B. Studies on the principles that govern the folding of protein chains. Nobel Lecture, p. 103-119, 1972.

BALAKRISHNAN, S. Very long instruction word processors. In: Resonance, v. 6, Springer India, p. 61-68, 2001.

BARney, B. Posix threads programming. 2009.

Disponível em https://computing.llnl.gov/tutorials/pthreads/ (Acessado em 27/02/2009)

Baxevanis, A. D.; Ouellette, B. F. F. Bioinformatics 2th edition: A practical guide to the analysis of genes and proteins. Wiley-Interscience, 2001.

Becker, O. M.; JR., A. D. M.; Roux, B.; Watanabe, M. Computational biochemistry and biophysics. CRC, 2001.

BELl, G.; GRAY, J. What's next in high-performance computing? Communications Of The $A C M$, v. 45, p. 91-95, 2002.

Berg, J.; Tymoczko, J.; Stryer, L. Biochemistry 5th ed. W. H. Freeman, 2002.

Bergeron, B. Bioinformatics computing. Prentice Hall, 2002. 
Berman, H. M.; Westbrook, J.; Feng, Z.; Gilliland, G.; Bhat, T. N.; Weissig, H.; Shindyalov, I. N.; Bourne, P. E. The protein data bank. 2000.

Disponível em http://www.rcsb.org/pdb/home/home.do (Acessado em 05/02/2009)

BRASIL, C. R. S. Algoritmos evolutivos multi-objetivo e modelos água/solvente para predição de estruturas de proteínas. Tese de Doutoramento, ICMC - USP, em andamento, 2010.

Brasil, C. R. S.; Bonetti, D. R. F.; Faria, E. D. F.; Delbem, A. C. B.; Silva, F. L. B. D. Evolutionary algorithms approaches for the protein structure prediction with new criteria. Biomat 2009 9th International Symposium on Mathematical and Computational Biology, v. 9, 2009a.

Brasil, C. R. S.; Delbem, A. C. B.; Bonetti, D. R. F.; Faria, E. D. F. Ab initio studies using hydrogen bond in evolutionary algorithm. 7th International Congress of Pharmaceutical Sciences, $2009 b$.

BUJNICKI, J. M. Prediction of protein structures, functions, and interactions. Wiley, 2009.

CANTÚ-PAZ, E. A survey of parallel genetic algorithms. Illinois Genetic Algorithms Laboratory, 1997.

Case, D.; Darden, T.; Cheatham, T.; III; Simmerling, C.; Wang, J.; Duke, R.; Luo, R.; Merz, K.; Wang, B.; Pearlman, D.; Crowley, M.; Brozell, S.; Tsui, V.; Gohlke, H.; Mongan, J.; Hornak, V.; Cui, G.; Beroza, P.; Schafmeister, C.; Caldwell, J.; Ross, W.; ; Kollman, P. Amber 8. http://ambermd.org/, university of California, San Francisco., 2004.

Chapman, B.; Jost, G.; VAn Der Pas, R.; Kuck, D. J. Using openmp: Portable shared memory parallel programming. The MIT Press, 2007.

Chivian, D.; Robertson, T.; Bonneau, R.; Baker, D. Ab initio methods. Structural Bioinformatics, v. 27, p. 547-557, 2003.

Clote, P.; Backofen, R. Computational molecular biology: An introduction. Wiley, 2002.

Cormen, T. H.; Leiserson, C. E.; Rivest, R. L.; Stein, C. Algortimos: Teoria e prática. Tradução da 2a ed. Rio de Janeiro, RJ: Editora Campus Ltda., 916 p., 2002.

CORPORATION, S. Lammps users manual. http://lammps.sandia.gov/, 2003.

CuI, Y.; Chen, R. S.; Wong, W. H. Protein folding simulation with genetic algorithm and supersecondary structure constraints. Proteins: Structure, Function, And Genetics, v. 31, p. 247257, 1998. 
DEB, K. Multi-objective optimization using evolutionary algorithms. New York: John Wiley \& Sons, 2001.

DiMasi, J. A.; Hansen, R. W.; GRABOwski, H. G. The price of innovation: new estimates of drug development costs. $a$, v. 22, p. 151-185, 2003.

Dongarra, J.; Sterling, T.; Simon, H.; Strohmaier, E. High-performance computing: Clusters, constellations, mpps, and future directions. IEEE CS and the AIP, , n. março/abril, 2005.

Eiben, A. E.; Smith, J. E. Introduction to evolutionary computing. Springer, 2003.

Eshelman, L. J.; SCHAFFER, J. D. Real-coded genetic algorithms and interval-schema. Morgan Kaufmann Publishers, 187-202 p., 1993.

EXPASY PROTEOMICS SERVER 2009.

Disponível em http: / / www . expasy • ch/sprot / (Acessado em 04/02/2009)

Fogel, G. B.; Corne, D. W. Evolutionary computation in bioinformatics. Morgan Kaufmann Publishers, 2003.

Foster, I. Designing and building parallel programs. Addison-Wesley, 1995.

Gibas, C.; JAMBECK, P. Developing bioinformatics computer skills. O’Reilly \& Associates, Inc., 2001.

Goldberg, D. E. The design of innovation. Kluwer Academic Publishers, 2002.

Grama, A.; Gupta, A.; KARYPIS, G.; KumAR, V. Introduction to parallel computing. Addison-Wesley, 2003.

Hockney, R. W.; Goel, S. P.; EAstwood, J. W. Quiet high-resolution computer models of a plasma. Journal of Computational Physics, v. 14, p. 145-158, 1974.

Holland, J. H. Adaptation in natural and artificial systems: An introductory analysis with applications to biology, control and artificial intelligence. University of Michigan Press, 1975.

HristakeVA, M.; Shrestha, D. Solving the 0-1 knapsack problem with genetic algorithms. In: Midwest Instruction and Computing Symposium, 2004.

IOzONE Iozone filesystem benchmark. 2009.

Disponível em http://www.iozone.org/

Jain, A.; Gambhir, P.; Jindal, P.; Balakrishnan, M.; Paul, K. Fpga accelerator for protein structure prediction algorithms. 5th Southern Conference on Programmable Logic, p. 123-128, 2009. 
Jones, D. T. Progress in protein structure prediction. Current Opinion in Structural Biology, v. 7, p. 377-387, 1997a.

JONES, D. T. Successful ab initio prediction of the tertiary structure of nk-lysin using multiple sequences and recognized supersecondary structural motifs. PROTEINS: Structure, Function, and Genetics, v. 1, p. 185-191, 1997b.

Jones, D. T.; TAYlor, W. R.; ThORnton, J. M. A new approach to protein fold recognition. Letters to Nature, v. 358, p. 86-89, 1992.

Krane, D. E.; RAYMer, M. L. Fundamental concepts of bioinformatics. Pearson Education, 2003.

LE, T. T.; REJEB, J. A detailed mpi communication model for distributed systems. Future Generation Computer Systems 22 (2006), v. 22, p. 269-278, 2006.

LENGAUER, T. Bioinformatics - from genomes to drugs. Wiley, 2002.

LESK, A. M. Introduction to bioinformatics. Oxford University Press, 2002.

Lima, T. W. Algortimos evolutivos para predição de estruturas de proteínas. Dissertação de Mestrado, Instituto de Ciências Matemáticas e de Computação, Universidade de São Paulo, São Carlos, SP, 2006.

Lima, T. W.; Delbem, A. C. B. Estruturas de dados eficientes para algoritmos evolutivos aplicados ao projeto de redes. Relatório Técnico 301, Insituto de Ciências Matemáticas e de Computação - USP, 2007.

Lodish, H.; Berk, A.; Matsudaira, P.; Kaiser, C. A.; Krieger, M.; Scott, M. P.; ZIPURSKY, L.; DARnElL, J. Molecular cell biology 5th edition. W. H. Freeman, 2003.

Marzzoco, A.; Torres, B. B. Bioquímica básica. Guanabara Koogan, 1999.

Nelson, D. L.; Cox, M. M. Lehninger principles of biochemistry fourth edition. w. H. Freeman, 2004.

Orengo, C.; Jones, D.; Thornton, J. Bioinformatics: Genes, protein and computers. BIOS Scientific Publishers, 2003.

Overflow, S. Performance of math functions. 2009.

Disponível em http://stackoverflow.com/questions/1522851/ performance-of-math-functions

PONDER, J. W. Tinker software tools for molecular design. 2001.

Disponível em http: / / dasher. wust l. edu/tinker (Acessado em 20/02/2009) 
PoskAnZER, J. Portable gray map. 2003.

Disponível em http://netpbm.sourceforge.net/doc/pgm.html

Quinn, M. J. Parallel computing: Theory and practice. McGraw-Hill, 1994.

QuInN, M. J. Parallel programming in c with mpi and openmp. McGraw-Hill, 2004.

RiverA, W. Scalable parallel genetic algorithms. Artificial Intelligence Review, p. 153-168, mayaguez PR 00681-9042, USA, 2001.

Rothlauf, F. Representations for genetic and evolutionary algorithms. Springer-Verlag Berlin Heidelberg 2006, universität Mannheim 68131 Mannheim Germany, 2006.

SALI, A. Comparative protein modeling by satisfaction of spatial restraints. Molecular Medicine Today, p. 270-277, 1995.

Disponível em http://salilab.org/pdf/041_SaliMolMedTod1995.pdf

SAntos, W. P. D. Evolutionary computation. In Teh, 2009.

SAROJ; Shaveta Research review and unresolved problems in parallel ga. ICCS, 2004.

SCHOFIEld, P. Computer simulation studies of the liquid state. Computer Physics Communications, v. 5, p. 17-23, 1973.

Setubal, J.; MeIDANis, J. Introduction to computational molecular biology. PWS Publishing Company, 1997.

DA Silva, V. B.; SiLVA, C. H. Modelagem molecular de proteínas-alvo por homologia estrutural. Revista Eletrônica de Farmácia, v. 4, p. 15-26, 2007.

van der Spoel, D.; Lindahl, E.; Hess, B.; van Buuren, A. R.; Apol, E.; Meulenhoff, P. J.; Tieleman, D. P.; Sijbers, A. L. T. M.; Feenstra, K. A.; VAn Drunen, R.; BERENDSEN, H. J. C. Gromacs user manual version 3.2. www.gromacs.org, p. 19-21, 2004. Disponível em http://www.vislab.uq.edu.au/users/manuals/gromacs/ manual-3.2.pdf

Stote, R.; Dejaegere, A.; Kuznetsov, D.; Falquet, L. Tutorial charmm. 1999. Disponível em http://www.ch.embnet.org/MD_tutorial/

Sullivan, F.; Mountain, R. D.; O’Connellf, J. Molecular dynamics on vector computers. Journal of Computational Physics, v. 61, n. 1, p. 138-153, 1985.

SYWERDA, G. Uniform crossover in genetic algorithms. Morgan Kaufmann Publishers Inc, 1989. 
TOP500 SUPERCOMPUTER SITES 2009.

Disponível em http: / / www . top500.org/ (Acessado em 21/02/2009)

TWYMAn, R. M. Advanced molecular biology a concise reference. Springer, 1998.

Webster, D. M. Protein structure prediction: Methods and protocols. Humana Press, 2000.

Westhead, D. R.; Collura, V. P.; EIdridge, M. D.; Firth, M. A.; Li, J.; Murray, C. W. Protein fold recognition by threading: comparison of algorithms and analysis of results. Protein Engineering, v. 8, p. 1197-1204, 1995.

Zaki, M. J.; Bystroff, C. Protein structure prediction 2th edition. Humana Press, 2008. 